\title{
Ice island deterioration
}

\author{
by \\ Anna Jean Crawford \\ A thesis submitted to the \\ Faculty of Graduate and Postdoctoral Affairs \\ in partial fulfillment of the requirements for the degree of \\ Doctor of Philosophy in Geography
}

\author{
Carleton University \\ Ottawa, Ontario
}

(C) 2018

Anna Jean Crawford 


\section{Abstract}

Ice islands are large, tabular icebergs that calve from ice shelves and floating ice tongues. Their drift and deterioration is of concern to offshore industry and influences the dispersal of freshwater from Earth's major ice sheets. However, the analysis and modelling of ice island deterioration is constrained by a lack of systematic studies using field and remotely sensed data.

The aim of this thesis is to improve our understanding of ice island deterioration through the use and development of novel techniques and datasets. It uses complementary field and remotely sensed datasets in three studies that individually focus on vertical deterioration (i.e., thinning), small-scale areal deterioration (e.g., wave erosion), and large-scale areal deterioration (i.e., fracture). The study subjects are ice islands in eastern Canadian waters that calved from the Petermann Glacier of northwest Greenland between 2008 and 2012.

The vertical deterioration of a grounded Petermann ice island (PII) was quantified with stationary ice penetrating radar (IPR), mobile IPR and ablation stake data measurements collected over three field campaigns. Derived basal ablation was used to calibrate a basal ablation model, which was applied in a separate study to quantify the spatial distribution of meltwater from the drift and deterioration of hundreds of PIIs. This study used the Canadian Ice Island Drift, Deterioration and Detection Database, which was generated through the analysis of thousands of RADARSAT-2 synthetic aperture radar scenes. The database was also used to evaluate the fit of statistical distributions to the size-frequency distributions of PIIs. The results indicate that fracture remained an influential deterioration process over the monitoring period. A third study found that deterioration on the order of $40 \mathrm{~cm}$ could be detected under optimal conditions with aerial photogrammetry with structure-from-motion processing and that this technique was superior to laser scanning. 
This thesis presents new insights into ice island deterioration processes. It also documents new techniques for measuring deterioration and contributes pertinent information to two major ice island research themes (i.e., hazards and freshwater vectors). Finally, many results and future research directions are applicable to ice island research conducted in both Polar Regions on planet Earth. 


\section{Acknowledgements}

The time that I have spent as a graduate student researching big, diminishing blocks of ice has been an incredible experience due to a wide support network. Derek Mueller's supervision was paramount, as was his encouragement, understanding and enthusiasm for innovation. I thank Gregory Crocker and Doug King for providing strategic and analytical guidance from the time of my comprehensive exam to thesis submission. I also greatly appreciate the thoughtful review of my thesis by Douglas MacAyeal (University of Chicago) and Shawn Kenney (Carleton University). It has been exciting to watch the Water and Ice Research Lab (WIRL) grow over my seven years in the Department of Geography and Environmental Studies (DGES), and I greatly value the relationships that have been fostered during this time. The generation of the Canadian Ice Island Drift, Deterioration and Detection (CI2D3) Database is an impressive achievement of the lab, and I would like to thank Ron Saper, Correy Shaad, Jeff Shephard, Adam Garbo and the GEOM 4009 students for all of the time and effort that they dedicated to this project. Luc Desjardins deserves special recognition, as the success of the project was a result of his painstaking work. His extensive ice island expertise provided direction for my own research on numerous occasions.

The financial and in-kind support provided by the Canadian Ice Service (CIS) was instrumental in the CI2D3 Database project as well as for my fieldwork. I would specifically like to thank Tom Zagon, Tom Carrieres, Hai Tran, Matt Arkett, Angela Cheng, Stephanie Tremblay-Therrien, Marilee Pregitzer, Leah Braithwaite and Dean Flett. All RADARSAT imagery utilized in this thesis was made available via joint partnership agreements with the CIS. RADARSAT data and products are (C) MacDonald, Dettwiler and Associates Ltd. (2010-2017), all rights reserved. RADARSAT is an official mark of the Canadian Space Agency. 
My field research would also not have been possible without the resources and support provided by ArcticNet and the crew of the CCGS Amundsen, including that of the logistics coordinator (Keith Levesque), chief scientists (Louis Fortier, Phillip Archambault, Jean-Éric Tremblay, David Barber and Tim Papakyriakou), helicopter pilots (Olivier Talbot, Guillaume Carpentier, Dick Morissette and Alan Roy), captains (Allan Gariépy and Allan Lacerte) and the numerous science and ship crew members that assisted me on and off the ice. Jonathan Gagnon and Lauren Candlish deserve recognition for their numerous forays on to the ice with me as do Gabriel Joyal, Etienne Brouard, Annie-Pier Trottier for orchestrating ship-based data collection.

I send many, many thanks to the affiliates of WIRL, Jill Rajewicz, Melissa Nacke and Graham Clark, who provided invaluable assistance during fieldwork and have been outstanding folks with whom to discuss research. The community of Qikiqtarjuaq, Nunavut graciously welcomed me during my stay in May 2016. I enjoyed sharing stories and learning from Jaypootie Moesesie, and I hope that our paths cross again.

I greatly appreciate the personal support that I received from Natural Sciences and Engineering Research Council (NSERC) of Canada, the Province of Ontario through the Ontario Graduate Scholarship program, the Department of Geography and Environmental Studies, Carleton University, Society of Naval Architects and Engineers (Arctic section) and the Weston Foundation. The CIS, Transport Canada (through the Network of Expertise on Transportation in Arctic Waters under the Northern Transportation Adaptation Initiative), Statoil Ltd., ArcticNet, Derek Mueller's NSERC Discovery Grant and the Northern Scientific Training Program all provided research funding. Members of the GreenEdge project (Joannie Ferland, Marie-Hélène Forget and Marcel Babin) are thanked for field assistance in Qikiqtarjuaq and sharing oceanographic data. 
Finally, I do not know where I would be without the continued enthusiasm from my mom, Dixie Smith, dad, John Crawford, and brother, Ian Dexter. Thank you for instilling the importance of going 'all-in' with hard, quality work. Finally, Kieran Jones deserves recognition for listening to my research in painstaking detail and dealing with weather stations on our back porch to providing all of the necessary hugs, laughs, commiserations and confidence boosts. Thank you for your friendship and care throughout it all. 


\section{Bibliography of integrated manuscripts}

This thesis is presented using the integrated manuscript format. I was the lead investigator of the studies associated with the manuscript chapters (i.e., chapters 4, 5 and 6). I was responsible for the field sampling plans, coordinating field and remote sensing data collection, analyzing data and writing the manuscripts. I also helped to secure the funding for the three research projects. Coauthors provided data, research advice and/or editorial comments. Chapter 5 has been published in Remote Sensing (see below). Chapter 4 will be revised and submitted to either the Journal of Glaciology or The Cryosphere. Chapter 6 will be revised and submitted to the Journal of Geophysical Research-Oceans.

Chapter 5 is reproduced from a journal article published in Remote Sensing. There are no reproduction restrictions on this article as it was published in this open access journal of the Multidisciplinary Digital Publishing Institute (MDPI). My supervisor and co-author, Derek Mueller, and I developed the objectives and methodology for the research associated with this coauthored material. We worked cooperatively to secure project funding and collect data during a field campaign in 2015. I processed and analyzed all data after initial processing (specifically Precise Point Position correction) of laser scan point clouds was conducted by Josh Samprey of Seahorse Geomatics to improve survey geolocation. This analysis is contained in the Remote Sensing article below, which I wrote and steered through peer-review. My first co-author, Derek Mueller, provided analytical and editorial advice. My second co-author, Gabriel Joyal, assisted with data collection and also provided editorial advice. Reviewer comments on the manuscript were incorporated at my discretion. 
Recommended citation:

Crawford AJ, Mueller D and Joyal G (2018) Surveying drifting icebergs and ice islands: Deterioration detection and mass estimation with aerial photogrammetry and laser scanning. Remote Sensing. 10:575, doi:10.3390/rs10040575.

\section{Thesis supervisor statement}

I, Derek Mueller, as co-author of "Crawford A, Mueller D, Joyal G (2018) Surveying drifting icebergs and ice islands: Deterioration detection and mass estimation with aerial photogrammetry and laser scanning. Remote Sensing 10: 575. doi:10.3390/rs10040575.”, acknowledge Anna Crawford as the lead contributing author of this manuscript. Anna designed and performed the field studies, obtained and analyzed the data, and wrote and revised the manuscript. I contributed to this published paper in her thesis as Anna's supervisor during her doctoral studies in geography. My contribution entailed discussion, advice, assistance and editorial remarks related to the experimental design, fieldwork, analysis and writing of this manuscript. My activities were entirely consistent with the role of thesis supervisor. 


\section{Table of contents}

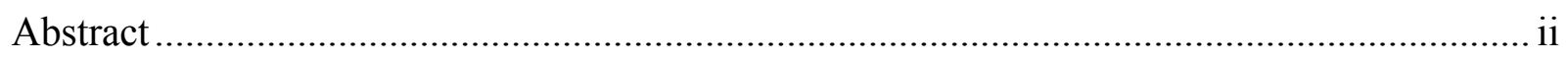

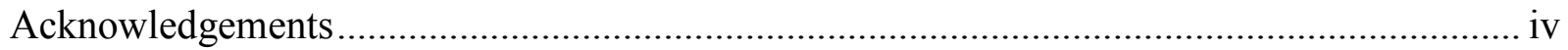

Bibliography of integrated manuscripts......................................................................... vii

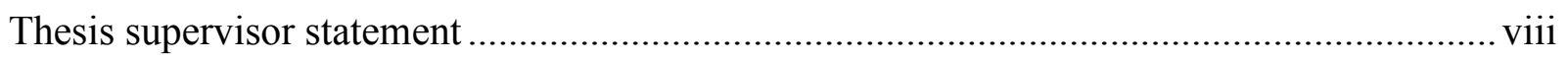

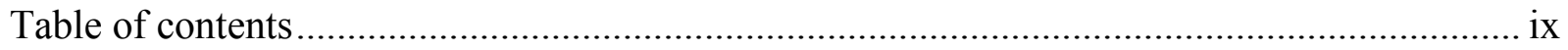

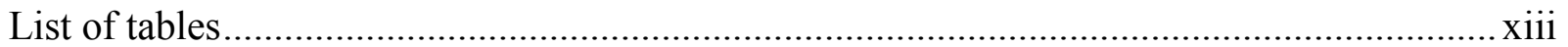

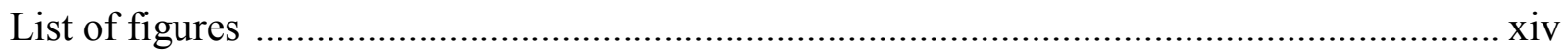

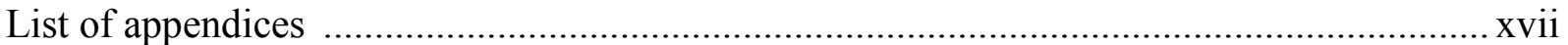

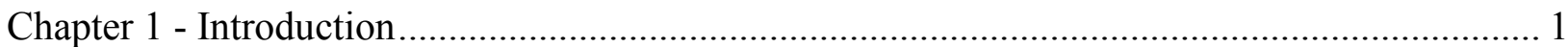

1.1 Ice islands in a changing climate and research justification ............................................. 1

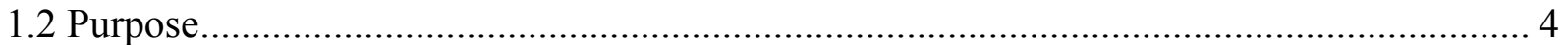

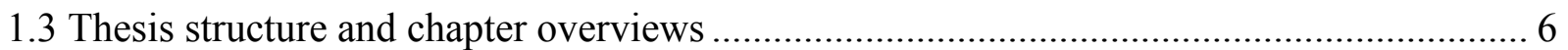

Chapter 2 - Background on deterioration processes and measurement techniques ....................... 9

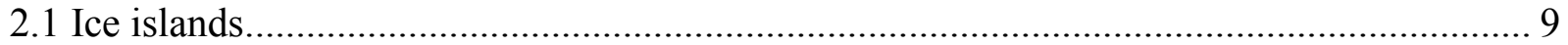

2.2 Fracture and detection with synthetic aperture radar..................................................... 12

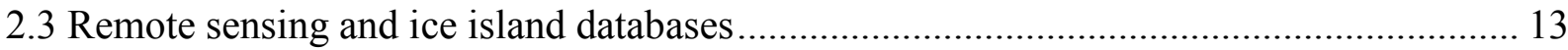

2.4 Freshwater inputs due to ice island deterioration ............................................................. 16

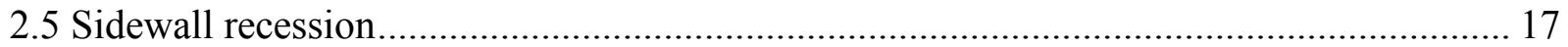

2.6 Sidewall recession surveying methods …………….................................................. 18

2.7 Thinning through surface and basal ablation .................................................................. 20

2.8 Observing ice island thinning with remote sensing and in-situ methods............................ 21

2.9 Summary and connection with thesis objectives .......................................................... 22

Chapter 3 - Rationale: study sites, data collection and data processing ...................................... 24

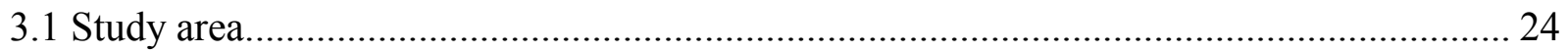

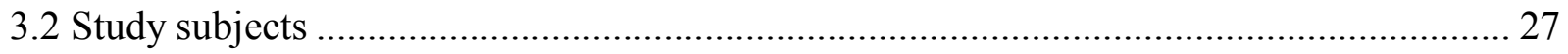

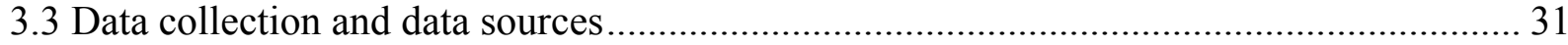

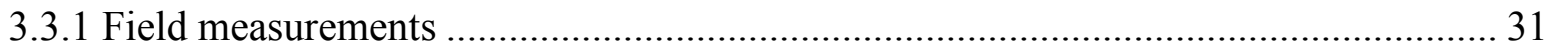

3.3.2 Field based surveying ...................................................................................... 36

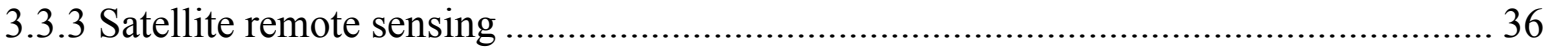




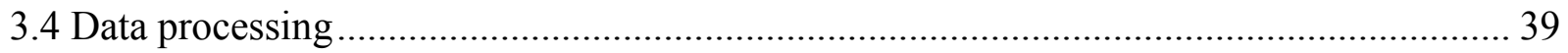

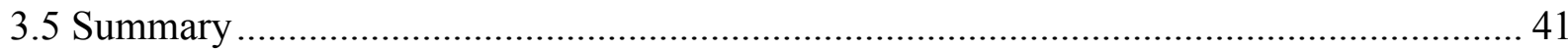

Chapter 4 - The thinning of 'Petermann Ice Island-A-1-f': Ablation magnitudes and model

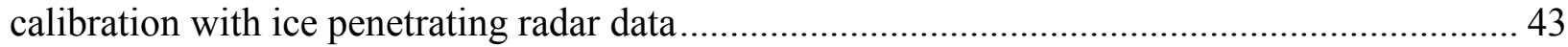

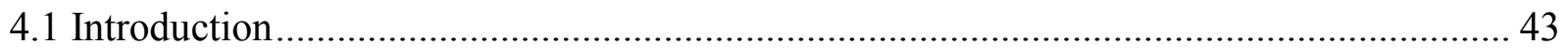

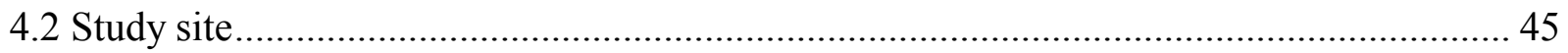

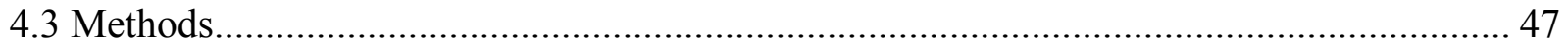

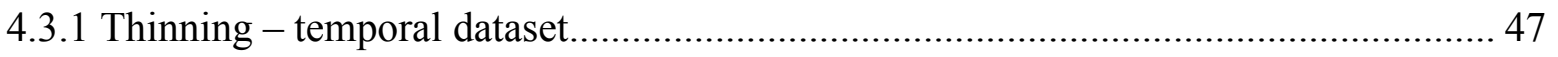

4.3.2 Surface extent changes and contributions to deterioration ....................................... 50

4.3.3 Environmental data collection ............................................................................... 51

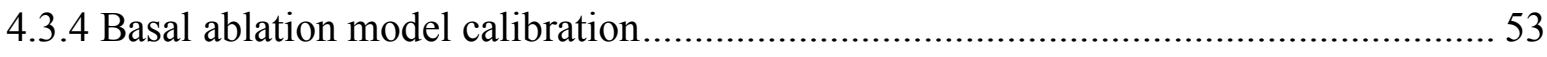

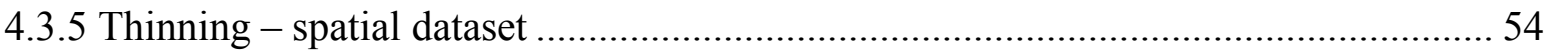

4.3.6 Grounding location and duration ........................................................................ 58

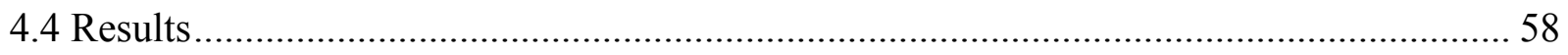

4.4.1 Temporal thinning variation and associated environmental conditions ...................... 58

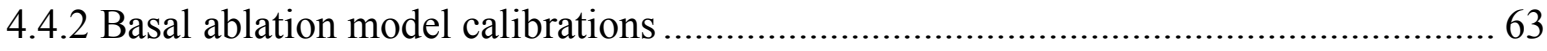

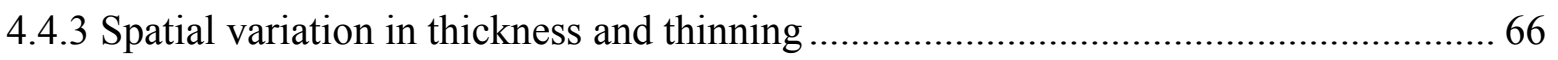

4.4.4 Areal reduction and contributions to PII-A-1-f deterioration .................................... 72

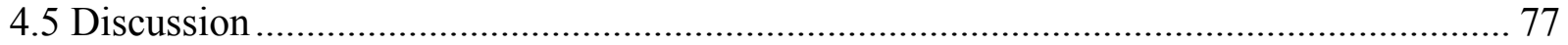

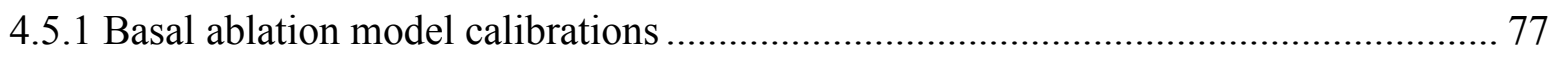

4.5.2 Monitored ablation processes: rates and contributions to overall deterioration ........... 80

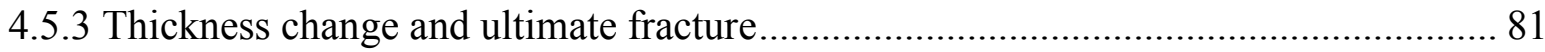

4.5.4 Fracturing and the evolution of PII-A-1-f prior to grounding .................................. 82

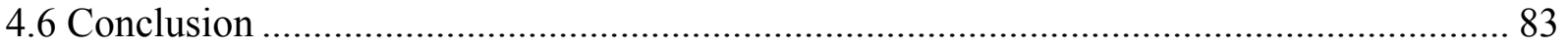

Chapter 5 - Surveying drifting icebergs and ice islands: Deterioration detection and mass estimation with aerial photogrammetry and laser scanning...................................................... 86

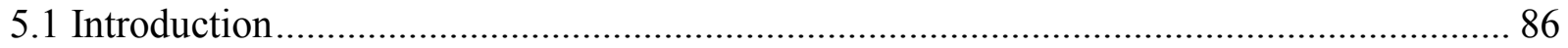

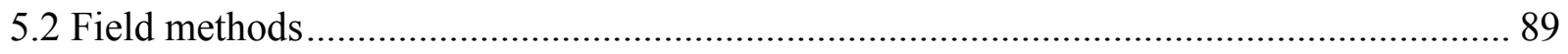

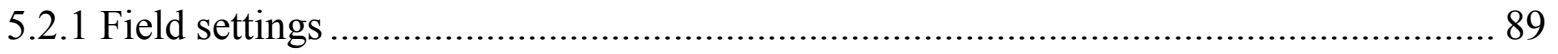

5.2.2 Marker/GPS deployment ................................................................................. 91

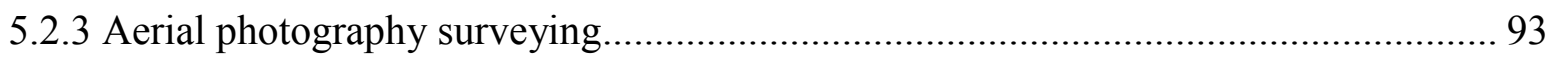




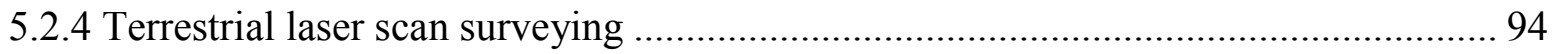

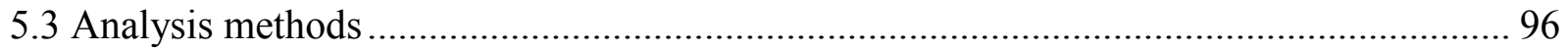

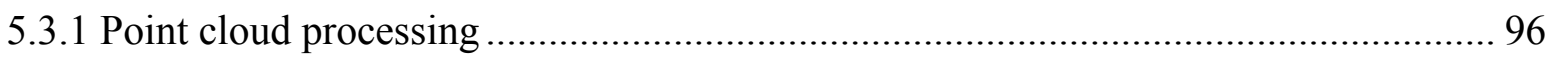

5.3.2 Point cloud comparison and DDT calculation ........................................................ 102

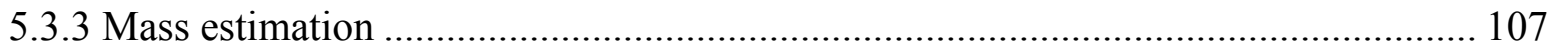

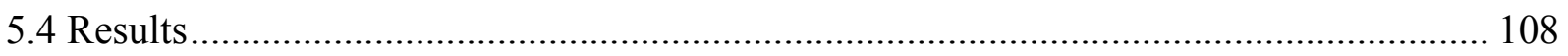

5.4.1 Iceberg characteristics and mass estimation ……..................................................... 108

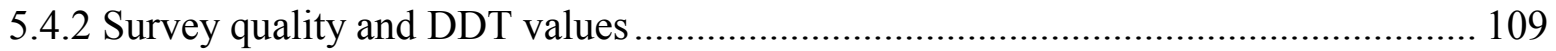

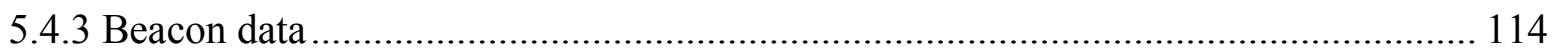

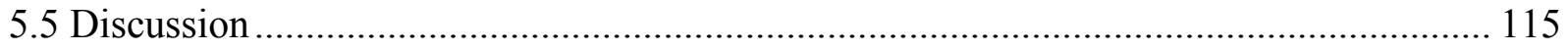

5.5.1 Data collection and processing considerations ..................................................... 115

5.5.2 Comparison to previous work and recommendations............................................. 120

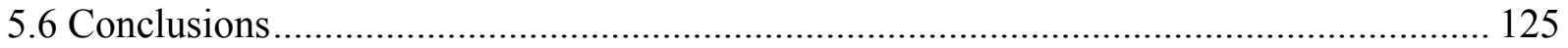

Chapter 6 - The aftermath of Petermann Glacier calving events (2008-2012): Ice island size distributions and meltwater dispersal................................................................................... 127

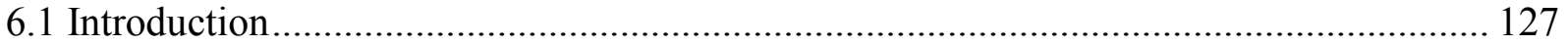

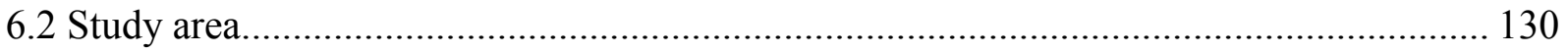

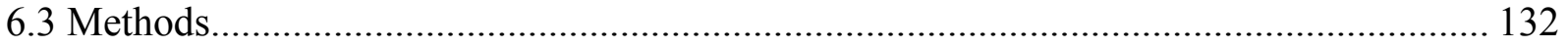

6.3.1 The CI2D3 Database and initial data sub-setting ................................................... 132

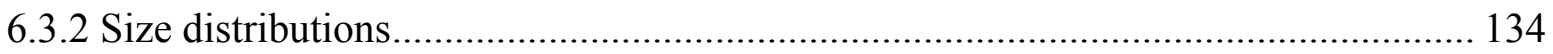

6.3.3 Meltwater dispersal .............................................................................................. 136

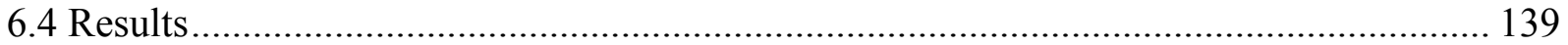

6.4.1 Overview of ice island drift and deterioration after Petermann Glacier calving events

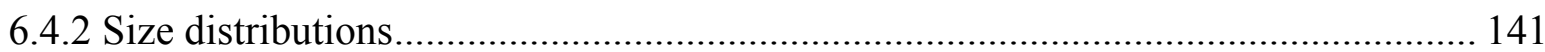

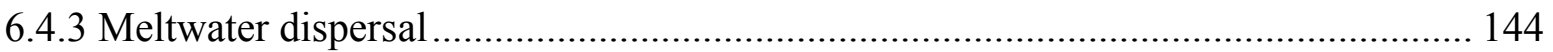

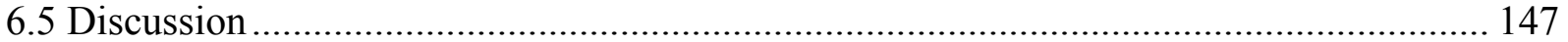

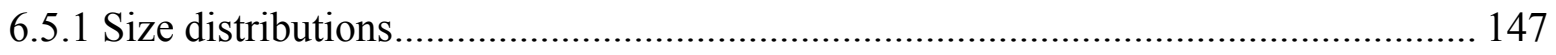

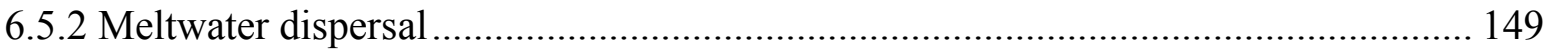

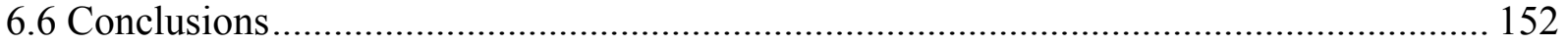

Chapter 7 - Conclusions and directions for future research ……………………………….... 155 


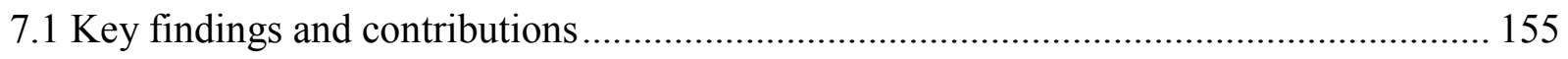

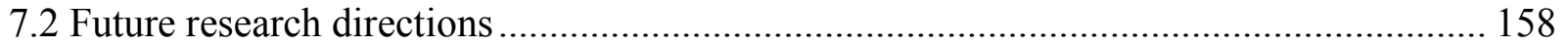

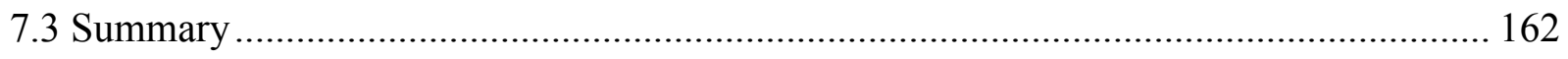

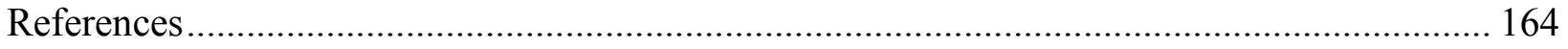




\section{List of tables}

Table 4.1: Ablation and total thinning magnitudes and rates per period.

Table 4.2: Descriptive statistics and sensitivity analysis results for the variables included in the forced convection basal ablation model calibration 65

Table 4.3: Descriptive statistics of ice island thickness, thinning, and surface ablation as measured by the mobile ice penetrating radar transect and ablation stake measurements conducted in 2016 .

Table 5.1: Quoted accuracies and calculated positional uncertainties used in data processing for Canatec beacons units (T. Sylvestre, personal communication), Solara FT2000 tracking beacons (Solara Remote Data Delivery, 2010) and higher-quality, dual-frequency GPS following Precise Point Positioning (PPP) processing using an online tool from Natural Resource Canada (TopCon, 2016; Natural Resources Canada, 2016) 93

Table 5.2: Aerial photography and terrestrial laser scanning (TLS) survey equipment

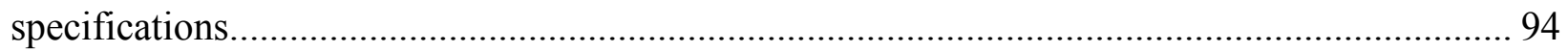

Table 5.3: General and technique-specific details pertaining to the surveys of i1 and i2......... 106

Table 5.4: Precision assessment of the aerial photography with structure-from-motion photogrammetry processing (SfM) and terrestrial laser scanning (TLS) surveys for i1 and i2 by survey scenario.

Table 5.5: Field campaign considerations for aerial photography surveying (with subsequent structure-from-motion (SfM) processing) and terrestrial laser scanning (TLS) surveying ........ 123

Table 6.1: Spatial snapshots used to assess variation in size distributions 135 


\section{List of figures}

Figure 2.1: Ice island terminology and deterioration processes.. ………….............................. 10

Figure 2.2: Source locations of Canadian Arctic ice islands. .................................................... 11

Figure 2.3: Example of an ice island observed with a satellite-borne synthetic aperture radar (SAR)

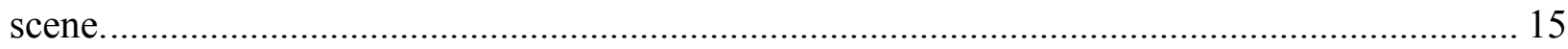

Figure 3.1: Ice island study subjects and other locations of interest ........................................ 25

Figure 3.2: Petermann Ice Island (PII)-A-1-f as situated in July 2016 ..................................... 28

Figure 3.3: Iceberg survey targets and surveying equipment used Chapter 5 .............................2 29

Figure 3.4: Example contents of the Canadian Ice Island Drift, Deterioration and Detection

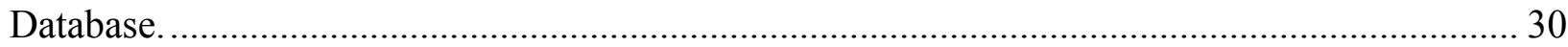

Figure 3.5: Simplified workflow associated with measuring ice thickness from ice penetrating

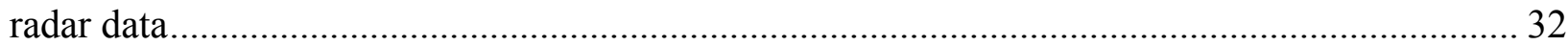

Figure 3.6: Ice islands identified in SAR images and the polygons (green outlines) that were digitized as part of the Canadian Ice Island Drift Deterioration and Detection Database ............ 38

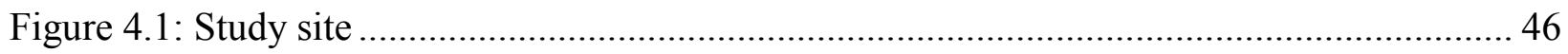

Figure 4.2: Instruments installed on Petermann Ice Island (PII)-A-1-f on 20 October 2015....... 48

Figure 4.3: Locations of the GreenEdge project and the July and September 2016 casts for temperature, salinity and current profiling near to Petermann Ice Island (PII)-A-1-f.................. 52

Figure 4.4: A radargram showing the reflected returns that represent the ice-water interface collected with a mobile ice penetrating radar (mIPR) system .................................................... 56

Figure 4.5: Total thickness change, surface ablation and basal ablation ..................................... 60

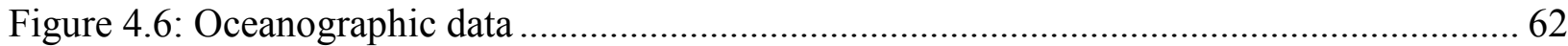

Figure 4.7: Petermann Ice Island (PII)-A-1-f thickness measurements collected in 2016 with a mobile ice penetrating radar (mIPR).

Figure 4.8: Spatial variation in morphology and thinning between May and September 2016 ... 69 
Figure 4.9: a) Thickness change on Petermann Ice Island (PII)-A-1-f calculated from repeat mobile ice penetrating radar (mIPR) transects displayed on a Fine-Quad RADARSAT-2 scene acquired on 28 September 2016 (shown in greyscale) .... . 71

Figure 4.10: Sidewall erosion and fracturing of Petermann Ice Island (PII)-A-1-f between November 2015 and September 2017 73

Figure 4.11: Percentage of original volume lost to areal extent reduction, surface ablation and basal ablation for Petermann Ice Island (PII)-A-1-f. 74

Figure 4.12: Deterioration history of Petermann Ice Island (PII)-A-1-f prior to grounding. ....... 76

Figure 5.1: Location and images of the surveyed icebergs, i1 and i2. Bathymetry data were obtained from the 2-minute Gridded Global Relief Data - ETOPOv2 (National Geophysical Data Center, 2006). 90

Figure 5.2: Surveying equipment. 91

Figure 5.3: Processing and analysis workflow for aerial photography data with structure-frommotion (SfM) processing or terrestrial laser scan (TLS) survey data..... 97

Figure 5.4: Example of the TLS point cloud drift correction procedure over three different survey segments 101

Figure 5.5: Simplified illustration of the Multiscale Model-to-Model Cloud Comparison algorithm 103

Figure 5.6: M3C2 algorithm output for SfM-generated point cloud comparison..................... 110

Figure 5.7: M3C2 algorithm output for TLS-generated point cloud comparisons

Figure 5.8: Histograms of $\varepsilon_{i}$ 112

Figure 5.9: Example of idealized ice loss due to the two general ice island deterioration types: a) 'chronic' deterioration occurring between Time 1 (T1) and Time 2 (T2), assuming here that all sidewalls recede at a slower rate than $b$ ) 'acute' deterioration that occurs at a specific location between $\mathrm{T}_{1}$ and $\mathrm{T}_{2}$. 116

Figure 5.10: Normal $(N)$ orientation and surface roughness between two compared point clouds. 119

Figure 6.1: Calving events at the Petermann Glacier 127 
Figure 6.2: Bathymetry and ocean currents in the study area (National Geophysical Data Center, 2006)

Figure 6.3: Illustration of Petermann ice island observations represented in the Canadian Ice Island Drift, Deterioration and Detection (CI2D3) Database 133

Figure 6.4: Ice island movement through the study area, colour coded by time since calving, for the a) 2008 , b) 2010 and c) 2012 Petermann Glacier calving events 140

Figure 6.5: Ice island size distributions and distribution modelling (2010) 142

Figure 6.6: Ice island size distributions and distribution modelling (2012) 143

Figure 6.7: Spatial distribution of meltwater input, shown in gigatonnes (Gt), into the study area over the time period that the drift and deterioration of ice islands originating from the a) 2008, b) 2010 and c) 2012 Petermann Glacier calving events were monitored. 145 


\section{List of appendices}

Appendix A: Stationary ice penetrating radar details................................... 184

Appendix B: Image processing and polygon digitization error......................... 185

Appendix C: List of symbols and acronyms..................................... 186 


\section{Chapter 1 - Introduction}

The research presented in this thesis concerns the physical processes that contribute to the deterioration of large, tabular icebergs. The 'ice island' study subjects used in this thesis were located in eastern Canadian waters and originated at the Petermann Glacier of northwest Greenland. The thesis also documents the development of techniques for the detection of threedimensional (3D) ice island deterioration, and the benefit of utilizing complementary field and remotely sensed observations is apparent. This introductory chapter provides justification for the specific objectives of this thesis and the need for continued ice island deterioration research in the context of a changing climate.

\subsection{Ice islands in a changing climate and research justification}

Immense, tabular icebergs have been described as 'ice islands' since the Resolution and Adventurer dodged the hazards during James Cook's 1772-1775 expedition to circumnavigate Antarctica (Herdman, 1959). These stable platforms were used for military operations and also served as research stations in the Arctic Ocean for 40 years, ending in 1992 (Belkin and Kessel, 2017; Van Wychen and Copland, 2017). They have been observed frequently in both Polar Regions as the conditions conducive to the calving of floating ice tongues (FITs) and ice shelves (i.e., reduced sea ice extents and warmer ocean and atmospheric temperatures) become more common with the onset of climate change (Copland et al., 2017). The reduction in Arctic sea ice extent increases the likelihood of open water adjacent to ice shelves and FITs (Copland et al., 2007; Zhang et al., 2013; IPCC, 2014). The decreased back-pressure exerted on these ice features leads to an increased susceptibility to calving, as does the reduced protection from ocean and wind driven waves (Herdes et al., 2012; Nick et al., 2013; Copland et al., 2017; Hill et al., 2017). 
Recent Arctic ice island calving events that have coincided with these conditions include the loss of Ayles Ice Shelf (Ellesmere Island) in 2005 (Copland et al., 2017) as well as the reduction of the Nioghalvfjerdsfjorden (Reeh et al., 2001) and Petermann (Münchow et al., 2014; L. Desjardins, personal communication) FITs in Greenland in 1997 and 2010, respectively. Increases in ocean and atmospheric temperatures have also been observed along Greenlandic and Antarctic coasts, causing thinning through increased surface and basal ablation, which, in combination with the aforementioned stresses, also increases the calving potential of FITs and ice shelves (Johnson et al., 2011; Nick et al., 2013; Liu et al., 2015; Hill et al., 2017). Copland et al. (2017) expect that these calving events will continue as the prerequisite conditions are projected to persist in the future (Nick et al., 2013; Straneo et al., 2013; Münchow et al., 2014).

A major focus of ice island research in Antarctica has been the magnitude and consequences of the freshwater dispersal from the Antarctic Ice Sheet due to the calving and drift of these massive icebergs (Gladstone et al., 2001; Silva et al., 2006; Smith, 2011; Merino et al., 2016; Stern et al., 2016). This spatial re-distribution can impact the physical, chemical and biological composition of surrounding ocean waters (Vernet et al., 2012; Smith et al., 2013; Stern et al., 2015), influence sea ice formation (Stern et al., 2016) and potentially contribute to climatic change through the disruption of ocean circulation patterns (Aoki et al., 2017). In addition, Scambos et al. (2008) suggest that the deterioration of ice islands as they drift to lower latitudes can be used as a proxy for the future impacts of climate change to large ice features (e.g., ice shelves) located at higher latitudes.

Ice islands and icebergs also have the potential to transport freshwater far from the Greenland Ice Sheet (Wagner and Eisenman, 2017; Marson et al., 2018); however, the dispersal of fresh water with drifting ice islands has been studied less frequently in the Arctic. Though often much smaller 
than their Antarctic counterparts, Arctic ice islands are still considered 'extreme ice features' (McGongial et al., 2011) and ice island and iceberg research in the Northern Hemisphere has often been driven by the related concerns of the offshore natural resource extraction and shipping industries. This is due to their large size as well as the production of smaller ice hazards throughout their deterioration (Sackinger Shoemaker, et al., 1985; McGonigal et al., 2011; Ballicater Consulting, 2012; Mueller et al., 2013; Fuglem and Jordaan, 2017). The offshore natural resource extraction industry incorporates both the occurrence probability and damage potential when calculating the risk magnitude associated with ice hazards (Ballicater Consulting, 2012; Fuglem and Jordaan, 2017), and zonal occurrence probability assessments have been conducted for both the western (Li et al., 1989; McGonigal et al., 2011) and eastern (C-CORE, 2005) Canadian waters. Petermann ice islands (PIIs) can pose direct risks to vessels and the natural resource extraction operations in the latter region (Peterson, 2011; Saper, 2011).

The paucity of in-situ ice island deterioration data hampers analytical and modelling efforts for both freshwater flux and hazard characterization. The lack of data is largely due to the logistical difficulties of gaining field access to ice islands in remote locations (Crawford, 2013; Mueller et al., 2013; Wagner et al., 2014). It is necessary to systematically conduct field operations to collect deterioration data for analysis, further develop remote sensing monitoring techniques and improve drift and deterioration models. Recent calving events at the Petermann Glacier in northwest Greenland have provided numerous study subjects that have been used to examine ice island deterioration in eastern Canadian waters (Forrest et al., 2012; Halliday et al., 2012; Wagner et al., 2014; Crawford et al., 2015, 2016; Stern et al., 2015). However, the current compilation of ice island deterioration research in this region exhibits the following three shortcomings: no long term field dataset of ice island thinning has been collected, a framework for quantifying the error 
associated with field deterioration assessment has not been developed and the ice island flux through eastern Canadian waters after relatively large Petermann Glacier calving events has not been comprehensively monitored and analyzed. The latter issue specifically concerns the region through which PIIs drift. However, the first two shortcomings pertain to ice island research conducted in both the Arctic and Antarctic.

\subsection{Purpose}

The overarching aim of this thesis is to improve the understanding of ice island deterioration through the development and use of novel techniques and datasets. The different techniques and datasets were used to investigate deterioration processes that occur at varying spatial and temporal scales. Together, this body of research provides a framework for understanding vertical deterioration (i.e., thinning through basal and surface ablation), small-scale areal deterioration (e.g., wave erosion), and large-scale areal deterioration (e.g., fracturing). Large-scale areal deterioration is implicated in ice island size distributions. The size-frequency distributions of ice islands in eastern Canadian waters are evaluated with a dataset that spans 2008 to 2012, and the same dataset is used to quantify meltwater dispersal after large calving events from the Petermann Glacier.

Small-scale areal deterioration and vertical deterioration are discussed in terms of changes that occur over daily, weekly and yearly timescales. It became apparent when developing a study to assess small-scale areal deterioration that it was unknown to what level existing surveying techniques could detect the deterioration of a drifting iceberg or ice island. The design of a specific study then evolved to determine this, and the results presented in Chapter 5 represent a substantial contribution to the observation of small-scale areal deterioration. While the subjects for each of 
the three studies originated at the Petermann Glacier, the findings from these investigations are pertinent to understanding ice island deterioration in both Polar Regions.

The five objectives of this thesis are listed below. The associated thesis chapter, general deterioration type and general type of data collection are included in parentheses.

1) Quantify ice island surface and basal ablation rates and the contribution of these processes to thinning and overall deterioration (Chapter 4, vertical deterioration, field data collection and satellite remote sensing).

2) Conduct the first field calibration of an ice island basal ablation model with field data (Chapter 4, vertical deterioration, field data collection).

3) Quantify the precision of aerial photography with structure-from-motion processing and terrestrial laser scanning survey techniques and evaluate their ability to detect ice island deterioration (Chapter 5, small-scale areal deterioration, field-based remote sensing).

4) Determine the optimal fit of statistical distributions to the size-frequency distributions of PIIs observed at different locations and time intervals after a calving event to infer the importance of different deterioration mechanisms (Chapter 6, large-scale areal deterioration, satellite remote sensing).

5) Quantify the spatial distribution of freshwater input in eastern Canadian waters from the drift and deterioration of PIIs (Chapter 6, large-scale areal deterioration).

In meeting these objectives, a number of new instruments, tools, and a dataset were developed to detect and monitor ice island deterioration. This represents a further contribution of this thesis. The necessity of undertaking investigations across a range of scales to investigate specific deterioration processes and develop a better understanding of complete, 3D ice island deterioration is demonstrated through the work presented in this thesis. The complementarity of field and remote 
sensing data collection for ice island deterioration analysis is also shown. This research provides a foundation for future ice island research in the Canadian Arctic, and yet is germane to the study of Antarctic ice islands as well.

\subsection{Thesis structure and chapter overviews}

This thesis is structured in an integrated manuscript format. Introductory material, provided in chapters 1, 2 and 3, sets the groundwork for the analytical studies presented in chapters 4, 5 and 6 . These substantive chapters are composed of standalone manuscripts that are published works, or are intended for publication soon after the completion of the thesis. Each of the three independent studies improves our knowledge regarding the detection of, and/or the physical processes contributing to, ice island deterioration. The three chapters are complementary with respect to scale, approach and deterioration process under study.

Chapter 1 (this chapter): Introduction: This chapter presents the importance of ice island research in the context of a changing climate and increased offshore activity. It also identifies current research needs and highlights how the three standalone, manuscript-based chapters are complementary to one another.

Chapter 2: Background on deterioration processes and measurement techniques: Chapter 2 explains the physical deterioration processes implicated in chapters 4, 5 and 6 . It also reviews previous literature that investigated these processes with common data collection and analysis methods. The chapter identifies and summarizes existing knowledge gaps that this thesis fills.

Chapter 3: Rationale: study sites, data collection and data processing: This chapter justifies the focus on ice islands originating from the Petermann Glacier and the choice of specific sites for field study. It provides the rationale behind the use of the data collection and analysis methods 
specifically used for this thesis. It also gives further details on these methods that are not included in the subsequent manuscript-based chapters.

Chapter 4: The thinning of 'Petermann Ice Island-A-1-f': Ablation magnitudes and model calibration with ice penetrating radar. This chapter analyzes the deterioration that occurs to the vertical dimension of an ice island and assesses thinning in terms of both spatial and temporal variation. I calibrated a commonly utilized basal ablation model using the first continuous, longterm field dataset of ice island thinning rate. The spatial variation in thinning is determined with repeat mobile ice penetrating radar (mIPR) transects. The observed thinning is put into context with respect to the overall ice island deterioration with satellite-borne synthetic aperture radar (SAR) acquisitions. The contributions of fracturing, surface and basal ablation to overall deterioration are quantified.

Chapter 5: Surveying drifting icebergs and ice islands: Deterioration detection and mass estimation with aerial photogrammetry and laser scanning. This work sets the stage for future ice island deterioration field campaigns by determining the minimum threshold of deterioration that must occur for detection by two commonly utilized iceberg surveying techniques: terrestrial laser scanning and aerial photography with structure-from-motion photogrammetry processing. Data for this error assessment were collected with triplicate surveys of two ice island fragments located offshore Newfoundland and Labrador, Canada. Discussion of the applicability of the two techniques to a range of data collection scenarios provides direction for future surveying campaigns with either industrial or research interests in mind. 
Chapter 6: The aftermath of Petermann Glacier calving events (2008-2012): Ice island size distributions and meltwater dispersal. This chapter provides the first assessment of deterioration that occurred across the full population of ice islands originating from Petermann Glacier calving events in 2008, 2010 and 2012. It evaluates the fit of statistical distributions to the size-frequency distribution of PIIs. The results are discussed in terms of dominant ice island deterioration processes, and the role of fracturing to ice island deterioration is revisited. The chapter also reports the first calculation of the spatial distribution of meltwater input through the region after such large calving events at northern Greenland FITs. The basal ablation model that was calibrated in Chapter 4 is used for this analysis. A newly constructed database, the Canadian Ice Island Drift, Deterioration and Detection (CI2D3) Database, was the main data source for this study.

Chapter 7: Conclusion. This chapter summarizes the key research findings of the work documented in this thesis. This includes the overarching, scientific contributions of the thesis and the specific outcomes of the individual manuscripts. The chapter relates the thesis research to the knowledge gaps presented in chapters 1 and 2 . 


\section{Chapter 2 - Background on deterioration processes and measurement techniques}

This chapter provides background on ice islands and the deterioration processes that are investigated in the subsequent manuscript-based chapters. It also reviews methods used to study ice island deterioration. Chapter 2 ends with a summary of identified knowledge gaps and how this thesis addresses them. Chapter 3 provides specific details regarding the methods used in this thesis.

\subsection{Ice islands}

Ice islands are classified as tabular icebergs due to their constant height above water and vertical sidewalls. They normally have lengths of $>500 \mathrm{~m}$, drafts (depth below waterline) between 60 to $75 \mathrm{~m}$ and freeboards (height above waterline) of $>5 \mathrm{~m}$ (McKenna, 2005; Peterson et al., 2009). However, thinner ice islands with smaller freeboards have been observed in the western Canadian Arctic (Jeffries, 1992). The above and below water portions are referred to as the sail and keel, respectively (Fig. 2.1).

Ice islands are referred to as 'tabular icebergs' in the Southern Hemisphere (Stern et al., 2017). While these Antarctic icebergs can be an order of magnitude larger than their Arctic counterparts, they are both referred to as ice islands in this thesis. Fracturing also generates smaller pieces that the Manual of Ice identifies as 'ice island fragments' (CIS, 2005). The sizes of initially calved ice islands can overlap with fragments generated through the fracture of ice islands originating from larger calving events. This thesis therefore regularly refers to both the initially calved ice islands as well as subsequently generated fragments as 'ice islands'. The term 'iceberg' is used when previous studies focused on these smaller study subjects or if a study was analyzing both icebergs and ice islands. 


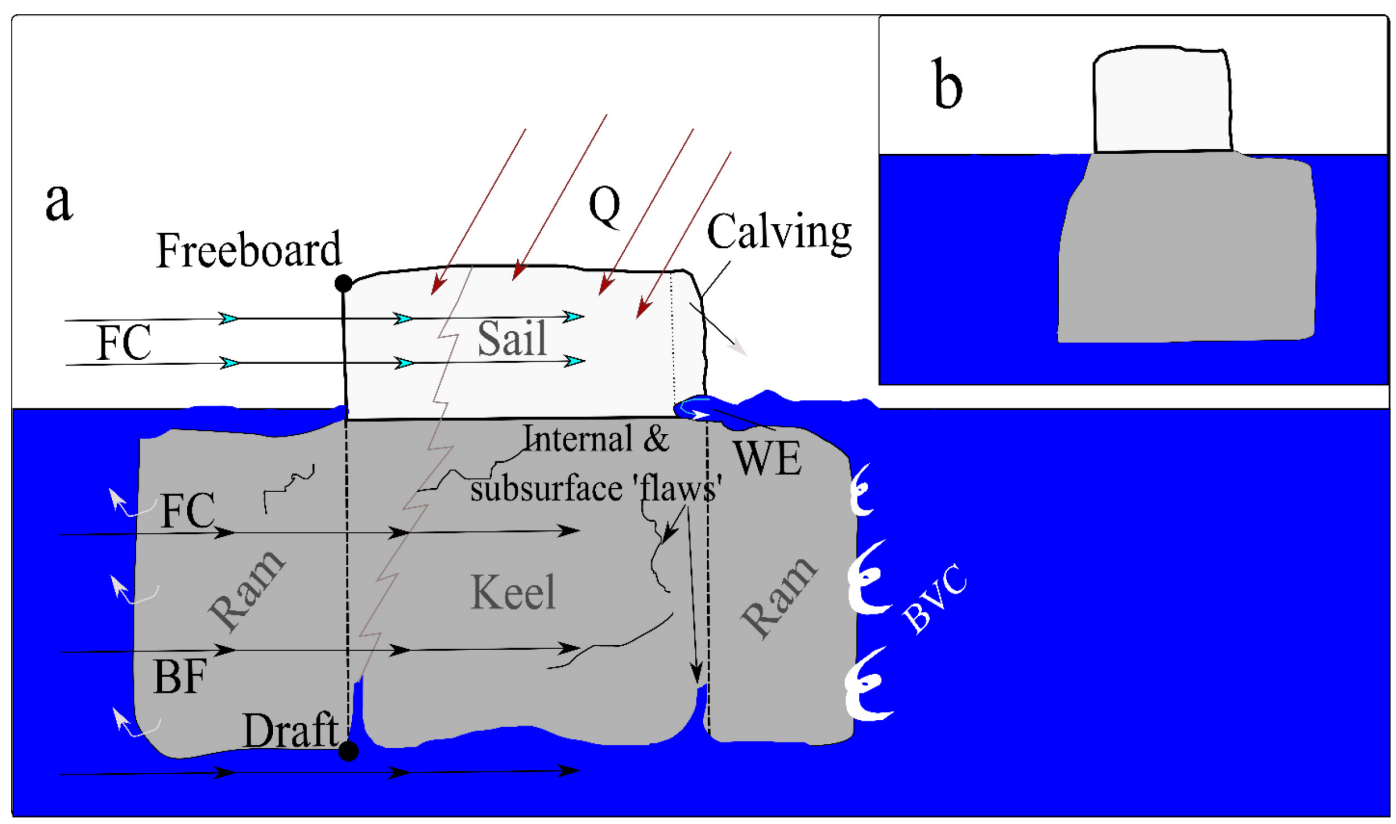

Figure 2.1: Ice island terminology and deterioration processes. a) An ice island prior to buoyancy-induced fracture (BF; stresses represented by white arrows) and calving. Other deterioration processes include forced convection (FC), buoyant-vertical convection (BVC; represented as thick white lines), wave erosion (WE) and radiative and turbulent fluxes (Q). b) The ice island after calving and BF along the line of stress denoted by the jagged line in a).

Ice islands located in the Canadian Arctic or sub-Arctic originate from thick coastal ice (i.e., ice shelves or FITs). Their primary sources are the ice shelves of northern Ellesmere Island and the FITs of northwest Greenland (Rudkin et al., 2005). Figure 2.2 shows these locations and examples of ice islands that originated from each region. 


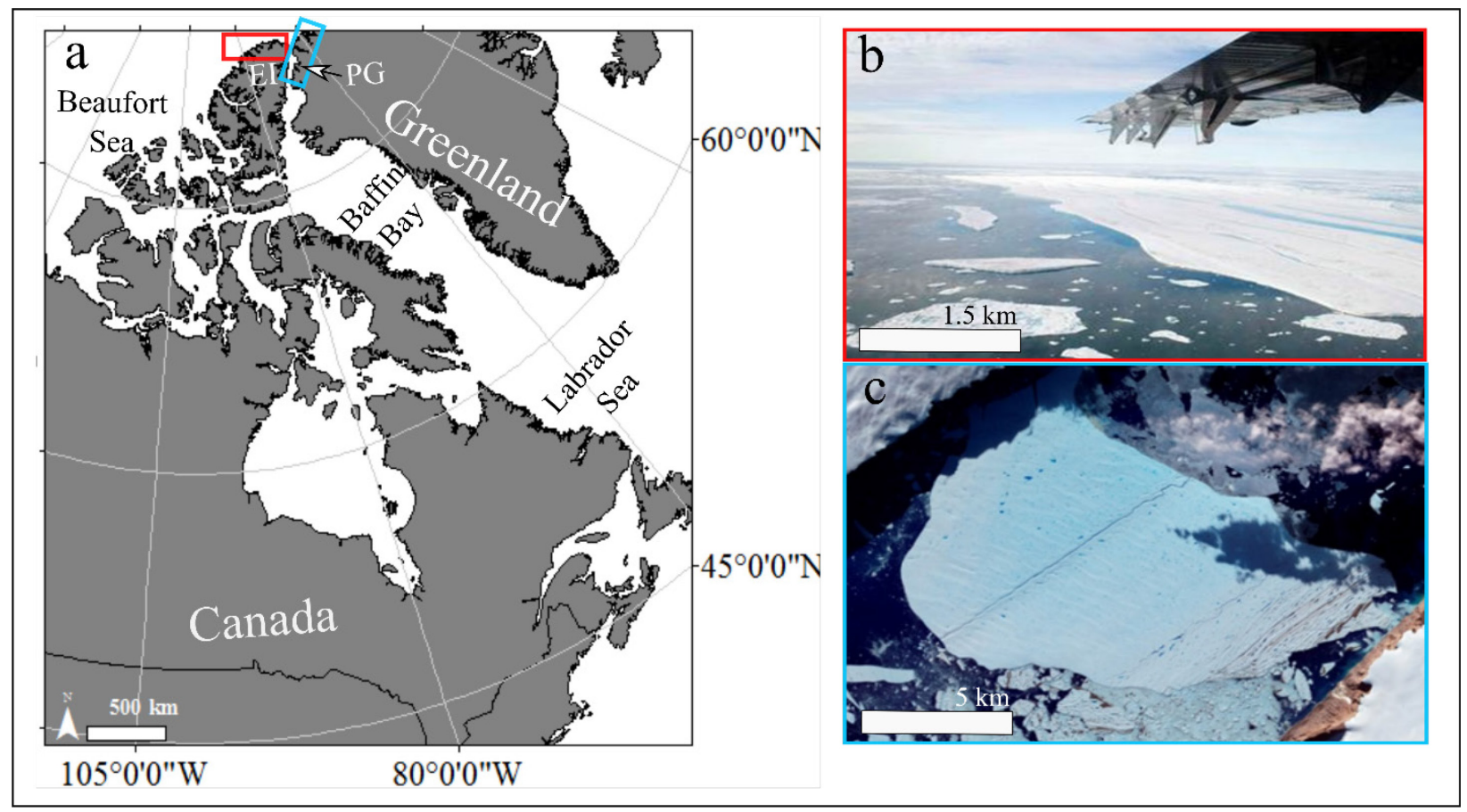

Figure 2.2: Source locations of Canadian Arctic ice islands. a) The ice shelves of northern Ellesmere Island (EI) and the floating ice tongues of northwest Greenland (including the Petermann Glacier (PG)) are within the red and blue rectangles, respectively. b) An ice island that calved from the Ward Hunt Ice Shelf of EI in 2008. c) The $\sim 130 \mathrm{~km}^{2}$ Petermann Ice Island which calved from the PG in 2012. The image in b) is courtesy of Sam Soja and originally contained in Mueller et al. (2013). c) is an ASTER (C) NASA) image from 2012-07-21.

North American ice island research in the 1980s and 1990s primarily focused on ice islands in the Beaufort Sea. Sackinger, Serson, et al. (1985) and Li et al. (1988) analyzed occurrence frequencies, Jeffries et al. (1987) analyzed geometry and internal ice structure, and Jeffries and Sackinger (1989a,b; 1990) assessed the capabilities of SAR to detect ice islands. Studies in eastern Canadian waters, such as Baffin Bay and the Labrador Sea, primarily began with the descriptions of ice island drift by Higgins (1989) and Newell (1993). The Petermann Glacier of northwest Greenland is the main source of ice islands in these water bodies and regional research has increased since 2003 following the calving and drift of the 2001 Petermann Ice Island (PII) (Peterson, 2005; Peterson et al., 2009; Peterson, 2011; Halliday et al., 2012; Lewis-Paley, 2015). 


\subsection{Fracture and detection with synthetic aperture radar}

The fracture of PIIs that are initially generated after Petermann Glacier calving events results in a flux of ice islands that drift through eastern Canadian waters (Crawford et al., 2018). Efforts are ongoing to model ice island fracture processes (Crocker et al., 2017, Stern et al., 2017). However, the location and timing of fractures is difficult to predict since structural flaws (i.e., pre-existing weaknesses) are often concealed (Savage, 2001; Scambos et al., 2008; Ballicater Consulting, 2012).

Fatigue is an important contributor to fracturing, as the threshold for failure decreases as surface (e.g., crevasses) or internal flaws extend with movement induced by passing ocean swells (Diemand et al., 1987; Scambos et al., 2008; Ballicater Consulting, 2012). Collisions with shoreline bathymetry have also been observed to induce fracture in the Antarctic (MacAyeal et al. 2008; Martin et al., 2010). Fracture can also result from buoyancy stress imposed by an underwater projection (also known as a 'ram', skirt' or 'foot') (Fig. 2.1). Such projections impart stresses towards the centre of an ice island and a fracture will ultimately occur at a location influenced by the length of the underwater projection as well as the thickness of the ice island and the composition of its internal flaws (Diemand et al., 1987; Scambos et al., 2005, 2008; Wagner et al., 2014).

Scambos et al. (2005) used true colour composite images produced from data collected by the satellite-borne Moderate Resolution Imaging Spectroradiometer (MODIS) to observe the deterioration of Antarctic ice islands and model buoyancy-induced fracture. Alternatively, Wagner et al. (2014) modeled this process after observing a buoyancy-induced fracture event that occurred to PII-B, a grounded ice island in western Baffin Bay. Such field data are valuable for analyzing specific deterioration mechanisms; however, it is necessary to collect data over large spatial and 
temporal extents to capture the recurrent fracturing and proliferation of ice islands after large ice island calving events at ice shelves or FITs. Data collection with satellite remote sensing is optimal for this task. However, systematic compilation of such data is necessary to identify and monitor the drift and deterioration of the numerous ice islands.

\subsection{Remote sensing and ice island databases}

Temporal and spatial assessments of iceberg occurrence offshore of Newfoundland (Crocker et al., 2004; C-CORE, 2005; Hill et al., 2008) and by a series of publications concerning Antarctic ice island distributions (Budd et al., 1980; Hamley and Budd, 1986; Jacka and Giles, 2007; Romanov et al., 2012; Tournadre et al., 2012, 2015, 2016) have relied upon iceberg and ice island databases. These publications evolved from using shipborne observations (Budd et al., 1980; Hamley and Budd, 1986; Jacka and Giles, 2007; Romanov et al., 2012) to remotely sensed altimetry data (Tournadre et al., 2012, 2015, 2016). The use of the latter greatly increased the areal extent under investigation and lessened the spatial bias of observations (Budd et al., 1980). Work by Tournadre et al. $(2015,2016)$ and the foundational research of Hamley and Budd (1986), Jacka and Giles (2007), and Romanov et al. (2012) inspired research conducted in this thesis on ice island size distributions. The above studies all focused on ice islands located in the Antarctic. The size distribution of ice islands present in eastern Canadian waters after Petermann Glacier calving events is currently unknown.

The National Ice Center (NIC; USA) uses remotely sensed SAR, visible, and infrared imagery to $\log$ the occurrence of Antarctic ice islands $>18.5 \mathrm{~km}$ in length in their database (Silva et al., 2006). Researchers at Bringham Young University (BYU) generated a database for Antarctic ice islands $>6 \mathrm{~km}$ in length from scatterometer data compiled since 1999 (Stuart and Long, 2011). The NIC and BYU databases were recently compiled into a single entity that contains information 
on over 500 single Antarctic ice islands (Budge and Long, 2018; BYU/NIC, 2017). Tournadre et al. (2015) used complementary altimetry data to add freeboard information to the NIC and BYU databases. With this enhanced database, Tournadre et al. (2015) determined the spatial distributions of ice island freeboard and length in various sectors of Antarctica. Tournadre et al. (2016) combined small $\left(<8 \mathrm{~km}^{2}\right)$ and large $\left(>200 \mathrm{~km}^{2}\right)$ ice island datasets to create the ALTIBERG database housed at CERSAT (Brest, France). The combination of the NIC, BYU and ALTIBERG databases now allows for estimates regarding the size distribution of ice islands and icebergs with surface areas between 0.1 and $10,000 \mathrm{~km}^{2}$ in the Southern Hemisphere (Tournadre et al., 2015, 2016).

Two large limitations exist with altimetry identification of icebergs. First, sea ice hinders the detection of icebergs and second, it is not possible to trace the movement and deterioration of individual ice islands (Merino et al., 2016). A benefit of satellite-borne SAR is the use of microwave energy that allows for image capture regardless of weather conditions (i.e., cloud cover) and polar night (Jeffries and Sackinger, 1990; Doerry and Dickey, 2004; Lewis-Paley, 2015). Jeffries and Sackinger (1989a) used air-borne SAR instruments to identify and monitor ice islands adrift in the Beaufort Sea. Space-borne SAR sensors, such as those accompanying the polar orbiting RADARSAT-1 and -2 (R1 and R2) (Canadian Space Agency; Seguin et al., 2014), Sentinel-1 (European Space Agency; Attema et al., 2010) and TerraSAR-X (German Aerospace Agency; Gantert et al., 2013) satellites now provide extraordinary coverage of the Arctic and Antarctic. Scenes acquired by the SAR sensors on the R1 and R2 satellites have been used for satellite remote monitoring of individual ice islands in the eastern (Halliday et al., 2012; Stern et al., 2015; Lewis-Paley, 2015; Crawford et al., 2016) and western (De Abreu et al., 2003; 
McGonigal et al., 2011; Crawford, 2013) regions of the Canadian Arctic. Figure 2.3 shows an example of an ice island captured in an R2 image.

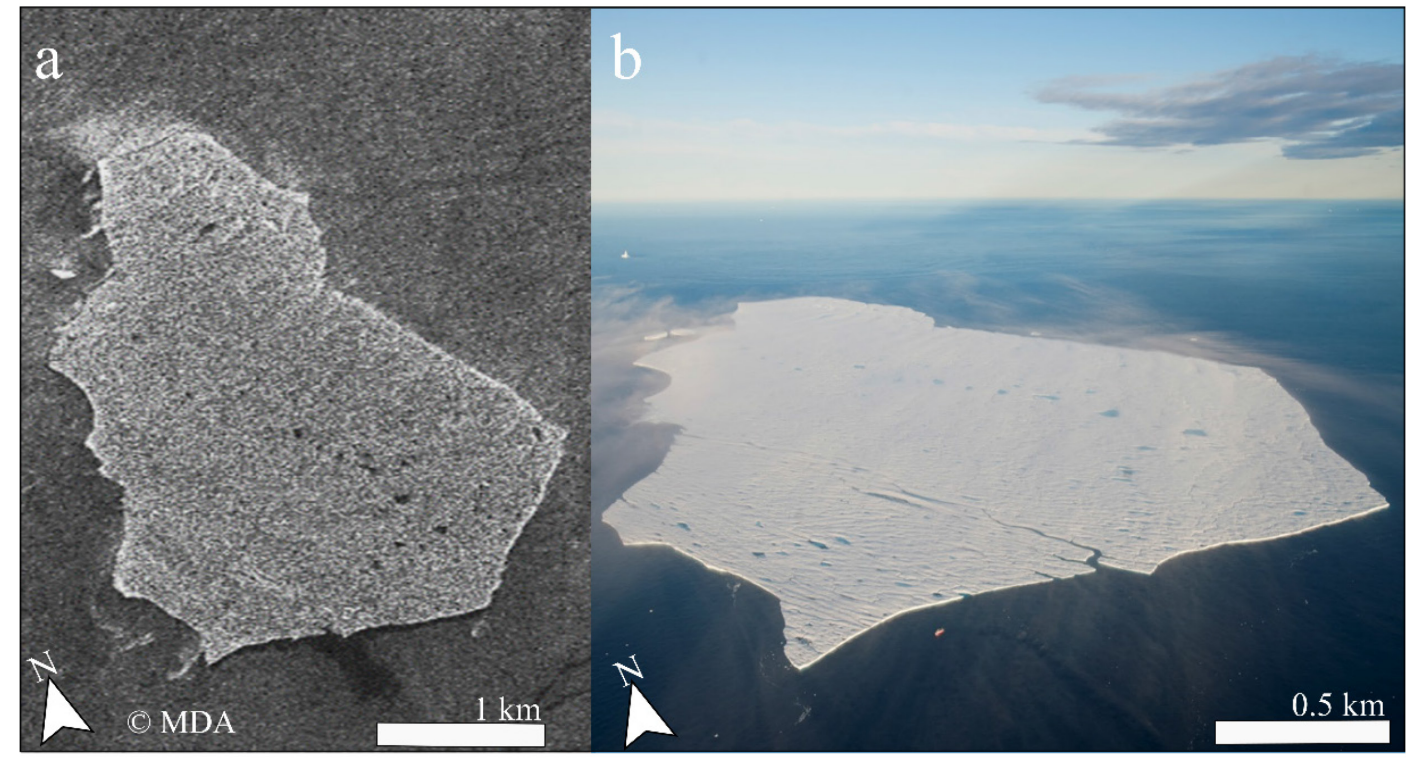

Figure 2.3: Example of an ice island observed with a satellite-borne synthetic aperture radar (SAR) scene. a) 'Petermann Ice Island (PII)-B-1' as imaged by RADARSAT-2 (R2) on August 8, 2012. b) PII-B-1 in an oblique camera image also taken in August 2012. Chris Packham provided the image in b). Note the scale in b) is approximate.

Tournadre et al. (2012) acknowledged the usefulness of SAR data for ice island detection and monitoring, but considered it a challenge to use for the study of ice island occurrence and deterioration over large spatial and temporal extents due to the large amount of data processing associated with SAR products. Wesche and Dierking (2015) were able to automate the identification of ice islands in a SAR dataset that covered the Antarctic coastline. However, this study was temporally limited to a 2-month period and was therefore an analysis of a snapshot in time as opposed to a longitudinal study to assess temporal changes in spatial and size distributions. In summary, lineage tracking is currently only available for the largest Antarctic ice islands ( $>$ 
$18.5 \mathrm{~km}$ in length; Tournadre et al., 2015). A comprehensive database that records the drift and deterioration of individual ice islands in the Northern Hemisphere does not exist.

\subsection{Freshwater inputs due to ice island deterioration}

The modelling studies of Gladstone et al. (2001), Silva et al. (2006), Martin and Adcroft (2010), Merino et al. (2016), Stern et al. (2016) and Rackow et al. (2017) all state the necessity to accurately model the drift and deterioration of Antarctic icebergs to better understand the impacts associated with freshwater dispersal. Merino et al. (2016) and Stern et al. (2016) state that the incorporation (or non-incorporation) of icebergs in general circulation models has an impact on the predicted coverage, thickness and location of sea ice formation due to the transport of freshwater far from its continental source. This has subsequent physical consequences on the surrounding ocean, such as the reduction of sea surface salinity and temperature plus an increase in the stratification of the water column near deteriorating ice islands (Stern et al., 2016).

Meltwater input resulting from deteriorating Antarctic ice islands also has biological impacts; Duprat et al. (2016) observed enhanced carbon levels and chlorophyll $a$ production over a radius up to 10 times the length of an ice island. Vernet et al. (2011) and Smith (2011) describe 'iceberg ecosystems' that are influenced by the presence of Antarctic icebergs. These icebergs cause biological (e.g., provision of minerals for diatoms), chemical (e.g., carbon and iron deposition) and physical (e.g., enhanced turbulence and upwelling) modifications to the structure of the water column (Helly et al., 2011; Smith, 2011; Stephenson et al., 2011; Vernet et al., 2011). Smith et al. (2013) infer that Arctic icebergs and ice islands could affect marine ecosystems through research conducted on Antarctic ice islands, and interest is rising in the role of icebergs in distributing freshwater from the Greenland Ice Sheet (Marsh et al., 2015; Enderlin et al., 2016; Wagner and Eisenman, 2017; Marson et al., 2018). However, a study has yet to be conducted with direct 
observations of ice island deterioration on the magnitude and dispersal of freshwater after large, episodic calving events at FITs in northwest Greenland.

\subsection{Sidewall recession}

Approximately $85 \%$ of the freshwater input from an individual ice island was estimated to be the result of processes that cause relatively small-scale areal change, or 'sidewall recession' (Ballicater Consulting, 2012). This involves wave erosion, forced or buoyant convection and calving (Fig. 2.1) (Savage, 2001; Ballicater Consulting, 2012). The term 'calving' can refer to the relatively small-scale break-off of overhanging slabs, as well as the break-off of an ice island from a FIT or ice shelf. In this thesis, I explicitly describe the latter as a 'calving event' or as occurring to tidewater glaciers or ice shelves. A low proportion (1 to $3 \%$ ) of iceberg and ice island melt is a result of buoyant convection, which is caused by the development of convection cells along keel sidewalls due to salinity and density differences between meltwater and ambient ocean water (Savage, 2001; Ballicater Consulting, 2012). Buoyancy-driven deterioration also largely affects tidewater glacier termini (Fried et al., 2015; Jackson et al., 2017). The resulting turbulence transfers heat to the keel of an ice island or submerged face of a tidewater glacier (White et al., 1980; Carroll et al., 2015). However, it has proven difficult to measure the magnitude of convective heat transfer to ice island keels and differentiate between the deterioration caused by this mechanism versus that caused by forced convection (Neshyba and Josberger, 1980; Ballicater Consulting, 2012). The differential movement between air or water and an ice island causes the latter (White et al., 1980; Savage, 2001). Deterioration of the above-water surfaces resulting from forced convection is minimal and likely causes $<5 \%$ of iceberg deterioration (Savage, 2001; Kubat et al., 2007). Section 2.7 discusses basal ablation, which results from this heat transfer process and affects the vertical dimension of an ice island, along with ice island thinning. 
Heat transfer by forced convection to the vertical sidewalls of an ice island, at and below the waterline, is more complex. Waves amplify forced convection at the waterline due to increased water velocity, resulting in wave erosion (Savage, 2001). Ballicater (2012) estimated that forced convection occurring at or below the waterline and not associated with wave erosion caused approximately $5 \%$ of the volume change undergone by a theoretical $1 \mathrm{~km}$ long ice island. Conversely, forced convection associated with wave erosion is responsible for the majority of the deterioration of an ice island. Progressive wave erosion along the waterline of an ice island creates a wave notch, and the slab of ice associated with the sail that remains above this wave notch will eventually break off after reaching a critical bending stress threshold (Fig. 2.1) (Robe et al., 1977; Savage, 2001; Ballicater Consulting, 2012). Combined, wave erosion and the subsequent calving of these overhanging slabs are estimated to cause approximately $80 \%$ of ice island and iceberg deterioration (El-Tahan et al., 1987; Ballicater, 2012). In addition, calving will lead to the development of underwater rams, which can eventually cause buoyancy-induced fracture (Fig.

2.1) (Diemand et al., 1987; Wagner et al., 2014).

\subsection{Sidewall recession surveying methods}

Satellite remote sensing does not provide adequate spatial or temporal resolution to observe the smaller-scale deterioration processes introduced in Section 2.5. Remote sensing data collection is therefore complemented by field programs that aim to detect small-scale deterioration (Venkatesh et al., 1985). At the same time, in-situ deterioration data are sparse due to the logistical difficulties, resource requirements (especially for longer-term observations), unpredictability of field success and the potentially dangerous nature of iceberg and ice island fieldwork (Robe et al., 1977; Venkatesh et al., 1985; Wagner et al., 2014). 
Previous iceberg deterioration studies have used stereo-photogrammetry to construct 3D iceberg representations by determining the elevation of common points captured in overlapping images (Robe and Farmer, 1976; Venkatesh et al., 1985; McKenna and Ralph, 2007). Enderlin and Hamilton (2014) used the same approach with repeat high-resolution WorldView-1/-2 stereosatellite imagery to build digital elevation models of icebergs and determine basal ablation rates. While high-resolution satellite imagery is increasingly available (Enderlin and Hamilton, 2014), structure-from-motion photogrammetry processing of aerial-photo surveys (SfM) is a relatively new, highly automated, low cost technique that does not rely on photo acquisition in traditional, parallel flight lines (Snavely et al., 2010; Fonstad et al., 2013). SfM uses algorithms that first identify corresponding points (or 'features') between photos in 2D and then use these to constrain the possible camera positions and finally triangulate the 3D locations of these feature points (Quan, 2010; Snavely et al., 2010; Fonstad et al., 2013). It is necessary to assign scale to the 3D point clouds that are generated through SfM processing, and ground control points are commonly used for this purpose (Westoby et al., 2012; Fonstad et al., 2013).

Terrestrial laser scanning (TLS) uses light detection and ranging (LiDAR) to generate 3D point clouds by measuring the time that light pulses, emitted across a range of angles, take to travel from the scanner to the target surface and back. For moving targets, such as icebergs, TLS surveys need to be corrected for drift. Iceberg surveys collected with TLS, aerial photography destined for SfM post-processing, and sonar have been conducted in the Canadian Arctic, Antarctica, Greenland fjords and offshore Newfoundland (Kimball and Rock, 2011, 2015; Hamilton et al., 2013; Wagner et al., 2014; Zhou et al., 2014; McGuire et al., 2016; Younan et al., 2016; Schild et al., 2017). Sonar is utilized for keel mapping, and similar to TLS, these surveys need to post-corrected for drift correction. Previous studies have used variations of iterative closest point algorithms to 
correct for iceberg drift. However, they are limited due to the application of constant translation and rotation magnitudes, when in reality, iceberg translation and rotation vary over the time that a survey is conducted (Kimball and Rock, 2011; McGuire et al., 2016). Kimball and Rock (2015) propose a sophisticated solution that uses a simultaneous localization and mapping approach to estimate the position of the surveying vehicle relative to the surveyed iceberg, as well as the trajectory of an iceberg. However, this method has only been tested with computer simulations. As such, the error of a field-tested workflow for detecting the deterioration of an iceberg or ice island has not been reported.

\subsection{Thinning through surface and basal ablation}

Turbulent and subsurface heat fluxes contribute to both surface and basal ablation, while the radiative flux only contributes to the former (Jansen et al., 2007; Crawford et al., 2015). The salinity gradient at the base of the ice island influences basal ablation, and ice island meltwater affects this gradient. The magnitude of basal ablation will also depend on the depth and salinitydependent freezing temperature at the keel depth of the ice island (White et al., 1980; Holland and Jenkins, 1999; Jansen et al., 2007).

The ablation occurring to the upper, horizontal surface of an ice island is referred to in this thesis as 'surface ablation' unless otherwise noted. Ballicater Consulting (2012) estimate that surface ablation resulting from radiative and turbulent heat transfer contributes relatively little (approximately $6 \%$ ) to overall ice island deterioration. Basal ablation theoretically contributes slightly more (approximately $8 \%$ ) due to greater forced convection occurring to the basal and submerged sidewall surfaces of an ice island (Section 2.5) (Savage, 2001; Ballicater Consulting, 2012). It is estimated that $13 \%$ of the overall deterioration of an ice island results from the 
combined ablation of the horizontal above- and below-water surfaces (Ballicater Consulting, 2012). However, very few field datasets of ice island ablation exist for comparison.

Crawford et al. (2015) and Halliday et al. (2012) report the few surface ablation rates recorded with field data collected from ice islands in the Canadian Arctic and sub-Arctic. Crawford et al. (2015) reported a mean July/August surface ablation rate of $3.3 \mathrm{~cm} \mathrm{~d}^{-1}$ and Halliday et al. (2012) reported a mean surface ablation rate of $4.9 \mathrm{~cm} \mathrm{~d}^{-1}$ for PII-A in the Labrador Sea in the summer of 2011. Surface ablation can also influence ice island fracture. Scambos et al. (2008) observed snowmelt to influence the rapid breakup of Antarctic ice islands through the stresses imposed by meltwater penetration into surface crevasses (Scambos et al., 2008).

Field observations of basal ablation are even sparser than those of surface ablation. Halliday et al. (2012) calculated an average basal ablation rate of $3.4 \mathrm{~cm} \mathrm{~d}^{-1}$ from spot ice thickness and surface ablation measurements collected from PII-A on two dates over the summer of 2011. Studies conducted on Antarctic ice islands report basal ablation magnitudes estimated from remotely sensed altimetry data and modeled surface ablation (Jansen et al., 2007; Bouhier et al., 2017). Due to the lack of field observations of ice island thinning and ablation, the calibration and validation of ice island basal ablation models has previously relied upon such estimated basal ablation rates and modeled oceanographic data.

\subsection{Observing ice island thinning with remote sensing and in-situ methods}

Ice island thickness is important for accurate drift forecasting, as the vertical extent of the keel and sail affect model output (Barker et al., 2004). Additionally, large amounts of basal and surface ablation, relative to areal change, will increase the likelihood of fracture events (Budd et al., 1980). Ice island keel dimensions are theoretically simple to approximate due to their tabular morphology (Ballicater Consulting, 2012); however, very few field observations of ice island thickness and 
thinning rates have been reported due to the challenges associated with returning to a rapidly deteriorating field site. Ice penetrating radar (IPR) thickness measurements of three ice islands in the eastern Canadian Arctic were documented by Hamilton et al. (2013), while Halliday et al. (2012) report thickness and thinning rates for PII-A while this $17 \mathrm{~km}^{2}$ ice island was adrift in the Labrador Sea. Thickness measurements and thinning calculations are all reported for spot locations in these studies, and in the case of Halliday et al. (2012) bulk thinning was calculated between two measurement dates.

Studies interested in the basal ablation of Antarctic ice islands have relied on deterioration estimates from satellite-borne altimetry data and surface ablation modelling (Jansen et al., 2007; Bouhier et al., 2017). Luckman et al. (2010) modeled the thickness of Antarctic ice islands from remotely sensed altimetry data sourced from the Geoscience Laser Altimetry System onboard ICESat (the 'Ice, Cloud and land Elevation Satellite'). Scambos et al. $(2005,2008)$ and Jansen et al. (2007) also used laser altimetry to monitor Antarctic ice island freeboard change. While the benefits of remote sensing for ice island thickness monitoring are great, Jacka and Giles (2007) noted that further research into the use of satellite-borne sensors is necessary for accurate ice island deterioration monitoring and stressed that techniques must be validated with field observations.

\subsection{Summary and connection with thesis objectives}

The previous sections provide background on the dominant ice island deterioration processes. These include thinning, processes leading to sidewall recession (e.g., wave erosion), and fracture. This chapter also reviewed the current body of ice island deterioration literature concerning these processes, their consequences, and methods utilized for their study.

Hundreds of ice islands were generated through the fracture of PIIs that calve from the Petermann Glacier (Crawford et al., 2018). However, the drift and deterioration of the numerous 
individual ice islands generated after Petermann Glacier calving events has not been analyzed. Ice island and iceberg databases compiled through the analysis of remotely sensed data are beneficial for this task due to their potential to cover large spatial and temporal extents. Field campaigns can collect higher resolution data that are valuable for the assessment of smaller-scale sidewall recession that results from a number of deterioration processes. Field data are also necessary for the calibration and validation of deterioration models. However, field observations are limited due to the inherit challenges associated with ice island fieldwork. Listed below are the limitations and gaps in the current body of literature that this thesis addresses. The associated objective (see Section 1.2) and manuscript chapter are included in parentheses.

- Field observations of ice island surface and basal ablation rates are limited (Objective 1, Chapter 4).

- Ice island basal ablation models have not been calibrated with field data (Objective 2, Chapter 4).

- The precision of TLS and SfM when applied to survey icebergs and ice islands is unknown; this is directly related to the ability of these techniques to detect the deterioration of these survey targets (Objective 3, Chapter 5).

- The size distribution of ice islands in eastern Canadian waters after Petermann Glacier calving events is unknown (Objective 4, Chapter 6).

- The spatio-temporal distribution of meltwater resulting from the deterioration of these ice islands has not been quantified (Objective 5, Chapter 6). 


\section{Chapter 3 - Rationale: study sites, data collection and data processing}

This chapter provides background on study locations and study subjects, and highlights the rationale for conducting concerted research on PIIs in eastern Canadian waters. Details regarding data collection and processing that are not included in the manuscript-based chapters are also included here.

\subsection{Study area}

The study subjects of this thesis are numerous ice islands and icebergs, all of which are known or believed to have originated from the Petermann Glacier of northwest Greenland $\left(80^{\circ} 45^{`} \mathrm{~N}\right.$, $\left.60^{\circ} 45^{\prime} \mathrm{W}\right)$. Figure 3.1 shows the location of the Petermann Glacier, relevant water bodies and the sites of ice island study subjects in this thesis. Historically, ice island calving events from the Petermann Glacier have been observed at intervals between 5 or 10 years (Higgins 1991); however, the glacier has been particularly active recently with calving events observed in 2008, 2010, 2011, 2012, 2013 and 2017 (Crawford et al., 2018; Desjardins et al., 2018; L. Desjardins, personal communication). The generation of ice islands is a typical result of the calving that occurs at FITs in northern Greenland (Higgins, 1989). These calving events are more akin to those that occur to Antarctic ice shelves than the smaller iceberg calving events from tidewater glaciers in southern Greenland (Enderlin et al., 2016). However, ice islands that originate from Greenland are often an order of magnitude smaller than their Antarctic counterparts (Tournadre et al., 2015). 


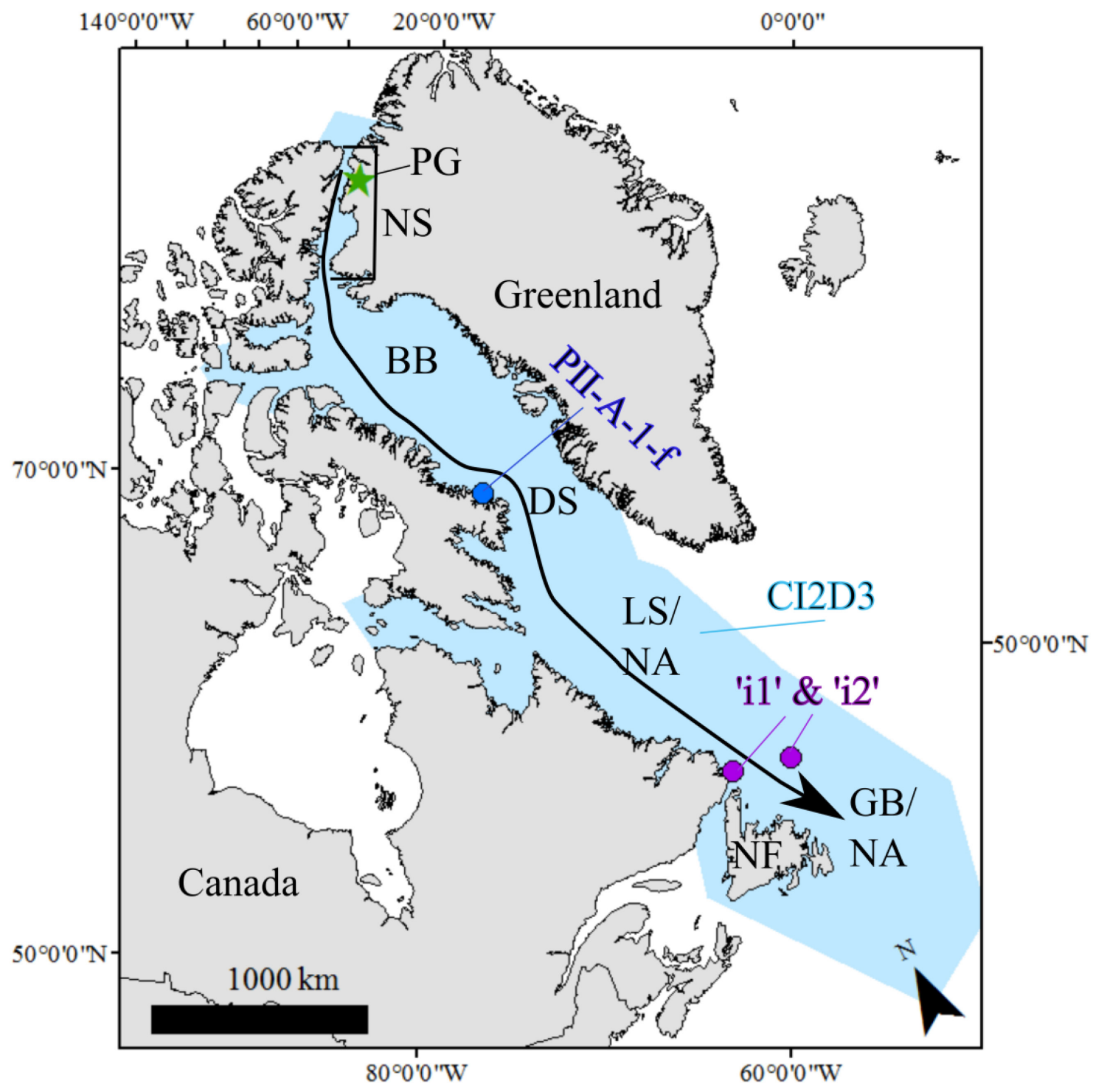

Figure 3.1: Ice island study subjects and other locations of interest. Petermann Ice Island (PII)A-1-f is the sole study subject of Chapter 4 (blue dot). Icebergs 'i1' and 'i2' are the survey targets utilized in Chapter 5 (purple dots). Ice islands represented in the Canadian Ice Island Drift, Deterioration and Detection (CI2D3) Database are the research subjects of Chapter 6 (light blue area). $\mathrm{PG}=$ Petermann Glacier, NS $=$ Nares Strait, $\mathrm{BB}=$ Baffin Bay, DS = Davis Strait, LS= Labrador Sea, GB = Grand Banks, NA= North Atlantic, NF = Newfoundland. The black arrow denotes the predominant trajectory of ice islands originating from northwest Greenland. 
Following the 2012 calving event, the terminus of the Petermann Glacier FIT was $\sim 25 \mathrm{~km}$ further inland than recorded since 1950 (Münchow et al., 2014). Increased ocean temperature and changing sea ice conditions and patterns of ocean circulation has increased the calving susceptibility of the glacier (Falkner et al., 2011; Münchow et al., 2014; Shroyer et al., 2017). Shroyer et al. (2017) state that the decreasing landfast ice extent in Nares Strait will allow warmer waters to enter Petermann Fjord, and they hypothesized that this will lead to further calving events by enhancing basal ablation, thinning, and structural weakening.

Episodic calving events from outlet glaciers in northern Greenland have produced massive ice islands that fracture into numerous smaller ice islands as they drift through the eastern Canadian Arctic and sub-Arctic (Crawford et al., 2018; Desjardins et al., 2018). Ice islands originating from northwest Greenland follow a southerly drift trajectory through Nares Strait and along the western edge of Baffin Bay in the Baffin Island Current (Newell, 1993; Tang et al., 2004). The fragments exit Baffin Bay through Davis Strait and then continue south in the Labrador Current through the Labrador Sea. They can potentially reach as far south as the Grand Banks of Newfoundland at $42^{\circ} \mathrm{N}$ (Newell, 1993; Tang et al., 2004; Peterson et al., 2011). Figure 3.1 shows the predominant trajectory of these ice islands.

The flux of ice islands through eastern Canadian waters after the 2008, 2010 and 2012 Petermann Glacier calving events has provided opportunities for unique analyses on ice islands from a consistent source. In general, ice islands that originate from northwest Greenland can pose a risk to the safe operations of offshore industry (Kubat et al., 2005) and also transport freshwater far from its source at the Greenland Ice Sheet (Marson et al., 2018). While this research will systematically study ice islands that originate from northwest Greenland, it will also inform ice island deterioration research in both of the Polar Regions. 


\subsection{Study subjects}

Different study subjects were chosen for chapters 4, 5 and 6 based on the study objectives as well as logistical constraints at the time of field operations. Chapter 4 focuses on the vertical deterioration of a single ice island, PII-A-1-f. The relative amount of ice lost to surface and basal ablation in comparison to areal deterioration processes was determined with SAR imagery. PII-A1-f was grounded at approximately $67^{\circ} 23^{\prime} \mathrm{N}, 63^{\circ} 18^{\prime} \mathrm{W}$ offshore of Baffin Island near the community of Qikiqtarjuaq, Nunavut for the duration of field data collection. It was first accessed in October 2015 via the CCGS Amundsen. Figure 3.2 shows PII-A-1-f in July 2016 near Qikiqtarjuaq, Nunavut.

The original aim for the research project associated with Chapter 4 was to target a drifting ice island. However, due to logistical constraints it was decided to target the grounded PII-A-1-f. Return trips to ice islands to ascertain deterioration are rarely possible. Instrumenting a grounded ice island made it possible to visit the ice island four times to collect a distinctive dataset for the ice island thinning analysis in Chapter 4. 


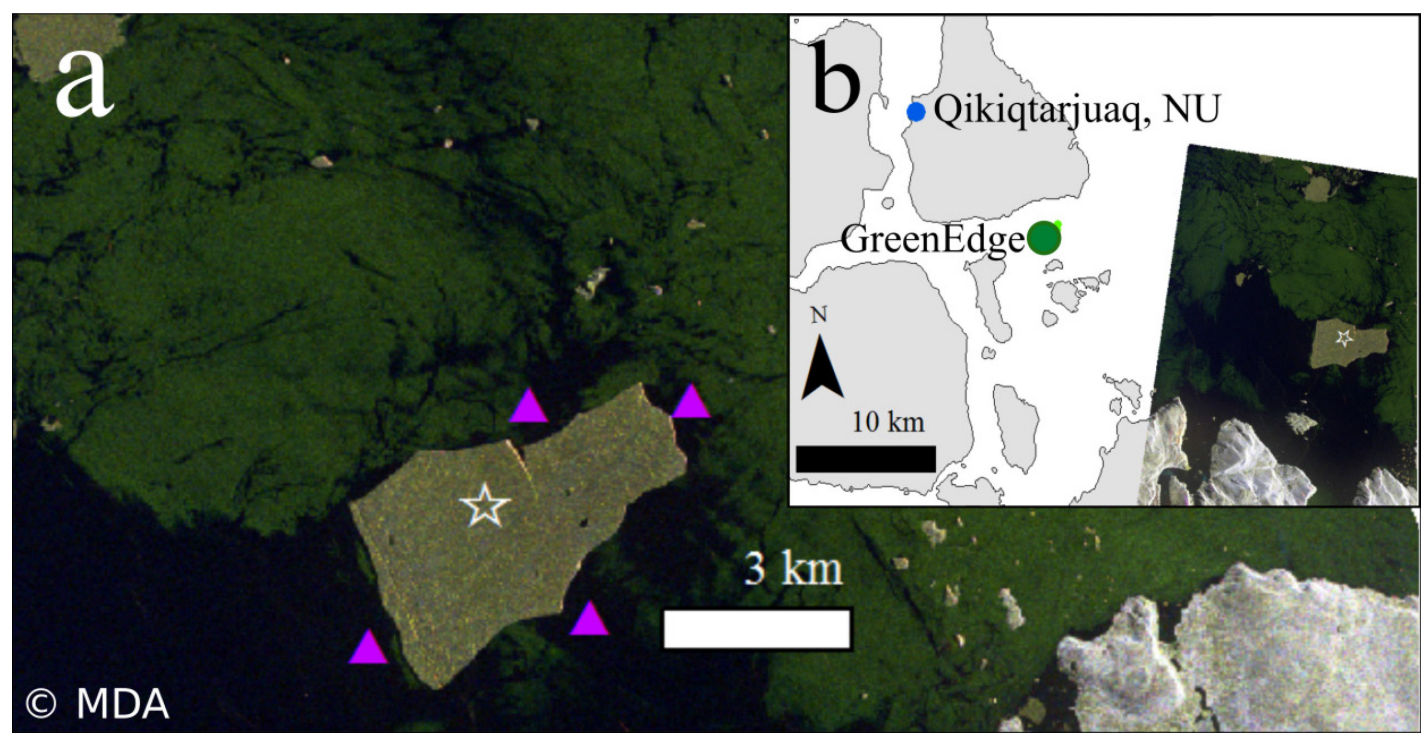

Figure 3.2: Petermann Ice Island (PII)-A-1-f as situated in July 2016. The scene is a RADARSAT-2 Fine-Quad acquisition (8 m nominal resolution; colour composite presentation red: $\mathrm{HH}$, green: $\mathrm{VV}$, blue: $\mathrm{HV}$ polarizations). The purple triangles denote the locations of conductivity, temperature, depth (CTD) profiles conducted by the CCGS Amundsen. The white star denotes the main field site. b) shows the location of PII-A-1-f in relation to the GreenEdge project location and the Hamlet of Qikiqtarjuaq, Nunavut.

Two tabular icebergs ('i1' and 'i2') located off the coasts of Newfoundland and southern Labrador served as study subjects in Chapter 5 (Fig. 3.3). The 2015 field campaign on the Canadian Coast Guard Ship (CCGS) Amundsen provided an opportunity to evaluate two surveying methods, SfM and TLS, for estimating iceberg mass and detecting deterioration. Multiple high-quality surveys of the two survey 'targets', as they are referred to in Chapter 5, were collected with the survey equipment shown in Figure 3.3. The precision analysis in Chapter 5 compares the 3D representations of the icebergs generated from this survey data. 


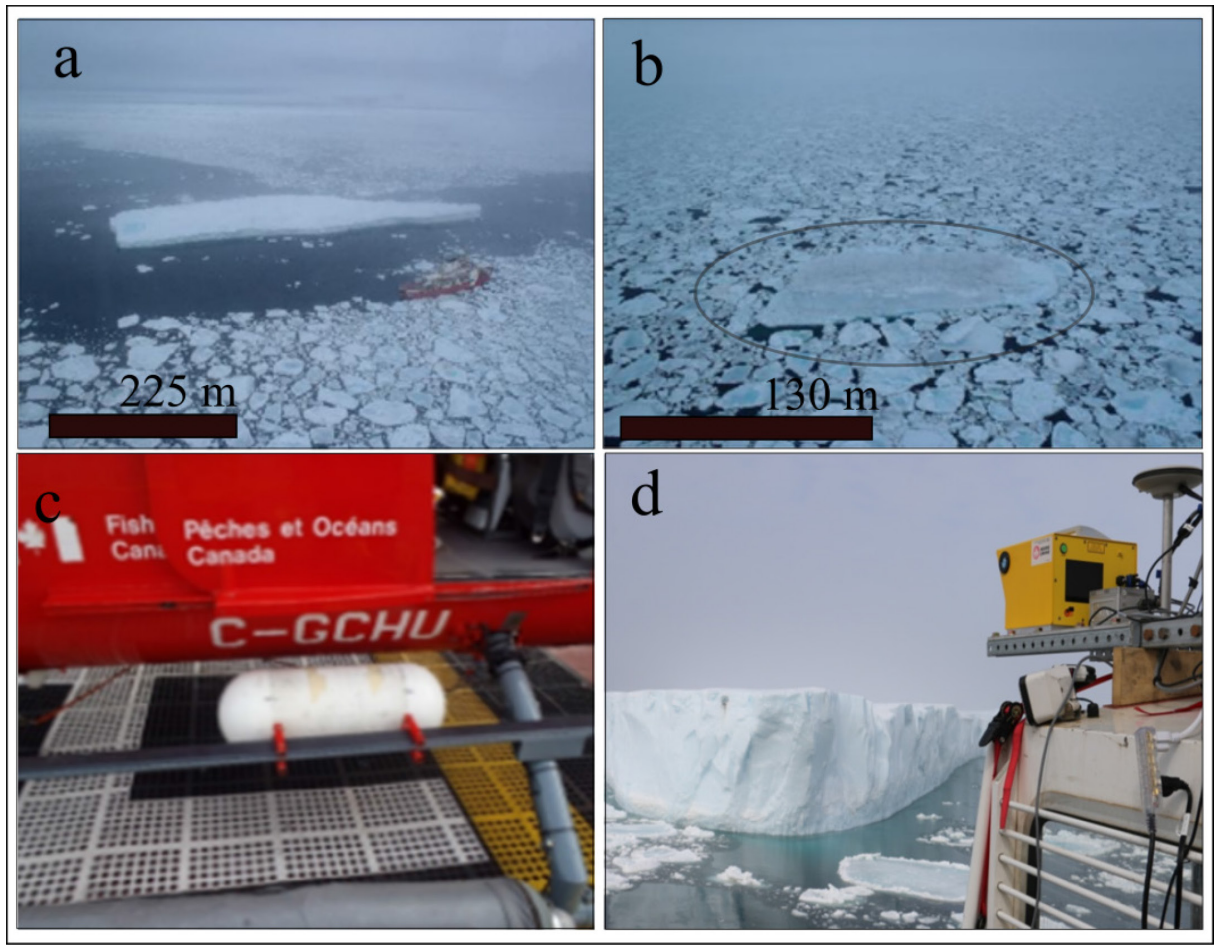

Figure 3.3: Iceberg survey targets and surveying equipment used Chapter 5. a) and b) show tabular icebergs 'i1' and 'i2', respectively. c) shows the external camera set-up on a helicopter for aerial photography surveying. d) shows the Optech Ilris-HD laser scanner situated on the CCGS Amundsen.

Chapter 6 relies on the CI2D3 Database, which includes hundreds of entries representing ice islands present in the study region following the three largest Petermann Glacier calving events that have occurred in the past 10 years (i.e., 2008, 2010 and 2012). Figure 3.4 includes an example from the database. 


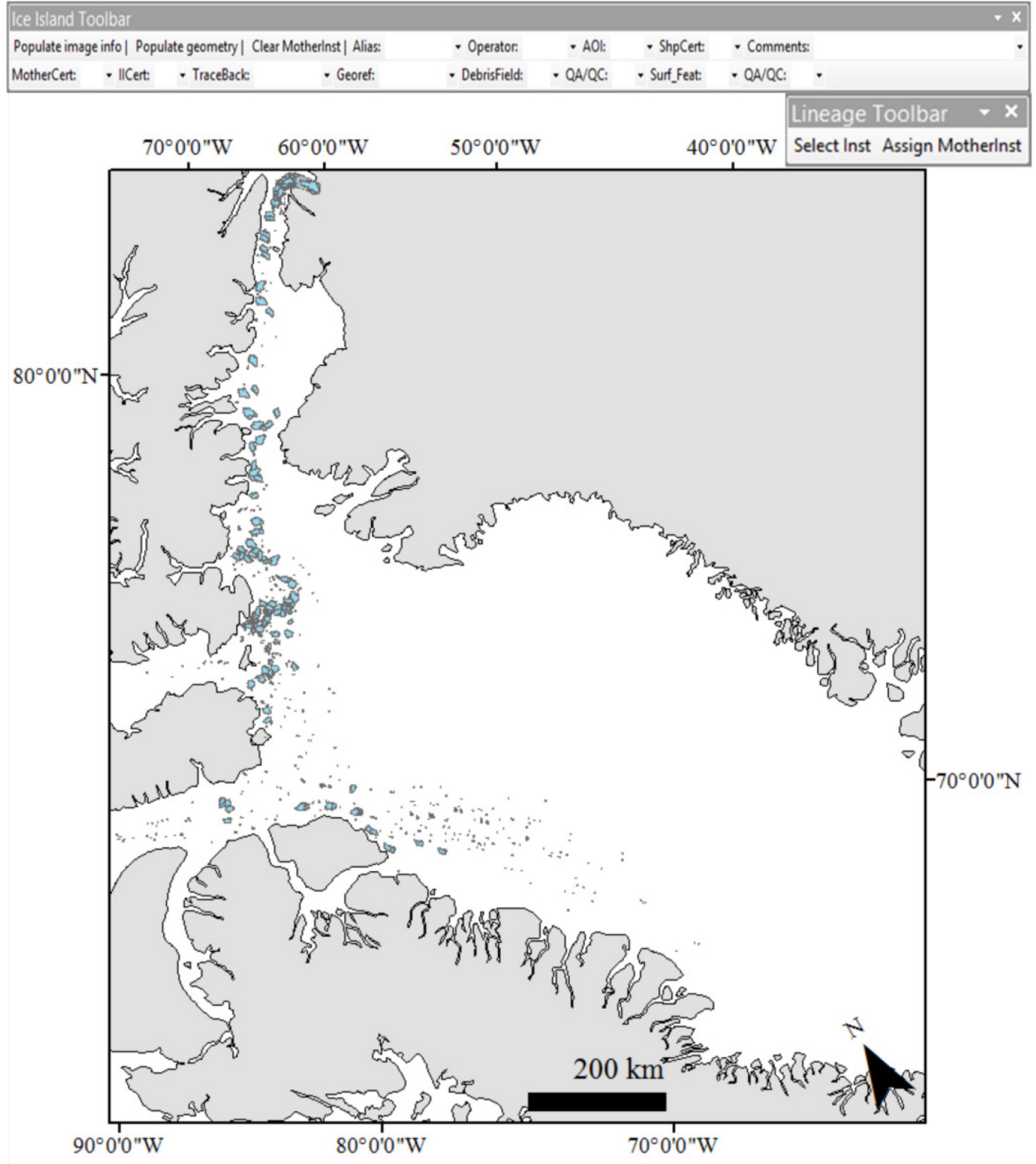

Figure 3.4: Example contents of the Canadian Ice Island Drift, Deterioration and Detection Database. The blue polygons represent repeated observations of ice islands that were monitored in 2010 and are included as database entries. Above the map are the customized toolbars used by the database operators. 


\subsection{Data collection and data sources}

The various deterioration processes and detection methods under study in this thesis each warrant distinct study designs. This section rationalizes the choice of datasets and methods used in the subsequent manuscript chapters.

\subsubsection{Field measurements}

On-ice field data collection was an important component of the analysis conducted in Chapter 4. The data collected from the study subject PII-A-1-f were collected at three locations: 1) a main field site on the ice island surface, 2) along an approximately $2 \mathrm{~km}$ transect which began and ended at the main site, and 3) multiple ocean sampling locations surrounding or in the vicinity of the ice island. This data collection was designed to analyze the thinning of the ice island, the spatial variability in thinning, and to calibrate a commonly used basal ablation model.

Ice penetrating radar, a standard method for determining ice thickness, was used extensively in Chapter 4 (Hubbard and Glasser, 2005). An IPR system transmits an electromagnetic wave through a dipole antenna. The signal penetrates through the ice and reflects off the ice-ocean interface due to the contrasting dielectric constant between ice and water. A receiver records the return signal and ice thickness is calculated using the two-way travel time (TWTT) between the reflected wave and an airwave that travels directly between the transmitter and receiver. The thickness calculation is based on the wave propagation speed in ice (Hubbard and Glasser, 2005). Figure 3.5 illustrates this concept for a mIPR. 


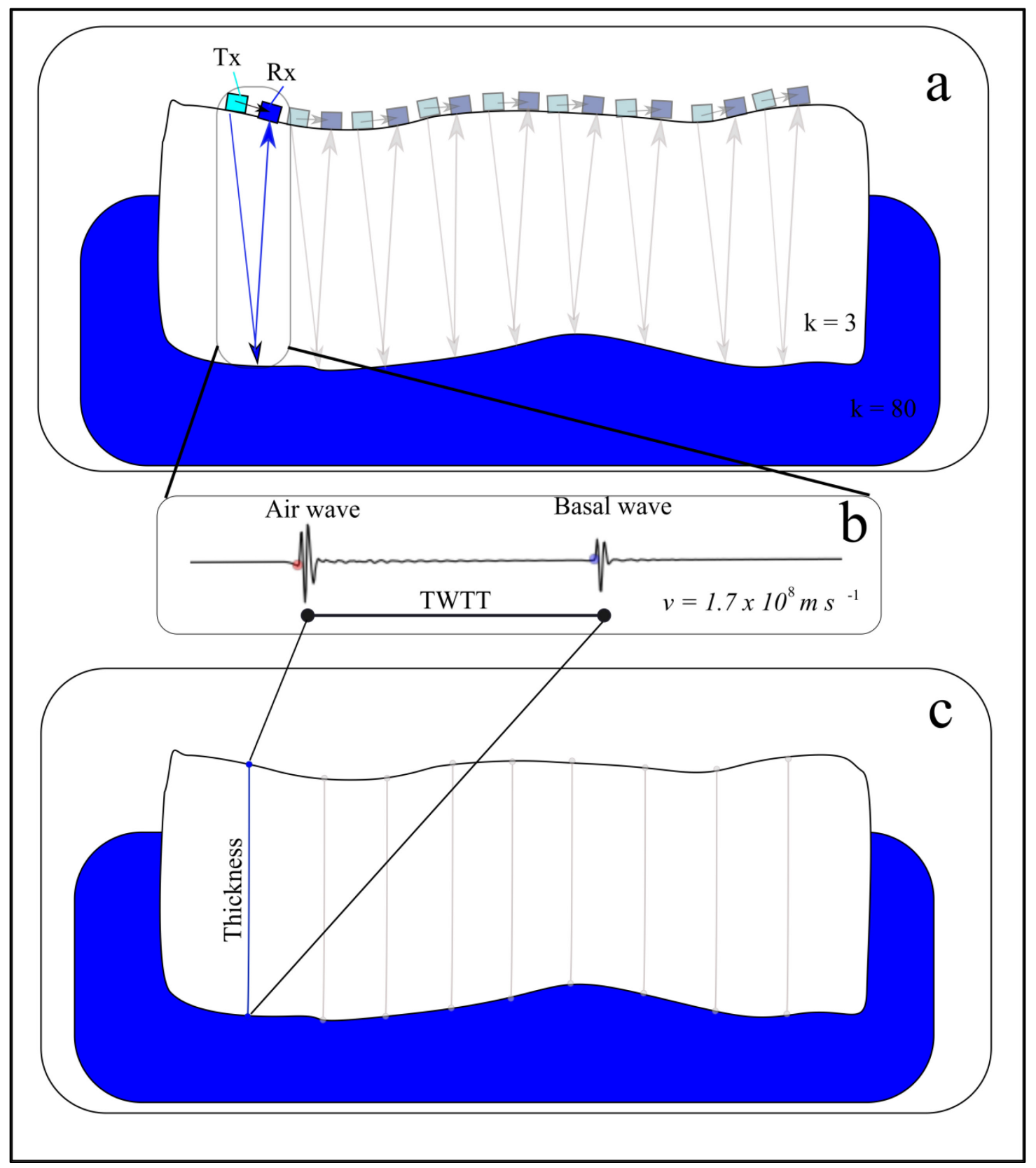

Figure 3.5: Simplified workflow associated with measuring ice thickness from ice penetrating radar data. a) A radar signal emitted from a transmitter (Tx) is reflected by the ice-water interface due to a change in dielectric constants $(\mathrm{k})$ at that boundary and is recorded by a receiver $(\mathrm{Rx}) . \mathrm{b})$ The two-way travel time (TWTT) between the airwave and the reflected wave is converted to an ice thickness (shown in c) using the velocity of a radar wave through ice $(v)$. 
A customized stationary ice penetrating radar (sIPR; Blue System Integration Ltd., Vancouver, Canada) was installed on PII-A-1-f in October 2015. While sIPR provides high temporal resolution and a direct thickness measurement, it only represents one point on the surface of the $13 \mathrm{~km}^{2}$ ice island. For this reason, repeat transects with a mIPR were used to ascertain the spatial variability in the thickness change of PII-A-1-f. The establishment of the main field site on PII-A-1-f required a full day of fieldwork, and no further time was available in October 2015 to collect a thickness profile with mIPR. Since PII-A-1-f was grounded, a visit to the ice island via snowmobile was possible in May 2016. An initial $3 \mathrm{~km}$ long ice thickness profile was established with an mIPR system from Blue System Integration Ltd. during this field visit. The mIPR receiver and transmitter were mounted on two sets of skis and retained at a constant separation of $9 \mathrm{~m}$ during surveying. A $25 \mathrm{MHz}$ antenna was used based on the success of previous mIPR surveys on other ice islands that I conducted with this antenna frequency. The transect was planned to be walkable in approximately 4 hours and to cross a topographic surface feature that was visible in R2 SAR imagery obtained prior to fieldwork.

A network of 10 ablation stakes was installed at intervals of $\sim 150$ to $500 \mathrm{~m}$ along the transect to determine the spatial variation in surface ablation. Thickness data collected again over a $2.4 \mathrm{~km}$ portion of the original mIPR transect in September 2016 and 8 ablation stakes were re-measured. The full transect was not accessible due to logistical constraints.

The sIPR, a Campbell Scientific SR50A sonic ranger (Campbell Scientific Canada Corp., Edmonton, Canada) and a series of 5 ablation stakes were installed at the main site on PII-A-1-f in October 2015. These instruments and stakes were used to measure total thickness and surface ablation, respectively. The sonic ranger accompanied a simple meteorological station. The sIPR and meteorological station were installed on two adjacent surface ridges to protect the instruments 
from meltwater ponding. They were not co-located on the same ridge due to the potential for the meteorological station to interfere with the IPR signal.

All instruments were designed to be expendable in the event that they were impossible to retrieve from a deteriorating ice island. For this reason, the sIPR and meteorological station included Iridium modems for remote data transmission. The sIPR electronics were custom designed for this project by Blue System Integration Ltd., while I designed the instrument enclosure and installation configuration.

The sIPR was set to measure ice thickness daily at a sampling rate of $125 \mathrm{MHz}$ to reduce power consumption and transmission cost. Total active time for the electronics was approximately $8 \mathrm{~min}$ $\mathrm{d}^{-1}$. Antenna frequency was decided based on the best resolution (shorter wavelength $=$ higher resolution) possible while guaranteeing the signal would penetrate through the full thickness of the ice island (longer wavelength $=$ greater penetration). A $40 \mathrm{MHz}$ antenna was used for PII-A-1-f based on IPR thickness measurements of other ice islands (Halliday et al., 2012; Crawford, 2013). The instrument enclosure and installation plan was designed for on-ice set-up, helicopter transport, and resistance to cold weather, meltwater, and local fauna. Full details on the sIPR system are found in Mingo et al. (forthcoming), Chapter 4 and Appendix A. A photograph is also included in Chapter 4.

The series of five ablation stakes installed at the main site were placed in the view of a Campbell Scientific CC5MPX camera that was on the meteorological station so that the surface conditions at the location of the sIPR could be monitored. Derived surface ablation magnitudes were used to calculate basal ablation magnitudes with the record of thickness change collected by the sIPR. Basal ablation was also calculated with data measured by the SR50A sonic ranger. The sonic ranger was chosen to measure continuous surface ablation, rather than a draw-wire sensor (Hulth, 
2010), due to its simple installation and the ability to easily log and telemeter data in conjunction with the other meteorological system components. The sonic ranger measures TWTT of an acoustic signal reflected from the ice/snow to measure the distance to the surface. A concurrent temperature measurement taken by a Campbell Scientific 109 thermistor probe was utilized to calibrate the travel time of the signal as the speed of sound is temperature dependent (Campbell Scientific, 2016). The firn layer at Petermann Glacier is negligible due to high levels of ablation in comparison to snowfall (Münchow et al., 2014). PII-A-1-f had also undergone appreciable surface ablation in transit to Baffin Bay and therefore was composed of firn-free ice.

The CCGS Amundsen collected conductivity, temperature, depth (CTD) and current profiles at multiple locations near PII-A-1-f in 2015 and 2016. Conductivity and temperature data were collected with SBE 4C and SBE 3plus sensors (Sea-Bird Electronics, Inc., Bellevue, USA), respectively. Current was measured with a Teledyne/RDI $300 \mathrm{kHz}$ Workhorse Monitor (WHM) lowered acoustic Doppler current profiler (LADCP; Teledyne RD Instruments, Poway, USA). Figure 3.2a shows the locations of the profiles collected in July 2016 adjacent to the ice island. The CCGS Amundsen also collected CTD casts adjacent to an oceanographic mooring at a longterm study location approximately $20 \mathrm{~km}$ northwest of PII-A-1-f that was associated with the GreenEdge project (Université Laval) (Fig. 3.2b). GreenEdge project members also collected CTD profiles at this location during a sea ice camp spanning several months, and a mooring collected ADCP-derived current measurements. The GreenEdge project used a SBE 49 FastCAT CTD (SeaBird Electronics, Inc., Bellevue, USA) and a Teledyne/RDI Workhorse Sentinel 300 kHz ADCP (Teledyne RD Instruments, Poway, USA). This dataset was beneficial for the basal ablation model calibration in Chapter 4 due to its greater temporal coverage relative to profiles collected by the CCGS Amundsen. Surveys of the surrounding bathymetry were collected with the on-board 30 
kHz Kongsberg EM-302 multibeam sonar (Kongsberg Gruppen ASA, Kongsberg, Norway) and processed by the Laboratoire de Géomorphologie Marine at Laval Université. Sound velocity profiles (converted from CTD profiles) were used to calibrate the sonar data (ArcticNet, 2017).

\subsubsection{Field based surveying}

SfM and vessel-based laser scanning are common techniques used to survey icebergs (Fugro, 2014; Wagner et al., 2014; McGuire et al., 2016; Younan et al., 2016). The study included in Chapter 5 was designed to assess the abilities of these techniques for mass estimation and detecting deterioration of icebergs and ice islands, as the uncertainty associated with these techniques when utilized to survey icebergs had not been previously reported. Three consecutive surveys with both techniques for iceberg surveys, and the associated point clouds were compared to determine the precision of the techniques. Figure 3.3 shows the general set-up of the survey equipment.

This study used two types of GPS units. One type consisted of tracking beacons, specifically Solara FieldTracker 2000 (Solara Remote Data Delivery Inc., Winnipeg, Canada) and Canatec (Canatec and Associates International Ltd., Calgary, Canada) units. These types of GPS receivers, which only track low-precision coarse/acquisition code, are commonly used for iceberg drift monitoring and are considered disposable. The other units were high quality dual-frequency, phase-tracking GPS receivers (TopCon Hiper V,Topcon Corp., Tokyo, Japan) and Trimble 5800 (Trimble, Sunnyvale, USA) units. Different GPS types were deployed on the two survey targets to quantify the influence of GPS precision on the survey precision.

\subsubsection{Satellite remote sensing}

The Canadian Ice Service (CIS; Environment and Climate Change Canada) uses R1 and R2 SAR images for operational sea ice charting, and a massive archive of SAR scenes is housed at the CIS (Crawford et al., 2018; Desjardins et al., 2018). The obstacles and limitations associated 
with the use of satellite SAR data to monitor ice island drift and deterioration were overcome to generate the CI2D3 Database with the data contained in the CIS archive. The CI2D3 Database was a joint initiative between the Water and Ice Research Lab (WIRL) at Carleton University and the CIS. It is the first comprehensive record of the ice island flux resulting from Petermann Glacier calving events; it captures the size and location of ice islands that were located in eastern Canadian waters between 82 and $42^{\circ} \mathrm{N}$ over a 5-year period (Crawford et al., 2018).

The database generation was designed to meet the objectives of Chapter 6 . The design included establishing the lineage of individual ice islands until their surface area decreased to $0.25 \mathrm{~km}^{2}$ (Fig. 3.6). This lineage record was used to extract several spatial and temporal snapshots of the ice island population in the study area. This information was used in Chapter 6 to evaluate the fit of statistical distributions to the size-frequency distributions of ice islands within these snapshots. The lineage establishment was also necessary to determine the spatial distribution of meltwater resulting from the drift and deterioration of PIIs through the study area, as it allowed for the calculation of surface area loss over time as well as the estimation of ice island thinning with surface and basal ablation modelling. 


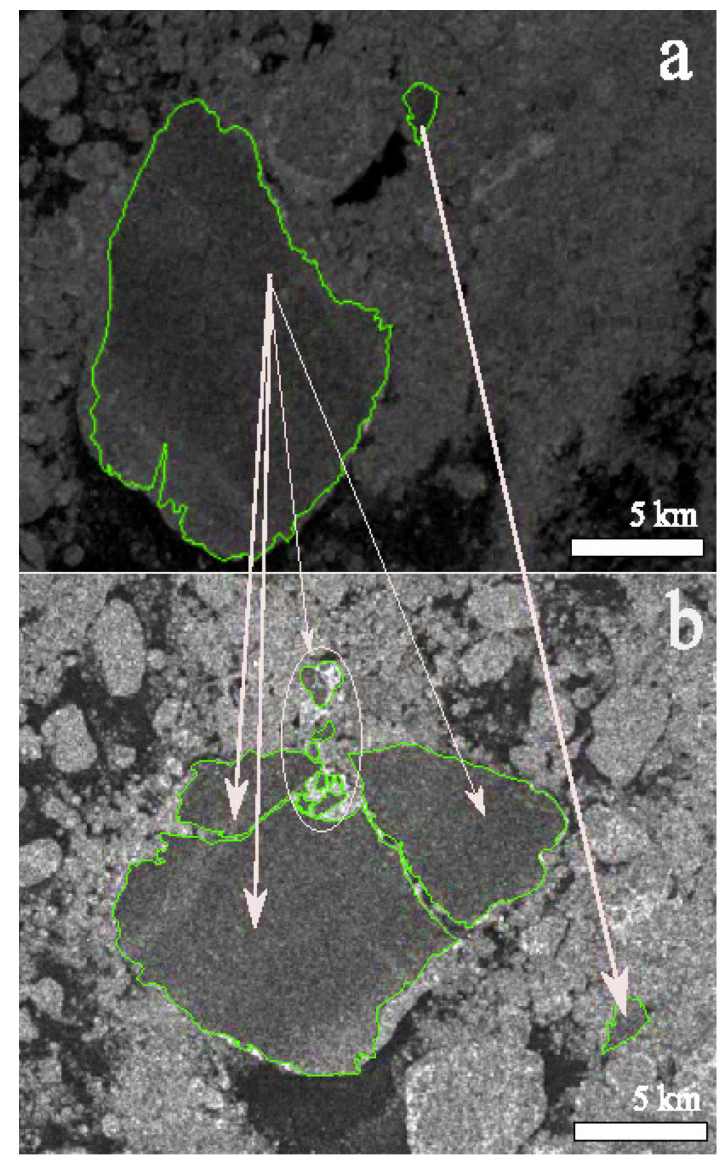

Figure 3.6: a) and b) Ice islands identified in SAR images and the polygons (green outlines) that were digitized as part of the Canadian Ice Island Drift Deterioration and Detection Database. The RADARSAT-2 (R2) images were taken 12 hours apart on October 9, 2010. The white arrows symbolize the lineage connections captured by the database. All R2 synthetic aperture radar imagery was made available courtesy of the Canadian Ice Service. The figure is reproduced from Crawford et al. (2018).

R2 images were also used to monitor the areal extent of PII-A-1-f, the study subject of Chapter 4 (Fig. 3.2). The images were ordered to aid in fieldwork planning, to coincide with fieldwork visits, and to monitor the surface area of the ice island. The series consisted of both Fine-Quad (8 m nominal resolution) and ScanSAR (100 m nominal resolution) R2 images. 
Subsets of R2 Fine-Quad scenes are represented in this thesis as colour composite images based on three of the four available channels. In these images, red represents $\mathrm{HH}$, green represents VV and blue represents HV polarization. Note that it is assumed that the $\mathrm{VH}$ channel and the HV channel contain the same information (Henderson and Lewis, 1998). The first letter in the two letter channel names represents the transmit orientation, while the second letter represents the receive orientation. The red and blue/green colouring of the R2 ScanSAR scenes is associated with the HH and HV channels used in dual-polarized modes (e.g., ScanSAR). Surface scattering from rough surfaces normally results in returns in the co-polarized channels (HH or VV), whereas volume scattering normally also contributes to the HV (i.e., cross-polarized) channels (Henderson and Lewis, 1998).

\subsection{Data processing}

In this thesis, I placed an emphasis on the use of, and contribution to, open source programming and data availability. For example, a number of customized Python (Python Software Foundation, Wilmington, USA) scripts were incorporated in the CI2D3 Database generation workflow to identify potentially useful SAR images in the CIS archive and process SAR data. Python scripts were also used to create customized ArcGIS (v. 10.2-10.5; ESRI, Redlands, USA) toolbars to fill the attribute fields of each entry since ArcGIS was the predominant software program used in the generation of the CI2D3 Database. The analyses conducted in this thesis were primarily conducted using R (R Core Team, 2013) and various supplementary R packages. A workflow that integrated a number of custom functions was scripted to correct TLS data in the survey technique analysis in Chapter 5. All of the R scripts written for the drift correction procedure, as well as the survey data, are publically available on the Polar Data Catalogue 
(www.polardata.ca/pdcsearch/PDCSearchDOI.jsp?doi_id=12818). The CI2D3 Database will also be publically available in 2018 at: https://www.polardata.ca/pdesearch/?doi_id=12678.

The CI2D3 Database is housed in a PostgreSQL/PostGIS database (The PostgreSQL Global Development Group, California, USA). CI2D3 Database entries were quality controlled with customized structured query language (SQL) queries. The queries were amalgamated and sent to the PostgreSQL database using a Python script. Data were extracted by SQL queries into RStudio (v. 0.99.903; RStudio, Boston, USA), an R language graphical user interface (GUI), for the analyses conducted in Chapter 6. The meltwater analysis in Chapter 6 used oceanographic data from the Nucleus for European Modeling of the Ocean (NEMO; Paris, France) v. 3.4 ocean model (Madec and the NEMO team, 2015) and the global deterministic prediction system reforecasts (CGRF) dataset of the Canadian Centre for Meteorological and Environmental Prediction (Smith et al., 2014; Environment and Climate Change Canada, Dorval, Canada) for surface and basal ablation modelling. Paul Myers at the University of Alberta supplied the NEMO and CGRF data at the best available temporal resolution. Oceanographic and atmospheric data that spatially and temporally matched the ice island observations in the CI2D3 Database were extracted with customized R scripts.

The Multiscale Model-to-Model Cloud Compare (M3C2) algorithm was used in Chapter 5 to determine the precision of SfM and TLS surveying for iceberg deterioration detection purposes. Terrestrial and cryospheric change detection studies have also used this algorithm (Lague et al., 2013; Westoby et al., 2016) and it is available in open source CloudCompare software (v. 2; Cloud Compare, n.d.). The benefit of directly comparing point clouds, instead of generating and comparing meshes or digital elevation models, is that spurious distances are not provided as output 
when data gaps are present and the included surface normal calculations account for noise in the data (Latypov, 2002; Lague et al., 2013).

Four software programs were utilized in the IPR data collection and processing of IPR data. IceRadar v. 4.4.1 and Stationary v. 3.1 were used for the mIPR and sIPR data collection, respectively. These programs were designed by Blue System Integration Ltd. (Vancouver, Canada) and are the standard data acquisition programs that accompany these purchased systems. The IceRadar Analyzer (v. 4.2.4; Blue System Integration Ltd.) software program provided gain and enhancing filters that aided in selecting the air and reflected waves in the sIPR dataset. The mIPR data were pre-processed through a series of Python scripts to prepare the data (i.e., attribute, timestamp and GPS formats) for use in the Radar Tools software program (Wilson, 2013). Radar Tools was used to visualize radar traces with gain and enhancing filters and migration techniques, select the air and reflected wave locations, and calculate ice thickness based on these selections.

The oceanographic data collected from the CCGS Amundsen were processed by Amundsen Science technicians and research assistants who quality control and archive ship data (ArcticNet, 2017). Bathymetry data were collected and processed with the Hips and Sips (v. 9.1.7; Teledyne CARIS, Inc., Fredericton, Canada) software suite and was provided as geotiff files at $5 \mathrm{~m}$ resolution. The GreenEdge oceanographic data were quality controlled prior to distribution.

\subsection{Summary}

The research objectives in this thesis were met using complementary field observations, remote sensing and data products. These data were used to investigate ice island thinning and small- and large-scale areal deterioration. The thinning rate of PII-A-1-f, an ice island grounded in Baffin Bay, was determined over a year following the development and deployment of an sIPR (Chapter 4). This unique dataset was supplemented by ablation stake and sonic ranger data to infer basal 
ablation rates and the thinning of the ice island was compared to overall deterioration through the interpretation of SAR data. Oceanographic data that were collected in close proximity to the ice island were used to conduct the first field calibration of a commonly used basal ablation model.

The capabilities of two commonly used surveying techniques to detect small-scale areal deterioration were compared in Chapter 5 using data collected during a dedicated field campaign. The precision of these techniques was quantified using consecutive, triplicate surveys of two tabular iceberg targets drifting offshore southern Labrador and Newfoundland. Results from this analysis will inform future iceberg and ice island surveying campaigns.

Finally, the large-scale areal deterioration of PIIs originating from the 2008, 2010 and 2012 Petermann Glacier calving events was quantified via analysis of the CI2D3 Database in Chapter 6. Analysis of this unique and comprehensive database produced the first estimates of meltwater distribution from Petermann Glacier calving events and the size distribution analysis is the first to be conducted for the full flux of PIIs generated after large calving events. In summary, these three studies investigate the processes implicated in the 3D deterioration of ice islands and develop new instruments, techniques and datasets for deterioration measurement and analysis. 


\section{Chapter 4 - The thinning of 'Petermann Ice Island-A-1-f': Ablation magnitudes and model calibration with ice penetrating radar data}

\subsection{Introduction}

Approximately 30 to $50 \%$ of the freshwater flux from the Greenland Ice Sheet is in the form of solid ice discharge (i.e., icebergs) (Enderlin et al., 2018). Icebergs and ice islands (large, tabular icebergs) transport freshwater far from their glacier origins and are important components of the ice-ocean system (Jansen et al., 2005). Hundreds of ice islands can pulse through the eastern Canadian Arctic and sub-Arctic after ice island calving events from the floating ice tongues in northwest Greenland (e.g., Ryder, Steensby or Petermann ice tongues) (Crawford et al., 2018; Chapter 6). These ice islands often ground on the continental shelf of Baffin Island in western Baffin Bay (Wagner et al., 2014; Crawford et al., 2018; Chapter 6). When ice islands or smaller icebergs ground they can disrupt benthic ecosystems (Dowdeswell and Bamber, 2007), put seafloor infrastructure at risk (Sackinger et al., 1988), and impact the biological and physical composition of ocean waters in their vicinity due to concentrated meltwater input resulting from their deterioration (Jansen et al., 2007; Stern et al., 2015). Grounding can also influence the deterioration of an ice island through either asymmetrical sidewall erosion due to patterns of upwelling and downwelling around its perimeter (Stern et al., 2015) or increased basal ablation rates resulting from greater differential velocities between the immobile ice island and ocean currents (Jansen et al., 2007). Enhanced basal ablation is particularly detrimental to the overall longevity of an ice island since decreased thickness, relative to a consistent areal extent, can reduce fracture resistance (Goodman et al., 1980).

Remotely sensed data are frequently used to monitor ice island thickness change due to the logistical difficulty and resources required to repeatedly conduct field visits to the same ice island 
(Wagner et al., 2014; Crawford et al., 2016). Ice island thinning has previously been estimated via freeboard monitoring with satellite-borne altimetry data (Scambos et al., 2005; Jansen et al., 2007; Tournadre et al., 2015; Bouhier et al., 2017), and the individual contributions of surface and basal ablation are derived with these estimations and/or and direct modelling (Jansen et al., 2007, Bouhier et al., 2017, Ballicater Consulting, 2012). Iceberg and ice island studies often use a relatively simple fluid-dynamics approach to model basal ablation (Bigg et al., 1997; Gladstone et al., 2001; Martin and Adcroft, 2010; Ballicater Consulting, 2012; Merino et al., 2016; Wagner and Eisenman, 2017). The forced convection model is based on the transfer of heat across a flat-plate due to the turbulent flow of the underlying water. A bulk heat transfer coefficient is used to estimate an ablation rate based on the differential velocity between the ice island and the ocean current and the driving temperature across the length of the ice island (Weeks and Campbell, 1973; Ballicater Consulting, 2012; Bouhier et al., 2017). Previous efforts to calibrate basal ablation models have relied upon remotely sensed datasets as well as potentially inaccurate modeled environmental data (i.e., ocean current speeds) (Jansen et al., 2007; Bouhier et al., 2017). This is largely due to the challenges associated with collecting high-resolution in-situ data for determining the individual contributions of surface and basal ablation to the total thinning of an ice island.

This study meets two research objectives by analyzing a unique dataset collected over four field visits to 'Petermann Ice Island (PII)-A-1-f', a $13 \mathrm{~km}^{2}$ ice island that was grounded to the north of the Cumberland Peninsula on the continental shelf of Baffin Island. The first objective is to quantify surface and basal ablation rates and the contribution of these processes to the thinning and overall deterioration of PII-A-1-f. Thinning magnitudes were derived from a thickness dataset that was compiled over an approximately 1-year period with the first stationary ice penetrating radar (sIPR) system to be successfully installed on an ice island. Repeat mobile ice penetrating 
radar (mIPR) measurements were used to quantify spatial variation in thickness and thinning, and a series of RADARSAT-2 (R2) synthetic aperture radar (SAR) scenes were used to quantify volume loss and put this deterioration into context regarding the pre-grounding history of PII-A1-f. The second objective of this study is to calibrate the parsimonious forced convection basal ablation model. The sIPR thickness record and an oceanographic dataset were used for the calibration, which is the first known iceberg basal ablation model calibration conducted with field data.

\subsection{Study site}

PII-A-1-f was a fragment of the $130 \mathrm{~km}^{2}$ PII that calved from the Petermann Glacier of northwest Greenland on 5 August 2012 (Crawford et al., 2018). The $13 \mathrm{~km}^{2}$ ice island fragment drifted into southern Baffin Bay where it became grounded in November 2014 at $67^{\circ} 24^{\prime} \mathrm{N}, 63^{\circ} 18^{\prime} \mathrm{W}$, approximately $10 \mathrm{~km}$ from the east coast of Baffin Island and $35 \mathrm{~km}$ southeast from the Hamlet of Qikiqtarjuaq, Nunavut (Fig. 4.1a). Ice island groundings are especially common just to the north of the Cumberland Peninsula due to the presence of many underwater shoals and ridges (Desjardins et al., 2018; Crawford, unpublished data). 


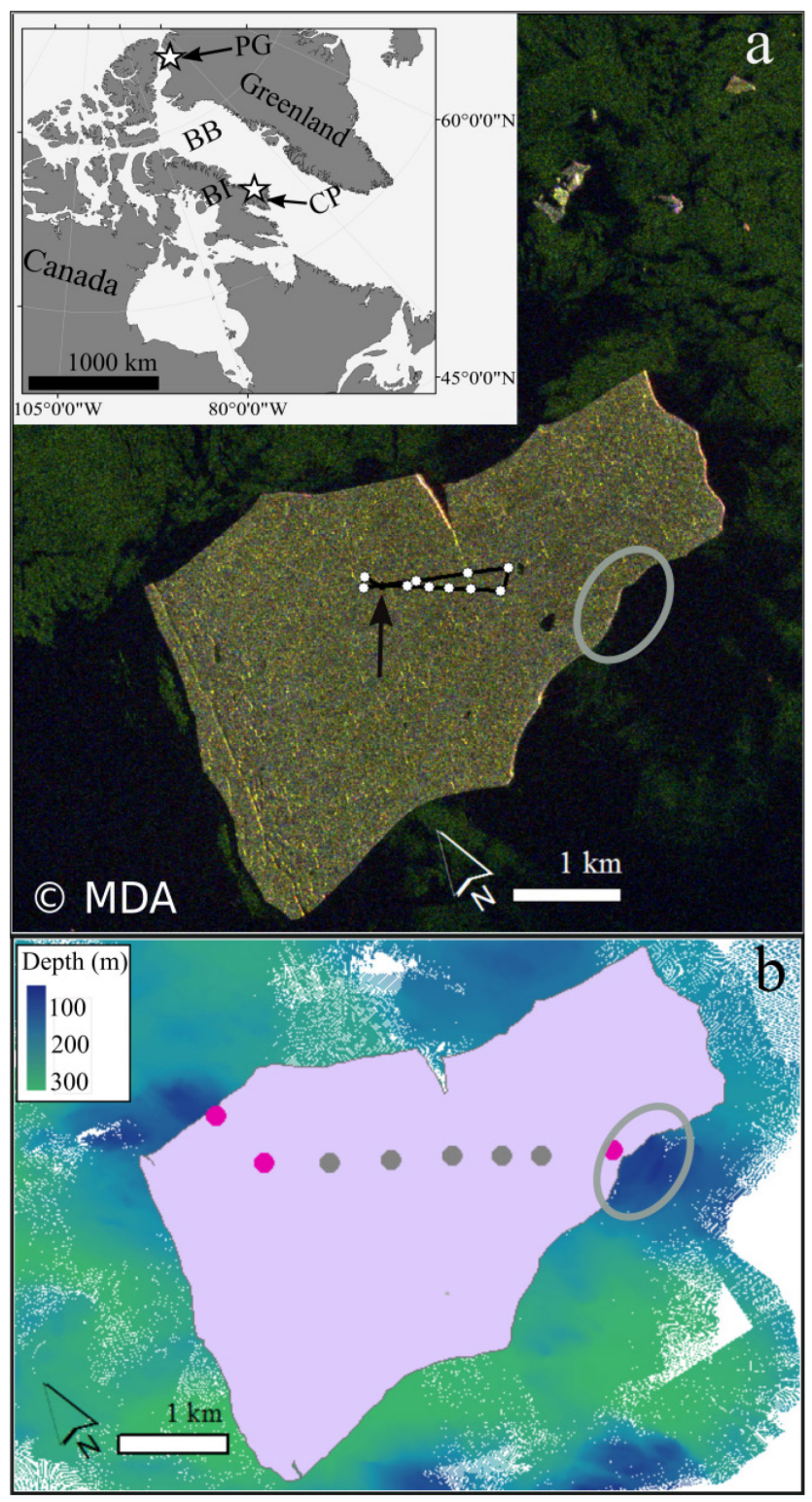

Figure 4.1: Study site. a) Petermann Ice Island (PII)-A-1-f imaged in a RADARSAT-2 Fine-Quad (8 m nominal resolution; colour composite presentation - red: $\mathrm{HH}$, green: VV, blue: HV polarization) scene on 27 July 2016. The arrow points to the location of the stationary ice penetrating radar and weather station. The $\sim 3 \mathrm{~km}$ mobile IPR transect is shown with the black line and the locations of the 10 ablation stakes are shown as white dots. The inset shows the location of PII-A-1-f (star) near the eastern coast of Baffin Island (BI), north of the Cumberland Peninsula $(\mathrm{CP})$, in Baffin Bay (BB) and its origin, the Petermann Glacier (PG), in northwest Greenland. b) Bathymetric depths around PII-A-1-f recorded by multi-beam sonar in October 2015 and July/September 2016 during the ArcticNet science cruises on board the CCGS Amundsen. The likely grounding point in July 2016 is circled in both panels. The pink circles denote locations along an underwater ridge and the grey circles are estimates of its extension under the ice island. 


\subsection{Methods}

\subsubsection{Thinning - temporal dataset}

PII-A-1-f was visited by four field teams between October 2015 and July 2017. Transportation was provided by the CCGS Amundsen icebreaker and its helicopter during the annual ArcticNet science cruises in October 2015, July 2016 and September 2016. An additional field campaign was completed in May 2016 when the field team accessed the ice island, then surrounded by sea ice, by snowmobile from Qikiqtarjuaq, Nunavut.

To ascertain the contribution of surface and basal ablation to total ice island thinning, a series of ablation stakes, a $40 \mathrm{MHz}$ sIPR, and a small meteorological station with a sonic ranger and camera were installed on PII-A-1-f on 20 October 2015 (Fig. 4.2). All data were telemetered daily via the Iridium satellite network. Ice thickness was recorded daily by the sIPR (Blue System Integration, Ltd., Vancouver, Canada) until 27 September 2016 at a resolution of $0.7 \mathrm{~m}$. Full details regarding this system set-up and measurement specifications can be found in Appendix A. The resulting step changes in ice thickness were interpolated linearly after truncating the data from the end of the first step (16 November 2015) to the beginning of the last recorded step (18 September 2016). 


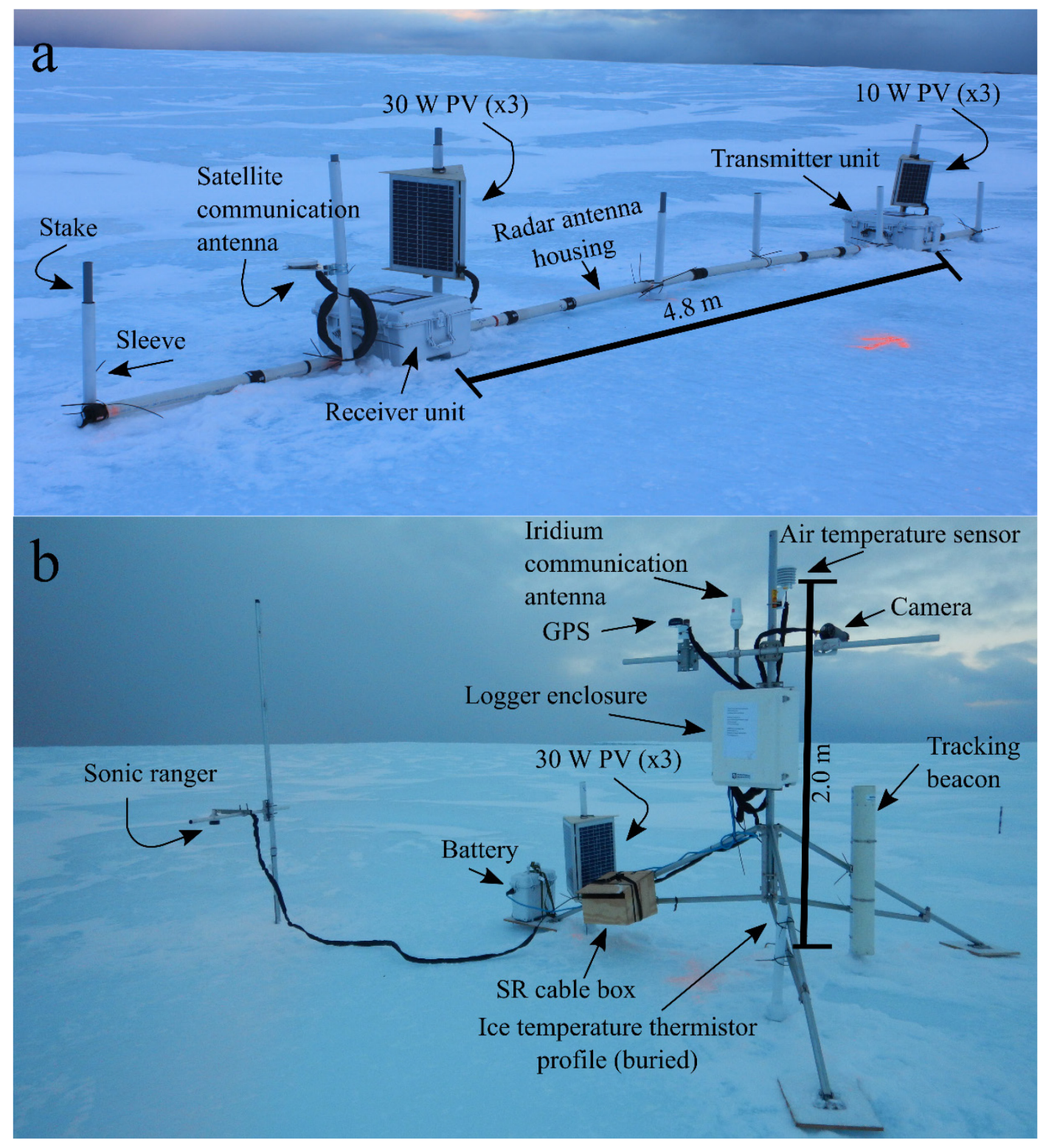

Figure 4.2: Instruments installed on Petermann Ice Island (PII)-A-1-f on 20 October 2015. a) Stationary ice penetrating radar (sIPR) components deployed 'in-line' and attached to eight sleeves that slid over stake anchors. b) Automatic weather station components, including a camera that acquired a weekly image of the sIPR. The two systems were installed $30 \mathrm{~m}$ apart on two ridges at the location denoted in Figure 4.1. PV = photovoltaic panel, $\mathrm{SR}=$ sonic ranger. 
Daily mean surface ablation was calculated from hourly SR50A sonic ranger (Campbell Scientific Canada Corp., Edmonton, Canada) height-above-surface (snow or ice) measurements. Surface ablation was also calculated from five ablation stakes that were placed between the meteorological station and the sIPR. No snow was present on the date when the stakes and instruments were installed. The ablation (or accumulation) at these stakes was assessed with weekly images acquired with a Campbell Scientific CC5MPX camera that was controlled by the meteorological station to visually check on the positioning of the sIPR system. The height of each stake was determined with the image processing program, ImageJ (v. 1.8.0) (Abramoff et al., 2004). The average weekly snow accumulation or ice ablation of the five stakes was calculated. A linear interpolation was applied to estimate daily ablation between these observations so that the sIPR, SR50 and ablation stake data were presented at a consistent time interval. Cumulative basal ablation was calculated by subtracting the cumulative, interpolated surface ablation from the ice thickness time series. Reported basal ablation values are calculated with the ablation stake data. The sonic ranger was approximately $30 \mathrm{~m}$ away from the sIPR and although the sonic ranger had higher temporal resolution, its position was not representative of conditions at the sIPR. The surface conditions at the ablation stakes and sIPR were shown to be similar in the photos, and the use of this surface ablation data provided the most realistic time series of basal ablation. The basal ablation magnitudes calculated with the interpolated thickness and surface ablation data were used to estimate the relative contributions of basal and surface ablation to total thinning over time periods characterized by the occurrence of surface ablation. 


\subsubsection{Surface extent changes and contributions to deterioration}

A series of R2 ScanSAR (100 m nominal resolution) scenes were used to qualitatively investigate the deterioration of PII-A-1-f before it grounded off Baffin Island in late 2015. Seven R2 Fine-Quad (8 m nominal resolution) SAR scenes were acquired between 1 November 2015 and 23 September 2017 to monitor the areal extent of PII-A-1-f while it was grounded. After image processing, a polygon representing the edge of an ice island was digitized in ArcGIS (v. 10.5; ESRI, Redlands, USA). The error associated with these digitizations was $0.07 \%$ (Appendix B). The digitized polygons of ice island extent were used to quantify the contribution of deterioration processes that caused a reduction in areal extent to the overall deterioration of PII-A-1-f. Areal reduction is caused by fracture and a combination of processes that result in smaller magnitudes of sidewall recession (e.g., forced and buoyant convection, wave erosion and calving of overhanging slabs; Fig. 2.1). These latter processes are grouped together and referred to as general 'decay' in this study.

The contributions of fracture, decay, surface ablation and basal ablation to the overall deterioration of PII-A-1-f were estimated. Large fracture events that occurred between September 2016 and September 2017 were identified with imagery acquired by the Moderate Resolution Imaging Spectroradiometer (MODIS) on the Terra satellite (NASA) in the NASA Worldview (v. 1.10.0) web application. An average rate of decay was calculated based on the areal reduction observed between R2 image acquisitions when fracturing was not observed. This rate was used to estimate the magnitude of areal reduction caused by decay when a fracture event of unknown size occurred between R2 image acquisitions.

The contribution of surface and basal ablation to the overall deterioration of the ice island was also quantified. For this analysis, a cubic spline was used to fill missing cumulative ablation values 
between 24 September 2016 and 21 October 2016. It was also assumed that the same surface and basal ablation magnitudes that occurred in the first year of observation also occurred between October 2016 and September 2017.

\subsubsection{Environmental data collection}

The ice island position was recorded hourly with a Garmin 6X-HVS GPS (Garmin International, Inc., Olathe, USA). Air temperature $\left(T_{A}\right)$ was measured with a 109 thermistor in a radiation shield (Campbell Scientific) at 1-minute intervals and logged as hourly averages. All data were recorded on a CR1000 datalogger (Campbell Scientific) and telemetered with an Iridium L-Band modem (9522B; Campbell Scientific).

Thirty-nine conductivity, temperature, depth (CTD) profiles were conducted with a SBE 49 FastCAT CT (Sea-Bird Electronics, Inc., Bellevue, USA) in association with the GreenEdge project (Université Laval) at $67^{\circ} 29^{\prime} \mathrm{N}, 63^{\circ} 47^{\prime} \mathrm{W}$ between 20 April and 22 July 2016. The GreenEdge sea ice camp was situated $20 \mathrm{~km}$ northwest of the grounding location of PII-A-1-f(Fig. 4.3a). Absolute salinity $\left(S_{A} ; \mathrm{g} \mathrm{kg}^{-1}\right)$ and conservative temperature $\left(\Theta ;{ }^{\circ} \mathrm{C}\right)$ measurements were reported at $1 \mathrm{~m}$ intervals. Current speed $\left(\mathrm{u} ; \mathrm{m} \mathrm{s}^{-1}\right)$ was calculated from measurements of the current vectors that were recorded at 30 minute intervals by the GreenEdge project at the same depth as the draft of the ice island with a Teledyne/RDI Workhorse Sentinel $300 \mathrm{kHz}$ acoustic Doppler current profiler (ADCP; Teledyne RD Instruments, Poway, USA). A linear interpolation was applied to fill missing values before daily average u was calculated. 


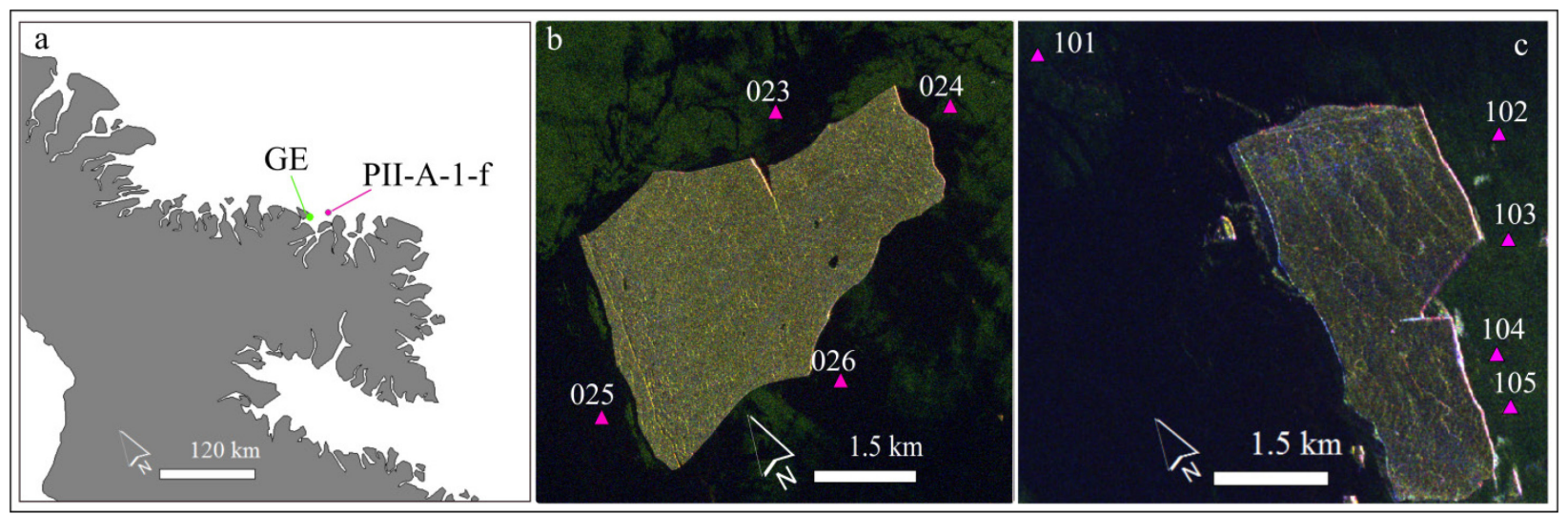

Figure 4.3: a) Locations of the GreenEdge project and the July and September 2016 casts for temperature, salinity and current profiling near to Petermann Ice Island (PII)-A-1-f. b) and c) show PII-A-1-f as imaged in two Fine-Quad (8 m nominal resolution; colour composite presentation - red: $\mathrm{HH}$, green: VV, blue: HV polarization) RADARSAT-2 scenes which were acquired on 27 July 2016 and 27 September 2016, respectively. The cast numbers in b) and c) correspond to profiles plotted in Figure 4.6.

The CCGS Amundsen conducted CTD profiling at PII-A-1-f on 28 July (4 casts) and 29 September (5 casts) 2016 as well as at the GreenEdge site on 29 July (2 casts) and 28 September (1 cast) (Amundsen Science Data Collection, 2016) (Fig. 4.3). $S_{A}$ and $\Theta$ were reported at $8 \mathrm{~m}$ intervals for all casts. The data collected from the CCGS Amundsen in the direct vicinity of PII-A1-f were compared to those recorded by the casts from the CCGS Amundsen collected at the GreenEdge project site. The GreenEdge oceanographic data were used for the basal ablation model calibration and sensitivity analysis due to the longer time series of data collection at this location in comparison to the 2 days of data collected by the CCGS Amundsen. A cublic spline interpolation was used to fill $S_{A}$ and $\Theta$ values for dates when no data were collected. 


\subsubsection{Basal ablation model calibration}

The forced convection basal ablation model was calibrated with observations of ice island thinning and recorded oceanographic data. The model (Eq. 4.1) estimates an ablation rate $\left(M_{b} ; \mathrm{m} \mathrm{d}^{-}\right.$ $\left.{ }^{1}\right)$ from the differential velocity $\left(\Delta \mathrm{u} ; \mathrm{m} \mathrm{s}^{-1}\right)$ and driving temperature $(\Delta T)$ across the length (L; m) of an ice island using a bulk heat transfer coefficient, $C\left(\mathrm{~m}^{2 / 5} \mathrm{~s}^{-1 / 5}{ }^{\circ} \mathrm{C}^{-1}\right)$ (Weeks and Campbell, 1973). In the calibration, it was assumed that the ice island was stationary and therefore $\Delta u$ is simply equivalent to u. $\Delta T$ was calculated as the difference between the ocean temperature at the keel depth and the melting point of ice (equivalent to the freezing point of the adjacent sea water). The melting point $\left(M_{p} ;{ }^{\circ} \mathrm{C}\right.$; ) was adjusted to account for the presence of meltwater on conditions at the ice-water interface with an established empirical relationship between the far field water temperature $(\Theta)$ and the freezing temperature of the far field ocean water $\left(T_{f} ;{ }^{\circ} \mathrm{C}\right.$; Eq. 4.2) (Løset, 1993; Kubat et al., 2007; Broström et al. 2009). $T_{f}$ was derived with $S_{A}$ and pressure ( $P$; dbar) as per TEOS-10 conventions (IOC, SCOR and IAPSO, 2010).

$$
\begin{aligned}
& M_{b}=C \times \Delta \mathrm{u}^{0.8} \times \frac{\Delta T}{\mathrm{~L}^{0.2}} \\
& M_{p}=T_{f} \times e^{-0.19\left(\Theta-T_{f}\right)}
\end{aligned}
$$

The GreenEdge oceanographic data time series covered one complete step change in ice thickness. $C$ was calibrated with the cumulative basal ablation associated with this step change in ice thickness and the cumulative driving force associated with the environmental variables included in Equation 4.1 (i.e., u, $\Delta T$ and L). Oceanographic data $\left(S_{A}, \Theta\right.$, and $\left.\mathrm{u}\right)$ were taken from depths of 90 to $92 \mathrm{~m}$. These values spanned the keel depths of the ice island at the beginning and end of this step change in ice thickness assuming $\rho_{i}=873 \mathrm{~kg} \mathrm{~m}^{-3}$ (Chapter 5) and hydrostatic equilibrium. $P$ was assumed to be the pressure at the keel depth. $\mathrm{L}$ was assigned as the mean of all 
distances between the sIPR location and all vertices of the PII-A-1-f outline digitized from R2 FQ imagery acquired on 27 July 2016.

The derived value of $C$ was used to estimate basal ablation over the subsequent step change in ice thickness to validate this model parameter. Oceanographic data collected by the GreenEdge project and the CCGS Amundsen were available for $25 \%$ of this $24 \mathrm{~d}$ period. The median value of $S_{A}, \Theta, \mathrm{u}$ and $\mathrm{L}$ were input into Equation 4.1 and the predicted cumulative basal ablation was compared to the observed ablation over the validation period.

An analysis was conducted to determine the sensitivity of $C$ to varying $\Delta \mathrm{u}, \Theta, S_{A}, \mathrm{~L}$ and P. A value of $C$ was first calculated based on the basal ablation and median value of each driving variable during the calibration time step. To test the sensitivity of the model, each driving variable was independently modified from the median value $\left(Q_{2}\right)$ to that associated with the first and third quartiles $\left(Q_{1}\right.$ and $\left.Q_{3}\right)$. Quartiles were used because the data were not normally distributed. The

upper and lower bounds for pressure were associated with the keel depths at the start and end of the calibration period. The percent change in the value of $C$ resulting from independently modifying each driving variable to these lower and upper bounds was then calculated.

\subsubsection{Thinning - spatial dataset}

Thickness data were collected over an approximately $3 \mathrm{~km}$ transect with an mIPR (Blue System Integration Ltd.; Mingo and Flowers, 2010) on 8 May 2016. A series of 10 ablation stakes, separated by 100 to $500 \mathrm{~m}$ were installed along the profile route (Fig. 4.1a). Eight of the stakes were re-measured during a field visit on 28 September 2016, and thickness data were collected over $2.4 \mathrm{~km}$ of the original transect.

A $25 \mathrm{MHz}$ antenna was towed by snowmobile (May) and foot (September) when collecting thickness data with the mIPR. Each measurement was stacked (averaged) 256 times in the 
IceRadar software program (v. 4.4.41b; Blue System Integration Ltd.). The mIPR oscilloscope digitizer waveform sampling interval was set to $250 \mathrm{MHz}$. A Topcon HiperV dual-frequency GPS (Topcon Corp., Tokyo, Japan) was also mounted on the mIPR. The mIPR and GPS both recorded at a $2 \mathrm{~s}$ measurement interval. All mIPR processing was conducted with Radar Tools (release 0.4), a library of Python scripts and tools that was used to standardize, clean, visualize, and process data contained in the raw radar data (Wilson, 2013). This program was also used to select the location of the air and reflected waves. The GPS locations recorded by the mIPR onboard GPS were replaced with those recorded by the Topcon Hiper V following post-correction using the precise point positioning (PPP) processing available through Natural Resources Canada (2016).

A 'dewow' high-pass filter and a linear gain control were used to decrease noise and enhance reflections seen in the return signal (Annan, 2009; Wilson, 2012, 2013). Gaps in the radargram that are associated with hyperbolae were left unpicked (Fig. 4.4). A Stolt (F-K) migration was applied to qualitatively assess the location of signal reflections over these sections which had large thickness gradients. 


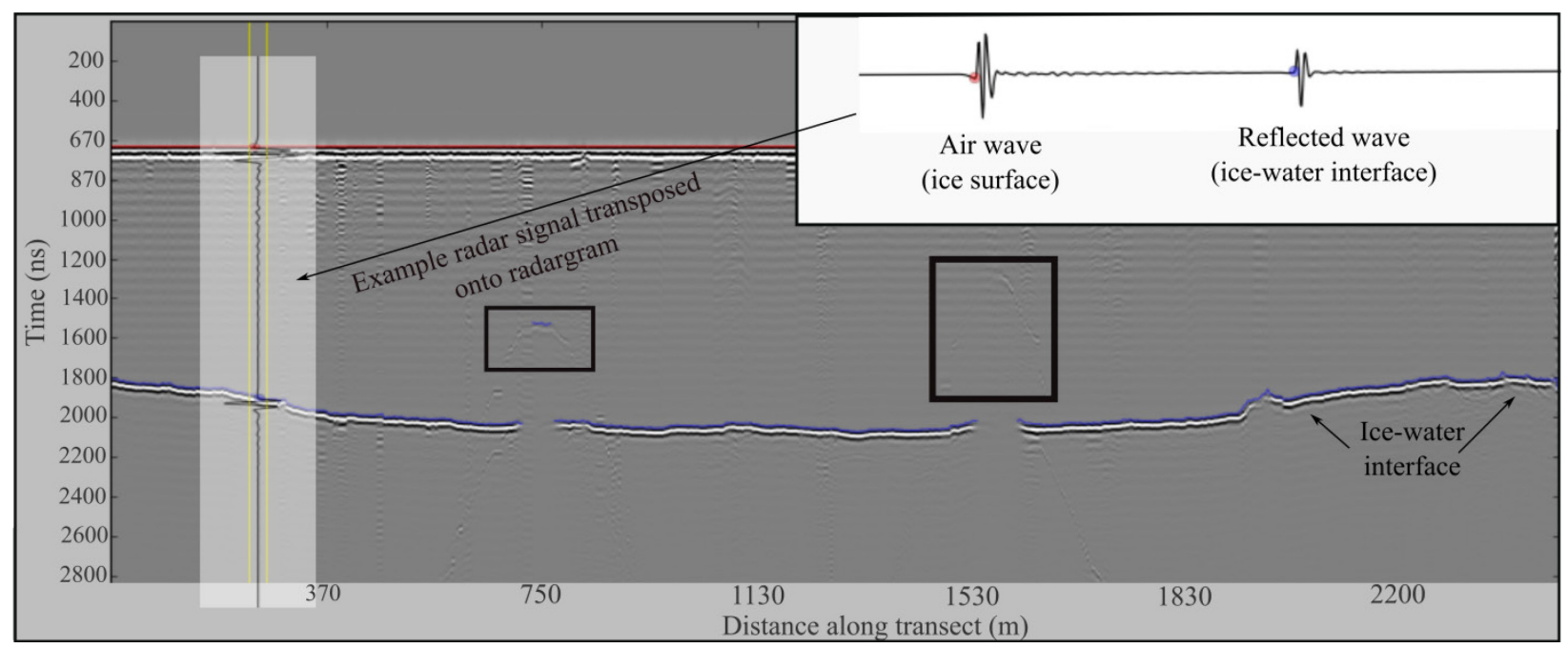

Figure 4.4: A radargram showing the reflected returns that represent the ice-water interface collected with a mobile ice penetrating radar (mIPR) system. Ice thickness was calculated from the two-way travel time between the air wave (red line) and the reflected wave (blue line). The inset shows the position of the air (red dot) and reflected (blue dot) waves as picked for a single IPR trace. The black squares surround faint hyperbolae observed in the radargram.

Ice thickness was calculated from the selected data with Equation 4.3 (Wilson, 2012):

$$
\mathrm{T}=\sqrt{\left(\frac{\left(t+\frac{s}{c}\right) \times v}{2}\right)^{2}-\frac{s^{2}}{4}}
$$

where $\mathrm{T}$ is thickness $(\mathrm{m}), s$ is the distance between the transmitting and receiving antennas $(\mathrm{m}), t$ is the time interval between the recording of the air and reflect waves by the receiver, and $c$ is the speed of the airwave $\left(3.0 \times 10^{8} \mathrm{~m} \mathrm{~s}^{-1}\right)$ traveling between the transmitter and receiver (Wilson, 2012). The speed of the radar wave in ice $(v)$ was set to $1.7 \times 10^{8} \mathrm{~m} \mathrm{~s}^{-1}$ (Macheret et al., 1993; Mortimer et al., 2012). The ice thickness resolution $( \pm 0.5 \mathrm{~m})$ was limited by $v$ and the waveform sampling interval of the mIPR system (Crawford, 2013; Rajewicz, 2017).

Snow was present on the ice surface when the mIPR transect was conducted in May 2016. However, an insufficient number of snow depth measurements were recorded to adequately account for the snow depth over the transect area and it was not possible to distinguish the snow/ice 
interface in the radargram. The full ice + snow thickness was therefore calculated using $v=1.7 \times$ $10^{8} \mathrm{~m} \mathrm{~s}^{-1}$. An additional uncertainty was added to the May ice thickness measurements based on the maximum snow depth $(78 \mathrm{~cm})$ recorded at three locations along the mIPR transect and $v=2.0$ $\mathrm{x} 10^{8} \mathrm{~m} \mathrm{~s}^{-1}$ for snow (Eq. 4.3; Haas and Druckenmiller, 2009). Photos taken at each ablation stake along the transect showed lower snow depths. Furthermore, the maximum snow layer thickness at the main site was $48 \mathrm{~cm}$. These observations support the use of $78 \mathrm{~cm}$ as a conservative estimate of snow depth across the transect. The errors associated with the resolution of the mIPR system and the conservative snow depth estimate were summed to determine the maximum amount that the ice thickness, as measured in May, could be overestimated $(1.1 \mathrm{~m})$. Uncertainty in thickness change calculations was determined by propagating the uncertainties in ice thickness resulting from the resolution of the mIPR system and the presence of snow $(-0.7$ to $+1.2 \mathrm{~m})$.

The magnitude of thinning that occurred between May and September 2016 was calculated between the closest pairs of mIPR traces recorded during each field visit. The September transect positions were adjusted relative to the orientation of PII-A-1-f in May by matching mIPR traces known to be collected at the same location (i.e., the ablation stakes) on the ice island to correct for a small amount of movement by the ice island between the two field visits.

An electromagnetic wave transmitted from an IPR spreads in a cone-shape as it penetrates downwards through the ice. The radius $(r)$ of its footprint at the ice-water interface is dependent on the centre frequency wavelength $(\lambda ; 25 \mathrm{MHz})$, relative permittivity of ice $(K ; 3)$, and the ice thickness (T; m) (Leucci et al., 2003), as per Equation 4.4.

$$
r=\frac{\lambda}{4}+\frac{\mathrm{T}}{\sqrt{K+1}}
$$

The location of traces that were compared between the May and September field visits were offset by varying distances. The percentage of overlap between corresponding radar footprints was 
calculated to provide a qualitative index of comparability between the May and September thickness measurements. The positions of thickness change measurements were categorized as $\geq$ $50 \%$ overlap, $\geq 30 \%$ overlap, $<30 \%$ overlap, and no overlap.

\subsubsection{Grounding location and duration}

Local bathymetry and the keel of PII-A-1-f were surveyed in July and September 2016 with a Kongsberg-EM-302 multibeam echosounder (Kongsberg Gruppen ASA, Kongsberg, Norway) situated on the CCGS Amundsen. The raw data were processed taking into account the sound velocity profiles based on CTD casts and tides (WebTide Tidal Prediction Model, v. 0.7.1; Bedford Oceanographic Institute, Dartmouth, Canada). The surveys were then processed to a $5 \mathrm{~m}$ resolution grid using HIPS and SIPS software (v. 9.1.7; Teledyne CARIS, Inc., Fredericton, Canada). The underwater ridge on which the ice island grounded was identified with the processed survey data. The presence of PII-A-1-f and the limited beam-angle of the echosounder made it impossible to map the bathymetry located below the centre of the ice island. The continuation of the ridge across this area was estimated by connecting the likely July grounding location and the shallowest surveyed bathymetry extending under the opposing sidewall of PII-A-1-f. The imagery acquired by MODIS that were used to constrain the timing of fracturing events was also used to monitor the position of the ice island and the dates that the ice island ungrounded.

\subsection{Results}

\subsubsection{Temporal thinning variation and associated environmental conditions}

Based on the raw sIPR thickness measurements (stepped grey/gray line in Fig. 4.5), PII-A-1-f decreased in thickness by $4.7 \pm 1.4 \mathrm{~m}$ over the eleven month collection period and $4.0 \pm 1.4 \mathrm{~m}$ over the time that daily basal ablation was estimated with the linearly interpolated thickness values (Fig. 4.5; Table 4.1). This latter time interval can be divided into three periods based on the 
occurrence and magnitude of surface ablation (Fig. 4.5; Table 4.1). Minimal surface ablation was observed over Period 1 (November to December 2015). The mean daily thinning rate tripled between periods 2 and 3, which spanned November 2015 to July 2016 and July to September 2016, respectively. This is a result of the onset of continuous surface ablation in mid-July (Table 4.1). Ninety-eight percent of the recorded surface ablation occurred in this period when $T_{A}$ was consistently $>0{ }^{\circ} \mathrm{C} . T_{A}$ was $>0{ }^{\circ} \mathrm{C}$ for $15 \%$ of the days in Period 2, however, this contributed to melting the snow that had accumulated on the ice surface instead of ice ablation (Fig. 4.5; Table 4.1). 


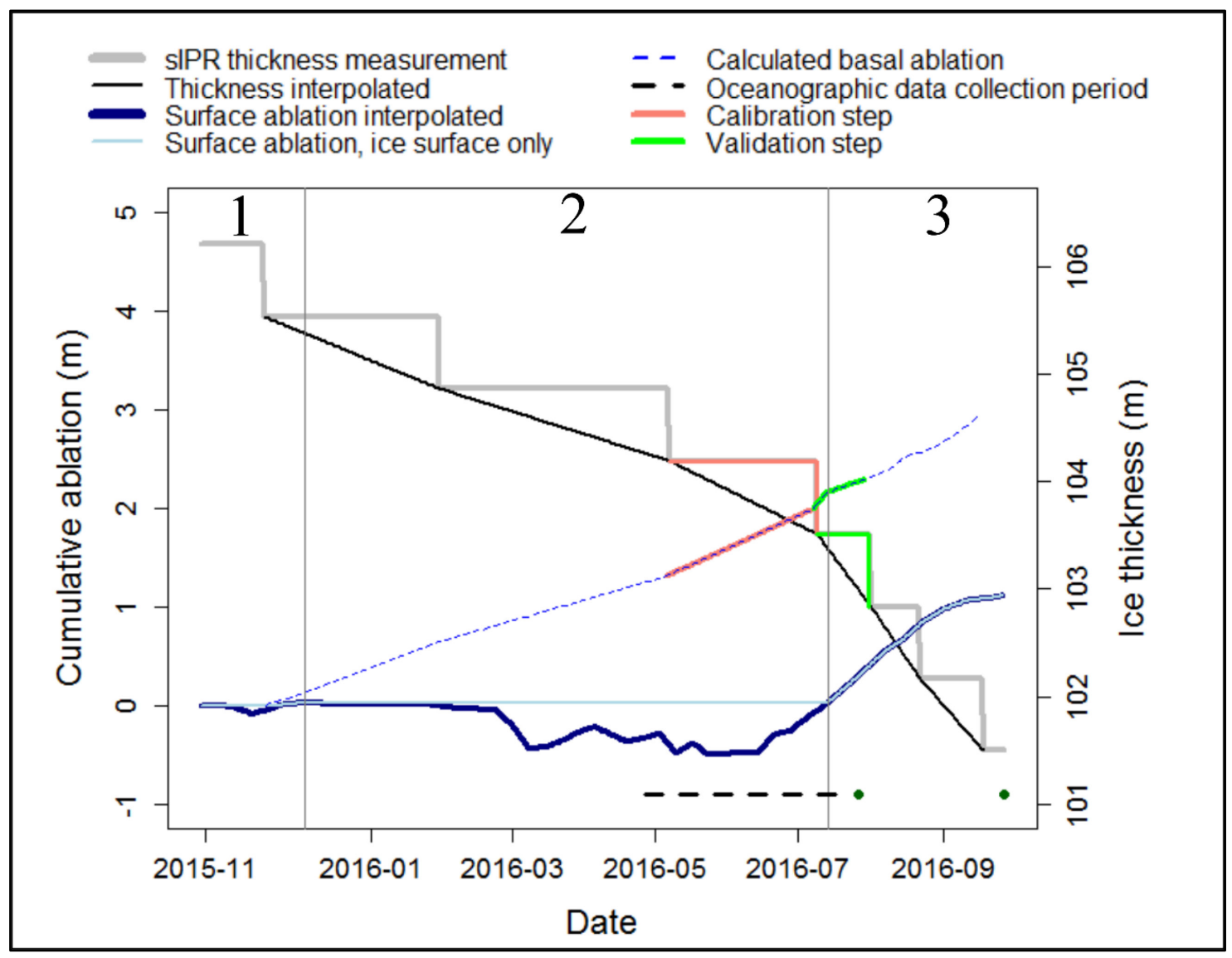

Figure 4.5: Total thickness change, surface ablation and basal ablation. The solid vertical lines denote periods when surface ablation was occurring (Periods 1 and 3 ) as per the ablation stake data and correspond with Table 4.1. The green dots represent timing of CTD profiling at Petermann Ice Island-A-1-f and the GreenEdge site by the CCGS Amundsen. These points represent the profiling that was conducted on consecutive days at these sites in July and September 2016. The horizontal, dashed black line denotes the time period when GreenEdge oceanographic data were available. The solid pink and green segments denote the thickness and basal ablation associated with model calibration and validation periods, respectively.

The mean $M_{b}$ for the entire period (i.e., November 2015 to September 2016) was almost three times greater than the mean $M_{s}$. However, this ratio varied seasonally. For example, the mean $M_{b}$ was seven times greater than the mean $M_{s}$ during Period 1 when only $2 \mathrm{~cm}$ of surface ablation was observed. In contrast, the mean $M_{s}$ was approximately $50 \%$ greater than the mean $M_{b}$ over Period 3 when over $1 \mathrm{~m}$ of surface ablation was observed over the two month duration (Fig. 4.5; Table 4.1). 
Table 4.1: Ablation and total thinning magnitudes and rates per period. Air temperature $\left(T_{A}\right)$ data for each period is also included. These values are associated with the time period that basal ablation rates were estimated with linear interpolation. Rounding error, at times, makes it appear that there are inconsistencies between the summed ablation and thinning magnitudes or between the ratios of surface : basal ablation magnitudes versus rates.

\begin{tabular}{|c|c|c|c|c|c|c|}
\hline Period & Dates & $\begin{array}{c}\text { Surface } \\
\text { ablation }(\mathrm{cm}) \\
\& \text { rate }\left(\mathrm{cm} \mathrm{d}^{-1}\right)\end{array}$ & $\begin{array}{c}\text { Mean } \\
T_{A} \\
\left({ }^{\circ} \mathrm{C}\right)\end{array}$ & $\begin{array}{c}\text { Days } T_{A} \\
>0^{\circ} \mathrm{C}\end{array}$ & $\begin{array}{c}\text { Basal } \\
\text { ablation }(\mathrm{cm}) \\
\& \text { rate }\left(\mathrm{cm} \mathrm{d}^{-1}\right)\end{array}$ & $\begin{array}{l}\text { Total thinning } \\
\quad(\mathrm{cm}) \& \\
\text { rate }\left(\mathrm{cm} \mathrm{d}^{-1}\right)\end{array}$ \\
\hline 1 & $\begin{array}{c}\text { 2015-11-16: } \\
2016-12-04\end{array}$ & $2(0.1)$ & -13 & 3 & $14(0.7)$ & $16(0.8)$ \\
\hline 2 & $\begin{array}{c}2016-12-05: \\
2016-07-14\end{array}$ & 0 & -15 & 33 & $200(0.9)$ & $200(0.9)$ \\
\hline 3 & $\begin{array}{c}\text { 2016-07-15: } \\
2016-09-14\end{array}$ & $106(1.6)$ & 3 & 65 & 78 (1.2) & $184(2.8)$ \\
\hline $1-3$ & $\begin{array}{c}2015-11-16: \\
2016-09-14\end{array}$ & $108(0.4)$ & -11 & 101 & $295(1.0)$ & 403 (1.3) \\
\hline
\end{tabular}

Basal ablation was responsible for $73 \%$ of the observed thinning between November 2015 and September 2016. The mean $M_{b}$ increased over the data collection period (Table 4.1). The increase in daily mean $M_{b}$ from 0.9 to $1.2 \mathrm{~cm} \mathrm{~d}^{-1}$ between periods 2 and 3 coincides with an increase of 0.1 ${ }^{\circ} \mathrm{C}$ in ocean temperature at the keel depth as recorded with the CTD casts taken by the CCGS Amundsen at PII-A-1-f in July and September 2016 (Fig. 4.6). 


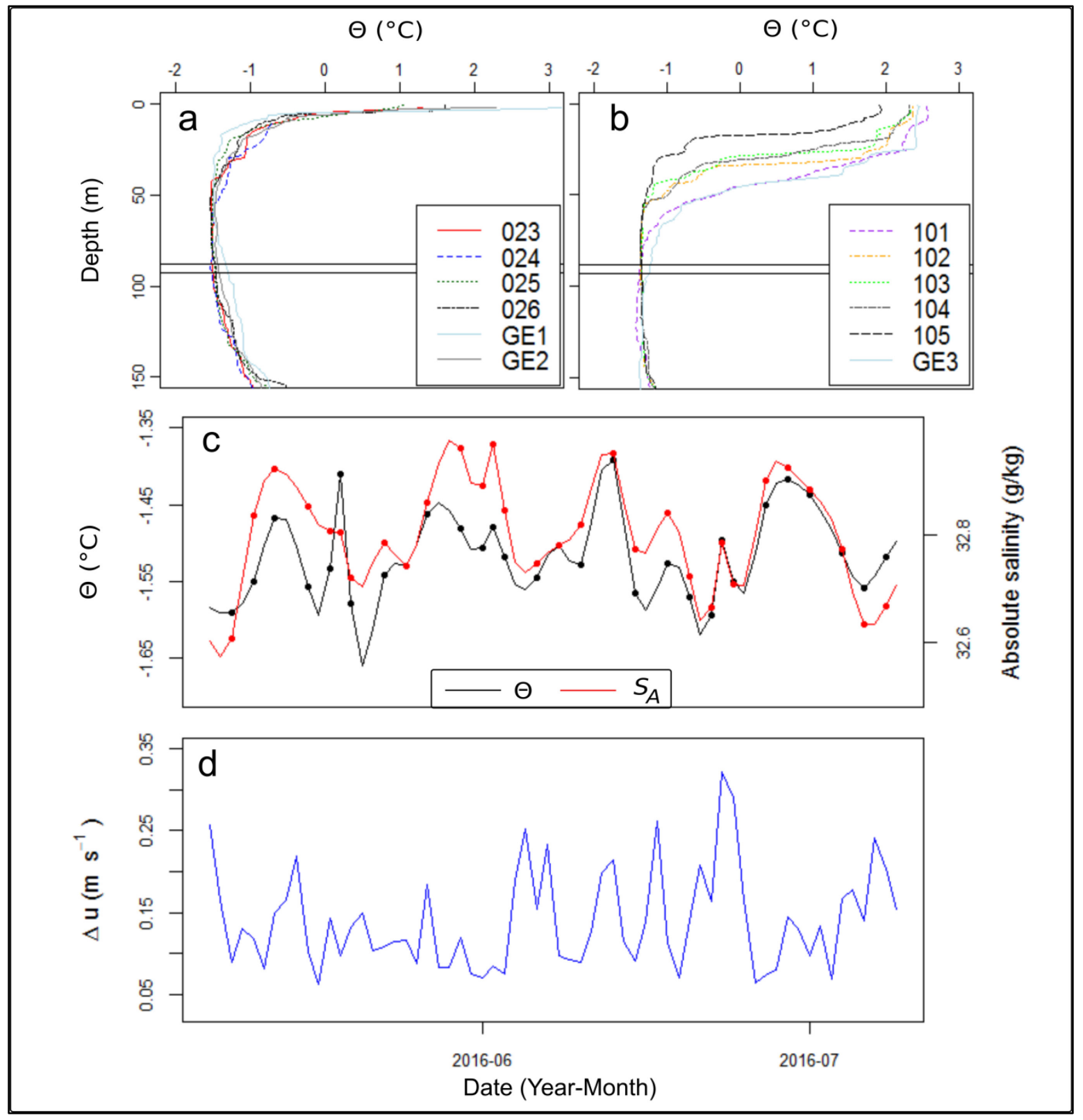

Figure 4.6: Oceanographic data. Temperature profiles recorded in a) July and b) September 2016 by the CCGS Amundsen. The horizontal lines denote the range of the keel depth of Petermann Ice Island (PII)-A-1-f over the study period. The cast numbers listed in the legend correspond to the cast locations shown in Figure 4.3 and refer to the number assigned during the 2016 CCGS Amundsen cruise. Data associated with profiles recorded at the GreenEdge (GE) location are also included. The GreenEdge and PII-A-1-f data were collected on consecutive dates. c) and d) show the oceanographic conditions at the GreenEdge site over the period associated with the basal ablation model calibration. $\Theta$ is conservative temperature, $S_{A}$ is absolute salinity and $\Delta \mathrm{u}$ is the differential velocity between the ice island and the ocean current. The points in c) represent recorded data. The lines represent the interpolated time series. 


\subsubsection{Basal ablation model calibrations}

Of the driving variables implicated in the basal ablation model, $\Delta \mathrm{u}$ had the greatest relative range of values recorded over the calibration period. A five-fold increase in $\Delta \mathrm{u}$ was seen between the minimum $\left(0.06 \mathrm{~m} \mathrm{~s}^{-1}\right)$ and maximum $\left(0.32 \mathrm{~m} \mathrm{~s}^{-1}\right)$ values. As expected, the range of $S_{A}$ observations was limited (32.5 to $33.0 \mathrm{~g} \mathrm{~kg}^{-1}$ ). Far-field ocean temperature $(\Theta)$ recorded at the GreenEdge site ranged from -1.7 to $-1.4{ }^{\circ} \mathrm{C}$, which corresponded with a range of $\Delta T$ values from 0.12 to $0.31{ }^{\circ} \mathrm{C}$. Pressure decreased from 91.0 to 90.4 dBar due to the observed thinning.

The $\Theta$ measurements collected by the CCGS Amundsen on two dates at the GreenEdge site were slightly greater than that recorded with the CTD casts taken closer to PII-A-1-f (Fig. 4.6). Variability in $\Theta$ over the data collection period at the GreenEdge site is shown in Figure 4.6c, and the median $\Theta$ value from the July CCGS Amundsen cast is the same as that of the GreenEdge time series used for the model calibration. $S_{A}$ at the GreenEdge location was not consistently greater or less than that at the PII-A-1-f location based on the CTD casts taken by the CCGS Amundsen in July and September 2016.

The calibration of the forced convection basal ablation model resulted in a value of $1.3 \times 10^{-5}$ $\mathrm{m}^{2 / 5} \mathrm{~s}^{-1 / 5}{ }^{\circ} \mathrm{C}^{-1}$ being fit to $C$, the bulk heat transfer coefficient. The observed cumulative basal ablation in the validation 'step' was under-predicted by $4 \%$ by the calibrated model. Relative change in the derived value of $C$ was used to assess the sensitivity of the ablation model to variation in the driving variables. Due to the linear relationship between $\Delta T$ and $M_{b}$ in Equation 4.1, it is apparent that a change in $\Delta T$ will have the greatest impact on $C$ if the driving variables are independently adjusted by a consistent percentage. However, in this study's sensitivity analysis, the driving variables are adjusted according to the variation in their respective data series. 
Based on their inter-quartile ranges, $\Theta$ and $S_{A}$ were relatively stable at the draft depth of the ice island. $\Delta T$ varied between 12 and $18 \%$, and $S_{A}$ and $P$ both varied by $1 \%$ or less. L was the driving variable with the greatest variation between two quartiles (Table 4.2). However, the $34 \%$ variation in $\mathrm{L}$ between $Q_{2}$ and $Q_{3}$ resulted in a minimal (6\%) change in the derived value of $C$. Though there was a large difference between the extreme observations of $\Delta \mathrm{u}$, the variation between quartiles was more constrained (28 to $30 \%$ ). However, this variation was large enough to modify the derived value of $C$ by 22 to $25 \%$, which is larger than the modification caused by varying $\Theta$ (12 to $18 \%$ ) regardless of the linear relationship between $\Delta T$ and $M_{b}$ (Table 4.2). 
Table 4.2: Descriptive statistics and sensitivity analysis results for the variables included in the forced convection basal ablation model calibration. The relative difference between the upper and lower bounds and the median of the model variables (e.g., ' $Q_{2}: Q_{3}$ ') are included in the table, along with associated percent change in the bulk heat transfer coefficient, $C$, compared to that found with the median values of all variables $\left(1.3 \times 10^{-5} \mathrm{~m}^{2 / 5} \mathrm{~s}^{-1 / 5}{ }^{\circ} \mathrm{C}^{-1}\right)$. The percent change between quartiles $(Q)$ for the far-field ocean temperature $(\Theta)$ is reported as the corresponding percent change to the driving temperature $(\Delta T)$. L = length, $S_{A}=$ absolute salinity, $\mathrm{P}=$ pressure.

\begin{tabular}{|c|c|c|c|c|c|c|}
\hline & $\Delta \mathbf{u}\left(\mathrm{m} \mathrm{s}^{-1}\right)$ & $\Delta T\left({ }^{\circ} \mathbf{C}\right)$ & L (km) & $S_{A}\left(\mathrm{~g} \mathrm{~kg}^{-1}\right)$ & $P($ dBar $)$ & $\boldsymbol{\Theta}\left({ }^{\circ} \mathbf{C}\right)$ \\
\hline Minimum & 0.06 & 0.12 & 0.9 & 32.5 & 90.4 & -1.7 \\
\hline Mean & 0.14 & 0.22 & 2.2 & 32.8 & 90.7 & -1.5 \\
\hline Maximum & 0.32 & 0.31 & 3.4 & 33.0 & 91.0 & -1.4 \\
\hline$Q_{1}$ & 0.09 & 0.19 & 1.8 & 32.7 & - & -1.6 \\
\hline$Q_{2}$ & 0.13 & 0.22 & 2.2 & 32.8 & 90.7 & -1.5 \\
\hline$Q_{3}$ & 0.17 & 0.25 & 2.9 & 32.9 & - & -1.5 \\
\hline$Q_{2}: Q_{3}(+\%)$ & 28 & 12 & 34 & 0.3 & $0.3 *$ & - \\
\hline $\begin{array}{l}\text { Relative change in C: } \\
\text { upper bound (\%) }\end{array}$ & 22 & 12 & 6 & 1.3 & 0.1 & 12 \\
\hline$Q_{2}: Q_{1}(-\%)$ & 30 & 18 & 16 & 0.2 & $0.3 *$ & - \\
\hline $\begin{array}{l}\text { Relative change in C: } \\
\text { lower bound (\%) }\end{array}$ & 25 & 18 & 3 & 1.0 & 0.1 & 18 \\
\hline
\end{tabular}

*This represents the percent change between $Q_{2}$ and the minimum or maximum values of $P$. 


\subsubsection{Spatial variation in thickness and thinning}

The ice island thickness over the mIPR transect ranged from $80.7_{-0.5}^{+1.1}$ to $127.1_{-0.5}^{+1.1} \mathrm{~m}$ in May and $77.3 \pm 0.5$ to $123.7 \pm 0.5 \mathrm{~m}$ in September 2016 (Table 4.3; Figs. 4.7 and 4.8a). Thinning was greater than maximum measurement uncertainty at all of the compared transect points across the approximately $2 \mathrm{~km}$ transect (Fig. 4.8). The mean rate of surface ablation between field visits was $0.9 \mathrm{~cm} \mathrm{~d}^{-1}$ (Table 4.3). However, this value does not reflect the seasonality of this deterioration process. The rate of surface ablation was likely near zero until approximately 15 July 2016 (the date that ablation of the ice surface began determined from the ablation stakes at the sIPR), and $1.5 \mathrm{~cm} \mathrm{~d}^{-1}$ after this date, which is slightly less than at the sIPR (Period 3, $1.6 \mathrm{~cm} \mathrm{~d}^{1}$; Table 4.1). The mean thinning rate of $3 \mathrm{~cm} \mathrm{~d}^{-1}$ across the transect was greater than the sIPR thinning rate calculated over the same time period $\left(\sim 2 \mathrm{~cm} \mathrm{~d}^{-1}\right)$.

Table 4.3: Descriptive statistics of ice island thickness, thinning, and surface ablation as measured by the mobile ice penetrating radar transect and ablation stake measurements conducted in 2016. Thickness change is reported for comparisons between May and September traces with overlap in their respective radar footprints at the ice-water interface. Mean and median values, as well as standard deviation $(\sigma)$ and interquartile range (IQR) are reported. Note that thickness decrease was normally distributed and thickness and surface ablation measurements were both left skewed.

\begin{tabular}{ccccc}
\hline & $\begin{array}{c}\text { May } \\
\text { thickness }\end{array}$ & $\begin{array}{c}\text { September } \\
\text { thickness }\end{array}$ & Thinning & $\begin{array}{c}\text { Surface } \\
\text { ablation }\end{array}$ \\
\hline Mean (m) & 117.7 & 113.7 & 4.0 & 1.2 \\
$\boldsymbol{\sigma}(\mathbf{m})$ & 9.2 & 8.9 & 0.8 & 0.1 \\
Median (m) & 118.0 & 122.11 & 4.0 & 1.2 \\
IQR (m) & 15.5 & 15.1 & 1.0 & 0.2 \\
Min (m) & 80.7 & 77.3 & 2.0 & 1.0 \\
Max (m) & 127.1 & 123.7 & 8.4 & 1.5 \\
Mean thinning rate (cm d $\left.\mathbf{~ d}^{-1}\right)$ & & & 2.8 & 0.9 \\
\hline
\end{tabular}




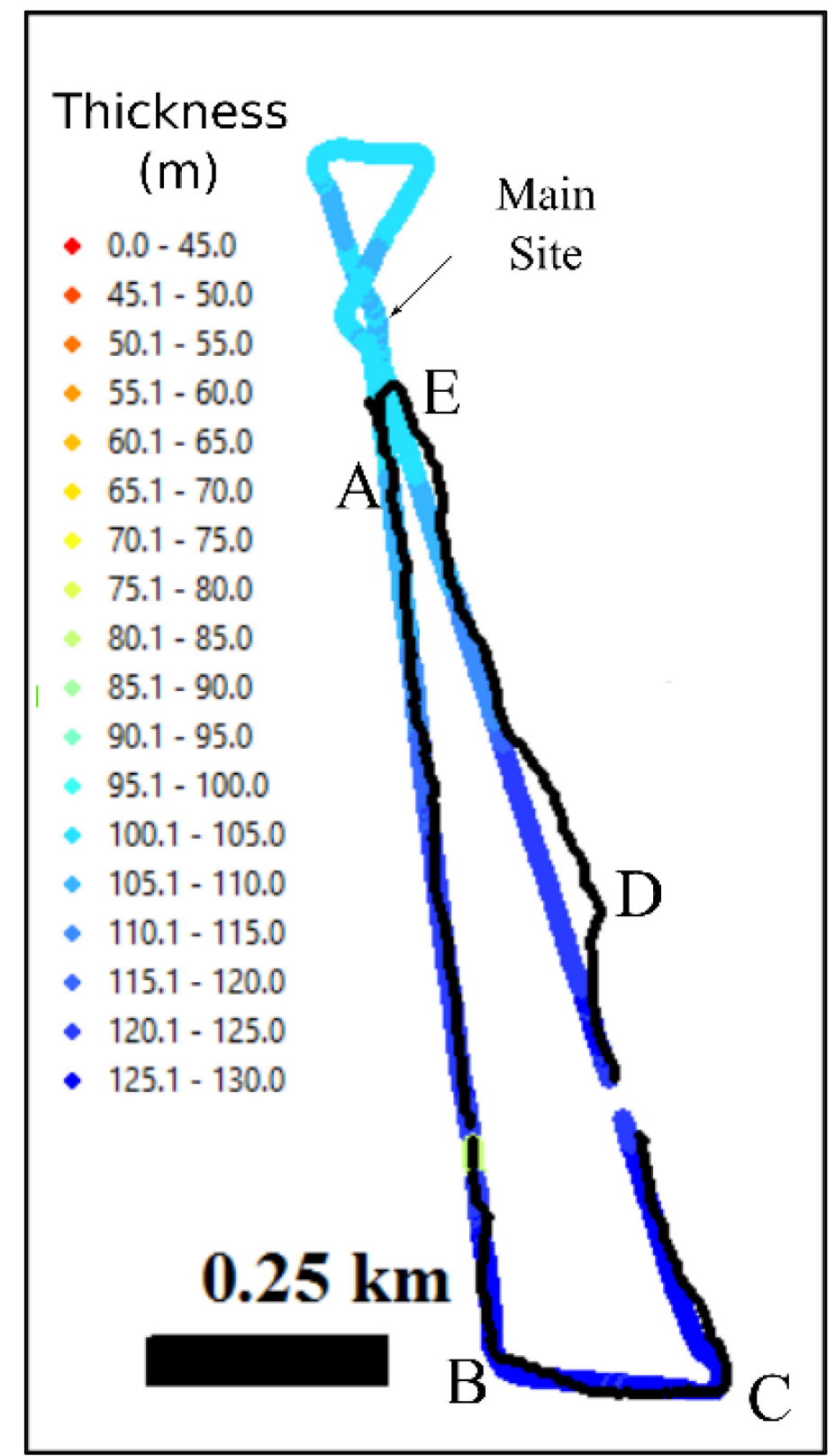

Figure 4.7: Petermann Ice Island (PII)-A-1-f thickness measurements collected in 2016 with a mobile ice penetrating radar (mIPR). Thickness values are shown for May and the September transect is overlayed with a black line. The arrow points to the location of the main fieldwork site where the stationary IPR and small meteorological station were installed (also shown in Fig. 4.1a). Upper-case letters are used to denote transect segments that are referred to in the text and figures 4.8 and 4.9 . 
Points A-E in figures 4.7, 4.8 and 4.9 are used to denote segments of the transect. A $50 \mathrm{~m}$ long section of ice that was approximately $80 \mathrm{~m}$ thick was recorded during both field visits along segment $\mathrm{AB}$ (Figs. 4.7 and $4.8 \mathrm{a}$ ). This section was approximately $40 \mathrm{~m}$ thinner than adjacent areas. The first of two hyperbolae identified in the radargram shown in Figure 4.4 is associated with this section. The second hyperbola identified in Figure 4.4 is located in the section along transect segment CD where the radar wave reflected from the ice-water interface could not be confidently distinguished in the radargram. This resulted in data gaps in figures 4.7, 4.8a,b and 4.9a. 

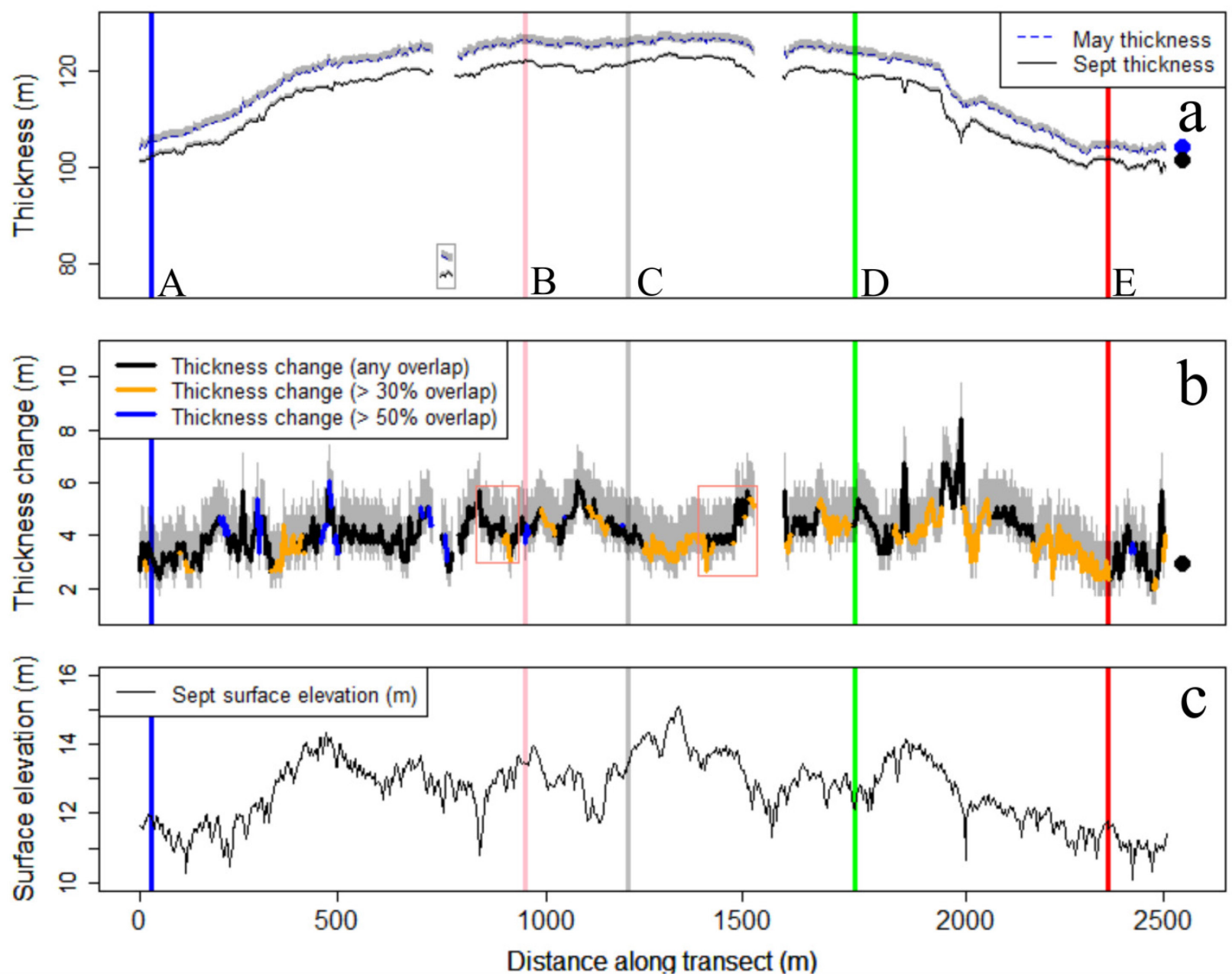

Figure 4.8: Spatial variation in morphology and thinning between May and September 2016. Distance along transects follows the direction shown in figures 4.7 and 4.9. Upper-case letters are used to denote transect segments referred to in the text and figures 4.7 and 4.9. a) Thickness observations. The grey box corresponds with the thin ice section also denoted in Figure 4.9. b) Thickness change. The pink boxes correspond with the thickness change gradients identified in Figure 4.9. Thinning data were categorized based on the amount of overlap between the May and September radar footprints. Grey shading in a) and b) denotes uncertainty in thickness measurements and thinning amounts, respectively. c) Elevation profile for September 2016 (Canadian Geodetic Vertical Datum of 2013, Natural Resources Canada, 2016). The larger, single points in a) and b) denote the respective thickness and thinning measured with data collected by the SIPR at the main site. 
A thickness gradient was apparent over the area covered by the transect, with thickness increasing by 1.7 and $1.8 \mathrm{~cm} \mathrm{~m}^{-1}$ over the $\mathrm{AB}$ and $\mathrm{CE}$ transect segments (Fig. 4.8). However, thickness was observed to decrease near the section of thin ice observed over the transect segment $\mathrm{AB}$ and the gap in the transect segment $\mathrm{CD}$. Though definitive selection of the air and basal wave locations could not be conducted to ascertain thickness at this location, the pair of in-line hyperbolae seen in both the May and September 2016 radargrams support the interpretation that this thinner section ran across transect segments $\mathrm{AB}$ and $\mathrm{CD}$. This section of thin ice is referred to as a 'subsurface feature'. A corresponding linear 'surface feature' is apparent in Figure 4.10. The magnitude of thinning ( 3 to $4 \mathrm{~m}$ ) observed over this section along segment $\mathrm{AB}$ (shown in the boxes in figures $4.8 \mathrm{a}$ and $4.9 \mathrm{a}$ ) was in the low to mid-range of the thinning observed along the entire transect. However, the general gradient in thinning magnitudes leading towards the surface and subsurface features (referred together as the 'paired feature') shows a similar pattern in both transect segments $\mathrm{AB}$ and $\mathrm{CD}$ (see pink boxes in figures $4.8 \mathrm{~b}$ and $4.9 \mathrm{a}$ ). Thinning magnitudes of 3 to $4 \mathrm{~m}$ increase to 5 to $6 \mathrm{~m}$ across a distance of $\sim 90-150 \mathrm{~m}$, ending at the surface feature and where a gap in the thickness record exists. 


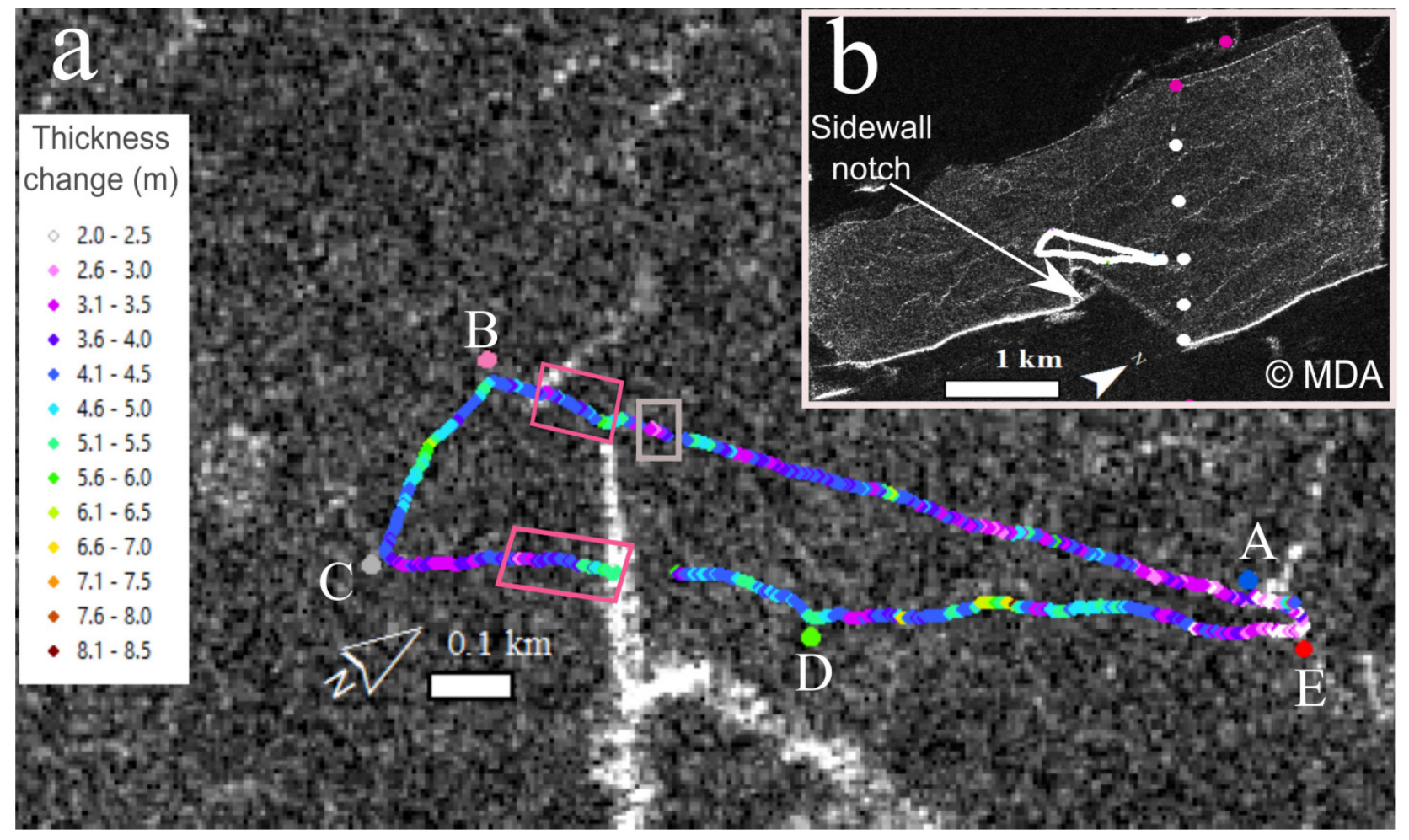

Figure 4.9: a) Thickness change on Petermann Ice Island (PII)-A-1-f calculated from repeat mobile ice penetrating radar (mIPR) transects displayed on a Fine-Quad RADARSAT-2 scene acquired on 28 September 2016 (shown in greyscale). A surface feature is apparent as a line of high backscatter (white) pixels starting at the sidewall notch. The grey box corresponds with the thinnest section of ice seen in figures 4.7 and 4.8 and the pink boxes denote regions with similar thickness change gradient which might lead to a paired surface/subsurface feature. The coloured circles and upper-case letters correspond with locations along the transect that are also shown in figures 4.7 and 4.8 and referred to in the text. b) The position of the September 2016 mIPR transect, shown as a white line, in relation to the entire ice island. The circles denote the approximate location of an underwater ridge that PII-A-1-f was grounded on. Pink circles identify locations of known shallow bathymetry $(<120 \mathrm{~m}$ depth) while grey points denote the estimated continuation of the shallow bathymetry. The geolocation error of the RADARSAT-2 scene was evaluated and minimal error in the position of the scene was observed. 


\subsubsection{Areal reduction and contributions to PII-A-1-f deterioration}

Basal and surface ablation caused a $3 \%$ decrease in the volume of PII-A-1-f over the on-ice data collection period (October 2015 - September 2016). Over this period, the ice island decreased in areal extent by $3.4 \pm 0.3 \mathrm{~km}^{2}$ from its initial size of $13.2 \pm 0.01 \mathrm{~km}^{2}$ (Fig. 4.10 ). It is estimated that $10 \%$ of this areal deterioration was a result of decay. The remaining $90 \%$ was estimated to be the result of a fracture event that occurred in September 2016. The areal reduction preferentially occurred near a sidewall notch, which was observed as a wedge-shaped cut into the ice island. The sidewall notch 'root' is the tip of this wedge (White et al., 1980) (Fig. 4.10).

Figure $4.1 \mathrm{~b}$ illustrates the bathymetry surrounding the ice island and locates the point at which the ice island was grounded in July 2016 on an underwater ridge. The ice island pivoted and translated along this ridge over the monitoring period. The ice island un-grounded in early November 2016 and then re-grounded closer to the Baffin Island coast. A $1 \mathrm{~km}^{2}$ fracture event occurred in early September 2017 (Fig. 4.10e). Later in that month the ice island again ungrounded, re-grounded and then fractured along the paired feature where the ice island was thinnest along the mIPR transect (Fig. 4.10f). 


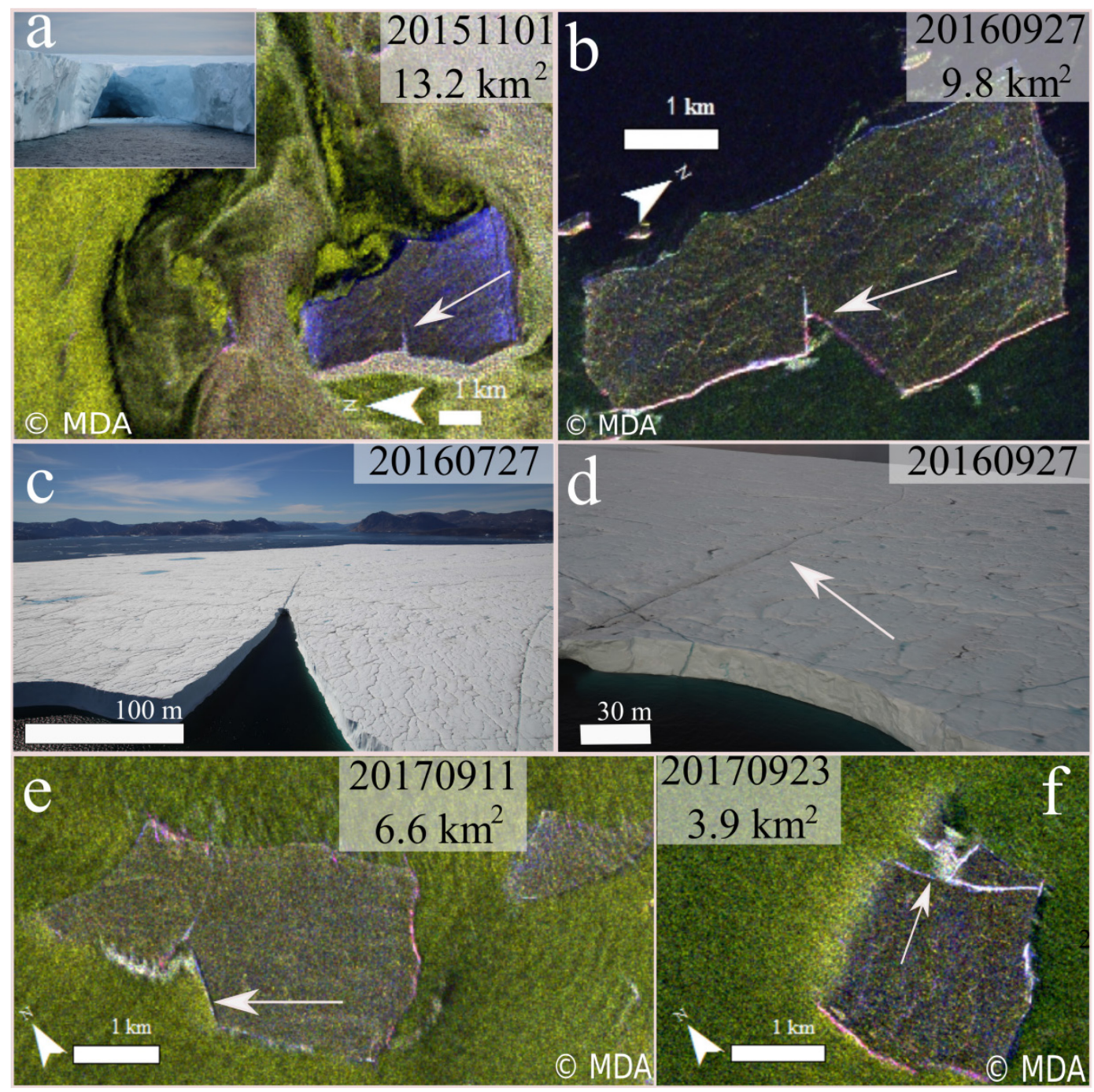

Figure 4.10: Sidewall erosion and fracturing of Petermann Ice Island (PII)-A-1-f between November 2015 and September 2017. Image acquisition dates and the ice island surface area are noted in panels a), b), e) and f). Panels c) and d) show the sidewall notch and surface feature along which the ice island ultimately fractured. The imagery are Fine-Quad RADARSAT-2 with $8 \mathrm{~m}$ nominal resolution, and colour composite visualization (red: HH, green: VV, blue: HV polarization). The inset in a) shows the root of the sidewall notch in October 2015. The white arrows point to the location of the sidewall notch and surface feature. Blue tones associated with the ice island are due to volume scattering and a relatively smooth surface, which results in relatively strong HV backscatter and relatively lower HH and VV backscatter. Photo credits: a, inset) P. DeRepentigny, c) L. Copland and d) L. Candlish. 
The observed fracture events are matched with the corresponding interval between R2 image acquisitions in Figure 4.11. The three observed fracture events were estimated to cause $85 \%$ of the observed areal reduction that occurred over the two years (November 2015 - September 2017) that PII-A-1-f was monitored with R2 imagery. The remaining $15 \%$ is estimated to be the result of decay. Together, fracture and decay caused the volume of PII-A-1-f to decrease by approximately $67 \%$ (Fig. 4.11). Conversely, the extrapolated basal and surface ablation magnitudes resulted in an estimated $7 \%$ volume change over the two years. The contribution of basal ablation to this volume change was approximately three times greater than the contribution of surface ablation.

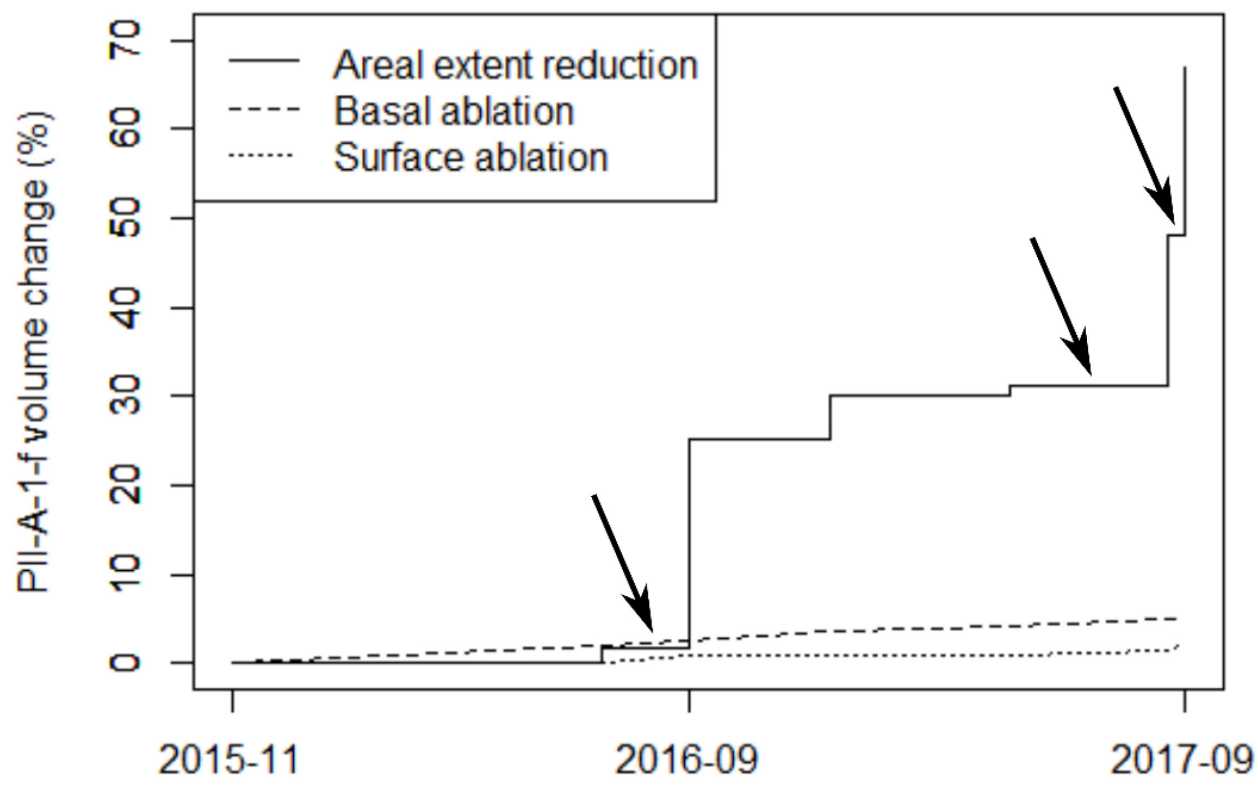

Date (Year-Month)

Figure 4.11: Percentage of original volume lost to areal extent reduction, surface ablation and basal ablation for Petermann Ice Island (PII)-A-1-f. Reduction in areal extent was determined from the analysis of a series of RADARSAT-2 scenes and, as such, the change in areal extent is, indicated by step changes on their acquisition dates . Arrows denote the time period between acquisitions over which each fracture event must have occurred. The basal and surface ablation contributions after data collected ended in September 2016 were extrapolated by applying the same ablation magnitudes to the same dates for the following year. 
It became apparent after investigating the history of PII-A-1-f through the collection of R2 ScanSAR scenes that the paired feature (Fig. 4.11) was a characteristic of the ice island prior to its grounding. The surface feature can be identified as early as November 2012 (Fig. 4.12a), and sidewall notches progressively enlarged on opposing sides of the ice island between June and July 2014 (Figs. $4.12 \mathrm{~b}$ and $4.12 \mathrm{c}$ ). The roots of both sidewall notches were located in the vicinity of the paired feature when it was observed in 2014. Only one sidewall notch was evident upon visiting PII-A-1-f in October 2015 due to deterioration between October and November 2014 along one sidewall. 


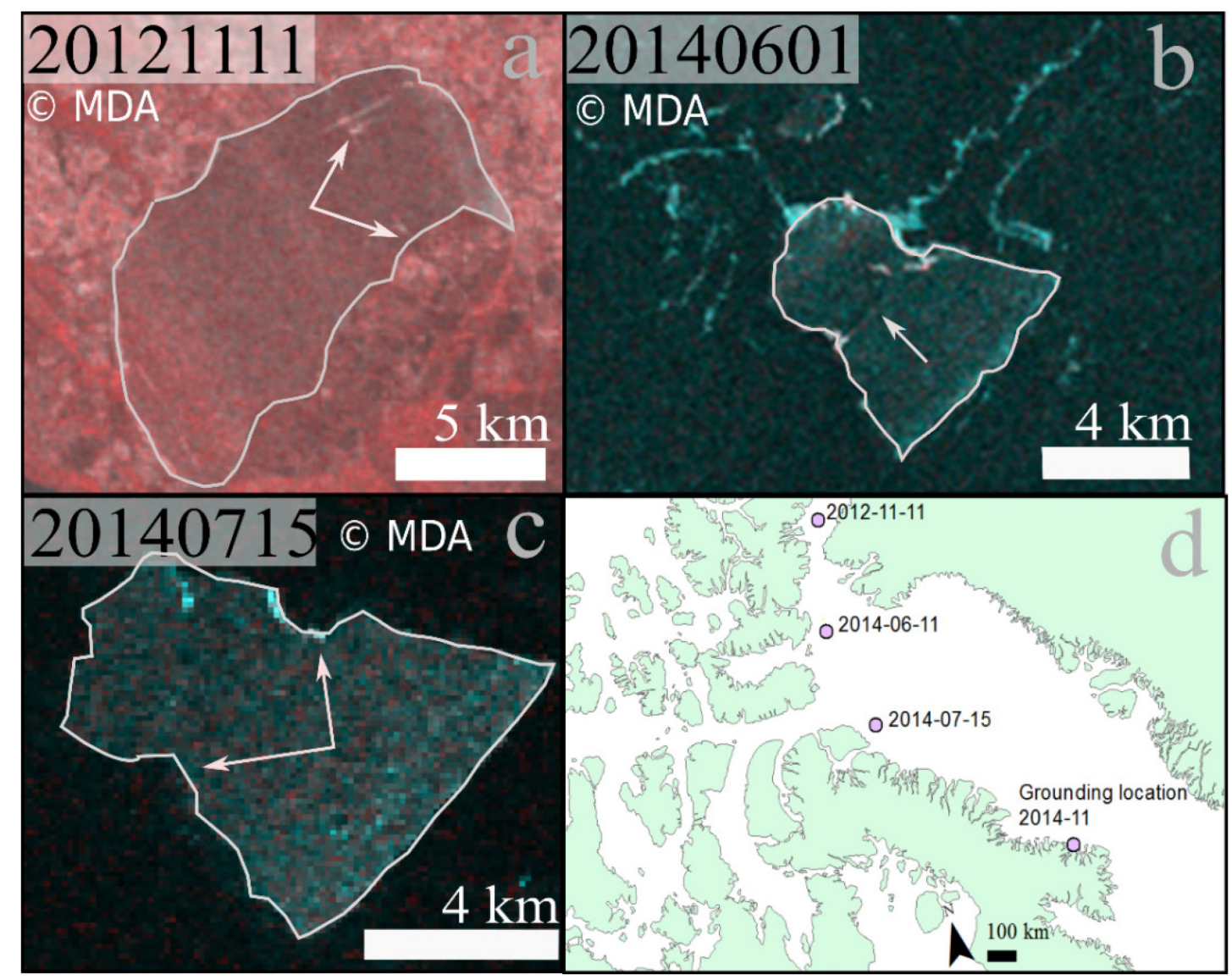

Figure 4.12: Deterioration history of Petermann Ice Island (PII)-A-1-f prior to grounding. a) Evidence of the surface feature can be seen at both sides of the ice island. b) The surface feature apparent in the centre of the ice island. c) Sidewall notches are seen on both sides of PII-A-1-f. White outlines have been added to aid identifying the sidewalls of the ice island. Panels a) to c) show RADARSAT-2 ScanSAR imagees (100 m nominal resolution, colour composite presentation - red: HH, blue and green; HV polarization). Blue tones associated with the ice island are a result of subsurface scattering and a relatively smooth air-ice surface, which results in relatively high HV backscatter and relatively low $\mathrm{HH}$ backscatter. The red background in a) is caused by high $\mathrm{HH}$ backscatter due to the presence of sea ice. Specular scattering away from the radar in open water in c) results in a dark background, d) Locations of PII-A-1-f at the time of the RADARSAT-2 SAR scene acquisitions in a) to c). 


\subsection{Discussion}

\subsubsection{Basal ablation model calibrations}

Two approaches are predominately used to model ice island and iceberg basal ablation (Bouhier et al., 2017). The first is the semi-empirical fluid-dynamics approach that is calibrated in this study; Equation 4.1 approximates melt resulting from the bulk energy transfer occurring within the complex boundary conditions that are present at the ice-water interface (Weeks et al., 1973; White et al., 1980). This model has been widely utilized for iceberg and ice island deterioration modelling in both the Arctic (Bigg et al., 1997; Ballicater Consulting, 2012; Wagner and Eisenman, 2017) and Antarctic (Gladstone et al., 2001; Martin and Adcroft, 2010; Merino et al., 2016). The second approach is based on the thermodynamic principles of heat (Bouhier et al., 2017). Holland and Jenkins (1999) and Hellmer and Obers (1989) document a complex three-equation thermodynamic model for ice shelf basal ablation, which represents both the salt and temperature flux across the ice-ocean interface. Jansen et al. (2007) calibrate the turbulent heat exchange coefficient within their model for ice island drift with modelled oceanographic data and repeat satellite-borne laser altimetry data of an Antarctic ice island, 'A-38B'. Basal ablation studies that use remotely sensed data should consider the contribution of surface ablation to detected elevation changes that are used to estimate keel thickness and basal ablation magnitudes. This is a limitation of the validation tests of the thermodynamic model and forced convection model conducted by Bouhier et al. (2017), as is the use of relatively uncertain (in comparison to field data) modeled oceanographic data. The latter critique also applies to the calibration conducted by Jansen et al. (2007) with an Antarctic study subject.

This is the first known field calibration of the heat transfer coefficient included in either the thermodynamic or forced convection models that are used to represent ice island basal ablation. 
The forced convection model directly incorporates $\Delta \mathrm{u}$, which was identified as an influential variable in the sensitivity analysis conducted in this study. The magnitude of $\Delta \mathrm{u}$ is implicated in the values assigned to the turbulent heat and salinity exchange parameters in the thermodynamic ice island ablation model (Jansen et al., 2007). It is important that these parameters are adjusted for varying values of $\Delta \mathrm{u}$ if the thermodynamic modelling approach is utilized for iceberg and ice island applications. The forced convection melt model is advantageous due to the direct incorporation of $\Delta \mathrm{u}$ as well as its computational simplicity.

The field dataset collected as part of this study lends itself well to the calibration of $C$ in the computationally simple, forced convection model. In previous iceberg and ice island literature $C$ has been assigned one of two values that differ by an order of magnitude. Weeks and Campbell (1973), Bigg et al. (1997), Martin and Adcroft (2010), Wagner and Eisenman (2017) and Bouhier et al. (2017) assign a value of $6.74 \times 10^{-6} \mathrm{~m}^{2 / 5} \mathrm{~s}^{-1 / 5}{ }^{\circ} \mathrm{C}^{-1}$ to $C$. The calibrated value of $1.3 \times 10^{-5} \mathrm{~m}^{2 / 5}$ $\mathrm{s}^{-1 / 5}{ }^{\circ} \mathrm{C}^{-1}$ is relatively close to the value assigned in the ice island deterioration model used by the Canadian Ice Service $\left(1.20 \times 10^{-5} \mathrm{~m}^{2 / 5} \mathrm{~s}^{-1 / 5}{ }^{\circ} \mathrm{C}^{-1}\right.$; Ballicater Consulting, 2012), which stems from the work of White et al. (1980). In previous studies, the same value for $C$ is used to predict ablation across all submerged iceberg and ice island sidewalls resulting from forced convection (Weeks and Campbell, 1973; White et al., 1980; Ballicater Consulting, 2012). However, the implicit assumption that the same parameter is valid for both cases remains untested and further research to parameterize this value for keel sidewalls should be conducted. Equation 4.2 should also be calibrated for drifting vs. grounded ice islands. This equation was developed to account for the plume of relatively cold and fresh, melt-inhibiting water produced by ablation of the submerged surfaces that has been observed to surround icebergs (Foldvik et al., 1980). This meltwater plume will be stripped from the keel as $\Delta \mathrm{u}$ increases, as is the case when an ice island is grounded (Jansen 
et al., 2007). Therefore, different parameterizations of Equation 4.2 are likely required for predicting the basal ablation of drifting versus grounded ice islands. This will require concerted study of the difference in the basal boundary layer conditions of grounded versus drifting ice islands. Observations of $\Delta \mathrm{u}$ for the drifting ice island case will be beneficial for this work and for correctly assigning values to this variable in Equation 4.1.

I note that it is inherently difficult to assign values to $\Delta \mathrm{u}$ that are representative of the conditions at the base of an ice island. For example, it is uncertain how geostrophic eddies will impact the turbulent flow under a grounded ice island. Tidal currents will also influence basal melt, especially for grounded ice islands (Jansen et al., 2007). The $0.1{ }^{\circ} \mathrm{C}$ difference in mean $\Theta$ within the keel depth window of two CTD casts acquired at the GreenEdge location on a single day in July 2016 illustrates the challenge of adequately representing oceanographic conditions at a specific location. Future calibrations and research regarding the boundary layer beneath an ice island could benefit from the use of autonomous underwater vehicles for obtaining direct observations of $u$ (and $\Theta$ ) under both grounded and drifting ice islands (Hamilton et al., 2013).

In this study, the GreenEdge dataset was the most appropriate for the calibration of the $C$ parameter, as the distribution of possible driving variable values was better constrained with the longer time series in comparison to the two snapshots of conditions closer to the ice island provided by the CCGS Amundsen. It would be more appropriate to validate the bulk heat transfer coefficient with basal ablation and oceanographic data collected at a different ice island or over a time period when oceanographic conditions varied greatly from those observed during the PII-A-1-f calibration period. The validation presented in this study, however, is useful for substantiating the calibrated coefficient until such optimal data is collected. The calibration could be further improved by obtaining a longer time series of oceanographic data in closer proximity to the ice 
island. Modifying the sIPR to record higher resolution data is also recommended. This would make it possible to discern thickness change at a more frequent interval and associate these higherquality thinning measurements with corresponding surface ablation and recorded oceanographic conditions.

As expected, modification of $\Theta$ (and consequently $\Delta T$ ) had a direct, linear effect on the calibrated value of $C$. However, the sensitivity analysis showed that modification of $\Delta \mathrm{u}$ between its respective quartiles resulted in greater changes to $C(22-25 \%)$ in comparison to that caused by modifying $\Theta(12-18 \%)$. This implies that it is important to accurately assign values to both of these variables when modelling basal ablation with the forced convection model or when conducting model calibration.

\subsubsection{Monitored ablation processes: rates and contributions to overall deterioration}

Field measurements of ice island basal ablation are extremely sparse. Halliday et al. (2012) report the only known previous value of $M_{b}$ for an ice island in eastern Canadian waters ('PII-A'). The average $M_{b}$ of $3.4 \mathrm{~cm} \mathrm{~d}^{-1}$ calculated in their study was greater than that observed for PII-A-1f. This is likely due to the higher $\Theta$ off the coast of Labrador where PII-A was drifting when visited, since the basal ablation rate for a drifting ice island should be lower than that of a grounded ice island due to decreased $\Delta \mathrm{u}$ and the protection of a meltwater plume.

Elevated ocean temperatures also contributed to the high, $13.5 \mathrm{~m} \mathrm{month}^{-1}$ basal ablation rate that was estimated for the grounded Antarctic ice island, 'A38-B'. Basal ablation was reported to cause $96 \%$ of the thinning of this ice island that had a surface extent of approximately $7600 \mathrm{~km}^{2}$ (Jansen et al., 2007), whereas only $73 \%$ of the thinning of PII-A-1-f was a result of this process. In addition to variation in $\Delta T$ and $\Delta \mathrm{u}$, the contribution of surface and basal ablation to the overall deterioration of an ice island will be also be influenced by the ratio of the horizontal to vertical surface extents 
of an ice island (Ballicater Consulting, 2012) and the decision to include or exclude areal reduction resulting from fracturing in a deterioration assessment. These factors need to be considered when comparing the reported contributions of various processes to the deterioration of different ice islands.

The data collected over an eleven month period at the main site on PII-A-1-f provide unprecedented information regarding the temporal thinning of an ice island. However, it is important to acknowledge that these data are representative of a single point on a large ice island. A comparison of the thinning and surface ablation observed over the $\sim 2 \mathrm{~km}$ transect versus the main site suggests that basal ablation recorded by the sIPR was lower than the average basal ablation elsewhere. A larger ablation stake network, greater coverage with mIPR transects, and higher resolution sIPR data are necessary to explore this difference.

\subsubsection{Thickness change and ultimate fracture}

While above average thinning was not observed in the vicinity of the paired feature on PII-A-1f, a gradient in thinning rate was observed (Fig. 4.9a) where transect segments BA and CD neared the surface feature from the southwest (as oriented in Figure 4.9). This suggests that the subsurface feature widened between the two field visits. It was not possible to discern the exact width of the subsurface feature in the collected radargrams, though the gap in thickness measurements along transect CD increased by $\sim 20 \mathrm{~m}$. A widening of this feature is likely due to enhanced turbulent ice-ocean energy exchange and buoyant vertical convection, which has been observed to occur with water flow within subsurface channels (Rignot and Steffen, 2008; Stanton et al., 2013).

The substantial fracture observed in September 2017 occurred along the paired feature that emanated from the root of the sidewall notch (Figs. 4.10 and 4.12). The ice island could have been subjected to increased tensile stress along this feature if an underwater ram developed. This would 
cause bending due to buoyancy forces acting at the periphery of the ice island (Diemand et al., 1987; Wagner et al., 2014). In addition, the continued thinning would reduce the relative thickness of the ice island and could decrease fracture resistance (Goodman et al., 1980; Jansen et al., 2005). This will happen more quickly if an ice island is grounded, as basal ablation could increase by a factor of three after an ice island stops freely drifting (Jansen et al., 2007).

\subsubsection{Fracturing and the evolution of PII-A-1-f prior to grounding}

The paired feature was originally aligned along the direction of flow of the Petermann Glacier prior to the 2012 PII calving event, so it is possible that the subsurface feature originated as a subsurface channel (c.f., Rignot and Steffen, 2008). However, the surface feature appeared in SAR imagery after repeated grounding events in Kane Basin and Baffin Bay. It is possible that these impacts may have initiated or contributed to the progressive development of the paired feature (MacAyeal et al., 2008; Martin et al., 2010). In addition, two opposing, fairly symmetrical sidewall notches developed while PII-A-1-f drifted in Baffin Bay. The surface feature propagated between the two sidewall notches before the ice island grounded near Qikiqtarjuaq, Nunavut (Fig. 4.12a,b), which implies that the development of the paired feature and sidewall notches were related. The progressive enlargement of the sidewall notches may have been caused by increased wave-induced turbulent heat flux within these wedge-shaped features (Robe et al., 1977; White et al., 1980).

Increasing the frequency of high-resolution SAR imagery acquisition would help to further differentiate the contribution of fracture vs. 'decay' processes to the overall deterioration of an ice island. In the case of PII-A-1-f, fracture was estimated to cause a $56 \%$ reduction in the areal extent over the time that it was monitored with R2 imagery. As ice island and iceberg deterioration modelling is currently a topic of interest in both of the Polar Regions (Stern et al., 2016; Wagner and Eisenman, 2017), further work is necessary to understand and parameterize the numerous 
deterioration mechanisms leading to ice island fracture (e.g., buoyancy forces, sidewall notch formation, flaw propagation). This will be a challenge, since the presence of subsurface features, like that observed on PII-A-1-f, or other macro- or micro-structure 'flaws' in the ice microstructure will govern the fracture pattern of an ice island (Goodman et al., 1980; Diemand et al., 1987). The generally undetectable nature of such subsurface features, and the individual 'stress pattern' of every ice island makes it nearly impossible to predict the location and timing of stochastic fracture events (Diemand et al., 1987; Ballicater Consulting, 2012). However, it is important to adequately represent fracturing in models as this process will influence the generation and dispersal of meltwater and potential ice hazards (Tournadre et al., 2015; Stern et al., 2016; Kirkham et al., 2017; Chapter 6).

\subsection{Conclusion}

This study focuses on the thinning of PII-A-1-f, an ice island that originated from a calving event at the Petermann Glacier in 2012 and was grounded in western Baffin Bay over a 2-year monitoring period. A unique field dataset was collected over four field visits between October 2015 and September 2016 and was used to report ice island thinning and ablation rates and calibrate a frequently used basal ablation model. This was the first such calibration with field data of ice island thinning and field-derived oceanographic conditions.

The time series of ice island thinning recorded with a customized sIPR showed the ice island thinned by $4.7 \mathrm{~m}$ over the 11 month on-ice data collection period. Basal ablation was responsible for $73 \%$ of the observed thinning. It was estimated that basal and surface ablation caused the ice island to decrease in volume by $7 \%$. This was minimal in comparison to the $67 \%$ volume change that resulted from the combination of processes that contributed to reducing the areal extent of PII- 
A-1-f. However, PII-A-1-f was likely more susceptible to fracture than if it had been freely drifting due to enhanced basal ablation and a corresponding quicker reduction in relative thickness.

PII-A-1-f likely fractured three times between September 2016 and September 2017. The final fracture occurred along the linear paired feature that was approximately $50 \mathrm{~m}$ wide and $40 \mathrm{~m}$ thinner than the adjacent surfaces. Augmented thinning was not observed at this feature; however, it potentially widened by $20 \mathrm{~m}$ over the summer of 2016 . The existence of such subsurface and internal 'flaws' influence ice island deterioration and are a challenge to incorporate into models of ice island fracture. Monitoring the evolution of pre-existing features (e.g., subsurface channels) that an ice island inherits from its parent glacier or ice shelf could aid in the prediction of fracture locations. Sidewall notches were also observed in the paired feature and further investigation into the connection between these features is warranted.

It is important to model ice island basal ablation accurately for predicting the impact of meltwater input on the ocean system (Jansen et al., 2007). Additionally, basal ablation will alter the relative thickness of an ice island, which will influence fracture likelihood (Goodman et al., 1980), drift patterns (Barker et al., 2004) and grounding locations (Sackinger et al., 1991). This is the first known study to calibrate the forced convection basal ablation model for ice island or iceberg use with field data of oceanographic conditions and ice island thinning. The use of field data removed uncertainty regarding estimated ablation rates from remotely sensed datasets. The calibrated value of the bulk heat transfer coefficient is in-line with the larger of two values (which varied by an order of magnitude) assigned in previous iceberg and ice island basal ablation models. It is important to conduct such field studies to develop and validate methods for modelling ice island thickness change (i.e., surface and basal ablation), as this will inform future deterioration investigations and improve ice island drift and deterioration forecasting in both of the Polar 
Regions (Barker et al., 2004). The calibration of the forced convection basal ablation model could also be used to predict when grounded ice islands might thin enough to drift free. This may be especially useful along the eastern coast of Canada where shipping and offshore industry operates, and where ice island grounding is a common occurrence.

In-situ data of ice island deterioration are sparse due to the numerous challenges associated with its collection, especially when this collection necessitates multiple return visits to the same ice island. The use of remote data transmission, such as that incorporated in the design of the sIPR deployed on PII-A-1-f, helps to mitigate this challenge. However, data collected over a greater spatial area with return field visits are of large value. It is recommended that more dedicated ice island field work be organized to further validate ablation models and assess the various processes by which an ice island deteriorates. 


\section{Chapter 5 - Surveying drifting icebergs and ice islands: Deterioration detection and mass estimation with aerial photogrammetry and laser scanning}

\subsection{Introduction}

Recent calving events from ice shelves and floating glacier tongues have created immense tabular icebergs in both the Arctic (e.g., Petermann Glacier: $\sim 300 \mathrm{~km}^{2}$ ) (Crawford et al., 2018) and Antarctic (e.g., Larsen-C Ice Shelf: $\sim 5,800 \mathrm{~km}^{2}$ ) (Hogg and Gudmundsson, 2017). Mass and dimensional estimates of these 'ice islands' are used by the offshore resource extraction and shipping industries to model the risk associated with these ice hazards, as well as that imposed by the smaller ice island fragments and icebergs produced during their deterioration (Kubat et al., 2007; Crocker et al., 2013; Allison et al., 2014; Fuglem and Jordaan, 2017). Deterioration model output is used in operational drift models that predict the trajectory and the mass of ice hazards through time and space (Kubat et al., 2005, 2007). Iceberg deterioration is also modeled to improve the understanding of the biological and physical influence of meltwater input to the surrounding ocean waters (Gladstone et al., 2001; Smith et al., 2013; Enderlin and Hamilton, 2014; Kimball and Rock, 2015; Enderlin et al., 2016; Merino et al., 2016). Unfortunately, the calibration and validation of both iceberg and ice island deterioration models has been hindered by a paucity of in-situ datasets that accurately capture both the morphological change and corresponding environmental data (Hamilton et al., 2013; Saper et al., 2015). This is largely due to logistical, financial and safety issues that accompany surveying these subjects in remote locations (McGill et al., 2011; Crawford et al., 2015). In addition, one must overcome the technical challenges associated with surveying a drifting iceberg or ice island (Kimball and Rock, 2011; McGill et al., 2011). While there is interest in collecting deterioration data, it is first necessary to determine the 
capabilities of available surveying techniques to ensure that meaningful deterioration magnitudes or mass estimates are reported.

$\mathrm{SfM}$ is a photogrammetric technique in which the $3 \mathrm{D}$ representation of a survey subject or scene is generated from a sequence of images based on the offsets between common features identified in three or more images taken from varying viewpoints. This is conducted through an iterative process that estimates 3D positions, camera positions and image parameters while optimizing the correspondence of these features (Quan, 2010; Snavely et al., 2010; Westoby et al., 2012; Fonstad et al., 2013; Thomson and Copland, 2016). This alleviates the reliance on a priori knowledge of the camera orientation and location of ground control points (GCPs) for scene reconstruction (Westoby et al., 2012; Javernick et al., 2014). However, such reference points are necessary for georeferencing and/or assigning scale to the resulting point clouds (Westoby et al., 2012; Fonstad et al., 2013). SfM processing has become a popular method in the geosciences, including glaciology, due to its low cost, utilization of high resolution data, ease of user implementation and practicality for surveying remote regions (Aber et al., 2010; Westoby et al., 2012; Whitehead et al., 2013; Beedle et al., 2014; Javernick et al., 2014; Ryan et al., 2015; Brun et al., 2016; Divine et al., 2016; Girod et al., 2017). Younan et al. (2016) demonstrated the use of photogrammetry for 3D iceberg modelling during an ice management-oriented field campaign offshore of Newfoundland and Labrador, Canada and Enderlin and Hamilton (2014) and Enderlin et al. (2016) use photogrammetric techniques to estimate iceberg subsurface melt with satellite remote sensing. Only a few of the past studies that used stereo-photogrammetry to determine iceberg shape and mass provided a relative uncertainty in their mass estimations (Robe and Farmer, 1976) or ultimate meltwater flux calculations (Enderlin et al., 2016). 
Terrestrial laser scanning (TLS) has been used to map cryospheric survey targets (Cook et al., 2014; Landy et al., 2015; Kamintzis et al., 2017), but typically within a fixed reference frame. TLS surveys of iceberg or ice island sails, as well as keel surveys conducted with sonar, must correct for iceberg roto-translation during data collection. The motion of the survey vessel (i.e., pitch, roll, yaw and heave) can be removed with data from an inertial navigation system (INS) (Eisen, 2012; Forrest et al., 2012; Kimball and Rock, 2015; McGuire et al., 2016). TLS and sonar were used by Wagner et al. (2014) when mapping a $14 \mathrm{~km}^{2}$ slowly rotating grounded ice island in the Canadian Arctic and Wang et al. (2015) combined TLS surveys with laser range finder data to map icebergs located offshore of Newfoundland and Labrador, Canada. C-CORE (2017) has also undertaken recent field campaigns to collect TLS and multi-beam sonar surveys of icebergs' sails and keels, respectively. McGuire et al. (2016) used an algorithm to rapidly correct for iceberg drift in sonar and TLS surveys to provide offshore industry with information regarding the size and shape of ice hazards. To our knowledge, there are no published error values for the use of TLS or SfM processing of aerial photography surveys of drifting icebergs.

This paper focuses on the application of aerial photography with structure-from-motion multiview stereo photogrammetry processing (referred to here as SfM) and TLS for mapping drifting icebergs. The objectives of this paper are three-fold: i) derive the deterioration detection threshold (DDT) associated with each of these two well-established surveying techniques, ii) determine the precision of iceberg mass estimates using each technique, and iii) evaluate the influence of using data collected by deployed GPS units of varying quality on the above DDT and mass estimate. In the Discussion we compare our results and workflow to previous research focused on mass estimation and change detection of icebergs and other topics pertaining to the cryosphere. We 
provide recommendations for future surveyors and explain the suitability of each survey technique to detect morphological changes caused by various physical deterioration processes.

In the absence of a definitive reference survey (e.g., Girod et al., 2017), we analyze the differences between 3D point clouds generated from consecutively acquired survey data to calculate the precision associated with each technique. These differences are used to determine the individual DDTs of the above surveying techniques. DDT is defined as the minimum magnitude of change (i.e., deterioration) that would have to occur between two surveys to be reliably detected (Lague et al., 2013). Using our methodology, which incorporates point cloud comparison algorithms developed by Lague et al. (2013) for geomorphological change analyses, this change would constitute a difference in a linear direction normal to the surface of an initial survey.

The two surveying methods are evaluated with consecutive, triplicate surveys over which time ( $<70$ minutes) we assume that no appreciable deterioration (i.e., from melting or calving) has occurred. Our survey subjects include two, freely drifting tabular icebergs, which were surveyed near Newfoundland and Labrador, Canada during a field campaign in April 2015. These icebergs were likely fragments of larger ice islands originating from the Petermann Glacier in 2012 (see Section 3.2). Regardless, our methods and results are transferable across the size range of small icebergs to large ice islands, as well as various iceberg morphologies.

\subsection{Field methods}

\subsubsection{Field settings}

A $130 \mathrm{~km}^{2}$ ice island calved from Petermann Glacier in northwest Greenland in 2012 and generated numerous ice islands, icebergs, and smaller fragments throughout its deterioration (Crawford et al., 2018). Figure 5.1 shows the location and field photos of the two, freely drifting tabular icebergs that we surveyed. The icebergs ('i1' and 'i2') were likely fragments of the 2012 
Petermann Ice Island. The surface ridging of il was similar to previously observed ice islands that originated from the Petermann Glacier. i1 and i2 were surveyed in triplicate from the CCGS Amundsen on 23 and 27 April 2015, respectively. il was situated at $51^{\circ} 28^{\prime} \mathrm{N}, 51^{\circ} 22^{\prime} \mathrm{W}$ while the smaller i2 was approximately $440 \mathrm{~km}$ to the northwest at $52^{\circ} 16^{\prime} \mathrm{N}, 55^{\circ} 13^{\prime} \mathrm{W}$.

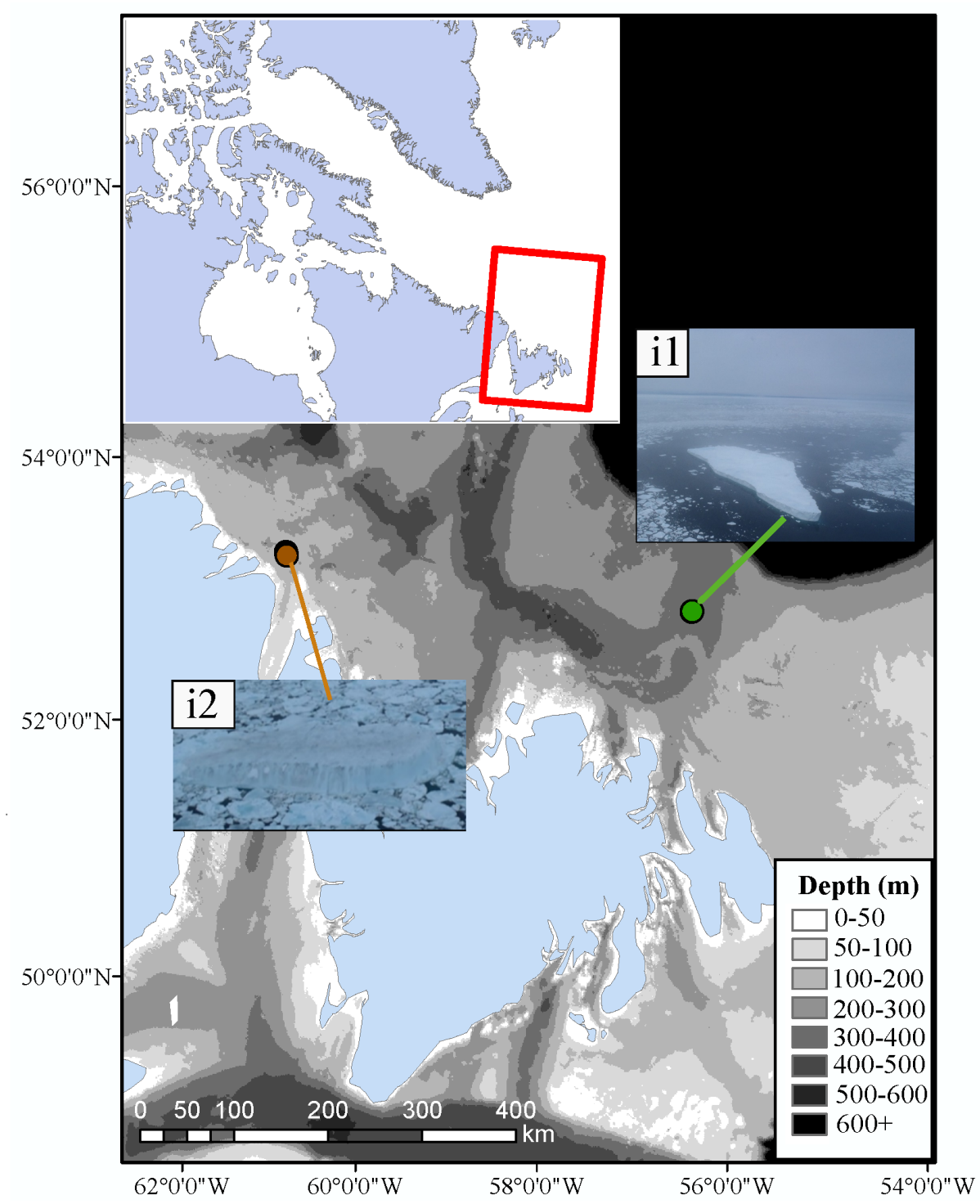

Figure 5.1: Location and images of the surveyed icebergs, i1 and i2. Bathymetry data were obtained from the 2-minute Gridded Global Relief Data - ETOPOv2 (National Geophysical Data Center, 2006). 


\subsubsection{Marker/GPS deployment}

Markers, paired with either single-frequency GPS tracking beacons (data telemetered) or dualfrequency GPS receivers (data logged internally), were deployed on i1 and i2 via helicopter prior to aerial photography and TLS surveying. The markers, shown in Figure 5.2, were composed of $0.4 \mathrm{~m}^{2}$ black burlap squares and were deployed to serve as recognizable features for the SfM image processing software during photo alignment. The GPS units were identified in multiple images to increase the quality of photo alignment.

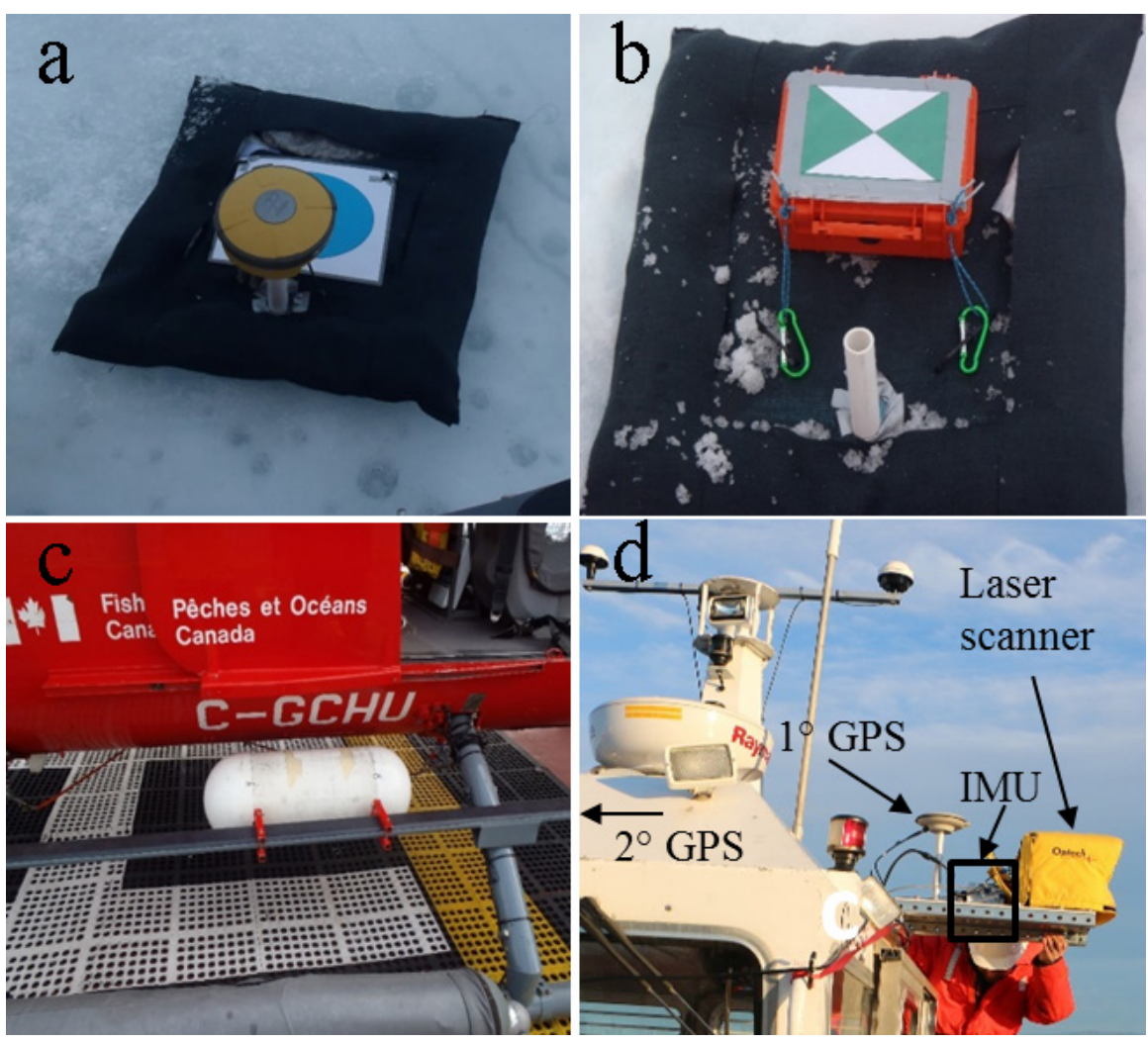

Figure 5.2: Surveying equipment. a) Marker paired with a dual-frequency GPS (Topcon Hiper V) unit, b) Marker paired with a tracking beacon (Solara FT2000), c) external mount for the Nikon D7100, and d) frame-mounted Optech Ilris laser scanner, inertial measurement unit (IMU), and GPS antennas. The second GPS antenna is situated out-of-sight on the far end of the frame. The GPS baseline was $3.3 \mathrm{~m}$. 
In the absence of a definitive reference survey, GPS data were used to assign each cloud point to a position in an 'iceberg reference frame' (IBRF). This is defined by the relative positions of cloud points that were collected when surveying the rotating and translating iceberg survey target (Eisen, 2012; Forrest et al., 2012). The IBRF was generated with GPS data that were also used to provide scale to SfM-generated point clouds (Section 5.3.1.1) and to correct the TLS point clouds for iceberg drift during surveying (Section 5.3.1.2). The deployed markers were also used in a calculation of inter-survey error (ISE) after the individual 3D point clouds were generated and scaled (Section 5.3.1.1).

The combination of each survey technique (SfM or TLS) and deployed GPS units (tracking beacons on i1 or high-quality, dual-frequency GPS receivers on i2) are the four survey scenarios that we evaluated. Table 5.1 contains the quoted accuracies for each type of deployed GPS unit. Examples of marker/GPS pairs that were used during SfM processing are shown in Figure 5.2a,b. Three markers, paired with either a Canatec tracking beacon (Canatec and Associates International Ltd., Calgary, Canada) $(\mathrm{n}=1)$ or a Solara FieldTracker 2000 beacon (Solara Remote Data Delivery Inc., Winnipeg, Canada) $(\mathrm{n}=2)$ were deployed on i1. Positions were measured at $5 \mathrm{~min}$ and $30 \mathrm{~s}$ intervals, respectively. Three markers were deployed on i2 and were paired with either a Topcon Hiper V (Topcon Corp., Tokyo, Japan) $(\mathrm{n}=2)$ or a Trimble 5800 (Trimble, Sunnyvale, USA) (n =1) dual-frequency GPS receiver, which recorded at a $5 \mathrm{~s}$ interval. Data logged by the dualfrequency receivers were post-corrected in kinematic mode using precise point positioning (PPP) processing of global navigation satellite system data (Natural Resources Canada, 2016), which also yielded uncertainty information regarding positional accuracy $\left(\sigma_{b x}, \sigma_{b y}\right.$ and $\left.\sigma_{b z}\right)$ (Table 5.1). Cantec and Associates reported their beacon accuracy as a $50 \%$ circular error probable value (Canatec Ltd, 2015), which was converted to standard deviation units ( $\sigma_{b x}$ and $\left.\sigma_{b y}\right)$, while Solara 
beacon positional uncertainty was derived from data collected by four stationary units over a 36 hr period (Table 5.1).

Table 5.1: Quoted accuracies and calculated positional uncertainties used in data processing for Canatec beacons units (T. Sylvestre, personal communication), Solara FT2000 tracking beacons (Solara Remote Data Delivery, 2010) and higher-quality, dual-frequency GPS following Precise Point Positioning (PPP) processing using an online tool from Natural Resource Canada (TopCon, 2016; Natural Resources Canada, 2016).

\begin{tabular}{cccc}
\hline & Canatec & $\begin{array}{c}\text { Solara } \\
\text { FT2000 }\end{array}$ & $\begin{array}{c}\text { PPP Dual-frequency } \\
\text { GPS }\end{array}$ \\
\hline Quoted accuracy H $(\mathrm{m})$ & 1.8 & $<2 \mathrm{~m}$ & -- \\
Quoted accuracy V $(\mathrm{m})$ & $\mathrm{N} / \mathrm{A}$ & $\mathrm{N} / \mathrm{A}$ & -- \\
$\sigma_{b x}(\mathrm{~m})$ & 2.7 & 7.9 & 0.03 \\
$\sigma_{b y}(\mathrm{~m})$ & 2.7 & 11 & 0.04 \\
$\sigma_{b z}(\mathrm{~m})$ & $\mathrm{N} / \mathrm{A}$ & $\mathrm{N} / \mathrm{A}$ & 0.07 \\
\hline
\end{tabular}

\subsubsection{Aerial photography surveying}

A 24.1 megapixel Nikon D7100 (Nikon Corp., Tokyo, Japan) with a fixed AF-S Nikkor 35 mm lens was externally mounted on the skid of the CCGS Amundsen's MMB Bo 105 helicopter to allow for near nadir-orientated image acquisition during photogrammetry surveying (Table 5.2; Figure 5.2c). A wireless intervalometer (CamRanger, Pinedale, USA) was used to initiate a series of image acquisitions for each flight line by an operator within the helicopter. Images were acquired at a $1 \mathrm{~s}$ interval and georeferenced with a Nikon GP-1 GPS accessory offering a $10 \mathrm{~m}$ root-mean-squared horizontal accuracy and an update rate of $1 \mathrm{~s}$. Flight lines were planned with a nominal flight speed ( 20 to $40 \mathrm{~m} \mathrm{~s}^{-1}$ ) and altitude ( 210 to $300 \mathrm{~m}$ ) to ensure $\sim 80 \%$ overlap and $\sim 40$ $\%$ side-lap between images. This resulted in a ground sampling distance between 2.4 and $3.4 \mathrm{~cm}$. Three consecutive surveys were completed for il over 26 minutes; however, only two aerial photography surveys were conducted over 14 minutes for the smaller i2, as inclement weather forced the helicopter to land. All surveys pertaining to either i1 or i2, conducted with either aerial 
photography or TLS, were completed in a short timeframe over which no appreciable deterioration was expected to occur. Details on the instruments and field execution for both aerial photography and TLS surveying are contained in Table 5.2.

Table 5.2: Aerial photography and terrestrial laser scanning (TLS) survey equipment specifications. RMS = root mean squared [error], GNSS = global navigation satellite system, SPAN = synchronous position, attitude and navigation [system], IMU = inertial measurement unit.

\begin{tabular}{|c|c|c|}
\hline & Aerial photography & TLS \\
\hline Sensor & Nikon D7100, $35 \mathrm{~mm}$ lens & Optech Ilris-HD \\
\hline Platform & MMB Bo 105 helicopter & CCGS Amundsen \\
\hline $\begin{array}{l}\text { Geo-referencing \& } \\
\text { Movement } \\
\text { Correction }\end{array}$ & $\begin{array}{l}\text { Nikon GP-1; GCP/GPS } \\
\text { arrays } \\
(10 \mathrm{~m} \text { RMS and } 1 \mathrm{~s} \text { update } \\
\text { rate) }\end{array}$ & $\begin{array}{l}\text { SPAN composed of } 2 \text { Novatel GNSS } \\
\text { receivers (GPS-701-GG and GPS- } \\
\text { 702-GG) and an IMAR iIMU-FSAS } \\
\text { motion sensor integrated through a } \\
\text { Novatel ProPak6 GNSS receiver } \\
\text { enclosure }\end{array}$ \\
\hline Viewing angle & Nadir & $\begin{array}{l}\text { Across }\left(90^{\circ}\right) \text { the survey platform } \\
\text { heading }\end{array}$ \\
\hline Frequency & $1 \mathrm{~s}$ acquisition interval & $10,000 \mathrm{~Hz}$ pulse repetition rate \\
\hline Overlap (\%) & 80 (overlap), 60 (sidelap) & -- \\
\hline Field of View $\left(^{\circ}\right)$ & 47 (diagonal) & 40 (vertical) \\
\hline
\end{tabular}

\subsubsection{Terrestrial laser scan surveying}

For TLS surveying, an Optech Ilris-HD ('Intelligent Laser Ranging Imaging System’) laser scanner (Optech Inc., Toronto, Canada), which used a $1535 \mathrm{~nm}$ wavelength, had a 10,000 Hz pulse repetition rate and a $40^{\circ}$ field of view. It was integrated with an INS consisting of an iIMU-FSAS (iMAR GmbH, St. Ingbert, Germany) motion sensor and a synchronous position, attitude and navigation (SPAN) system (NovAtel Inc., Calgary, Canada). The latter included two NovAtel GPS antennas for heading measurement (Table 5.2). The TLS and INS were situated on a custom-built 
telescoping steel frame, mounted on the ship's barge, with a $3.3 \mathrm{~m}$ baseline between the two global navigation satellite system (GNSS) antennas (Fig. 5.2d). High sea ice concentrations impeded the deployment of the barge on which the survey instruments were mounted. Data were therefore collected with the instruments as originally positioned but while the barge was stowed on the CCGS Amundsen's deck. The laser scanner was situated at an elevation of $\sim 15 \mathrm{~m}$ above the sea surface at this location. INS and TLS data were acquired and integrated by Hypack® (Version 2015; Xylem Inc., Middletown, USA) software and the position of the TLS survey points was recorded in Universal Transverse Mercator (UTM) projection. A PPP solution, found with the POSPac MMS (Version 7.1; Applanix, Richmond Hill, Canada) software, improved the accuracy of the points at a later date.

Both icebergs were surveyed by TLS over three consecutive circumnavigations by the CCGS Amundsen. Surveying was conducted over 68 and 45 minutes for i1 and i2, respectively. The distance between the ship and the icebergs ranged between 20 and $110 \mathrm{~m}$ for $\mathrm{i} 1$ and between 60 to $140 \mathrm{~m}$ for i2. A geolocation error was found in the i2 INS dataset, which likely stemmed from a poor sky view and multi-pathing of the satellite signal associated with GPS configuration on the CCGS Amundsen. This was corrected by using a time-based offset between the ship's C-Nav3050 (Oceaneering International, Inc., Houston, USA) differential GNSS receiver and the survey INS position. All survey data and processing scripts can be found under Polar Data Catalogue entry 12818. 


\subsection{Analysis methods}

\subsubsection{Point cloud processing}

\subsubsection{Structure-from-motion photogrammetry}

Photoscan Pro (v. CC 2014) (Agisoft LCC, St. Petersburg, Russia) was used to derive 3D models from aerial photography surveys with SfM processing methods. The output is referred to here as 'SfM point clouds'. This software contains algorithms for feature matching and point cloud generation, and provides post-processing tools for scale transformation and coordinate assignment in the IBRF (Ryan et al., 2015; Brun et al., 2016). Photos that captured a portion of the survey target were imported into the software and aligned with the highest accuracy alignment setting. Photo resolution was upscaled by a factor of four with bilinear interpolation to aid the recognition of surface features (Agisoft, personal communication). During the alignment step, camera positions and orientations were also calculated and a sparse point cloud was generated through iterative bundle adjustment. This adjustment iteratively optimizes scene coordinates and camera locations to minimize re-projection errors (Trigg et al., 2000; Westoby et al., 2012; Agisoft LCC, 2014). Since photo alignment does not rely on georeferenced photos, there was no need to correct for drift (Younan et al., 2016). Point cloud distortion was decreased with an optimization procedure, which improves the estimation of point coordinates and camera orientations based on reference coordinates assigned to the deployed GPS units (Agisoft LCC, 2014). To do this, the GPS units were identified in each image, and a dense point cloud was then constructed with the calculated camera orientations at the highest quality setting. These basic processing steps, as well as those involved with point cloud comparison, are illustrated in Figure 5.3. 


\section{SfM : TLS}

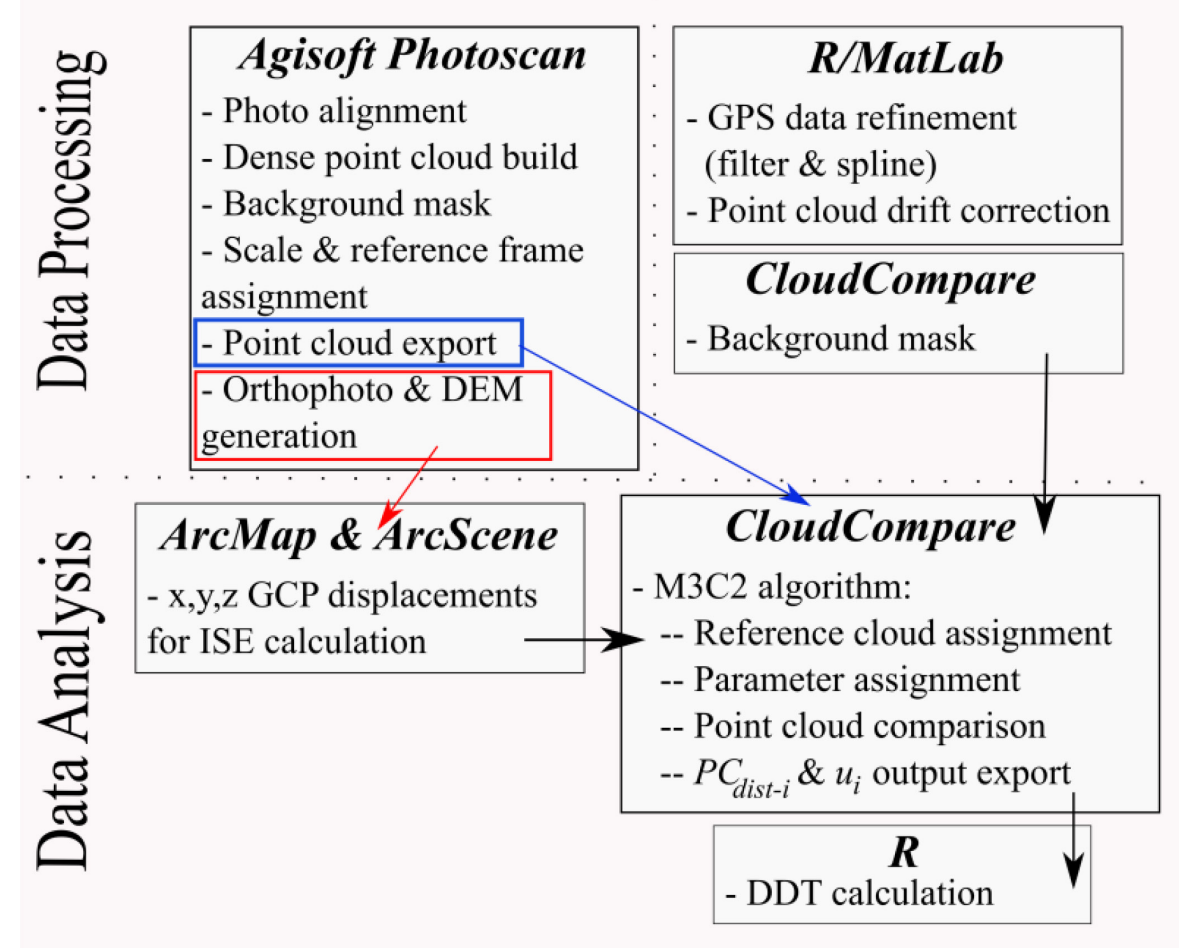

Figure 5.3: Processing and analysis workflow for aerial photography data with structurefrom-motion (SfM) processing or terrestrial laser scan (TLS) survey data. The headings in each box refer to the software program used for the listed workflow steps. Red and blue arrows are used to differentiate the workflow associated with the products of SfM processing. DDT = Deterioration detection threshold, ISE = inter-survey error, M3C2 = Multiscale Model-to-Model Cloud Comparison algorithm, $P C_{\text {dist }-i}=$ distance between point clouds at core points, $u_{i}=$ uncertainty in $P C_{\text {dist }-i \text {. }}$

Point clouds generated from SfM processing were scaled by assigning a distance value between the identified GPS units. The mean Euclidean distance between the three GPS units (the 'interGPS distances') was calculated from the positions logged over the total duration of a survey type (i.e., all aerial photography surveys of i1). The GPS units deployed on il did not record at a constant interval, so a cubic spline interpolation at $1 \mathrm{~s}$ intervals between transmissions was conducted to calculate 2D inter-GPS distances between corresponding timestamps. 3D inter-GPS distances were calculated from the positions logged at $5 \mathrm{~s}$ intervals by the GPS units deployed on i2 since elevation data were provided by the dual-frequency GPS receivers. 
Points that represented the surrounding ocean and sea ice were removed manually following a visual assessment. The first of the three surveys was designated to be a reference point cloud for the purpose of survey comparisons. This point cloud was cropped to a wider extent than subsequent survey point clouds to improve the chance that all points in the compared clouds would have corresponding points to be compared to on the reference cloud (Section 5.3.2.1).

A point cloud registration error, representing the uncertainty of the positions assigned to a $3 \mathrm{D}$ model during photo alignment and point cloud georeferencing (Marani et al., 2016), is usually calculated with respect to a definitive reference survey (c.f., Westoby et al., 2016). This error could be introduced into the workflow by incorrectly identifying the centre of GPS units in imagery or photo-alignment issues in AgiSoft Photoscan. A definitive reference survey to which we could compare our 3D iceberg models was not available. Therefore, we used the marker centres as common points in each survey (Habib et al., 2004) and derived a proxy registration error which we refer to as the ISE. We examined orthophotographs $(2.8 \mathrm{~cm}$ pixel spacing $)$ and DEMs $(5.7 \mathrm{~cm}$ pixel spacing) after image alignment and point cloud scaling to extract the $x, y$ (from orthophotographs) and $z$ (from DEM) position of the three marker centres for each survey. We then calculated the difference in the orthophoto/DEM-derived marker position between the three surveys and took the mean of these differences $(n=9$; three marker positions compared across

three surveys) to represent ISE. We assume these errors to be isotropic and uniform across the survey target's surface (c.f., Westoby et al., 2016).

\subsubsection{Terrestrial laser scanning}

TLS surveys were corrected for iceberg drift with custom R (v. 3.0.2) and Matlab (v. R2015A) scripts. This procedure involved determining distances and offset angles between cloud points and deployed GPS units by matching timestamps and then re-projecting the cloud points in an IBRF. 
Canatec and Solara beacon data were first splined with a natural cubic curve to constant time intervals due to slight logging interval variations. Positions from two GPS units per iceberg were Kalman filtered (forward-stepping) and Kalman smoothed (backward-stepping) to improve estimates of these GPS locations. An isometric Kalman gain was applied and visually tuned for each beacon type. The Kalman filtered data were passed through a natural cubic spline with a 0.1 s interval output to improve timestamp matching between the GPS and cloud points.

Figure 5.4 provides a simple schematic of the offset angles and distances, calculated below, that were used in the drift correction procedure. Points were matched with the GPS position recorded with the closest timestep. The distance $(d)$ between the positions of one GPS unit and each cloud point was calculated with Equation 5.1 while equations 5.2 and 5.3 were used to calculate the heading between the cloud point and the same GPS unit $\left(h_{p c}\right)$. It is irrelevant which GPS units are used for the offset calculations so long as they are used consistently in their respective roles. The differences in $x$ and $y$ Cartesian coordinates are denoted with $d x$ and $d y$, respectively.

$$
\begin{aligned}
& \left.d=\sqrt{\left(d x^{2}+d y^{2}\right.}\right) \\
& \text { If } d y<0, h_{p c}=c \times d y \times \pi+\operatorname{atan}(d x / d y) ; \text { else } h_{p c}=\operatorname{atan}(d x / d y) .
\end{aligned}
$$

$c$ is equal to 1 or -1 based on the sign of the corresponding $d x$ of the survey point, with a value of 1 assigned if $d x=0$. Finally, if $h_{p c}<0$ :

$$
h_{p c}=h_{p c}+2 \times \pi .
$$

A heading in degrees was found by multiplying $h_{p c}$ by $180 / \pi$. The offset ( $h_{O F F}$ ) between $h_{p c}$ and the heading between the two GPS units $\left(h_{G P S}\right)$, and calculated $d$, were used in Equations 5.4 and 5.5 to correct cloud points to $x^{\prime}, y^{\prime}$ positions in an IBRF defined with an origin at $x_{0}, y_{0}$ and a heading 
of $0^{\circ}$. The assigned values of $x_{0}, y_{\mathrm{o}}$ and the initial heading are arbitrary as the distance and angle offsets to each cloud point will remain consistent.

$$
\begin{aligned}
& x^{\prime}=x_{o}+\left(d \sin \left(\left(h_{\text {OFF }}\right) / 180 \times \pi\right)\right) \\
& y^{\prime}=y_{o}+\left(d \cos \left(\left(h_{O F F}\right) / 180 \times \pi\right)\right)
\end{aligned}
$$




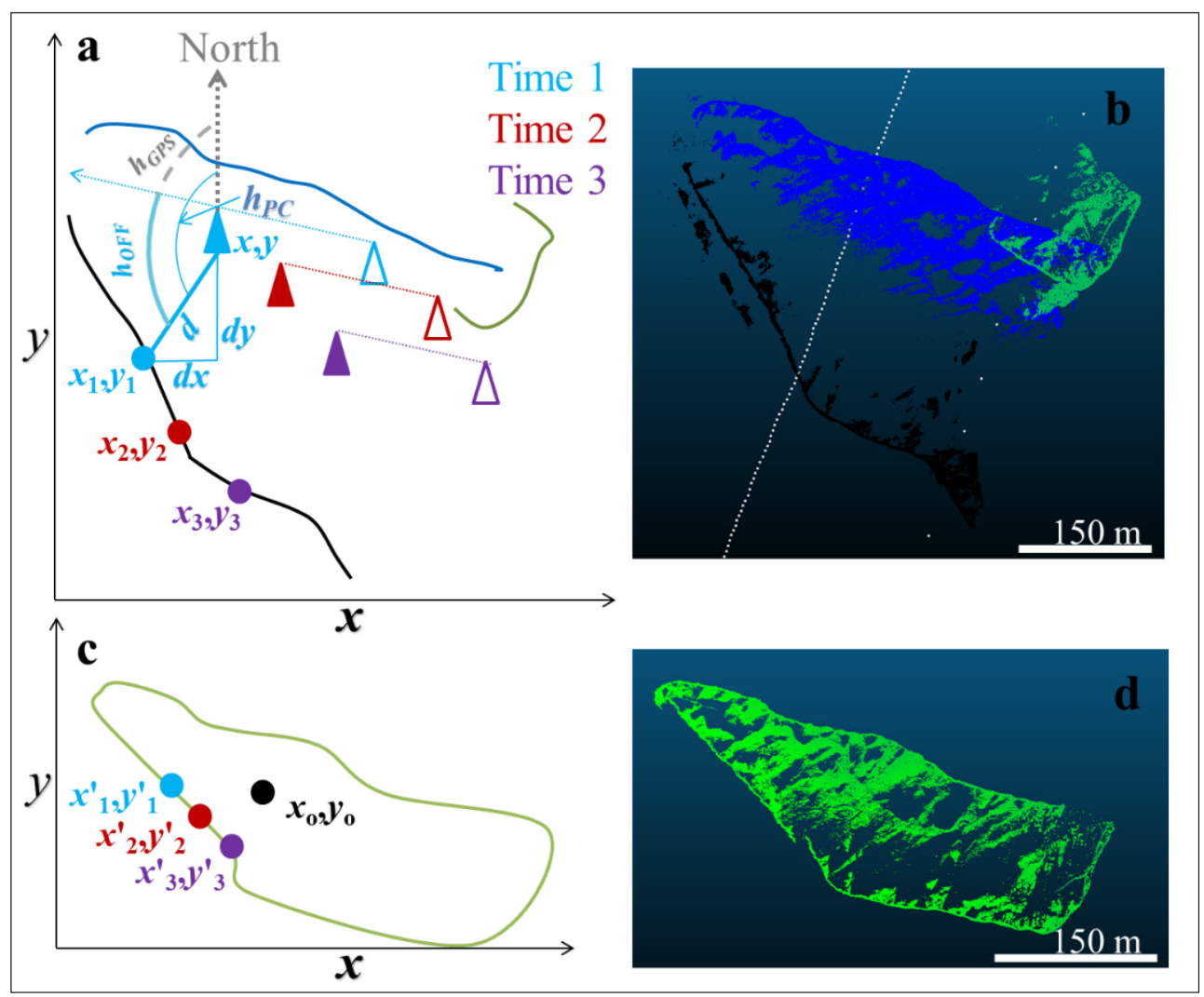

Figure 5.4: Example of the TLS point cloud drift correction procedure over three different survey segments. Panels a) (schematic; segment 1: blue line, segment 2: green line, and segment 3: black line) and b) (actual; segment 1: blue point cloud, segment 2: green point cloud and segment 3: black point cloud) show uncorrected point clouds. Panels c) and d) show the corrected version. The offsets used in the drift correction procedure are illustrated in panel a; points (circles) collected at three time steps (denoted by subscripts and colours) were matched with two GPS positions (triangles) with the closest timestamps (illustrated with corresponding colours). The Euclidean distance $(d)$ and heading $\left(h_{p c}\right)$ were found between cloud points with $x$ and $y$ coordinates and one of the GPS units (filled triangle). The heading between both GPS units $\left(h_{G P S}\right)$ was also found at each time step. The offset heading $\left(h_{O F F}\right)$ is the difference between $h_{p c}$ and $h_{G P S} . d$ was calculated with the difference in $x$ and $y$ positions between the cloud point and the GPS unit (i.e., $d x$ and $d y$ ). Three example points and the positions of the two GPS units at the time that the point was collected are shown. Panel b) shows the drift experienced by il during the survey with each survey segment along with white dots representing Solara FT2000 (left) and Canatec tracking beacon (right) locations. Point clouds were corrected $(\mathrm{c}, \mathrm{d})$ by re-projecting each point into the iceberg reference frame $\left(x^{\prime}, y^{\prime}\right)$ from a common set of coordinates $\left(x_{0}, y_{0}\right)$ by using the relative distance and heading for each cloud point found above. 


\subsubsection{Point cloud comparison and DDT calculation}

The corrected point clouds, one corresponding to each SfM point cloud or TLS survey, were opened in CloudCompare (v2) where background sea ice returns were manually removed from the TLS point clouds. CloudCompare is an open-source point cloud comparison software program that has been successfully used to detect landform changes (Barnhart and Crosby, 2013; Lague et al., 2013; Joyal et al., 2016; Westoby et al., 2016), and was the software program used in this study to compare point clouds representing the individual surveys of each tabular iceberg.

\subsubsection{The Multiscale Model-to-Model Cloud Comparison algorithm}

The precision of each surveying technique was determined by calculating the linear distance between the drift-corrected point clouds in CloudCompare with the Multiscale Model-to-Model Cloud Comparison (M3C2) algorithm (Lague et al., 2013; Westoby et al., 2016). By eliminating the need to grid or mesh by directly comparing point clouds, no spurious distance values are returned due to varying point density $\left(\rho_{p}\right)$, data gaps and noise (Latypov, 2002; Lague et al., 2013).

The M3C2 algorithm creates cylindrical volumes around a subset of core points that are oriented normal to the surface of the reference point cloud. The reference point cloud was subset by a factor of 5 to 10 to generate a group of core points to decrease processing time, as suggested by Lague et al. (2013). The distances between the core points in the reference cloud and analogous points in the compared point cloud ( $\left.\mathrm{PC}_{\text {dist }-i}\right)$ were then found (Fig. 5.5). The subscript $i$ denotes the values associated with each individual core point. The direction of the normal vectors were determined based on a plane that was fit to all points within a user-defined diameter, $D$, from each core point (Fig. 5.5). $D$ was set to be sufficiently large ( $>20-25$ times the roughness of the point cloud surface) to ensure that small-scale surface roughness variations did not bias the calculation 
of normal vectors (Lague et al., 2013; Westoby et al., 2016). The normal scale assessment criterion, $\xi$, was used to ensure that $D$ was adequately assigned:

$$
\xi_{i}=D / \sigma_{i}(D)
$$

where $\sigma_{l i}(D)$ is the surface roughness of the reference cloud, calculated as the standard deviation of each point to the plane found at scale $D$ centred around each core point (i) (Lague et al., 2013; Westoby et al., 2016). We aimed to assign a value of $D$ that satisfied the condition $\xi_{i}>20$ (equivalent to a normal orientation error of $<2 \%$ ) for $98 \%$ of core points, as did Westoby et al. (2016) and Lague et al. (2013).
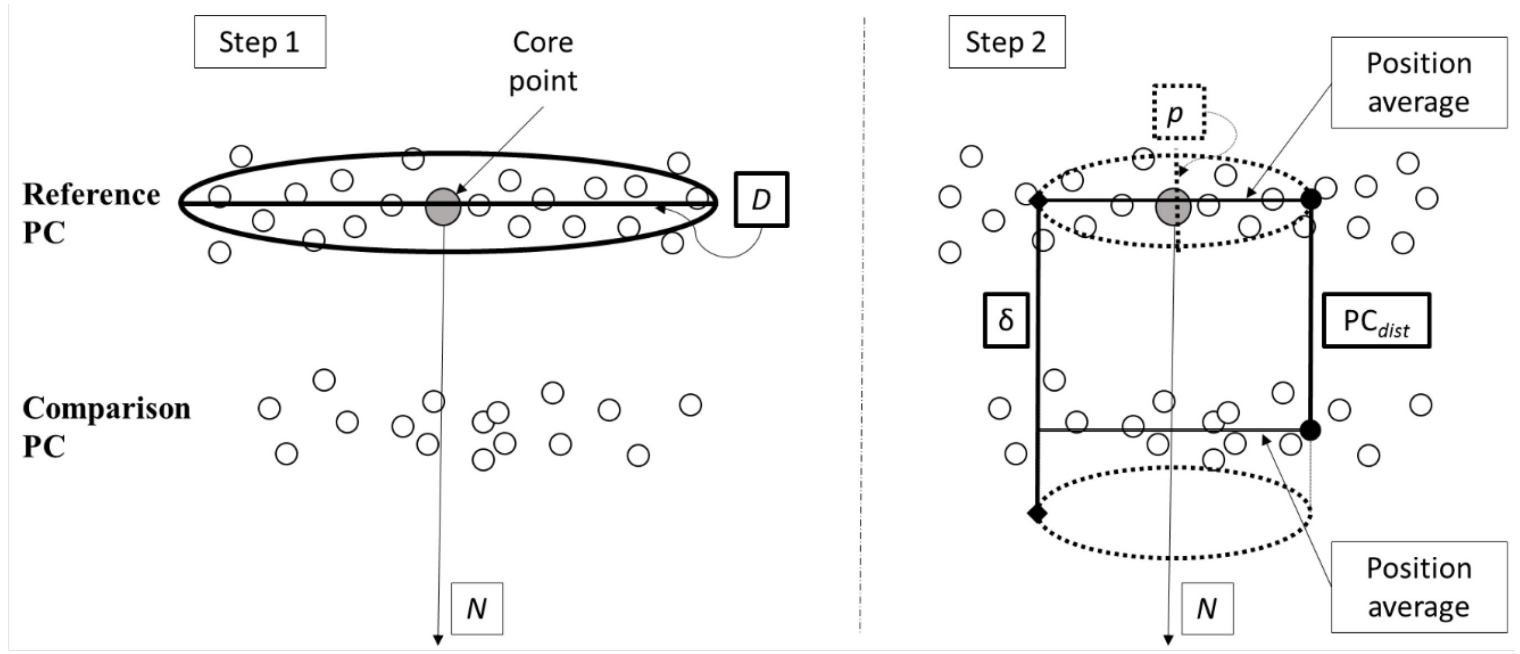

Figure 5.5: Simplified illustration of the Multiscale Model-to-Model Cloud Comparison algorithm. In step 1, the surface normal $(N)$ is determined by fitting a plane to the points (open circles) within a user-defined diameter, $D$, from each core point (grey circle). In step 2, a cylinder with diameter $p$ is centred on the core point and projected along the direction represented by $N$. The algorithm projects the cylinder both above and below the core point, but the figure shows the projection in a single direction for simplification. The cylinder length is the maximum search distance $(\delta)$ and this defines a space where matching points in both point clouds are averaged and differenced to calculate the point cloud distance $\left(\mathrm{PC}_{\text {dist }-i}\right)$. The open circles represent cloud points. The grey circles represent core points. Adapted from Lague et al. (2013). 
The projection scale $(p)$ and maximum search distance $(\delta)$ defined the diameter and length (respectively) of the cylinder that was projected in the direction of the surface normal at each core point (Fig. 5.5) (Lague et al., 2013; Westoby et al., 2016). $\delta$ was set to decrease computation time and can be thought of as an outlier removal as points beyond this distance will not be included in $\mathrm{PC}_{d i s t}$ or $u$ calculations. The value of $p$ was set to ensure that an average of five or more points were within the cylindrical projection space based on the $\rho_{p}$ of the reference cloud (Lague et al., 2013). The locations of all cloud points in the normal direction and contained within the cylinder were averaged for both the reference and compared point clouds by the $\mathrm{M} 3 \mathrm{C} 2$ algorithm and were used to calculate the $\mathrm{PC}_{\text {dist- } i}$ between the two point clouds at each core point (Lague et al., 2013; Girardeau-Montaut, no date).

In addition to computing $\mathrm{PC}_{d i s t}, \mathrm{M} 3 \mathrm{C} 2$ output includes a $95 \%$ confidence interval (or uncertainty; $u_{i}$ ) for each $\mathrm{PC}_{\text {dist }-i}$ value. This considers the fact that two surveys will always have slightly different surface roughness at any given location, which could cause spurious distances to be calculated. Equation 5.7 considers this in the calculation of $u$ with the inclusion of surface roughness $\left(\sigma_{1 i}\right.$ and $\left.\sigma_{2 i}\right)$ of the reference and compared point cloud as well as the $\rho_{p}\left(\rho_{l p}\right.$ and $\left.\rho_{2 p}\right)$ within the projected cylinder (Lague et al., 2013):

$$
u_{i}= \pm 1.96\left(\sqrt{\sigma_{1 i} \times \rho_{1 p}^{2} / n_{1}+\sigma_{2 i} \times \rho_{2 p}^{2} / n_{2}}+\text { ISE }\right)
$$

where $n=$ number of points within the projected cylinder. The ISE (traditionally, the registration error) value is an optional parameter which is added to the confidence interval in the calculation of $u_{i}$. The inclusion of point cloud alignment error along with surface roughness in this uncertainty calculation is a strength of the M3C2 algorithm (Barnhart and Crosby, 2013; Lague et al., 2013), which resulted in a more conservative uncertainty estimation and final DDT calculation. Our study 
uses $u$ and $\mathrm{PC}_{\text {dist }}$ to detect an iceberg-specific DDT. This was done through a separate bootstrapping analysis which is described in Section 5.3.2.4.

\subsubsection{Structure-from-motion photogrammetry derived point clouds}

Optimal M3C2 parameters were determined using the most complete survey for both icebergs (i2, survey 1) and these settings $(D=2.3 \mathrm{~m}, p=0.29 \mathrm{~m}, \delta=8.2 \mathrm{~m})$ were used for all SfM point cloud comparisons. The value of $D$ satisfied the normal assessment criterion conditions set above and is in line with the $2 \mathrm{~m}$ value used by Westoby et al. (2016) for a blue ice moraine complex in Antarctica. The reference point cloud was sub-sampled at $0.15 \mathrm{~m}$ spacing to select core points. As described in Section 5.3.1.1, each SfM point cloud was scaled using common inter-GPS distances. Any potential scaling error which may result from GPS position error is therefore identically assigned to all point clouds.

\subsubsection{Terrestrial laser scanning point clouds}

Optimal M3C2 parameters $(D=14 \mathrm{~m}, p=1.8 \mathrm{~m}, \delta=24 \mathrm{~m})$ for all TLS point cloud comparisons were determined from survey 1 of $\mathrm{i}$. The reference cloud was sampled at $0.89 \mathrm{~m}$ spacing for core point assignment. $D=14 \mathrm{~m}$ resulted in $95 \%$ of points showing $\xi>20$. The value of $D$ would need to be increased to $25 \mathrm{~m}$ to meet the recommended $98 \%$ threshold (Lague et al., 2013). We decided not to increase $D$ to $25 \mathrm{~m}$ because the quality of the TLS surveys was obviously poor upon initial inspection due to a combination of low $\rho_{p}$ and noise imposed due to physical characteristics of the ice, instrument noise, varying viewpoints while surveying, and drift correction (Table 5.3). It was impossible to assign an ISE value in the M3C2 comparisons since there were no known common points between TLS surveys. However, the positional accuracy of TLS point cloud data hinges on the accuracy of the GPS data used for drift correction and, in this manner, potential positional error was incorporated into the comparisons. 
Table 5.3: General and technique-specific details pertaining to the surveys of i1 and $i 2$. Values in parentheses represent a range. SfM $=$ structure-from-motion photogrammetry, TLS = terrestrial laser scanning, DEM = digital elevation model, ISE = Inter-survey error. *Values are representative of surveys after cleaning in AgiSoft Photoscan or CloudCompare and are calculated across the surveys' entire surface extent (i.e., data gaps were included if present).

\begin{tabular}{|c|c|c|c|}
\hline & Survey information & III-1 & III-2 \\
\hline \multirow{6}{*}{ 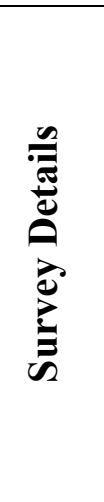 } & Survey date & 23 Apr 2015 & 27 April 2015 \\
\hline & Surface area $\left(\mathrm{m}^{2}\right)$ & $5.30 \times 10^{4}$ & $7.00 \times 10^{3}$ \\
\hline & Length, Width (m) & $4.5 \times 10^{2}, 1.5 \times 10^{2}$ & $1.3 \times 10^{2}, 0.7 \times 10^{2}$ \\
\hline & Location & $51^{\circ} 28^{\prime} \mathrm{N}, 51^{\circ} 22^{\prime} \mathrm{W}$ & $52^{\circ} 16^{\prime} \mathrm{N}, 55^{\circ} 13^{\prime} \mathrm{W}$ \\
\hline & GPS Units & $\begin{array}{l}\text { Canatec beacon } \\
\text { (1); Solara FT2000 } \\
\text { (2) }\end{array}$ & $\begin{array}{l}\text { TopCon Hiper V } \\
\text { (2); Trimble } 5800 \\
\text { (1) }\end{array}$ \\
\hline & GPS measurement interval (s) & $300 ; 30$ & $5 ; 300$ \\
\hline \multirow{9}{*}{ 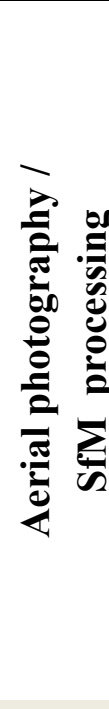 } & SfM surveys (\#) & 3 & 2 \\
\hline & Lines per survey (\#) & $5-8$ & 3 \\
\hline & Survey altitude (m) & $\begin{array}{l}\text { Surveys } 1 \& \text { 2: } 300 \\
\text { Survey 3: } 210\end{array}$ & 210 to 300 \\
\hline & Ground sampling distance $(\mathrm{cm})$ & $\begin{array}{l}\text { Surveys } 1 \& 2: 3.4 \\
\text { Survey } 3: 2.4\end{array}$ & $3.1-3.4$ \\
\hline & Average point density (points $\mathrm{m}^{-2}$ )* & $3.1 \times 10^{2}$ & $6.2 \times 10^{2}$ \\
\hline & Average \# points per survey* & $59 \times 10^{6}$ & $12 \times 10^{6}$ \\
\hline & ISE (m) & 0.4 & 0.2 \\
\hline & Orthophoto resolution $(\mathrm{cm})$ & 2.8 & 2.8 \\
\hline & DEM resolution & 5.7 & 5.7 \\
\hline \multirow{3}{*}{$\stackrel{2}{1}$} & TLS surveys (\#) & 3 & 3 \\
\hline & Average point density (points $\mathrm{m}^{-2}$ )* & 12.5 & 7.7 \\
\hline & Average \# points per survey* & $18 \times 10^{5}$ & $11 \times 10^{4}$ \\
\hline
\end{tabular}




\subsubsection{Deterioration detection threshold computation}

The minimum amount of iceberg deterioration between successive surveys that can be reliably detected by a given survey scenario is its DDT (Lague et al., 2013). Due to the low number of surveys which we have to conduct these comparisons, DDT is expressed as the right-tailed $95 \%$ confidence interval of the bootstrapped statistic $(\varepsilon)$ in Equation 5.8 (Canty, 2002; Chernick and LaBudde, 2011):

$$
\varepsilon_{i}=\left|\mathrm{PC}_{\text {dist }-i}\right|+u_{i}
$$

where $\varepsilon$ represents the precision corresponding with each individual core point. The $\varepsilon_{i}$ values associated with each survey scenario, found with the output of all point cloud comparisons associated with a given survey technique and GPS unit type, were amalgamated for the 1,000 bootstrap sample iterations. This was conducted to determine associated DDT values.

\subsubsection{Mass estimation}

Iceberg volume was estimated with CloudCompare's 2.5D Volume algorithm (CloudCompare, 2015) for both survey techniques. Reference point clouds, which had previously been cropped to a wider extent for the $\mathrm{M} 3 \mathrm{C} 2$ analysis, were cropped to match the other point clouds. A 0.1 by $0.1 \mathrm{~m}$ grid spacing was assigned, and the maximum height for points within each grid cell was used to compute the volume. Empty grid cells were filled with a linear interpolated height value. The total mass $(M)$ of each iceberg was then calculated with Equation 9 from the sail (i.e., above water) volume $(V$ ) for each individual survey using the buoyancy calculation from (McKenna and Ralph, 2007):

$$
M=\rho_{i} \times\left[\rho_{w} /\left(\rho_{w}-\rho_{i}\right)\right] \times V,
$$

where $\rho_{w}$ is water density $\left(1,025 \mathrm{~kg} \mathrm{~m}^{-3}\right)$ and $\rho_{i}$ is ice density. The latter was assigned a value of $873 \mathrm{~kg} \mathrm{~m}^{-3}$. This was the average density of a $1 \mathrm{~m}$ ice core retrieved from a grounded ice island 
during the field campaign. Like the two surveyed icebergs, this ice island is believed to originate from the Petermann Glacier. The value of $\rho_{i}$ is usually assumed in analyses of Greenland ice tongues, ice islands and icebergs and values between 900 and $920 \mathrm{~kg} \mathrm{~m}^{-3}$ have been assigned in the past (Enderlin and Hamilton, 2014; Sulak et al., 2017). While our assigned $\rho_{i}$ value is derived from a single ice island, we feel that it is best to use available in-situ data when possible. We note that our mass estimations do not account for density gradients, which may exist due to saturation below the waterline. This would result in underestimation of the iceberg mass.

The precision relative to the iceberg mass (i.e., relative uncertainty) is found with the difference in mass estimates between individual surveys. The relative uncertainty percentages are the same for both mass and volume, as the two measures are directly proportional. In addition, the relative uncertainty will not change based on the assigned $\rho_{i}$. We state both mass (tonnes) and volume $\left(\mathrm{m}^{3}\right)$ when reporting direct magnitudes.

\subsection{Results}

\subsubsection{Iceberg characteristics and mass estimation}

The length (L), width (W), and 2D surface extent of each survey target was determined in ArcGIS from SfM generated geotiffs (Table 5.3). i1 had a surface area of $5.30 \times 10^{4} \mathrm{~m}^{2}$ and a relatively level surface with a mean freeboard (height above waterline) of $\sim 12 \mathrm{~m}$. The smaller iceberg, i2, had a surface area of $7.00 \times 10^{3} \mathrm{~m}^{2}$ and a sloped surface from a maximum freeboard of $\sim 9 \mathrm{~m}$ to a minimum of $\sim 2 \mathrm{~m}$. i1 had a mass of $4.2 \times 10^{6}$ tonnes and volume of $4.8 \times 10^{6} \mathrm{~m}^{3}$. i2 had a mass of $7.5 \times 10^{5}$ tonnes and volume of $8.6 \times 10^{5} \mathrm{~m}^{3}$. An average mass difference of $22 \%$ was found for the estimates generated from the i1 SfM point clouds. Mass estimates from the i2 SfM point clouds, which had the best coverage from any survey scenario, differed by only $4 \%$. However, there were only two surveys from which comparisons could be made for this survey 
scenario. The TLS surveys of i1 and i2 had average mass differences of $19 \%$ and $11 \%$, respectively.

\subsubsection{Survey quality and DDT values}

Illustrative examples of CloudCompare's M3C2 algorithm output for the SfM and TLS point cloud comparisons are provided in figures 5.6 and 5.7, respectively. Table 5.4 contains summary statistics of both SfM and TLS generated point cloud comparisons and the distribution of $\varepsilon$ for each survey scenario is shown in Figure 5.8 along with the calculated DDT values.

Table 5.4: Precision assessment of the aerial photography with structure-from-motion photogrammetry processing (SFM) and terrestrial laser scanning (TLS) surveys for i1 and i2 by survey scenario. Each scenario is determined by the combination of the surveying technique and GPS type used. TB = tracking beacon, GPS = dual-frequency GPS receiver, $\mathrm{PC}_{\text {dist }}=$ distance between point clouds, $u=$ uncertainty, $\mathrm{DDT}=$ deterioration detection threshold.

\begin{tabular}{ccccc}
\hline Precision analysis metrics & \multicolumn{2}{c}{ SfM } & \multicolumn{2}{c}{ TLS } \\
& TB & GPS & TB & GPS \\
\hline Absolute Mean $\mathrm{PC}_{\text {dist }}(\mathrm{m})$ & 1.1 & 0.18 & 2.2 & 1.4 \\
Mean $u(\mathrm{~m})$ & 0.9 & 0.4 & 0.08 & 0.05 \\
DDT $(\mathrm{m})$ & 2.5 & 0.40 & 6.6 & 3.4 \\
\hline
\end{tabular}




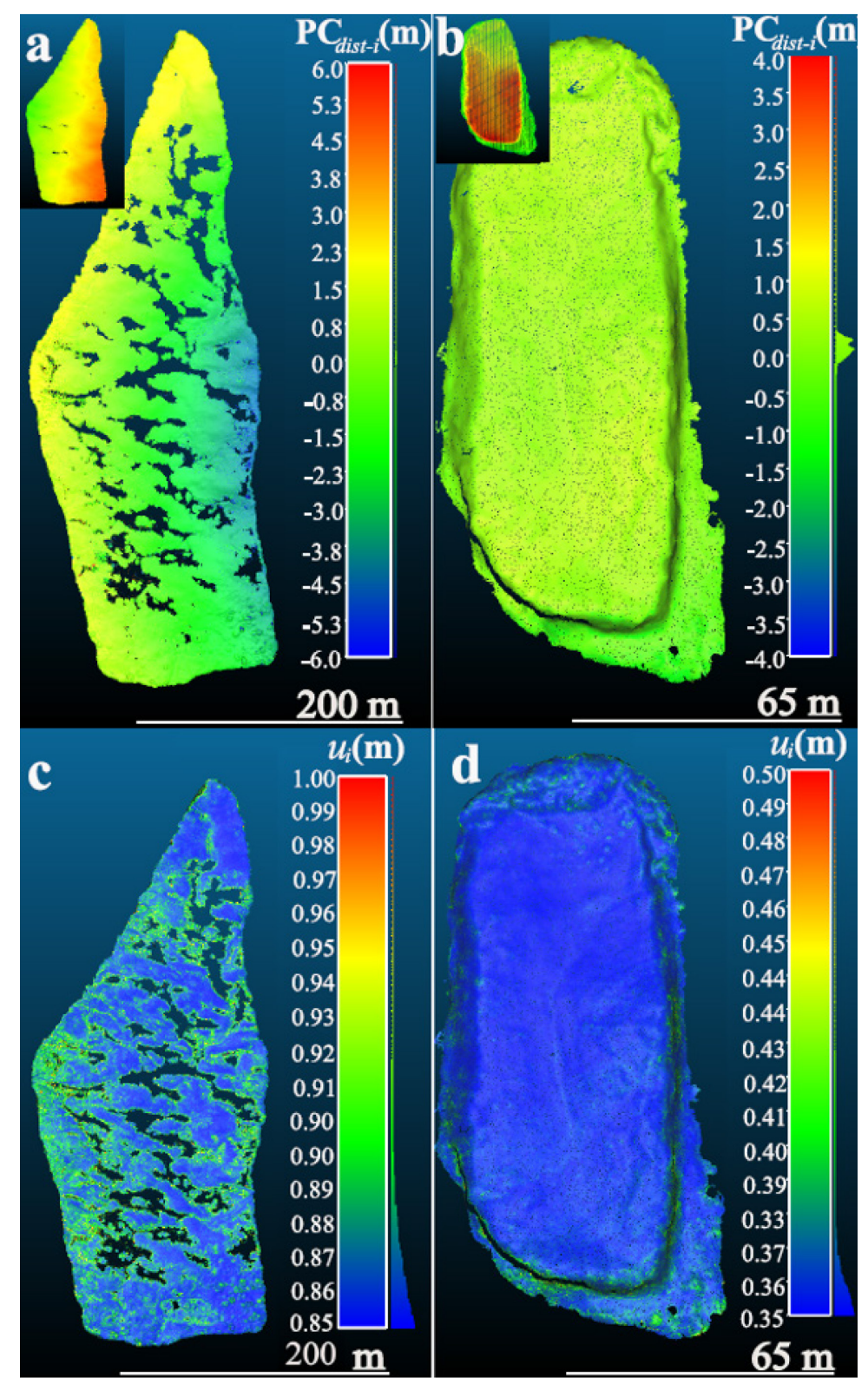

Figure 5.6: M3C2 algorithm output for SfM-generated point cloud comparison. a) and b) show the distance between triplicate point clouds $\left(\mathrm{PC}_{\text {dist }-i}\right)$ for $\left.\mathrm{i} 1 \mathrm{a}\right)$ and $\mathrm{i} 2 \mathrm{~b}$ ), respectively. Uncertainty $\left(u_{i}\right)$ in these distances at the $95 \%$ confidence level is illustrated in panels c) and d) for i1 and i2, respectively. Histograms to the right of the colour scale bar depict the frequency of the corresponding values. The insets in panels a) and b) contain example point clouds of each iceberg before $\mathrm{M} 3 \mathrm{C} 2$ point cloud differencing. Inset colours represent height values where red represents the higher elevations. Observed ice rubble was located in the region pictured at the top of the inset in b). The ram (i.e., an underwater 'foot' or 'skirt' that often forms underneath the waterline) likely became exposed at the opposing side of $i 2$. The low elevations at the bottom of the inset represent the ram. Note the variation in scale between panels and in comparison to Figure 5.7. 

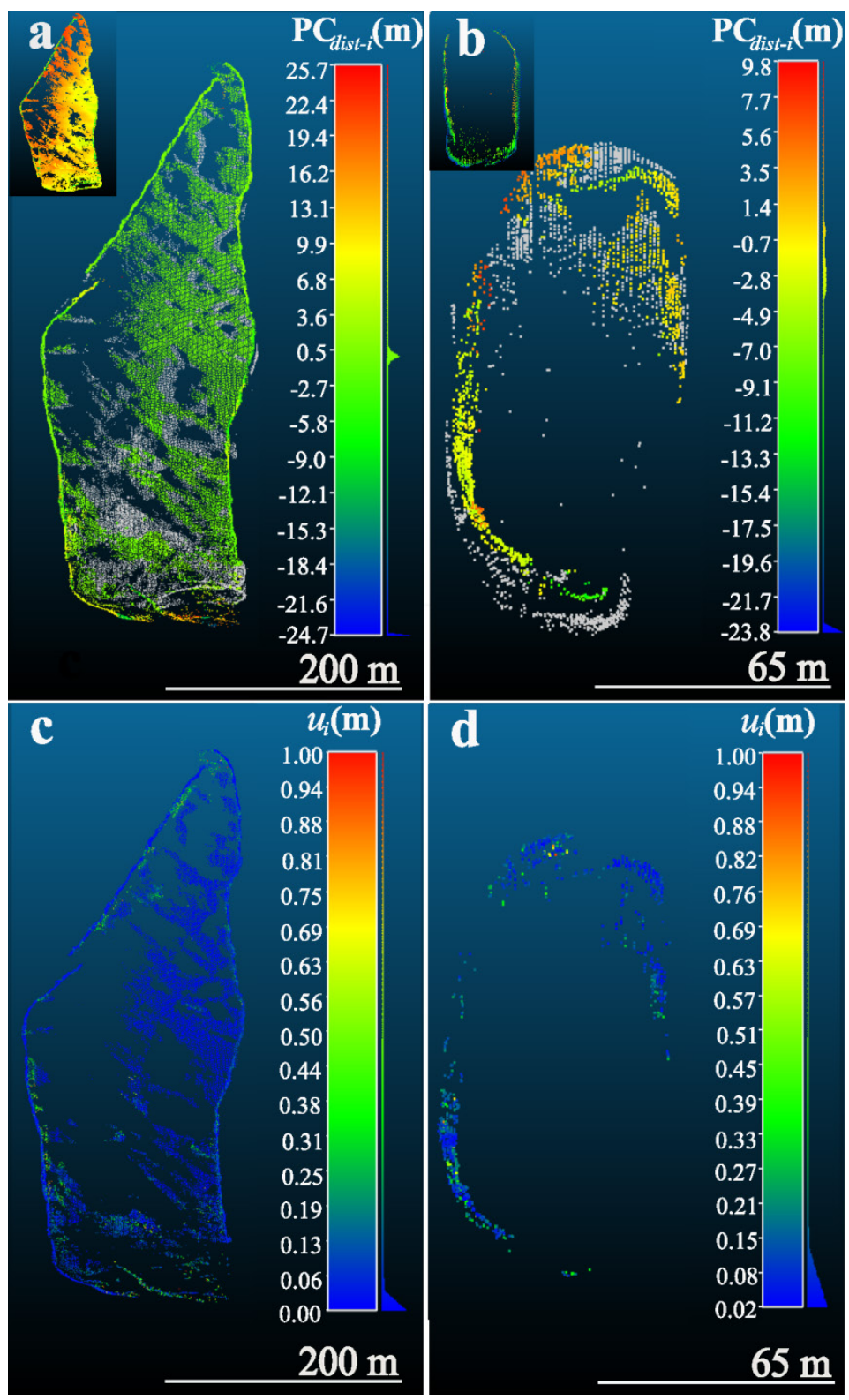

Figure 5.7: $\mathrm{M} 3 \mathrm{C} 2$ algorithm output for TLS-generated point cloud comparisons. a) and b) show the distance between triplicate point clouds $\left(\mathrm{PC}_{\text {dist-i }}\right)$ for $\mathrm{i} 1$ and $\mathrm{i} 2$, respectively. Gray points represent ' $\mathrm{NA}$ ' values where corresponding points between the two clouds did not exist. The uncertainty $\left(u_{i}\right)$ in these distances at the $95 \%$ confidence level is illustrated in c) and d) for il and i2, respectively. Histograms to the right of the colour scale bar depict the frequency of the corresponding values. Point size was augmented in comparison to Figure 5.6 to aid visualization. The insets in a) and b) contain example point clouds of the respective ice island before $\mathrm{M} 3 \mathrm{C} 2$ point cloud differencing. Inset colours represent height values where red represents the higher elevations. Survey line misalignment can be seen in a) and is an artifact of the point cloud correction procedure. Note the variation in scale between panels and in comparison to Figure 5.6. 

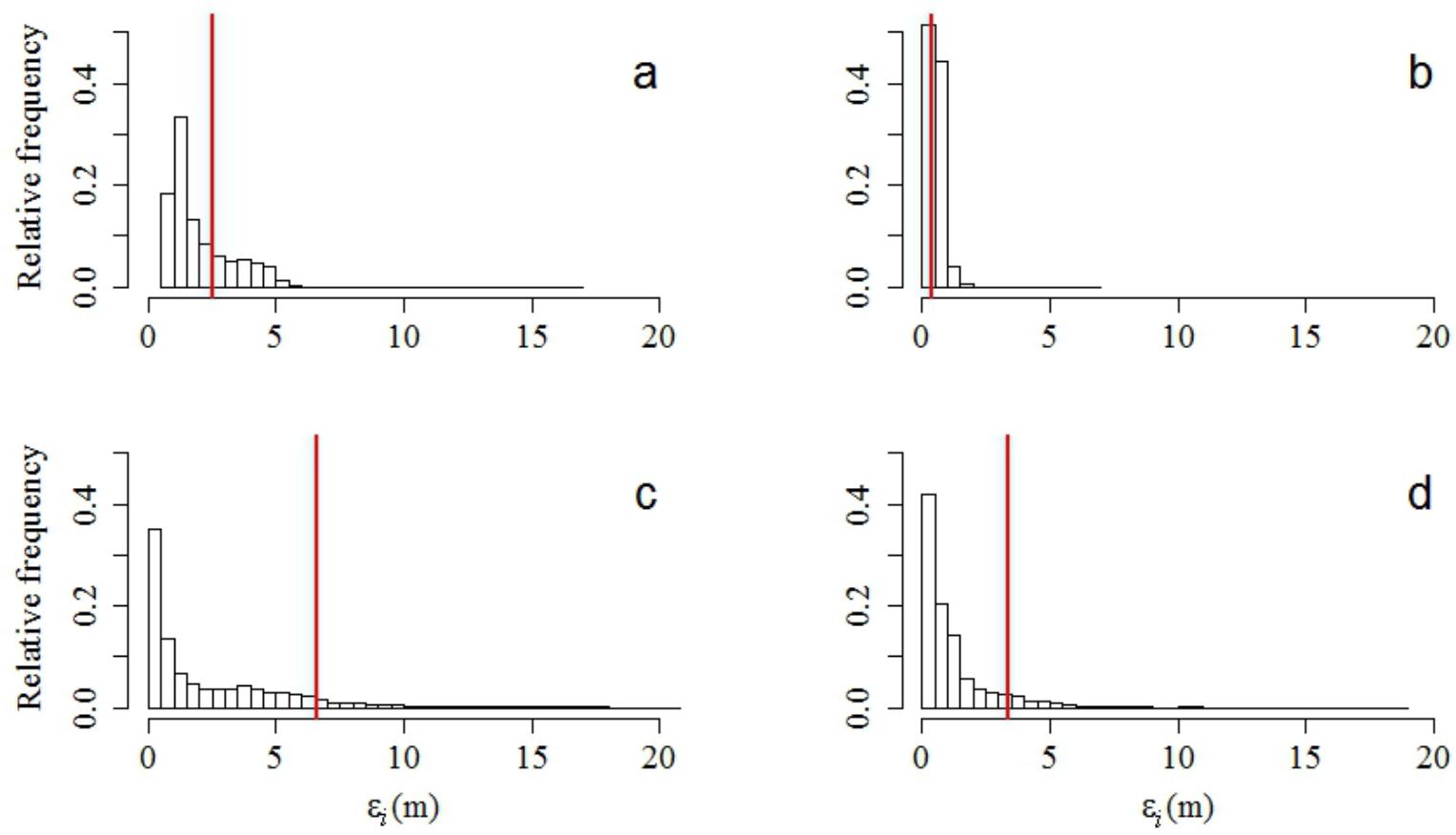

Figure 5.8: Histograms of $\boldsymbol{\varepsilon}_{\boldsymbol{i}}$, which is equal to the summed M3C2 difference $\left(\mathrm{PC}_{\text {dist }-i}\right)$ and $95 \%$ distance uncertainty $\left(u_{i}\right) \mathrm{M} 3 \mathrm{C} 2$ output after amalgamation for the SfM point cloud comparisons of a) i1 and b) i2, and TLS point cloud comparisons of c) i1 and d) i2. The red vertical lines represent the level of detection (DDT) for each survey scenario.

\subsubsection{Aerial photography with SfM processing}

The i1 point cloud comparison yielded a mean absolute $\mathrm{PC}_{\text {dist }}$ of $1.1 \mathrm{~m}$. There was a large dispersion in the individual $\mathrm{PC}_{\text {dist }-i}$ values $(\sigma=1.7 \mathrm{~m})$ (Figs. 5.6a and 5.8a), and both the mean $\mathrm{PC}_{\text {dist }}$ and $u$ were greater than those of $\mathrm{i} 2$ (Figs. 5.6b and 5.8b; Table 5.4). This was mostly due to the poorer quality of the GPS units deployed on i1, which increased the value assigned as the registration error (our ISE) in the $\mathrm{M} 3 \mathrm{C} 2$ algorithm. The influence of GPS accuracy can also be seen in panels $\mathrm{c}$ and $\mathrm{d}$ of Figure 5.6, which illustrate the difference in $u_{\mathrm{i}}$ values between the $\mathrm{i} 1$ and i2 surveys. It is also apparent that there were gaps in survey data for the upper horizontal surface of il in spite of generally high $\rho_{p}$ values for both survey targets (Fig. 5.6; Table 5.3). Gaps in the 
coverage of il's upper horizontal surface coincided with 'featureless' regions in the original photographs. These gaps may have been caused by shadowing, smooth surfaces resulting from meltwater freezing, and/or illumination angles that created 'wash-out' or glare.

The DDT values for $\mathrm{i} 1$ and i2 were 2.5 and $0.40 \mathrm{~m}$ (Table 5.4), respectively, which again underscores the benefit of using the higher-quality dual-frequency GPS receivers over the tracking beacons. In addition, the $\mathrm{PC}_{\text {dist }-i}$ values were more evenly distributed over the surface of i2 in comparison to il (Fig. 5.6a,b). However, the distribution in $u$ (Fig. 5.6d) showed that the distances calculated along the sidewalls and lower elevations of i2 were relatively more error-prone than those associated with the horizontal upper surface. These locations were likely less well covered during aerial photography surveying due to the nadir-viewing angle of the camera or were associated with ice rubble that was observed at lower elevations. With such low $\mathrm{PC}_{\text {dist-i }}$, the DDT value for i2 was predominately a result of the associated $u$ values.

\subsubsection{Terrestrial laser scan surveying}

Over the three consecutive TLS surveys, i1 translated $1280 \mathrm{~m}$ and rotated $27^{\circ}$, while i2 translated $820 \mathrm{~m}$ and rotated $9^{\circ}$. This equates to a drift of $\sim 0.3 \mathrm{~m} \mathrm{~s}^{-1}$ for both icebergs. In comparison to the SfM point clouds, the TLS data had greater $\mathrm{PC}_{\text {dist }}$ values. There were also relatively more regions that could not be compared across surveys due to incomplete survey coverage and lower $\rho_{p}$. The average $\rho_{p}$ of all TLS surveys was an order of magnitude lower than that of the SfM point clouds (Table 5.3). This can be visually assessed by comparing the insets of figures 5.7a and 5.7b to those of the SfM point clouds in figures 5.6a and 5.6b. The poor coverage of the upper surface in both il and i2 (Fig. 5.7) was likely due to specular reflection or weak returns given the high incidence angle, reflectivity of the ice surface and increased beam footprint (c.f., Landy et al., 2014, and Soudarissanane et al., 2011). These factors resulted in incomplete 
comparisons between surveys and larger DDT values relative to SfM point clouds. DDT values for i1 and i2 were 6.6 and 3.4 m, respectively (Fig. 5.8c,d; Table 5.4).

\subsubsection{Beacon data}

GPS accuracy determined the variability of inter-GPS distances. The mean inter-GPS distances were calculated with data collected over the duration of all surveys and these values were used for SfM scale assignment. The average relative standard deviations of the inter-GPS distances were $2.7 \%$ for the tracking beacons and $0.01 \%$ for the high-quality GPS units. Because the same values were consistently used to scale all point clouds corresponding to a certain survey target, it was not necessary to consider the error imposed by variability in the inter-GPS distances. However, this would need to be considered if the GPS units were repositioned between surveys. Lower SfM point cloud ISE values, assigned for the $\mathrm{M} 3 \mathrm{C} 2$ point cloud comparisons, were associated with the more precise dual-frequency GPS receivers (Table 5.3).

The relatively high potential positional error in the Solara $\left(\sigma_{b x}=2.9 \mathrm{~m}, \sigma_{b y}=2.9 \mathrm{~m}\right)$ and Canatec $\left(\sigma_{b x}=7.9 \mathrm{~m}, \sigma_{b y}=11 \mathrm{~m}\right)$ tracking beacons (Table 1$)$ negatively impacted the quality of the TLS drift correction. This is seen in the larger absolute mean $\mathrm{PC}_{\text {dist }}$ value of $2.2 \mathrm{~m}$ for TLS point clouds which were corrected with the tracking beacon data, in spite of the Kalman filtering and smoothing. The higher recording frequency and lower potential positional error of the dualfrequency GPS receivers $\left(\sigma_{b x}=0.03 \mathrm{~m}, \sigma_{b y}=0.04 \mathrm{~m}\right.$; Table 5.1) resulted in improved Kalman filter solutions and the subsequent drift correction (absolute mean $\mathrm{PC}_{\text {dist }}=1.4 \mathrm{~m}$ ). 


\subsection{Discussion}

\subsubsection{Data collection and processing considerations}

\subsubsection{Detection thresholds and monitoring iceberg deterioration processes}

To measure the magnitude and spatial distribution of iceberg deterioration with a given survey technique, the deterioration that transpires between surveys must exceed DDT. This, in turn, hinges on the surveying technique (SfM vs TLS) and geolocation accuracy (the four 'survey scenarios'), the rate of the deterioration process, the time elapsed between surveys, and the extent of the affected area. We discuss the implications of DDT and survey precision further using values from our study's survey scenarios and grouping deterioration processes into those resulting in 'chronic' or 'acute' morphological changes.

Chronic deterioration represents general and relatively slow changes over a large surface area (Fig. 5.9). Ballicater Consulting (2012) estimated the rate of horizontal melt at the waterline from wave erosion, one chronic deterioration mechanism, to be $\sim 2.7 \mathrm{~m} \mathrm{~d}^{-1}$ in conditions likely to be encountered offshore of Newfoundland and Labrador, Canada. Deterioration at this rate could be confidently detected after 1.3 days with repeat TLS surveying drift-corrected with GPS data logged by dual-frequency receivers given the calculated DDT values (Table 5.4). However, this same deterioration could be detected within 4 hours if the aerial photography with SfM processing technique was employed. Chronic sidewall recession caused by radiation and forced convection is much harder to detect. Assuming a rate of $0.3 \mathrm{~m} \mathrm{~d}^{-1}$ (Ballicater Consulting, 2012; Crawford et al., 2015) is representative, deterioration from this process could be reliably measured if employing dual-frequency GPS receivers within 8 days with TLS surveying or 1.3 days with SfM processing of aerial photography. 


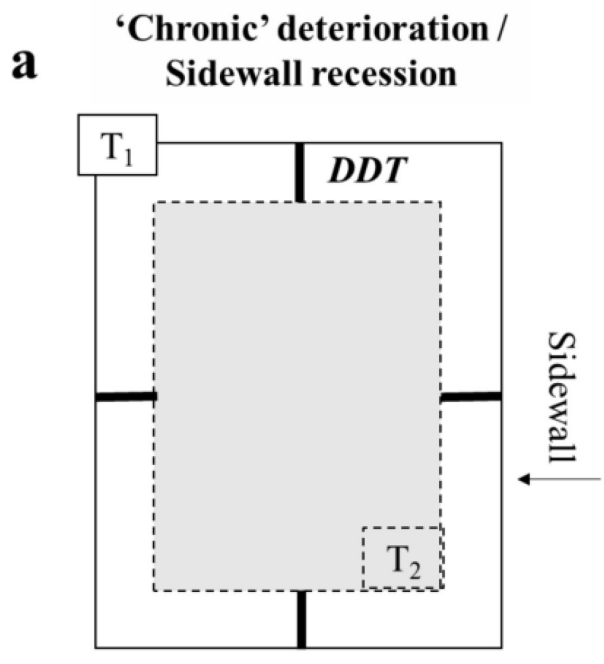

Overhead perspective

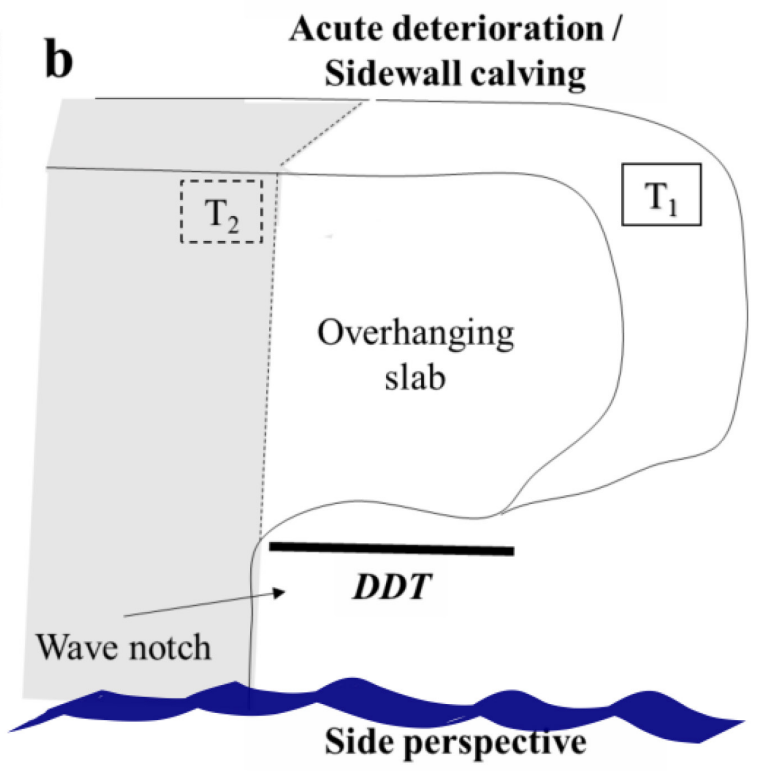

Figure 5.9: Example of idealized ice loss due to the two general ice island deterioration types: a) 'chronic' deterioration occurring between Time 1 (T1) and Time 2 (T2), assuming here that all sidewalls recede at a slower rate than b) 'acute' deterioration that occurs at a specific location between $T_{1}$ and $T_{2}$. The example of acute deterioration in $b$ ) is the calving of an overhanging slab that is created through chronic wave erosion at the waterline.

Equation 5.10 can be used to estimate the amount of ice that must be lost before detecting chronic deterioration with repeat surveys given the L, W and freeboard ( $f$ ) (in $\mathrm{m}$ ) of an idealized rectangular ice island/iceberg (Fig. 5.9a):

$$
M=((\mathrm{L} \times \mathrm{W})-(\mathrm{L}-\mathrm{DDT}) \times(\mathrm{W}-\mathrm{DDT})) \times f \times \rho_{i},
$$

The equation assumes that surface recession occurs uniformly over the sidewalls of an iceberg sail. For example, $2.7 \times 10^{4}$ tonnes of ice $\left(3.2 \times 10^{4} \mathrm{~m}^{3}\right)$ would have to be lost by a $1 \times 2 \mathrm{~km}$ ice island with a freeboard of $13 \mathrm{~m}$ before detection with SfM and dual-frequency GPS deployment. An iceberg with the approximate dimensions of i2 would have to lose $1.1 \times 10^{3}$ tonnes $\left(1.3 \times 10^{3} \mathrm{~m}^{3}\right)$ before it would be possible to detect the associated deterioration under the same surveying 
conditions. These values represent 0.02 and $0.23 \%$ of the mass and volume of each ice island, respectively.

These examples relate to deterioration occurring to iceberg sidewalls that result in the change in horizontal ( $\mathrm{L}$ and $\mathrm{W}$ ) extents. The chronic lowering of the surface from radiation and turbulent heat fluxes (Crawford et al., 2015), which affects the vertical dimension, is also possible to detect with these surveying techniques. However, the influence of buoyancy on freeboard height would need to be considered when reporting deterioration magnitudes.

Unlike chronic deterioration, acute deterioration will be immediately detectable with repeat surveying, as long as the dimensions of the calved piece are greater than the survey technique DDT (Fig. 5.9b). Equation 5.11 can be used to estimate the mass loss associated with the minimum detectable acute deterioration event given the surface area $\left(A\right.$, in $\left.\mathrm{m}^{2}\right)$ of the calved piece, the DDT and $\rho_{i}$.

$$
M=A \times \operatorname{DDT} \times \rho_{i}
$$

The value of DDT greatly influences the mass loss required for detection. For example, assuming a $4 \times 5 \mathrm{~m}$ growler were to calve from an iceberg sail, SfM processing of aerial photography surveys with dual-frequency GPS correction would detect this event if it weighed more than 7.0 tonnes $\left(8.0 \mathrm{~m}^{3}\right)$, but it would need to be more than 59 tonnes $\left(68 \mathrm{~m}^{3}\right)$ using the TLS technique with dual-frequency GPS. 


\subsubsection{M3C2 algorithm}

The ISE is used in Equation 5.7 to calculate the corresponding $u$ for each $\mathrm{PC}_{\text {dist }-i}$ calculation associated with the SfM comparisons, as are $\rho_{p}$ and the $\sigma_{i}$ of the reference and compared point cloud surfaces. The $\sigma_{i}$ will be influenced by instrument noise (e.g., incidence angle and range

noise), genuine surface roughness, GPS and INS errors, and the correct orientation of the normal vector with respect to the surface of both point clouds. The size of $D$ is crucial for the determination of surface normal orientation. It needs to be large enough that it is not influenced by small scale surface roughness, which can result in the incorrect orientation of normal vectors and spurious distance calculations. However, large scale surface orientation changes (i.e., naturally-occurring corners), such as the transition from the vertical sidewall to the horizontal upper surface of a tabular iceberg, can be occluded if $D$ is too large.

Since no deterioration likely occurred between consecutive surveys in our study, each unique $\mathrm{PC}_{\text {dist }-i}$ calculation should have the same normal orientation even if calculated with a large $D$ patch size. If the compared survey did have a different normal orientation in comparison to the reference point cloud, this would be reflected in a large value of $u_{i}$ through the inclusion of $\sigma_{2 i}$ in Equation 5.7 (Fig. 5.10). Likewise, if $D$ occludes a face orientation change on the reference point cloud this will be reflected by an increase in $\sigma_{l i}$. A lower $\rho_{p}$ for either the reference or compared point clouds will also be reflected in increased $u_{i}$ values (Eq. 5.7). The possibility of occluding surface orientation changes should be considered by future surveyors who aim to detect deterioration with any surveying technique (e.g., SfM, TLS, or sonar). A method of obtaining reasonable $\rho_{p}$ at edges should be favoured so that $u$ and DDT can be minimized in these critical locations. 


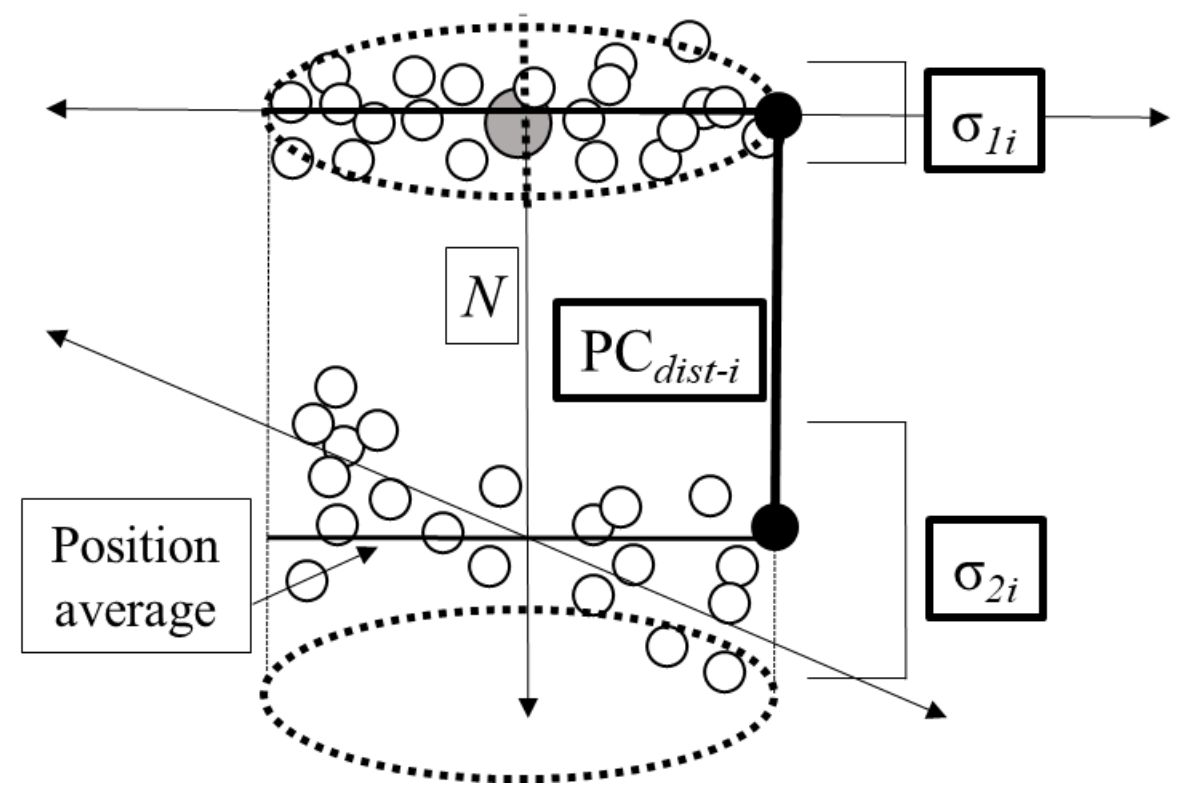

Figure 5.10: Normal $(N)$ orientation and surface roughness between two compared point clouds. Misalignment between the surface orientations of the reference (top) and compared (bottom) point clouds is represented by thin arrows. This misalignment is captured by the large surface roughness of the compared cloud $\left(\sigma_{2 i}\right)$ and will increase the uncertainty $\left(u_{i}\right)$ of the calculated distance between the two point clouds $\left(\mathrm{PC}_{\text {dist }-i}\right)$. The reference cloud's surface roughness is represented by $\sigma_{1 i}$. The open circles represent cloud points. The grey circle represents a core point. The black circles denote the end of the thicker line representing $\mathrm{PC}_{\text {dist }-i}$.

One of the large benefits of the M3C2 algorithm is that all points are retained for the normal orientation computation while the use of core points used for the calculation of $\mathrm{PC}_{\text {dist }}$ and $u$ decreases processing time (Barnhart and Crosby, 2013). While the use of core points was adequate for our evaluation, which did not expect deterioration to occur between surveys, future users of the $\mathrm{M} 3 \mathrm{C} 2$ algorithm should be attentive with this subsampling step in the event that they are interested in discerning very small-scale deterioration magnitudes. 


\subsubsection{Comparison to previous work and recommendations}

\subsubsection{Deterioration detection and mass estimation}

Our analysis based the DDT calculation on the precision of 3D models generated by aerial photography surveying with SfM processing and TLS surveying. We are not aware of another study that has conducted such an analysis or determined this threshold for drifting icebergs or ice islands. The DDT values derived from the two aerial photography with SfM processing survey scenarios in our study $(0.4$ and $2.5 \mathrm{~m})$ envelope those reported in past studies that used this technique to assess changes in the vertical dimension of their cryospheric research subjects (Beedle et al., 2014; Ryan et al., 2015; Divine et al., 2016). Robe and Farmer (1976) estimate a $10.5 \%$ error in their mass calculation method by propagating the errors associated with each step of their stereo-imagery processing workflow. However, these error estimates were based on static dimensions for $\mathrm{L}$ and $\mathrm{W}$ in a simplified volume estimate equation and cannot be expected to adequately represent the complex surface of an iceberg. Smith and Donaldson (1987) used a sextant and sidescan sonar to survey icebergs and report a $10 \%$ error for their mass estimates. Our mass estimates generated from surveys associated with low quality tracking beacon deployment had similar error values to those reported previously ( $\sim 10 \%$ to $20 \%)$. However, we saw in our study that surveying an iceberg target with SfM, paired with dual-frequency GPS unit deployment, provides an impressively high precision for mass estimation (4\%).

The increasing spatial and temporal resolution provided by new satellite programs will improve the ability to monitor the deterioration of numerous icebergs and ice islands over large areas or timespans. For example, Enderlin and Hamilton (2014) use $0.55 \mathrm{~m}$ horizontal resolution WorldView stereo-image pairs to estimate daily linear area-averaged melt rates of icebergs with uncertainties ranging from 8 to $100 \%$. Regardless, these estimations and the associated freshwater 
flux values are useful to constrain the role of iceberg meltwater on ocean properties over relatively large regions. In contrast, our technique assessment is necessary before further field based studies can be conducted to study the physical processes linked to observed deterioration.

\subsubsection{Surveying workflows}

Future surveyors using TLS for iceberg and ice island study should consider deploying markerGPS pairs where they can be seen and identified in the TLS point cloud for the determination of a registration error (ISE). Along with Ryan et al. (2015), who found that a limited number of markerGPS pairs inhibited the relative accuracy of SfM-generated glacier DEMs, we recommend that a number of strategically placed markers with high-quality GPS reference (i.e., GCPs) be deployed before future aerial photography surveys for georeferencing validation during SfM processing. In this study, markers were included in $60 \%$ to $80 \%$ of the images for i2's two surveys, but only between $20 \%$ and $60 \%$ for the larger i1.

Eisen (2012), Fugro (2014), Hamilton et al. (2013), McGuire et al. (2016), Younan et al. (2016), and Zhou et al. (2014) have all previously generated 3D iceberg maps from iceberg keel surveys conducted with multi-beam echo-sounders. Our drift correction approach can also be utilized for correcting these keel surveys. Kimball and Rock (2015) developed a vessel-based terrain relative navigation method for conducting autonomous underwater vehicle (AUV)mounted sonar surveys to map the keels of large, tabular Antarctic icebergs. Estimates of the iceberg's translation and rotation, derived relative to that of the AUV, were used to correct Doppler sonar range data and create the keel map. Alternatively, McGuire et al. (2016) corrected TLS iceberg surveys with average drift velocity and rotation magnitudes derived by aligning consecutive surveys with an iterative closest point matching algorithm (McGuire et al., 2016). While GPS deployment is not a requirement when using the approaches of Kimball and Rock 
(2015) or McGuire et al. (2016), these techniques must estimate iceberg translation and rotation. $3 \mathrm{D}$ model generation of a moving target is typically improved when a motion model is incorporated in the survey processing workflow to account for variations in the rate of translation and rotation (Held et al., 2014; Kimball and Rock, 2015). Corrections that employ a constant drift velocity may be adequate for ice management purposes where it is necessary to rapidly process survey data to generate information regarding the size and shape of hazards (McGuire et al., 2016). However for deterioration studies, more accurate positioning will likely be required to guarantee high-quality results.

\subsubsection{Future iceberg and ice island surveying}

Table 5.5 includes a number of important considerations associated with each technique during iceberg or ice island surveying field campaigns. A valuable characteristic of SfM that was apparent in this study is the potential to $\log$ an order-of-magnitude greater $\rho_{p}$ than TLS (Leberl, 2010). This contributed to the superior deterioration detection and mass estimation capabilities of the technique. The imagery also provides a user with additional information to aid in the interpretation of the 3D models and/or point cloud comparisons (Held et al., 2014). To decrease the chances of gaps in survey coverage on this surface (Fig. 5.6a), we recommended conducting aerial photography surveying during overcast conditions to improve contrast. This will optimize image quality and provide an adequate number of tie-points for SfM processing (Fonstad et al., 2013). Another alternative is to use bathymetric LiDAR, which uses a green wavelength and would not be affected by melt ponding (Divine et al., 2016) or shadowing, and could be used to map both the ice island and shallow surrounding bathymetry $(<50 \mathrm{~m})$ depth during an airborne survey. 
Table 5.5: Field campaign considerations for aerial photography surveying (with subsequent structure-from-motion (SfM) processing) and terrestrial laser scanning (TLS) surveying. This list includes some of the factors that surveyors may contemplate when deciding between the use of these two survey techniques for future research programs. Costs are approximate. Further discussion on the benefits and limitations of these techniques for glaciological studies can be found in Ryan et al. (2015).

\begin{tabular}{ccc}
\hline $\begin{array}{c}\text { Survey Conditions \& } \\
\text { Requirements }\end{array}$ & $\begin{array}{c}\text { Aerial Photography / } \\
\text { SfM Processing }\end{array}$ & TLS \\
\hline Survey duration (min) & $\sim 6$ & $\sim 15-20$ \\
Best coverage locations & $\begin{array}{c}\text { Upper surface, aerial } \\
\text { sidewall extent }\end{array}$ & Sidewalls \\
Difficult coverage locations & Sidewalls & Upper surface \\
Optimal deterioration \\
process to detect \\
$\begin{array}{c}\text { Calving, fracturing, full } \\
\text { sail sidewall recession }\end{array}$ & $\begin{array}{c}\text { Waterline wave } \\
\text { erosion }\end{array}$ \\
Survey platform $/$ cost hr ${ }^{-1}$ & $\begin{array}{c}\text { Helicopter } \$ 1,500 \\
\text { high winds }\end{array}$ & $\begin{array}{c}\text { High sea state, } \\
\text { sea ice }\end{array}$ \\
Survey equipment - & $\sim \$ 3,700$ & $\sim \$ 150,000$ \\
total cost & & \\
Tracking beacon cost & $\sim 200$ \\
Dual-frequency GPS cost & $\$ 15,000(2$ units + associated equipment $)$ \\
\hline
\end{tabular}

We recommend acquiring both oblique imagery with a vessel-mounted camera or with an additional aerial pass with an off-nadir camera angle along with vertical photographs to adequately cover steep surfaces (Westoby et al., 2012). Improving coverage should help to reduce the $u_{i}$ values associated with $\mathrm{PC}_{\text {dist }}$ values calculated along sidewalls and edges, as seen in the $\mathrm{SfM}$ point comparison output for i2 (Fig. 5.6d). If an oblique survey is not conducted, surveyors should be cautious when interpreting small deterioration magnitudes observed around edges and sidewalls 
due to the increased uncertainty at these locations, as the DDT values that we provide are an average determined from the $\mathrm{PC}_{\text {dist }-i}$ and $u_{i}$ values determined across the entire ice surfaces.

If future surveyors utilize vessel-based TLS surveying, it will be best suited for the observation of sidewalls and developing wave notches due to instrument mounting location and viewing angle. A benefit of vessel-based TLS surveying is that the resulting point cloud processing takes less time compared to SfM processing once a drift correction workflow is developed (Divine et al., 2016). Additionally, vessel-based surveying is not hindered by poor sky conditions to the same extent as helicopter-based aerial surveying. However, we believe that the benefits of SfM outweigh these limitations. Exploring the use of uninhabited aerial vehicles (UAVs) is recommended, as their use could alleviate the dependency on costly, weather-sensitive helicopters, and data collection via fixed-wing UAVs is already increasingly utilized in glacier (Whitehead et al., 2013; Bhardwaj et al., 2016) and iceberg or ice island (McGill et al., 2011) investigations. To truly be independent of helicopter use, one would additionally need to use an alternative method for marker/GPS deployment such as that developed by McGill et al. (2011) in the Southern Ocean.

A different method for assigning scale or collecting data, such as that documented by Wang et al. (2015) or Younan et al. (2016), would need to be utilized if one wanted to conduct aerial photography surveying without marker/GPS deployment. It is important that the error of these alternative methods be reported for the continued development and comparison of iceberg and ice island surveying methods. For high precision surveying, we recommend that marker/dualfrequency GPS pairs are permanently deployed, or re-deployed in the same position for each survey. This will ensure that the point clouds associated with each survey are consistently scaled. 


\subsection{Conclusions}

This research provides the first quantification of DDT for drifting icebergs or ice islands with observations made through SfM processing of repeat aerial-photo surveys or TLS surveys. In addition, it details a method of iceberg drift correction using GPS data as well as protocols for point cloud generation and comparison. The quality of GPS units deployed on the iceberg surface for drift correction greatly influenced the precision of the survey data, which yielded a large range (0.40 to $6.6 \mathrm{~m}$ ) in DDTs (Table 4). We also calculate the relative uncertainty of our iceberg mass estimates based on our repeat survey data and found that we can repeatedly derive an iceberg's mass within $4 \%$ when using aerial photography and SfM processing techniques. These survey techniques can now be utilized in the offshore environment to provide upper and lower bound estimates of an iceberg's mass based on the uncertainties associated with the particular surveying scenario.

The two surveying techniques differed in terms of their capability to detect specific deterioration processes, along with logistical, instrumental and platform considerations for field campaigns (Table 5.5). Based on our experience, we recommend that ice island or iceberg field campaigns utilize SfM processing of aerial photography surveys for deterioration observations after considering survey target characteristics, environmental conditions, and campaign objectives. This is due to the decreased cost of equipment, additional visual information provided by imagery, high point density, relatively lower noise of point clouds, the lower DDT values and better mass estimation capabilities of this technique that will allow for confident reporting of morphological changes in greater detail. To reduce reliance on helicopters, we also recommend the integration of one or more of the following into an iceberg aerial photography survey system: 1) oblique vessel mounted cameras, 2) UAV platforms for aerial photography survey and/or 3) UAV tracking 
beacon delivery or an alternative method for scaling SfM point clouds such as reported by Wang et al. (2015). This will dramatically decrease cost, allow for the use of survey vessels without helidecks, and alleviate some weather limitations associated with helicopter flying. An off-nadir circumnavigation of the survey target's sidewalls should also be added to improve sidewall coverage for waterline deterioration detection. Surveying campaigns may also include the use of multi-beam sonar (Kimball and Rock, 2015; McGuire et al., 2016) to both validate the volume and mass estimations made with the sail surveys as well as to capture the wave and thermal erosion occurring at the ice-water-air interface.

Future deterioration measurements via repeat surveys from a dedicated vessel, along with concurrent environmental observations (e.g., current, wind, temperature), will provide much needed in-situ data for iceberg drift and deterioration analysis and model development. These efforts can then be applied to mitigate the risks associated with offshore industrial operations, as well as for fundamental research into the physical and ecological implications of the influx of iceberg meltwater into the ocean. Offshore stakeholders who are concerned with ice hazards in a more immediate sense can utilize the surveying techniques to provide mass estimates while being aware of the error bounds of these estimates. With this information and the auxiliary considerations discussed in this paper, ice island and iceberg surveyors can now plan field campaigns (e.g., technique, platform, GPS quality) based on the subject of interest (i.e., deterioration modelling or mass estimation) and the required quality of the end product. 


\section{Chapter 6 - The aftermath of Petermann Glacier calving events (2008-2012): Ice island size distributions and meltwater dispersal}

\subsection{Introduction}

Immense, tabular icebergs, or 'ice islands', have been generated by recent calving events at ice shelves and floating ice tongues (FITs) in both of the Polar Regions (Nick et al., 2012; Straneo et al., 2013; Bigg et al., 2014). Examples include the 5,800 $\mathrm{km}^{2}$ ice island that broke away from the Larsen-C Ice Shelf in Antarctica in 2017 and three ice islands that calved in relatively rapid succession between 2008 and 2012 from the Petermann Glacier of northwest Greenland (Münchow et al., 2014; NASA, 2017; Crawford et al., 2018). These three Arctic ice islands had surface extents between approximately 30 and $300 \mathrm{~km}^{2}$ (Fig. 6.1) (Crawford et al., 2018).
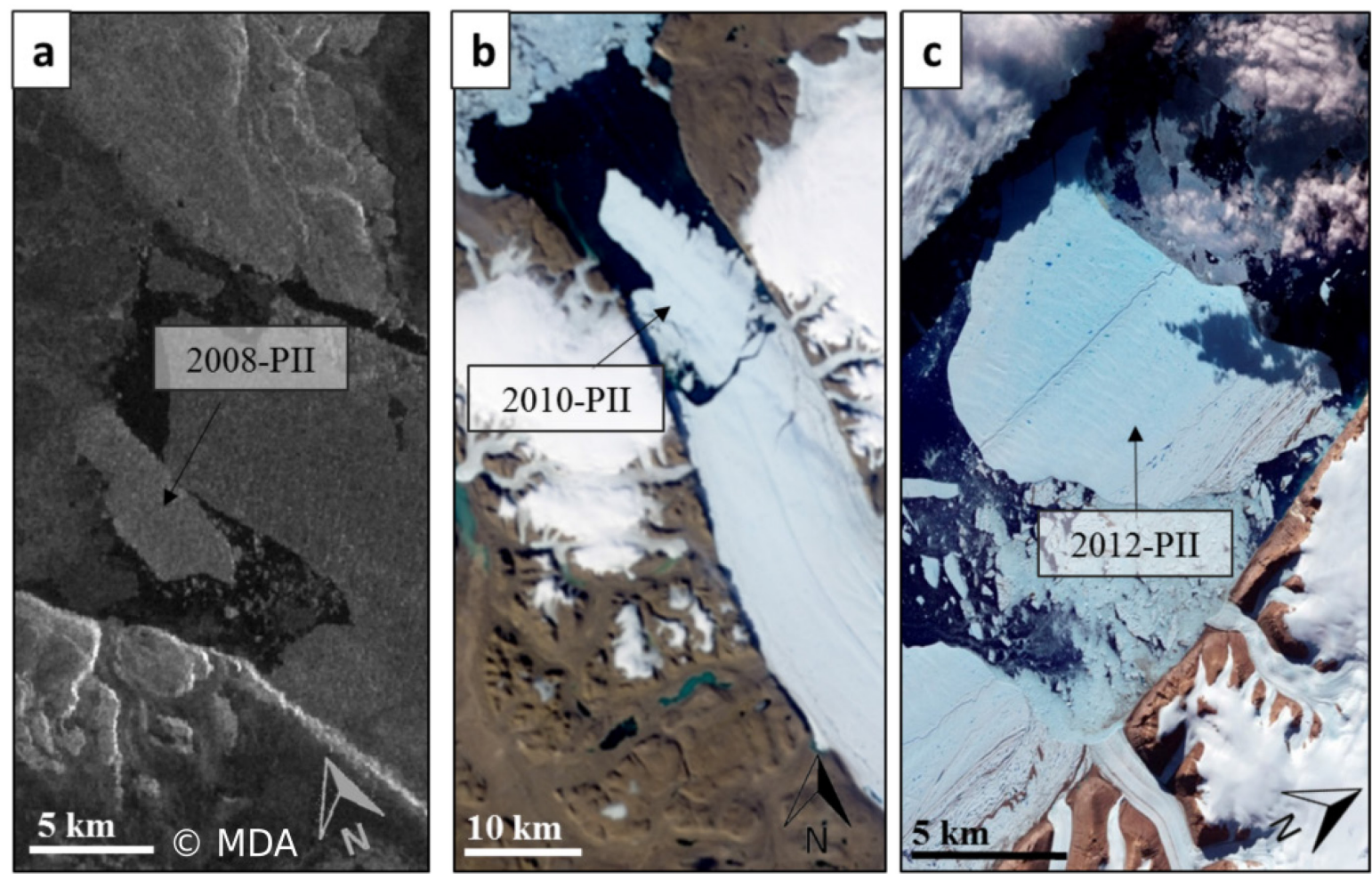

Figure 6.1: Calving events at the Petermann Glacier. a) July 2008; Envisat (ECCC, 2013), b) August 2010; MODIS AQUA (NASA, 2010), and c) July 2012; ASTER TERRA (NASA, 2012). 
Research concerning ice islands and the many ice island fragments produced during their deterioration has predominantly been dedicated to two subjects: their potential as hazards to shipping and offshore industrial operations (Li et al., 1989; McGonigal et al., 2011; Peterson, 2011; Haas, 2012; Mueller et al., 2013; Fuglem and Jordaan, 2017), and the dispersal of fresh meltwater as they deteriorate during drift (Gladstone et al., 2001; Smith, 2011; Merino et al., 2016). Arctic research has historically focused on the former. Ice islands originating from Greenland and Ellesmere Island fracture and generate numerous smaller ice islands, as well as bergy bits (100$300 \mathrm{~m}^{2}$ ) and growlers $\left(20 \mathrm{~m}^{2}\right)$, which represent hazards to regional industrial interests (Sackinger, Shoemaker, et al, 1985; Newell, 1993; CIS, 2005; Peterson et al., 2009; Peterson, 2011).

Antarctic research has concentrated on the distribution of meltwater inputs into the Southern Ocean resulting from the melt of ice islands, as well as the resulting biological, physical and chemical consequences to the surrounding water column (Helly et al., 2011; Smith et al., 2013; Duprat et al., 2016; Raiswell et al., 2016). A series of studies since 1980 used shipborne observations to assess the distribution patterns of Antarctic ice island fragments and infer rates of deterioration through size and concentration data (Budd et al., 1980; Hamley and Budd, 1986; Jacka and Giles, 2007; Romanov et al., 2012). The most recent additions to this research by Tournadre et al. $(2012,2015,2016)$ incorporated altimeter, scatterometer, optical and SAR remote sensing datasets (Long et al., 2002; Stuart and Long, 2011; Fletcher et al., 2016), which greatly increased the spatial coverage of the distribution analyses and also extended the size classes included within the dataset.

Ice islands and icebergs are an important component of the freshwater flux from both the Antarctic and Greenland ice sheets due to their potential to distribute meltwater over large regions (Luckman et al., 2010; Stern et al., 2015; Enderlin et al., 2016, 2018). More concerted research is 
now being undertaken on this topic in Arctic and sub-Arctic waters (Stern et al., 2015; Enderlin et al., 2016; Wagner and Eisenman, 2017; Marson et al., 2018). However, it is a challenge to monitor numerous ice islands over their entire life spans (Merino et al., 2016; Stern et al., 2016; Rackow et al., 2017). This has made it difficult to analyze deterioration and estimate the spatial and temporal dispersal of meltwater following specific ice island calving events.

This study touches upon both of these research themes by using the new Canadian Ice Island Drift, Deterioration and Detection (CI2D3) Database (Crawford et al., 2018) to investigate the downstream consequences of the 2008, 2010 and 2012 Petermann Glacier calving events. The first objective of this study is to evaluate the fit of statistical distributions to the size-frequency distribution of Petermann ice islands (PIIs). Iceberg and ice islands in the Arctic and Antarctic have previously been described to be well represented by log-normal or power-law size-frequency distributions (Tournadre et al., 2015; Enderlin et al., 2016; Stern et al., 2016; Kirkham et al., 2017). The nature of these distributions reflect the processes (e.g. fracture, smaller-scale calving, wave erosion) that contribute to iceberg or ice island deterioration (Kirkham et al., 2017), and the results of this analysis are discussed in this context.

The second objective of this study is to quantify the spatial distribution of meltwater through eastern Canadian waters resulting from the drift and deterioration of the numerous ice islands that originated from the aforementioned Petermann Glacier calving events. The potential consequences of this meltwater flux over varying spatial scales are discussed. The CI2D3 Database tracks the lineage of ice islands until they decrease to approximately $0.25 \mathrm{~km}^{2}$ in surface area (Crawford et al., 2018). It is this lineage information and thorough monitoring that made it possible to conduct these analyses for the individual PIIs observed in satellite-borne SAR imagery that was acquired between July 2008 to December 2012. 


\subsection{Study area}

Northwest Greenland contains a number of glaciers (i.e., Petemann, Ryder and Steensby glaciers) that terminate in FITs and episodically calve large ice islands (Higgins, 1989; Fig. 6.2). The Petermann Glacier itself drains approximately $4 \%$ of the Greenland Ice Sheet and calves once every 5 to 10 years (Higgins, 1991; Münchow et al., 2014). Recent calving events have occurred in 2001, 2008, 2010, 2011, 2012, 2013 and 2017 (Crawford et al., 2018; Desjardins et al., 2018; L. Desjardins, personal communication).

Ice islands that calve from the northwest Greenland FITs fracture into numerous individual ice islands that follow a southward drift trajectory. Figure 6.2 illustrates the dominant currents and bathymetry that influence ice island drift routes through the study area. Ice islands become caught in the cyclonic Baffin Island Current after passing over a sill separating Kane Basin from Baffin Bay (Fissel, 1982; Tang et al., 2004). Ice islands typically follow the edge of the Baffin Island continental shelf next to a steep shelf break (Newell, 1993; Tang et al., 2004). They exit Baffin Bay through Davis Strait and enter the Labrador Sea where they continue south in the Labrador Current (Newell, 1993; Tang et al., 2004). Ice islands from northwest Greenland have been observed as far south as $42^{\circ} \mathrm{N}$ (Crawford et al., 2018). In this location offshore of Newfoundland, ice islands encounter warmer waters associated with the North Atlantic Current, which hastens their disintegration (Bigg et al., 1997; Fig. 6.2). 


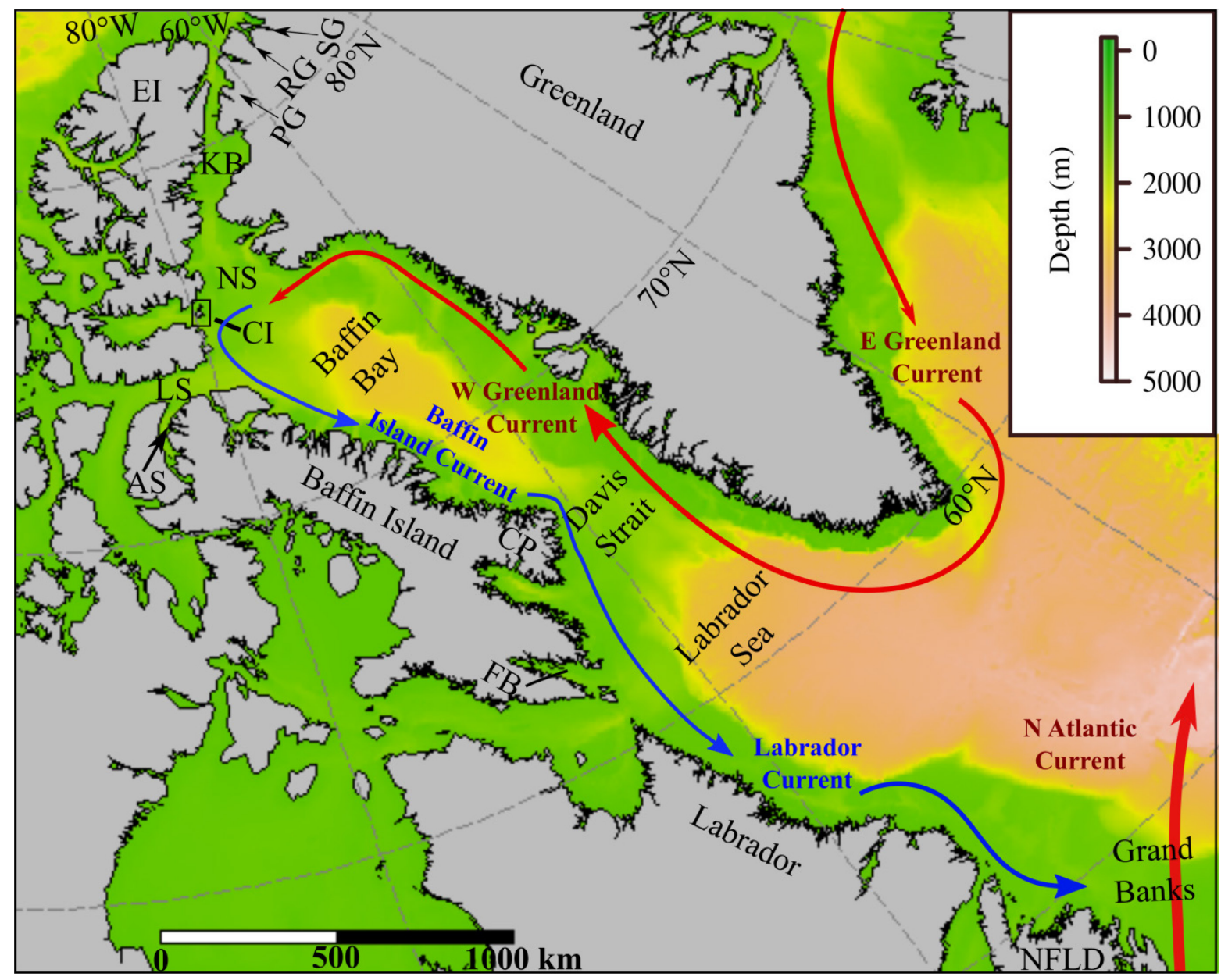

Figure 6.2: Bathymetry and ocean currents in the study area (National Geophysical Data Center, 2006). $P G=$ Petermann Glacier, $R G=$ Ryder Glacier, $S G=$ Steensby Glacier, $K B=K$ Kane Basin, LS = Lancaster Sound, NFLD = Newfoundland, CP = Cumberland Peninsula, AS = Admiralty Inlet, $\mathrm{CI}=$ Coburg Island, EI = Ellesmere Island, NS = Nares Strait, FB = Frobisher Bay. 


\subsection{Methods}

\subsubsection{The CI2D3 Database and initial data sub-setting}

The geospatial CI2D3 Database contains $>15,000$ entries representing observations of $>900$ individual ice islands. All of these ice islands were descendants of the large initial ice islands that calved from the Petermann Glacier and other northwest Greenland FITs between 2008 and 2012 (Crawford et al., 2018). To generate the CI2D3 Database, ice islands were identified in SAR scenes obtained from the Canadian Ice Service (CIS) archive. These were primarily RADARSAT-1 and -2 (Canadian Space Agency) ScanSAR Wide acquisitions with nominal resolutions of $100 \mathrm{~m}$. A polygon was delineated to represent the surface extent of each identified ice island in ArcGIS (v. 10.2-10.5; ESRI, Redlands, USA) and a number of geospatial and qualitative attribute fields were populated using customized GIS tools. Ice islands were tracked at a minimum 2-week observation interval, although a greater observation frequency was usually realized. The lineage connection between repeat observations of a tracked ice island, or between a 'mother' ice island and the 'daughters' that are created through fracturing, was captured in the database and is illustrated in Figure 6.3a.

Uncertainty in the digitized surface area, calculated as the coefficient of variation between database technicians, was $6.2 \%$. Full details regarding the data sources, generation workflow and uncertainty assessment associated with the CI2D3 Database are provided in Crawford et al. (2018) and the database documentation and requirements files (Saper and Crawford, 2016; Crawford et al., 2017) are found at https://wirl.carleton.ca/ci2d3. The database will be uploaded to the Polar

Data Catalogue, a public repository, in the summer of 2018 (https://www.polardata.ca/pdcsearch/PDCSearch.jsp?doi_id=12678). 


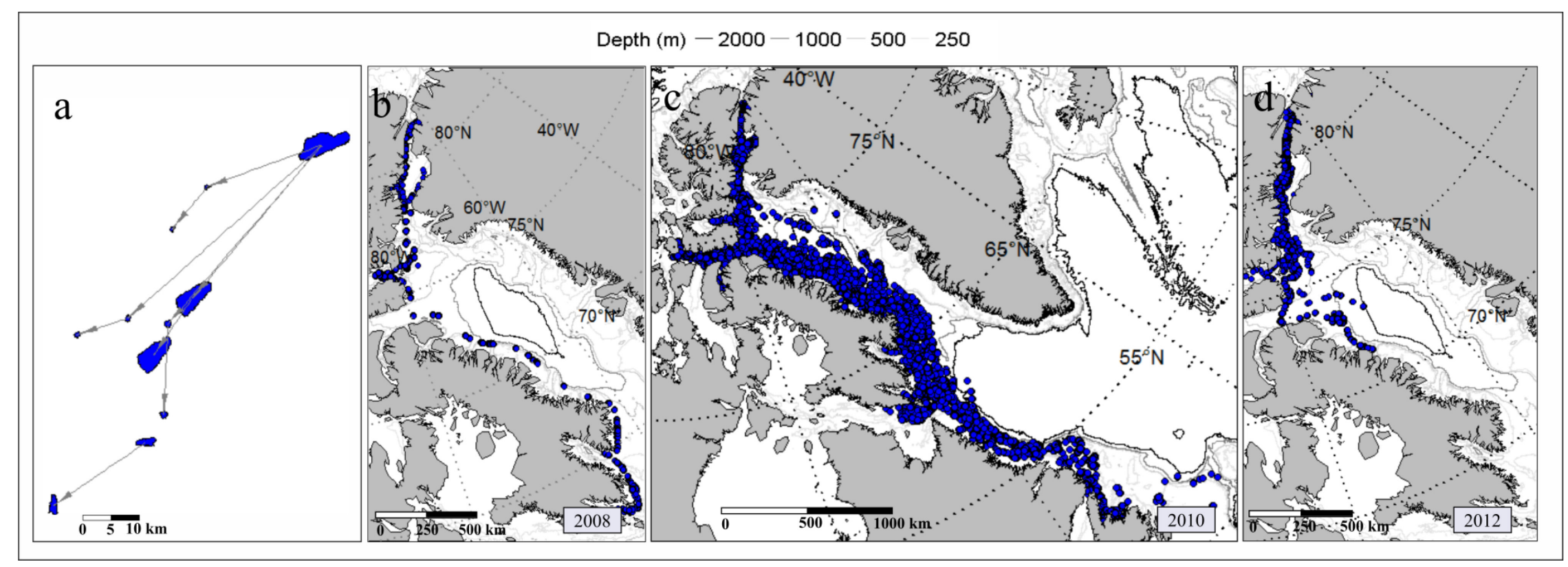

Figure 6.3: Illustration of Petermann ice island observations represented in the Canadian Ice Island Drift, Deterioration and Detection (CI2D3) Database. a) Example of the lineage connection established between repeat observations of an ice island and between mother and daughter ice islands. Panels b), c) and d) show all database entries associated with the 2008,2010 and 2012 Petermann Glacier calving events, respectively, represented as blue points. The database currently includes entries of ice islands that were observed through December 2012. 
This study focuses on the flux of ice islands following the 2008, 2010 and 2012 Petermann Glacier calving events. As of April 2018, the database contained 332, 8025 and 1823 ice island observations associated with the 2008, 2010 and 2012 calving events, respectively (Fig. 6.3). Ice islands associated with the 2008 calving event were monitored until there were no longer any identifiable ice islands $>0.25 \mathrm{~km}^{2}$ in the study area. The record of ice islands associated with the 2010 and 2012 calving events is incomplete, since monitoring ended after December 2012. The ice islands associated with the 2008, 2010 and 2012 calving events had been monitored for 1, 2.5 and 0.5 years after their respective calving events as of April 2018 .

Finally, a note on terminology: the Manual of Ice defines an ice island fragment as a 'piece of an ice island that has broken away from the main mass' (CIS, 2005). It is difficult to distinguish the 'main mass' with increasing time after an initial glacier calving. For this reason, and also due to the overlap in sizes between ice islands and fragments from different sources and calving events, all individual pieces are referred to as 'ice islands' in this study. The term 'ice island' is not used traditionally to describe large, tabular icebergs that originate from Antarctica. However, all Arctic and Antarctic large, tabular icebergs are referred to as 'ice islands' throughout this paper for simplicity. Smaller, non-tabular and tabular icebergs discussed in other publications are still referred to as 'icebergs'.

\subsubsection{Size distributions}

I evaluated the fit of a number of statistical distributions to the size-frequency distribution of PIIs originating from the 2010 and 2012 calving events. The size-frequency distribution of ice islands originating from the 2008 calving event was not used in this analysis due to the low number of ice island observations associated with this calving event. Database entries were subset to include only the first representation of each ice island fragment per 2-week period to remove 
sampling bias. Eight of these periods, each separated by a period of approximately 6 months, served as 'snapshots' to evaluate if the best fit distribution was consistent over time. The study area was divided into six spatial 'snapshots', regions of $10^{\circ}$ latitude that broadly represent major water bodies (Table 6.1), to assess if the best fit distribution was consistent across the drift range of PIIs. Only the first observation of ice islands associated with the 2010 and 2012 calving events were included in each spatial snapshot.

Table 6.1: Spatial snapshots used to assess variation in size distributions.

\begin{tabular}{ccc}
\hline Spatial snapshot & Water bodies & Latitude Range $\left({ }^{\circ} \mathbf{N}\right)$ \\
\hline 1 & Nares Strait/northern & \\
Baffin Bay & $\geq 75$ \\
2 & Baffin Bay & $<75, \geq 65$ \\
3 & Labrador Sea & $<65, \geq 55$ \\
4 & southern Labrador Sea; & $<55$ \\
\hline
\end{tabular}

All analyses were conducted in R (v. 3.0.2) (R Core Team, 2013). Power-law, log-normal, normal, exponential, gamma, Weibull and log-logistic probability distributions were fit to the observed ice island size-frequency distributions at each temporal and spatial snapshot. Truncation of the dataset at $0.25 \mathrm{~km}^{2}$ was accounted for using the fitdistrplus, FAdist and poweRlaw $\mathrm{R}$ packages (Aucoin, 2015; Delignette-Muller et al., 2017; Gillespie, 2017). A comparison of the quality of the fitted distributions was conducted based on their individual Kolmogorov-Smirnov statistic using the truncgof R package (Wolter, 2015). 


\subsubsection{Meltwater dispersal}

The spatial dispersal of meltwater resulting from the drift and deterioration of the ice islands generated after each calving event was calculated based on surface area change between each successive observation in the CI2D3 Database and thickness change estimated using basal and surface ablation modelling. Initial thicknesses of $76 \pm 6(1 \sigma)$ and $182 \pm 16 \mathrm{~m}$ were assigned to the ice islands created from the 2010 and 2012 calving events (Münchow et al., 2014). The thickness of the 2008 PII was estimated to be $62.3 \pm 6.8 \mathrm{~m}$ based on the draft observed when it drifted over a mooring at $80.5^{\circ} \mathrm{N}$ on 11 August 2008 (H. Melling, unpublished data), and assigned values of $873 \mathrm{~kg} \mathrm{~m}^{-3}$ (Chapter 5) and $1025 \mathrm{~kg} \mathrm{~m}^{-3}$ for ice density $\left(\rho_{i}\right)$ and water density $\left(\rho_{w}\right)$, respectively. Thickness was back-calculated for all of the ice islands associated with the 2008 calving event that were observed prior to this date (i.e., between 13 July and 11 August 2008) with the following basal and surface ablation models.

Basal ablation $\left(M_{b}, \mathrm{~m} \mathrm{~d}^{-1}\right)$ was modeled by considering the turbulent exchange of heat across a flat plate (Weeks and Campbell, 1973). $M_{b}$ is related to the differential velocity $\left(\Delta \mathrm{u} ; \mathrm{m} \mathrm{s}^{-1}\right)$ between the ocean current and ice island drift, and the difference in temperature $\left(\Delta T\right.$; $\left.{ }^{\circ} \mathrm{C}\right)$ between the underlying ocean water and the melting point $\left(M_{p}\right)$ across its waterline $\mathrm{L}(\mathrm{m})$ with Equation 6.1.

$$
M_{b}=C \times \Delta \mathrm{u}^{0.8} \frac{\Delta T}{\mathrm{~L}^{0.2}}
$$

$C$ was assigned a value of $1.3 \times 10^{-5} \mathrm{~m}^{2 / 5} \mathrm{~s}^{-1 / 5}{ }^{\circ} \mathrm{C}^{-1}$ (Chapter 4). $M_{p}$ was calculated with Equation 6.2 , an empirical relationship that accounts for the influence of meltwater on the salinity of the iceocean boundary layer and, consequently, the melting point of the ice (Løset, 1993; Kubat et al., 2007).

$$
M_{P}=T_{f} \times e^{-0.19\left(T_{e}-T_{f}\right)}
$$


In Equation $6.2, T_{e}$ is the water temperature at the keel depth and $T_{f}$ is the far-field freezing temperature of ocean water at the same depth (Løset, 1993; Broström et al., 2009). $T_{f}$ is calculated with salinity (S: psu) and pressure (dbar) at the ice island keel depth (Fofonoff and Millard, 1983).

Equations 6.1 and 6.2 were forced with 5-day average ocean temperature and salinity from the $1 / 12^{\circ}$ resolution regional Arctic and Northern Hemisphere Atlantic configuration of the Nucleus for European Modelling of the Ocean (NEMO) v.3.4 ocean model (Madec and the NEMO team, 2015). $\Delta \mathrm{u}$ was set to $0.067 \mathrm{~m} \mathrm{~s}^{-1}$, the mean value associated with the modeled drift of 'PII-A' from the 2010 calving event. These data were provided by the CIS from an internal, unpublished study. The parameterization of $\Delta \mathrm{u}$ is a potential source of uncertainty for the $M_{b}$ calculations within the thinning model (Chapter 4). A sensitivity analysis on the dispersal of meltwater input after the 2008 calving event was conducted to illustrate the effect of varying the assigned value of $\Delta u$. For this sensitivity analysis, the assigned value of $\Delta u$ was adjusted by $1 \sigma\left(+0.047 \mathrm{~m} \mathrm{~s}^{-1}\right)$, as calculated from the same internal, unpublished study conducted by the CIS.

Surface ablation $\left(M_{s}, \mathrm{~m} \mathrm{~d}^{-1}\right)$ was calculated with a temperature index melt model, where a degree-day factor (DDF; $\mathrm{m}$ water equivalent (w.e.) ${ }^{\circ} \mathrm{C}^{-1} \mathrm{~d}^{-1}$ ) relates positive degree days (PDDs) $\left({ }^{\circ} \mathrm{C}\right)$ to an ablation magnitude (Eq. 6.3; Pellicciotti et al., 2005).

$$
M_{s}=\mathrm{DDF} \times \mathrm{PDD}
$$

A value of $6.4 \mathrm{~mm}$ w.e. ${ }^{\circ} \mathrm{C}^{-1} \mathrm{~d}^{-1}$ was assigned to the DDF parameter (Crawford et al., 2015). PDDs were calculated using hourly $2 \mathrm{~m}$ air temperature data from the global deterministic prediction system reforecasts (CGRF) dataset of the Canadian Centre for Meteorological and Environmental Prediction, Environment and Climate Change Canada) (Smith et al., 2014). The ocean and atmospheric data for the NEMO or CGRF grid cell where the ice island was located at the time of observation was used and the thinning of the concerned ice island was then hindcasted. The 
equations were run iteratively, so previous thinning was taken into account when determining the depth bin from which to extract $T_{e}$ and $S$. Keel depth was also corrected for adjustments in hydrostatic equilibrium after each change in thickness.

The thinning experienced between successive ice island observations was calculated with $M_{b}$ and $M_{s}$. The meltwater input was then calculated based on the volume lost due to thinning across the surface area of each ice island and the volume associated with decreases in surface area. Surface area loss was calculated between successive observations of a tracked ice island, or determined from unaccounted surface area based on the combined surface extents of daughter ice islands following a fracture event.

The areal extent of individual ice islands occasionally fluctuated due to satellite imagery artifacts and digitization uncertainty. Apparent increases in ice island volume were subtracted from previously calculated meltwater input to ensure that this extra volume was not double counted in the analysis. Therefore, extent fluctuations do not alter net freshwater input associated with individual calving events if they are completely documented. However, due to the relatively shorter time period over which the ice islands that originated from the 2012 calving event were monitored, these fluctuations can give the impression that a relatively large volume is added onto the ice islands. This situation arose for only $6 \%$ of the observed fracture events and $0.5 \%$ of the repeat observations of a single ice island that was monitored over time. The volume associated with these increases in surface extent were removed to provide a more realistic meltwater input scenario after the 2012 Petermann Glacier calving event.

Ice islands that ceased to be tracked in the CI2D3 Database were converted to meltwater. This would occur when an ice island fell below the $0.25 \mathrm{~km}^{2}$ areal extent threshold or became impossible to identify in SAR imagery. Meltwater volume and mass were calculated from ice 
volume loss assuming a $\rho_{i}$ of $873 \mathrm{~kg} \mathrm{~m}^{-3}$ (Chapter 5). These values were aggregated by 2-week time periods across a 50 x $50 \mathrm{~km}$ grid. The time-integrated meltwater flux was also calculated in $\mathrm{mSv}$ (milli-Sverdrups) across the same grid. To estimate meltwater discharge into the Baffin and Labrador currents, the meltwater flux was calculated after aggregating the meltwater input over larger regions of the study area. These three regions represented Petermann Fjord and Kane Basin, Baffin Bay, and the Labrador Sea/North Atlantic. For clarification, the term 'input' is used to refer to meltwater mass or volume and the term 'flux' to refer to the rate of meltwater input.

\subsection{Results}

\subsubsection{Overview of ice island drift and deterioration after Petermann Glacier calving events}

The drift trajectories of ice islands associated with the 2008, 2010 and 2012 Petermann Glacier calving events generally followed a route south through Nares Strait and continued along the western edge of Baffin Bay and the Labrador Sea. The 2008 PII calved on 13 July with an initial surface area of $30.0 \pm 1.9 \mathrm{~km}^{2}$. Four other ice islands ranging from $0.3 \pm 0.02$ to $5.39 \pm 0.3 \mathrm{~km}^{2}$ that most likely calved directly from the Petermann Glacier were also observed in the following days. The main ice island fractured twice in Nares Strait in August 2008 and was not observed to

fracture again until May 2009, though its surface area did decrease from $21.8 \pm 1.4 \mathrm{~km}^{2}$ to $11.0 \pm$ $0.7 \mathrm{~km}^{2}$. This ice island rapidly deteriorated in the spring of 2009 when 15 small ice islands were generated. The last ice island linked to the 2008 calving event was observed at the mouth of Frobisher Bay, southeastern Baffin Island in July 2009 (Fig. 6.4a). 


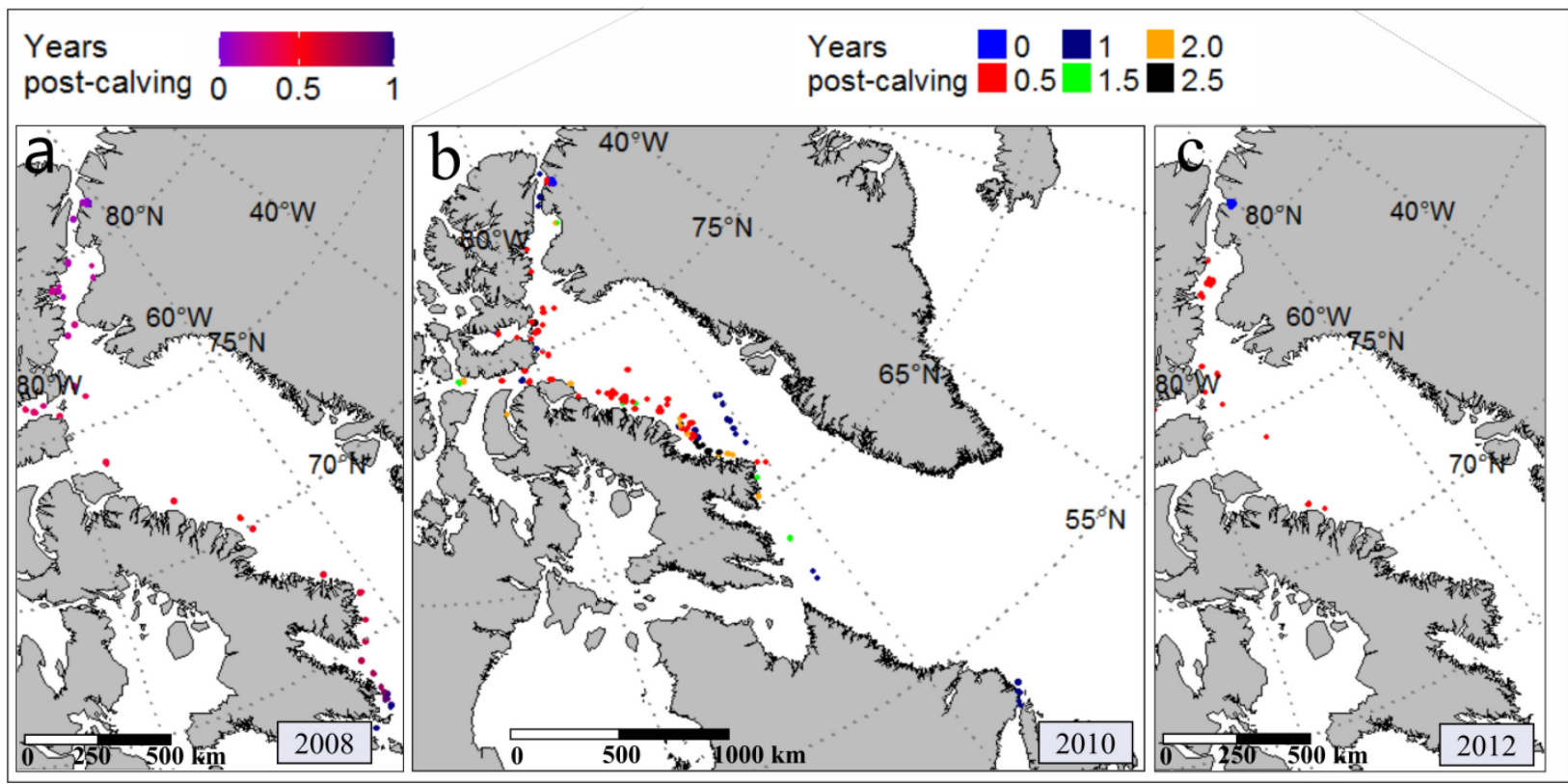

Figure 6.4: Ice island movement through the study area, colour coded by time since calving, for the a) 2008, b) 2010 and c) 2012 Petermann Glacier calving events. The 2010 and 2012 events are subset to represent the 'snapshots' of the ice island populations analyzed in the size distribution analysis. Ice islands associated with the 2008 event were monitored until all ice islands were no longer identifiable ( $1 \mathrm{yr}$ post-calving). The colouring used for the temporal snapshots in panels $b$ ) and c) correspond to the distributions shown in figures 6.5 and 6.6. Note the colour gradient scale used for the 2008 event. Ice islands associated with the 2010 and 2012 events were tracked for 2.5 and 0.5 years post-calving, respectively.

At $292.7 \pm 18.1 \mathrm{~km}^{2}$, the 2010 PII was an order-of-magnitude larger than the $2008 \mathrm{PII}$, and a far greater number of ice islands were generated through its break-up (Fig. 6.3b). Three smaller ice islands of $5.1 \pm 0.4,1.5 \pm 0.1$ and $2.6 \pm 0.2 \mathrm{~km}^{2}$ also calved on 5 August 2010 yielding a total loss of $20.0 \pm 0.1 \mathrm{Gt}$ of ice. The 2012 PII was initially $136.9 \pm 8.5 \mathrm{~km}^{2}$, or $21.8 \pm 0.1 \mathrm{Gt}$. The CI2D3 Database follows the 2010 and 2012 PIIs until December 2012. At this time, eight ice islands associated with the 2010 calving event remained in the study area. The combined surface area of these ice islands represented $10 \%$ of the original surface extent of this calving event. Twenty-one ice islands and $90 \%$ of the original surface extent of the 2012 calving event remained in the study area when monitoring ended (Fig. 6.4c). 


\subsubsection{Size distributions}

The ice island populations following the 2010 and 2012 Petermann Glacier calving events were consistently dominated by smaller ice island sizes. This is illustrated in the empirical cumulative density functions where ice island surface area (x-axis) is plotted against the cumulative probability of occurrence of that ice island size or $\mathrm{P}($ Surface area) (Figure 6.5 and 6.6). For example, the majority of ice islands were $<1 \mathrm{~km}^{2}$ for over $90 \%$ of the assessed temporal and spatial snapshots (Figs. 6.5 and 6.6). While smaller ice islands dominated the 2010 and 2012 size distributions, the same pattern was not seen for the 2008 dataset. This was due to the limited fracturing experienced by the main ice island, which retained a relatively large surface area as it drifted through the study area.

Based on the Kolmogorov-Smirnov test statistic comparison, the observed size-frequency distributions of all spatial and temporal snapshots were best represented by a power-law distribution. A log-logistic model provided the second best fit to the size-frequency distributions of over $90 \%$ of the tested snapshots. The log-normal distribution was less representative, in comparison to the power-law, log-logistic and Weibull distributions, of the observed sizefrequency distributions for all tested temporal and spatial snapshots. 


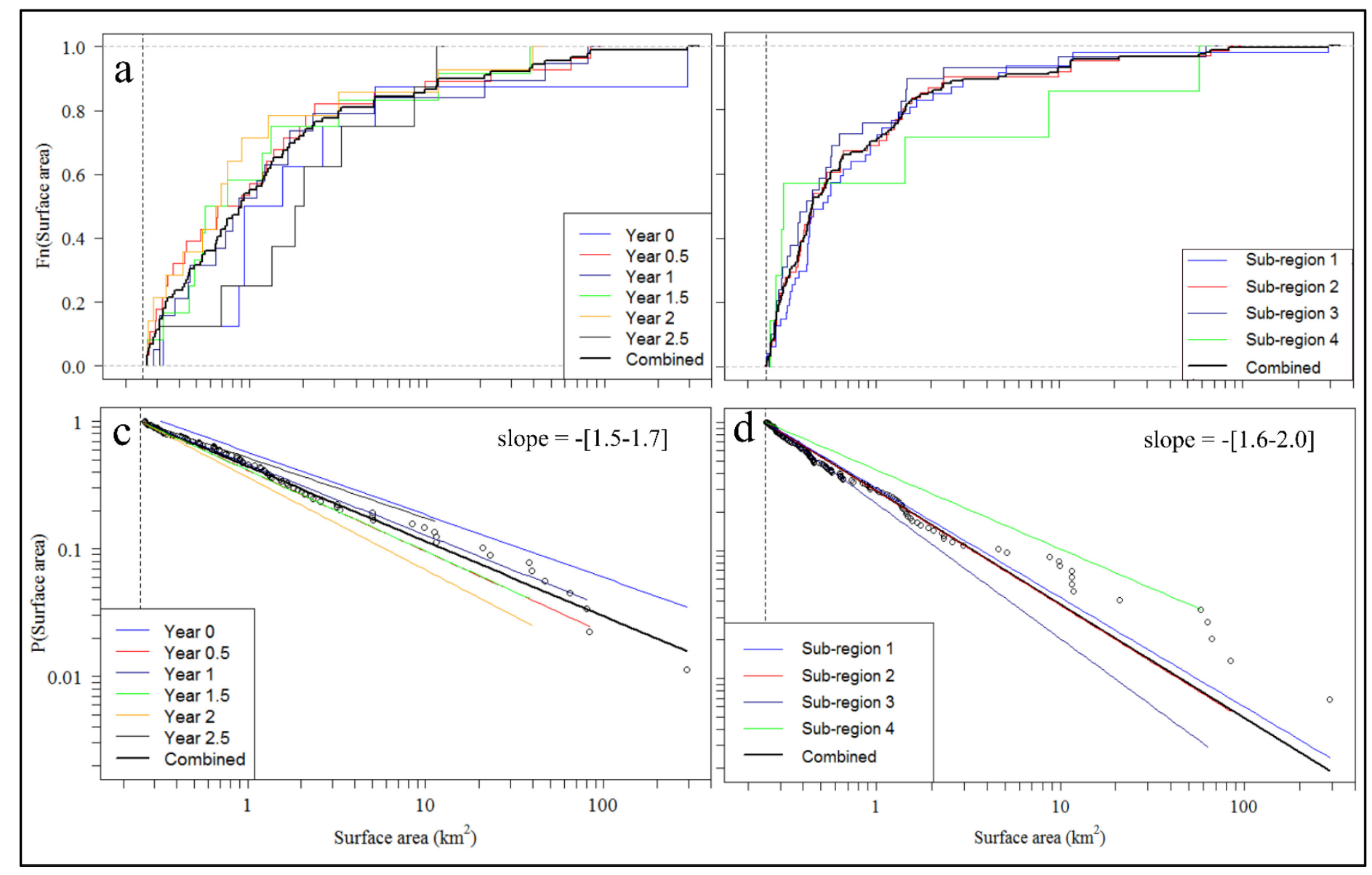

Figure 6.5: Ice island size distributions and distribution modelling (2010). Empirical cumulative size-frequency distributions of ice islands associated with the 2010 Petermann Glacier calving event by a) temporal and b) spatial snapshots. Power-law model fits for the $\log -\log$ complementary cumulative distribution function of ice island surface area for the same temporal and spatial snapshots are shown in c) and d), respectively. The snapshots were aggregated to create the 'combined' power-law distributions (open circles). The vertical dotted line in each panel represents the $0.25 \mathrm{~km}^{2}$ threshold under which ice islands were not regularly included in the Canadian Ice Island Drift, Deterioration and Detection (CI2D3) Database and therefore were not considered in this analysis. The colouring of panels a) and c) corresponds to that in Figure $6.4 \mathrm{~b}$. 


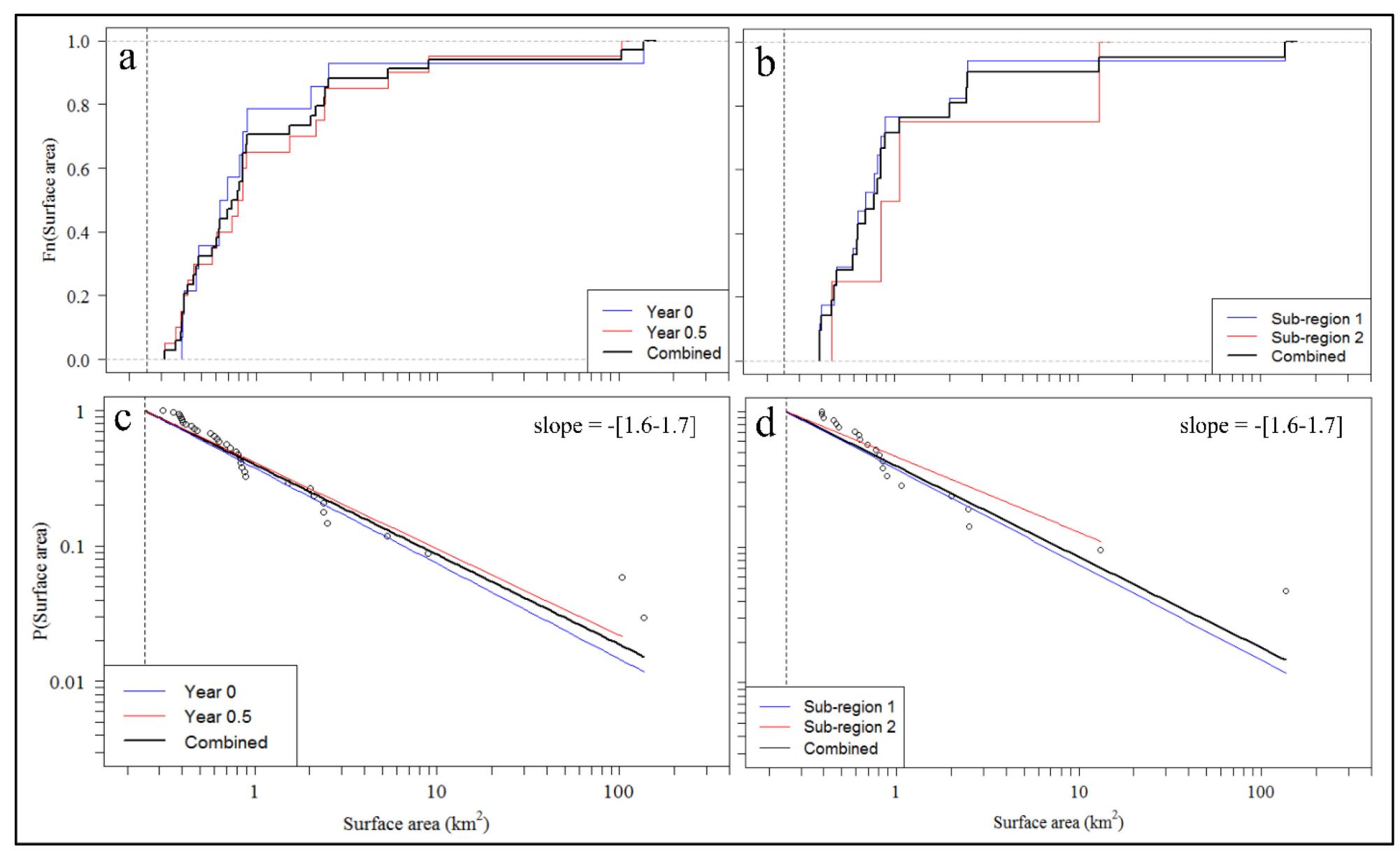

Figure 6.6: Ice island size distributions and distribution modelling (2012). Empirical cumulative size-frequency distributions of ice islands associated with the 2012 Petermann Glacier calving event by a) temporal and b) spatial snapshots. Power-law model fits for the $\log$ - log complementary cumulative distribution function of ice island surface area for the same temporal and spatial snapshots are shown in c) and d), respectively. The snapshots were aggregated to create the 'combined' power-law (open circles). The vertical dotted line in each panel represents the $0.25 \mathrm{~km}^{2}$ threshold under which ice islands were not regularly included in the Canadian Ice Island Drift, Deterioration and Detection (CI2D3) Database and therefore were not considered in this analysis. The colouring of panels a) and c) corresponds to that of Figure 6.4c. 
The slopes of the fitted power-law models for each of the temporal and spatial snapshots $(-2.1$ to -1.6) are shown in the complementary cumulative distribution function plots of figures 6.5 and 6.6 (panels $\mathrm{c}$ and $\mathrm{d}$ ). Here, $\mathrm{P}$ (surface area) refers to the percent of observations of the ice island surface area less than or equal to a given value. The mean slope of the power-law distributions fit to the 2010 snapshots was 1.7 with a standard deviation of 0.2 . The slopes associated with the power-law fits to the 2012 snapshots were very similar $(1.7 \pm 0.1)$.

\subsubsection{Meltwater dispersal}

Approximately $2.1 \mathrm{Gt}$ of freshwater was contained in the ice island that calved from the Petermann Glacier in 2008. The ice island that calved in 2010 contained almost ten times the amount of freshwater compared to the 2008 event. The initial ice island that calved in 2012 was less than half the extent of the 2010 ice island. However, its mass of approximately $22 \mathrm{Gt}$ was similar due to a much greater thickness. The magnitude of meltwater input into Nares Strait, Baffin Bay, and the Labrador Sea due to the deterioration of these three original ice islands is shown in Figure 6.7. It is noted that small ice islands $\left(<0.25 \mathrm{~km}^{2}\right)$ that were no longer monitored in the CI2D3 Database were included as meltwater in Figure 6.7, as per the analysis methods that were introduced in Section 6.3.3. The meltwater that is shown in Figure 6.7 represents 100, 93 and 16 $\%$ of the freshwater associated with the original ice islands that calved from the Petermann Glacier in 2008, 2010 and 2012, respectively. 


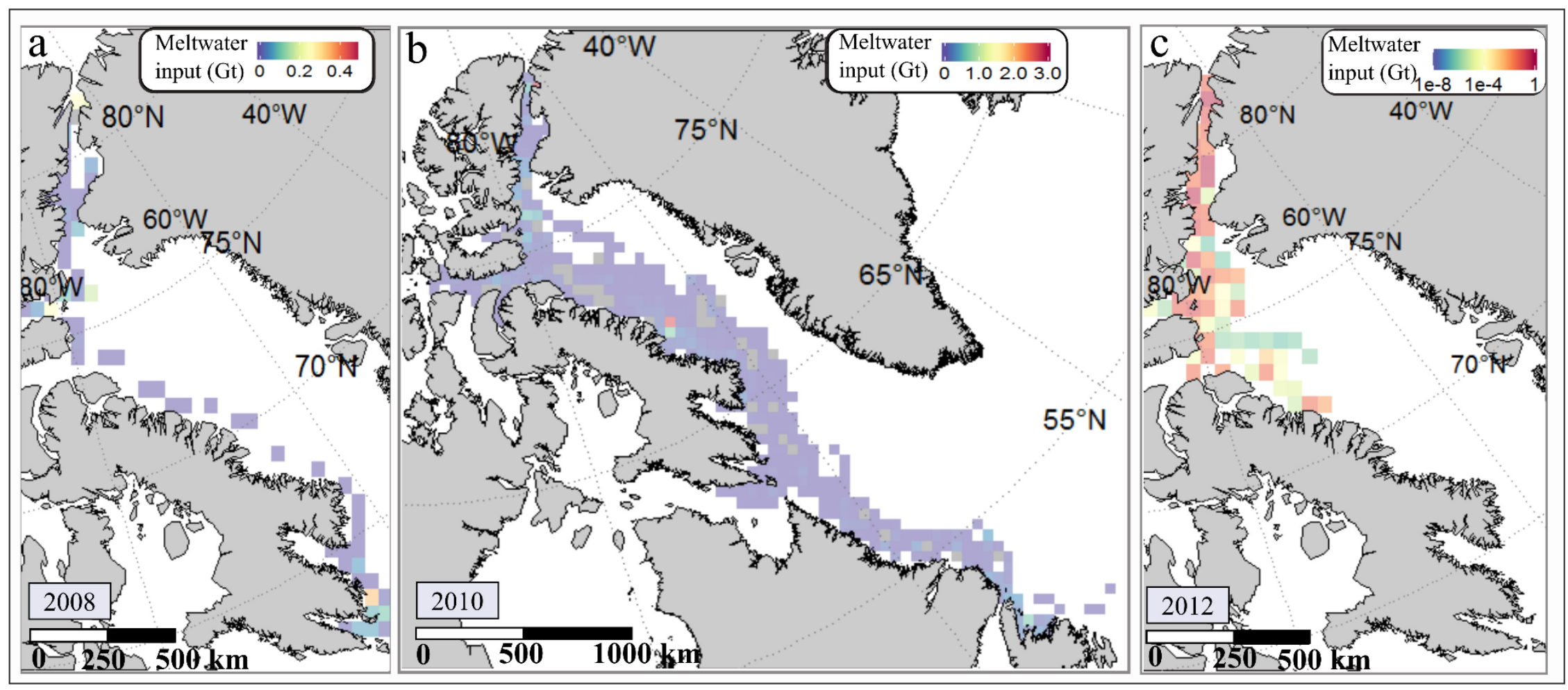

Figure 6.7: Spatial distribution of meltwater input, shown in gigatonnes (Gt), into the study area over the time period that the drift and deterioration of ice islands originating from the a) 2008 , b) 2010 and c) 2012 Petermann Glacier calving events were monitored. Ice islands associated with the 2008 event were monitored until all ice islands were no longer identifiable (1 year postcalving). Ice islands associated with the 2008 and 2012 events were tracked for 2.5 and 0.5 years post-calving, respectively. Note the change in colour scales between the panels and the logarithmic colour scale used for c). Locations where no ice islands were observed are denoted by the white background. Grey cells denote where fluctuation in ice island volume was calculated due to digitization uncertainty and caused unrealistic augmentation of solid ice volume. Small ice islands $\left(<0.25 \mathrm{~km}^{2}\right)$ that were no longer monitored in the CI2D3 Database are included as meltwater in the grid cell that they were last observed. 
A relatively large quantity of meltwater was input within and at the mouth of Petermann Fjord after each calving event (Fig. 6.7). The meltwater flux in the Petermann Fjord reached $0.3 \mathrm{mSv}$ in the first two weeks after the 2012 calving event, and $0.5 \mathrm{Gt}$ of meltwater was input at this location over the time that the associated ice islands were monitored. The meltwater flux in the fjord was seven times greater $(2.1 \mathrm{mSv})$ after the 2010 Petermann Glacier calving event. In total, $2.7 \mathrm{Gt}$ of meltwater input was calculated at this location following this calving event (Fig. 6.7).

Ice island grounding in the northwest portion of Baffin Bay and along the continental shelf of Baffin Island resulted in relatively high meltwater inputs at these locations. For example, meltwater fluxes of approximately $0.4 \mathrm{mSv}$ were observed in the late summer of 2011 in the grid cell associated with 'PII-B', an ice island that was grounded in this location for 15 months (Crawford et al., 2016). Increased meltwater input magnitudes and time-integrated fluxes also coincided with regions where ice islands fully deteriorated, or at least to the point that they were no longer tracked in the CI2D3 Database. For example, approximately $0.7 \mathrm{Gt}$, or $35 \%$ of the mass of the 2008 ice island was input at the mouth of Frobisher Bay following a large breakup event (Fig. 6.7a, lower right). Meltwater fluxes for individual grid cells in this region reached $0.1 \mathrm{mSv}$ during this time. Large meltwater inputs were also observed off southern Labrador and Newfoundland where many ice islands that originated from the 2010 calving event fully deteriorated.

The greatest flux of meltwater north of Baffin Bay was observed after the 2012 Petermann Glacier calving event. A meltwater flux of $0.7 \mathrm{mSv}$ was calculated for this area approximately 7 weeks after the July calving event. The greatest meltwater flux into the Baffin Bay $(0.5 \mathrm{mSv})$ and Labrador Sea/North Atlantic (0.8 mSv) regions occurred approximately 1 year following the 2010 calving event. 
The amount of meltwater input in a single $50 \mathrm{~km}^{2}$ grid cell varied by as much as $33 \%$ when the value assigned to $\Delta \mathrm{u}$ was varied by $+1 \sigma$. However, this relative difference was negatively correlated with the amount of meltwater input within the grid cell $(\mathrm{r}=-0.52, \mathrm{p} \leq 0.05)$. The impact of variation in $\Delta \mathrm{u}$ was therefore more influential, relatively speaking, when minimal surface area reduction was taking place and the majority of deterioration was a result of basal ablation. This is supported by a significant negative correlation between the relative difference in meltwater input and the surface area loss per grid cell $(\mathrm{r}=-0.32, \mathrm{p} \leq 0.05)$.

\subsection{Discussion}

\subsubsection{Size distributions}

Approximately $80 \%$ of ice islands in the spatial and temporal snapshots were $<10 \mathrm{~km}^{2}$ (Figs. 6.5 and 6.6). This supports previous findings that most mass will be contained within a few large ice islands while the ice island population will be dominated by smaller ice islands, which are difficult to detect in SAR imagery (Saper, 2011; Wesche and Dierking, 2015; Rackow et al., 2017). Therefore, these smaller ice islands, icebergs, bergy bits and growlers pose greater risks to offshore operations such as shipping and resource extraction (Saper, 2011). Icebergs charts are routinely produced in the North Atlantic where the resource extraction industry is active (Karlsen

et al., 2001). However, the spatial coverage of these charts does not extend into the Canadian Arctic, and only ice islands $>5 \mathrm{~km}$ in length are regularly included on regional sea ice charts generated by the CIS (CIS, 2005).

The finding that the size-frequency distributions of PIIs were best represented by a power-law model is informative for future predictions of the size-frequency distributions of ice hazards. The mean slope of the power-law distributions that were fit to the temporal and spatial snapshots was -1.7 for both the 2010 and 2012 calving events. This value is very close to that reported by 
Tournadre et al. (2016) $(-1.5 \pm 0.3)$ for the size-frequency distribution of Antarctic ice islands. This suggests that ice islands in both Polar Regions deteriorate through a complex set of fracture and fragmentation mechanisms and, that these processes occur across a range of ice island sizes (Tournadre et al., 2016; Kirkham et al., 2017). The power-law model representation also suggests that, similar to tidewater glacier and ice shelf calving, ice island deterioration is a form of 'brittle fragmentation' (Stern et al., 2016; Tournadre et al., 2016; Kirkham et al., 2017). This involves the stochastic propagation of cracks through a solid, as modelled by Spahn et al. (2014).

In contrast, Kirkham et al. (2017) and Tournadre et al. (2012) found that the size-frequency distribution of smaller icebergs located further from glacier calving sites was better represented by a log-normal model. Kirkham et al. (2017) explain that deterioration is increasingly dominated by a relatively small set of melt processes (e.g., forced convection, wave erosion) as icebergs travel away from source glaciers. Conversely, larger icebergs (and ice islands) are subject to a more complex set of deterioration processes (e.g., large-scale fracture, smaller-scale calving and ablation). This results in a wide range of ice island surface areas and a situation in which a lognormal model can display characteristics that are similar to a power-law model (Tournadre et al., 2016; Kirkham et al., 2017). Mathematically, log-normal models converge towards power-law models as the variation in the variable of interest (i.e., surface area) increases. The quadratic term in the log-normal density function is then minimized and the linear term correspondingly becomes more influential (Mitzenmacher, 2004; Tournadre et al., 2016). The finding that the power-law distribution provided the best fit for all temporal and spatial snapshots suggests that the complexity of deterioration processes to which the PIIs were subject did not substantially decrease over the study area or time period that they were monitored. 


\subsubsection{Meltwater dispersal}

While fracturing alters ice island size distributions, it also influences meltwater production. It causes further dispersal of meltwater as individual ice islands drift apart after a fracture event (Tournadre et al., 2012). It also increases the surface area to volume ratio, which will cause an ice island to be more susceptible to other meltwater generating deterioration processes (e.g., wave erosion) (Kirkham et al., 2017; Stern et al., 2017). The dispersal of meltwater with the drift and deterioration of icebergs and ice islands is often discussed in terms of the impact on fjord dynamics, local ocean properties and ocean circulation patterns (Stern et al., 2015; Enderlin et al., 2016; Wagner and Eisenman, 2017).

The strength of the Atlantic Meridional Overturning Circulation (AMOC) is of concern when considering the increasing freshwater flux from the Greenland Ice Sheet and potential consequences to global ocean circulation and energy transfers (Bamber et al., 2012; Gillard et al., 2016; Yang et al., 2016). In their modelling studies, Gillard et al. (2016), Wagner and Eisenman (2017) and Marson et al. (2018) note that direct meltwater input from the Greenland Ice Sheet or via iceberg deterioration could affect deep-water convection and potentially lead to AMOC disruption in the North Atlantic. However, a sustained freshwater flux anomaly of at least $7 \mathrm{mSv}$ in the North Atlantic is thought to be necessary to substantially slowdown the AMOC (Brunnabrend et al., 2015; Yang et al., 2016). (For reference, the Baffin Island Current transports $\sim 93 \mathrm{mSv}$ of liquid freshwater to the northern Labrador Sea (Curry et al., 2014).) This study shows meltwater fluxes rose by 0.5 and $0.8 \mathrm{mSv}$ in the Baffin Island and Labrador currents, respectively, after recent calving events at the Petermann Glacier. Therefore, while this meltwater was likely transported to the North Atlantic, fluxes of this magnitude will not independently have an adverse effect on the AMOC (Yang et al., 2016). However, such additions of meltwater do augment an 
already increasing meltwater flux from the Greenland Ice Sheet that concentrates in the Labrador Sea (Yang et al., 2016). Further ocean modelling studies that focus on the fate of iceberg meltwater input at the ocean surface should be conducted to understand its role in regional ocean circulation patterns (Gillard et al., 2016).

At a more local scale, large meltwater input magnitudes were calculated within Petermann Fjord after the 2008, 2010 and 2012 calving events and a maximum flux of $2.1 \mathrm{mSv}$ was reached after the 2010 calving event. A layer between $\sim 200$ and $500 \mathrm{~m}$ depth in Petermann Fjord is highly influenced by a meltwater plume from basal ablation at the grounding line of the glacier (Johnson et al., 2011), and meltwater resulting from iceberg deterioration will likely remain above this layer. Meltwater input from iceberg deterioration could affect the physical composition of surface waters in Greenland fjords by influencing fjord circulation and altering the availability of heat for further glacier melt (Enderlin et al., 2016; Moon et al., 2018). Further research on the relationship between the sources of freshwater input in Petermann Fjord (i.e., glacial discharge, iceberg deterioration and melt of the FIT), and subsequent melt rates of the FIT and icebergs with the fjord would be an interesting addition to this research subject.

Outside Petermann Fjord, an elevated meltwater input was seen to coincide with grounding 'hot spots' along the eastern coasts of Ellesmere, Devon and Baffin islands. For example, the deterioration of the grounded PII-B at $69^{\circ} \mathrm{N}$ off the east coast of Baffin Island contributed to a meltwater flux of approximately $0.4 \mathrm{mSv}$ in the corresponding grid cell. Stern et al. (2015) and Nacke (2016) are the few recent Arctic studies that focused on alterations to the physical and biological water column caused by ice island deterioration. The capacity for Arctic ice islands to impact the ocean ecosystem has previously been questioned due to the difference in ice island sizes and which nutrients limit productivity of the ocean ecosystem in the two Polar Regions. However, 
Smith et al. (2013) postulate that Arctic icebergs will impact the ocean column by promoting upwelling (as observed by Stern et al., 2015), decreasing stratification, increasing the delivery of nutrients, and increasing biological activity. Further in-situ observations are necessary to support these hypotheses.

\subsubsection{Meltwater analysis considerations}

The distribution of meltwater by single Antarctic ice islands throughout their drift in the Southern Ocean has been documented by Schodlok et al. (2006), Jansen et al. (2007), and Helly et al. (2011). Likewise, regional meltwater input in the Antarctic has been estimated with models (Gladstone et al., 2001; Martin and Adcroft, 2010; Bigg et al., 2014; Merino et al., 2016; Stern et al., 2016) and analysis of the large Antarctic datasets compiled by the National Ice Centre (Silva et al., 2006) and the French Centre National d'Etudes Spatiales (Tournadre et al., 2012, 2015, 2016). However, it has not yet been possible to calculate more accurate ablation rates and determine the location and magnitude of meltwater inputs over the full size range of Antarctic ice islands due to lineage connections only being available for those $>18.5 \mathrm{~km}$ in length (Merino et al., 2016). Lineage tracking within the CI2D3 database removes this constraint and allows the spatial distribution of meltwater input to be determined.

Uncertainty in estimation of the magnitude and location of deterioration/meltwater input is introduced by the time interval between observations, the manual digitization workflow used in generating the CI2D3 Database, the assumed thickness of the initial ice islands, and modelled thinning rates. In regards to the latter, a constant value was assigned to $\Delta \mathrm{u}$ when modelling $M_{b}$. In reality $\Delta \mathrm{u}$ will fluctuate due to, for example, wind forces, the presence of sea ice, or ice island grounding. It is recommended that field campaigns be designed to collect in-situ ice island drift and ocean current data to constrain the range of observed values of $\Delta u$ and calibrate equation 4.1 
for the drifting ice island case. Similar over- or under-estimation of meltwater input will arise from assigning inappropriately high or low values to the $C$ and DDF parameters when modelling $M_{b}$ and $M_{s}$, respectively.

The conversion of ice islands that ceased to be monitored before they fully deteriorated introduces uncertainty to the estimated spatial distribution of meltwater. Ice islands of this size could potentially drift across numerous grid cells before they fully deteriorate. The meltwater associated with these terminal ice islands represented approximately 30,50 and $40 \%$ of the total meltwater input calculated after the 2008, 2010 and 2012 calving events, respectively. It is possible that ice islands that ceased to be monitored would have drifted out of the grid cell in in which they were last observed. In this case, the spatial distribution of meltwater presented in Figure 6.7 would be, most likely, shifted towards more southern latitudes due to the dominant drift trajectory of ice island in this region (Newell, 1993). A future study could refine the meltwater input estimation by modeling the subsequent drift and deterioration of these small ice islands. The results of the size distribution analysis may also be used to estimate the mass associated with smaller versus larger fragments. The former would be more likely to fully deteriorate in the concerned grid cell while larger ice islands may drift into adjacent grid cells. Finally, it is also possible that an ice island will travel through more than one NEMO or CGRF grid cell between observations. This is a potential limitation when longer time intervals existed between observations of an individual ice island that was monitored over time.

\subsection{Conclusions}

The CI2D3 Database was used to conduct the first deterioration analysis for the full flux of ice islands generated after the 2008, 2010 and 2012 Petermann Glacier calving events. These investigations into the repercussions of Petermann Glacier calving events contribute to two 
dominant ice island research themes: ice islands as hazards and their role in meltwater dispersal from the major ice sheets. In regards to the latter, the spatial distribution of meltwater input was quantified with the drift and deterioration of the 2008 (2.1 Gt), 2010 (20 Gt) and 2012 (22 Gt) PIIs. The calculated meltwater fluxes were not large enough to weaken the AMOC. However, this meltwater contributes to the increasingly freshwater flux from the Canadian Arctic Archipelago and the Greenland Ice Sheet, which Yang et al. (2016) suggests could be weakening the stability of this important circulation system. Areas of augmented meltwater input after Petermann Glacier calving events included locations prone to grounding (i.e., the east coast of Baffin Island) and within Petermann Fjord. The impact of meltwater on ocean waters in relatively close proximity to ice islands has been more concertedly studied in the Antarctic than in the Arctic, and it is recommend that further research be dedicated to this topic in the Northern Hemisphere.

Hundreds of individual ice islands drifted through the eastern Canadian Arctic and sub-Arctic due to recurrent fracturing after initial calving events at the Petermann Glacier. It was found that the size-frequency distributions of PIIs were well represented by a power-law model. This was consistent across temporal and spatial snapshots, which suggests that fracturing caused by various mechanisms continued to be important deterioration process as time elapsed from the original calving event and as ice islands drifted through the study region. These results can inform shipping and natural resource extraction operations in the study area as to the likely distribution of ice hazard sizes after large Petermann Glacier calving events. The size-distribution analysis will also be of use for initializing general circulation models with iceberg components (Stern et al., 2016).

In total, the 2008, 2010 and 2012 PIIs were responsible for the greatest areal loss from any marine-terminating Greenland glacier monitored between 1999 and 2013 (Jensen et al., 2016). The 2010 calving event was almost double the annual ice discharge across the grounding line of the 
Petermann Glacier (Rignot and Steffen, 2008) and 40 times greater than yearly iceberg production (Higgins, 1991). Increased ocean and atmospheric temperatures and reduced sea ice extents will continue to destabilize ice shelves (Liu et al., 2015; Shroyer et al., 2017), and a calving event > $120 \mathrm{~km}^{2}$ in surface extent is anticipated to occur at the Petermann Glacier in the coming years (Münchow et al., 2016). The deterioration of the numerous ice islands generated after these large calving events will continue to be an important subject of study due to their hazard implications as well as their role in the distribution of freshwater from the major ice sheets. 


\section{Chapter 7 - Conclusions and directions for future research}

\subsection{Key findings and contributions}

The research presented in this thesis was designed to meet the overall aim of improving our understanding of ice island deterioration across a range of spatial and temporal scales using novel techniques and datasets. Studies were undertaken to examine the processes and consequences of thinning and large-scale areal deterioration (presented in chapters 4 and 6 , respectively). A third study was conducted to assess the ability of popular surveying techniques to detect small-scale areal deterioration (presented in Chapter 5). It is necessary to understand these limitations before meaningful deterioration magnitudes can be measured by future surveys. The conclusions drawn from these studies that are related to the five objectives of this thesis (see Section 1.2) are provided below.

Objective 1: quantify ice island surface and basal ablation rates and the contribution of these processes to thinning and overall deterioration

The surface and basal ablation of PII-A-1-f was monitored for one year with a series of ablation stakes, a sonic ranger, and the first sIPR to be successfully deployed on an ice island. The average basal ablation rate between November 2015 and September 2016 was $1.0 \mathrm{~cm} \mathrm{~d}^{-1}$. Surface ablation occurred between July and September 2016 at a rate of $1.6 \mathrm{~cm} \mathrm{~d}^{-1}$. Surface and basal ablation combined caused the volume of PII-A-1-f to decrease by $7 \%$. This was small in comparison to the $67 \%$ decrease caused by deterioration processes that reduced the areal extent of the ice island. The spatial variation in thinning $(\sigma=0.8 \mathrm{~m})$ was assessed with repeat $\mathrm{mIPR}$ transects. The presence of a linear ice feature with both surface and subsurface components was approximately $40 \mathrm{~m}$ thinner than the mean thickness recorded over the transect. This feature was influential in the ultimate fracture of the ice island. The susceptibility to fracture likely increased with the progressive 
decrease in the relative thickness of PII-A-1-f (Goodman et al., 1980), which occurs more rapidly when an ice island is grounded due to the increased differential velocity between the ice island and ocean currents (Jansen et al., 2007).

Objective 2: conduct the first field calibration of an ice island basal ablation model with field data

Chapter 4 reports on the first field calibration of the bulk heat transfer coefficient in a forced convection basal ablation model that is often utilized in iceberg and ice island deterioration models (Bigg et al., 1997; Gladstone et al., 2001; Martin and Adcroft, 2010; Ballicater Consulting, 2012; Merino et al., 2016; Wagner and Eisenman, 2017). This calibration utilized the thinning dataset collected by the sIPR and sonic ranger from November 2015 to September 2016 and a concurrent oceanographic dataset. The calibrated value of the bulk heat transfer coefficient $\left(C=1.3 \times 10^{-5}\right.$ $\mathrm{m}^{2 / 5} \mathrm{~s}^{-1 / 5}{ }^{\circ} \mathrm{C}^{-1}$ ) was very close to the value assigned in the ice island deterioration model developed for the CIS (Environment and Climate Change Canada) by Ballicater Consulting (2012) that is based on the work of White et al. (1980). The calibrated value was used in Chapter 6 to model the basal ablation of ice islands to quantify the spatial distribution of meltwater after large Petermann Glacier calving events.

Objective 3: quantify the precision of aerial photography with structure-from-motion processing and terrestrial laser scanning survey techniques and evaluate their ability to detect ice island deterioration

Chapter 5 presents the first comprehensive assessment of the limits of detection associated with TLS and SfM surveying to measure small-scale areal deterioration of iceberg and ice island sails. The study found that SfM processing provided superior capabilities with regards to deterioration detection through a comparative analysis of consecutively collected triplicate surveys with the M3C2 algorithm in CloudCompare (Lague et al., 2013). This study provides the DDT associated 
with four different survey scenarios defined by the survey technique and quality of GPS units deployed prior to surveying. A DDT of $0.4 \mathrm{~m}$ was associated with SfM surveying with high-quality GPS deployment. This was eight times better than that found for TLS surveying when using the same GPS units. The quality of the GPS unit was found to greatly influence the DDT associated with the surveying techniques. The DDT associated with SfM increased from 0.4 to $2.5 \mathrm{~m}$ when lower-quality tracking beacons were utilized. Future surveyors can now conduct iceberg and ice island mapping campaigns with an understanding of the limitations of these techniques for mass estimation and deterioration detection.

Objective 4: determine the optimal fit of statistical distributions to the size-frequency distributions of PIIs observed at different locations and time intervals after a calving event to infer dominate deterioration mechanisms

The research presented in Chapter 6 relied upon the CI2D3 Database, a dataset generated in WIRL at Carleton University in collaboration with the CIS using satellite remote sensing data (Crawford et al., 2018). Stern et al. (2016) identified the need to validate the use of power-law models to represent Arctic icebergs size distributions. The results in Chapter 6 fill this knowledge gap for the ice island case. A power-law model indeed did provide the most reasonable representation of PII size-frequency distributions. This suggested that fracture, resulting from a variety of fracture mechanisms, remained an important process by which the PIIs deteriorated regardless of time or distance from the original Petermann Glacier calving event (Tournadre et al., 2016; Kirkham et al., 2017). From this and the mean slope of -1.7 it was possible to infer that ice islands that originate from the FITs of northwest Greenland are similar to Antarctic ice islands in regards to their deterioration. 
Objective 5: quantify the spatial distribution of freshwater input in eastern Canadian waters from the drift and deterioration of Petermann ice islands

The study presented in Chapter 6 is the first to report the spatial dispersal of meltwater through eastern Canadian waters from ice island deterioration following recent calving events at the Petermann Glacier. The areal decrease of individual ice islands was monitored with the lineage information captured within the CI2D3 Database (Crawford et al., 2018). The meltwater produced through surface and basal ablation was modeled with a temperature index ablation model and forced convection ablation model, respectively. Augmented meltwater input was observed in Petermann Fjord, in the vicinity of grounded ice islands, and where ice islands ultimately deteriorated below the areal threshold set for monitoring. Meltwater fluxes of 2.1 and $0.4 \mathrm{mSv}$ were reached after the 2010 calving event in Petermann Fjord and in the 50 x $50 \mathrm{~km}$ grid cell associated with the grounded 'PII-B'. Such freshwater flux magnitudes are on the order of those observed in southern Greenland fjords (Enderlin et al., 2016) and have the potential to alter fjord circulation patterns (Enderlin et al., 2016; Moon et al., 2018) and ocean properties (Stern et al., 2015).

\subsection{Future research directions}

The work presented in this thesis highlights the importance of field data collection for ice island deterioration analyses. It is recommended that dedicated field campaigns of adequate duration be conducted for further data collection. Another recommendation of this thesis is to test and report the uncertainty associated with all deterioration detection observation methods. The key findings and contributions associated with meeting the research objectives of this thesis, summarized in Section 7.1, provide information that future research can build upon. New research questions have 
come to light based on the findings of this thesis. The sections below provide suggestions for future research regarding the topics covered in chapters 4-6.

\section{Grounded vs. drifting basal ablation model calibration}

Chapter 4 provides a calibration of the bulk heat transfer coefficient included in a forced convection basal ablation model that is often used in ice island deterioration models. This calibration was the first to be conducted with field data, which was collected from a grounded ice island in the eastern Canadian Arctic. Re-deployment of the sIPR system on a drifting ice island would provide an opportunity to determine if the coefficient needs to be assigned different values for grounded versus drifting ice islands.

The forced convection basal ablation model is sensitive to changes in differential velocity. However, such in-situ data are not known to exist for an ice island. Ice island drift velocity and ocean current field data collection would be a valuable contribution of future fieldwork. For example, this information would be utilized to better constrain the assignment of a differential velocity value in the basal ablation model associated with the spatial distribution of freshwater analysis in Chapter 6.

\section{Small-scale areal deterioration observation and analysis}

Chapter 5 provides quantitative and qualitative information to researchers who aim to measure ice island deterioration with repeat surveying. Following my protocol, it is now possible to determine what magnitude of ice island deterioration is meaningful after surveying campaigns. Along with concurrent environmental measurements, such observations are necessary for deterioration analyses and deterioration model calibration (e.g., the calibration conducted in Chapter 4). The survey workflow presented in Chapter 5 was dependent on a helicopter for GPS unit deployment and photograph acquisition. Future researchers may use UAVs for these steps. 
Researchers can choose the survey technique and GPS unit that are optimal for their research objective based on information provided in Chapter 5 regarding cost, deterioration detection thresholds, deterioration rates, and deterioration processes of interest.

\section{Model development-fracture}

The availability of the CI2D3 Database makes numerous analyses involving the drift and deterioration of ice islands possible. The research presented in Chapter 6 is the first conducted with this unique and comprehensive dataset. Fracturing is an important ice island deterioration process; however, its stochastic nature presents a large challenge for the incorporation of this deterioration mechanism into operational models or larger-scale general circulation models. Researchers undertaking this work will be able to utilize the CI2D3 Database to develop and validate fracture models. This model development can go forward with the knowledge that the size distributions of ice islands in both of the Polar Regions can be well represented by a power-law model.

The development of sidewall notches near a subsurface feature was observed in Chapter 4 and fracture was ultimately associated with this location. Literature regarding ice island deterioration has only occasionally mentioned sidewall notch development; however, future research into subsurface features (e.g., channels) and fracture may provide new insights into an important deterioration process.

\section{Improvements to spatial distribution of meltwater analysis}

Ice islands that fall below $0.25 \mathrm{~km}^{2}$ are not concertedly monitored in the CI2D3 Database. These small ice islands were converted to meltwater in the analysis presented in Chapter 6. It is likely that some of these ice islands drifted out of the $50 \times 50 \mathrm{~km}$ grid cell in which they were last

observed. Future studies could use improve this aspect of the analysis by modelling the small ice 
islands' drift and deterioration or estimating the mass of small versus large fragments with the results of the same chapter's size-distribution analysis. Smaller fragments would be more likely to totally deteriorate in the concerned grid cell, while larger ice islands would be more likely to drift into adjacent grid cells.

\section{Impacts of meltwater inputs}

The impact of freshwater dispersal due to meltwater input resulting from the deterioration of drifting ice islands is already a large topic of research in the Antarctic. Chapter 6 identified locations of augmented meltwater input due to the deterioration of PIIs during their southerly drift through eastern Canadian waters. One of these locations was Petermann Fjord itself. The impact of such freshwater input on fjord stratification is presently a topic of research in southern Greenland fjords. However, further research regarding the impact on the dynamics of Petermann Fjord after large calving events is warranted due to the difference in calving magnitude, calving rate and ocean circulation patterns at this northern location. Little is known at present regarding the impact of ice island meltwater input on the physical, chemical and biological composition of ocean waters once ice islands are adrift (or grounded) in Nares Strait, Baffin Bay, the Labrador Sea and further south in the North Atlantic. Further research into these potential impacts could focus on regions of augmented freshwater input identified in Chapter 6. This work would provide

further insight into differences between the two Polar Regions in regards to the consequences of meltwater on the properties of the surrounding ocean. 


\subsection{Summary}

Together, the studies presented in this thesis provide a framework for understanding the processes and implications of vertical deterioration (i.e., thinning through basal and surface ablation), small-scale areal deterioration (e.g., wave erosion) and large-scale areal deterioration (e.g., fracturing). This work meets the overarching aim of the thesis to improve the understanding of ice island deterioration through the development and use of novel techniques and datasets. Along with the various spatial scales mentioned above, the various techniques and datasets were also used to assess deterioration over a range of time scales.

The complementarity of remote sensing and field data collection is apparent throughout the research presented in this thesis. For example, it was beneficial to use the CI2D3 Database, generated through analysis of satellite SAR acquisitions, for the evaluation of ice island size distributions in Chapter 6. The vertical deterioration study presented in Chapter 4, however, relied upon a unique field dataset that recorded ice island ablation over a 1-year time span. Many studies that investigate ice island thinning have relied upon estimates of basal and surface ablation from satellite altimetry sensors and modeled oceanographic data. The thickness and oceanographic data collected in association with Chapter 4 made it possible to conduct the first calibration of the bulk heat transfer coefficient included in an ice island basal ablation model with field data. This is an important contribution to ice island deterioration modelling, and it was used in Chapter 6 to model the basal ablation of ice islands during the quantification of the spatial distribution of meltwater after Petermann Glacier calving events. In Chapter 4, thickness change could not have been put into context regarding the overall ice island deterioration without SAR-derived areal deterioration data. This reduction in areal extent was largely caused by fracturing. An infrequently discussed 
fracture mechanism was observed, and further research on sidewall notch formation and ultimate fracture is recommended.

This thesis provides important information regarding the deterioration of ice islands, "the most massive features known in the Arctic Ocean" (Jeffries, 1987), by studying Petermann ice islands located in eastern Canadian waters. Much of this work can also be applied to ice islands in the Southern Hemisphere. The presentation of this thesis comes at an important time, as a large Petermann Glacier calving event of approximately 120 to $150 \mathrm{~km}^{2}$ is anticipated and climate changes accelerate calving rates of floating ice tongues and ice shelves in both Polar Regions (Münchow et al., 2016). 


\section{References}

Aber JS, Marzolff I and Ries JB (2010) Small-format Aerial Photography. Amsterdam, The Netherlands: Elsevier. 266 pp.

Abramoff MD, Magalhaes PJ and Ram SJ (2004) Image processing with ImageJ. Biophotonics International 11(7): 36-42.

Agisoft LCC (2014) Photoscan User Manual: Professional Edition. Agisoft LCC: St. Petersburg, Russia. $154 \mathrm{pp}$.

Allison K, Crocker G, Tran H and Carrieres T (2014) An ensemble forecast model of iceberg drift. Cold Regions Science and Technology 108: 1-9. doi:10.1016/j.coldregions.2014.08.007.

Amundsen Science Data Collection (2016) CTD data collected by the CCGS Amundsen in the Canadian Arctic. Processed Data. Version 3. doi:AN/ccin12713. Archived at www.polardata.ca, https://doi.org/10.5884/12713. Accessed on 18 October 2016.

Annan AP (2009) Electromagnetic principles of ground penetrating radar. In Jol H (ed) Ground Penetrating Radar Theory and Applications. Oxford, United Kingdom: Elsevier. pp: 3-40.

Aoki S, Kobayashi R, Rintoul SR, Tamura T, Kusahara K (2017) Changes in water properties and flow regime on the continental shelf off the Adelie/George V Land coast, East Antarctica, after glacier tongue calving. Journal of Geophysical Research Oceans. 122: 6277-6294. doi:10.1002/2017JC012925.

ArcticNet (2017) Canadian Research Icebreaker CCGS Amundsen Sub - Bottom Profiler Field Procedures Manual. v. 3.1.67 pp.

Attema E, Davidson M, Snoeij P, Rommen B and Floury N (2010) Sentinel-1 mission overview. Proceedings of the 8th European Conference on Synthetic Aperture Radar. Aachen, Germany doi:0.1109/IGARSS.2009.5416921.

Aucoin F (2015) Package 'FAdist'. CRAN Repository. v. 2.2. https://github.com/tpetzoldt/FAdist.

Ballicater Consulting (2012) Ice Island and Iceberg Studies 2012. Contract Report No. 12-01. Ottawa, Canada: Canadian Ice Service, Environment Canada. 73 pp.

Bamber J, van den Broeke M, Ettema J, Lenaerts J and Rignot E (2012) Recent large increases in freshwater fluxes from Greenland into the North Atlantic. Geophysical Research Letters: 39(19). https://doi.org/10.1029/2012GL052552.

Barker A, Sayed M and Carrieres T (2004) Determination of iceberg draft, mass and crosssectional areas. Proceedings of the $14^{\text {th }}$ International Offshore and Polar Engineering Conference. Toulon, France. pp. 1-6. 
Barnhart T and Crosby B (2013) Comparing two methods of surface change detection on an evolving thermokarst using high-temporal-frequency terrestrial laser scanning, Selawik River, Alaska. Remote Sensing 5: 2813-2837. doi:10.3390/rs5062813.

Beedle MJ, Menounos B and Wheate R (2014) An evaluation of mass-balance methods applied to Castle Creek Glacier, British Columbia, Canada. Journal of Glaciology 60: 262-276. doi:10.3189/2014JoG13J091.

Belkin IM and Kessel SA 14. Russian drifting stations on Arctic ice islands. In Copland L and Mueller D (eds) Arctic Ice Shelves and Ice Islands. Dordrecht, Netherlands: Springer. pp. 367394. doi:10.1007/978-94-024-1101-0_14.

Bhardwaj A, Sam L, Akanksha Martín-Torres FJ and Kumar R (2016) UAVs as remote sensing platform in glaciology: Present applications and future prospects. Remote Sensing of the Environment 175: 196-204. doi:10.1016/j.rse.2015.12.029.

Bigg GR, Marsh R, Wilton D and Ivchenko V (2014). B31-a giant iceberg in the Southern Ocean. Ocean Challenge 20: 32-34.

Bigg GR, Wadley MR, Stevens DP and Johnson JA (1997) Modelling the dynamics and thermodynamics of icebergs. Cold Regions Science and Technology 26: 113-135.

Bouhier N, Tournadre J, Rémy F and Gourves-Cousin R (2017) Melting and fragmentation laws from the evolution of two large southern ocean icebergs. The Cryosphere Discussions. In review. doi:10.5194/tc-2017-208.

Braithwaite RJ (1990) Positive degree-day factors for ablation on the Greenland Ice Sheet studied by energy-balance modelling. Journal of Glaciology 41(137): 153-160.

Broström G, Melsom A, Sayed M and Kubat I (2009) Iceberg Modeling at Met. No: Validation of Iceberg Model. Report 17/2009. Blindern, Norway: Norwegian Meteorological Institute. $36 \mathrm{pp}$.

Brun F, Buri P, Miles ES, Wagnon P, Steiner J, Berthier E, Ragettli S, Kraaijenbrink P, Immerzeel WW and Pellicciotti F (2016) Quantifying volume loss from ice cliffs on debris-covered glaciers using high-resolution terrestrial and aerial photogrammetry. Journal of Glaciology 62(234): 1-12. doi:10.1017/jog.2016.54.

Brunnabend S-E, Schröter J, Rietbroek R and Kusche J (2015) Regional sea level change in response to ice mass loss in Greenland, the West Antarctic and Alaska. Journal of Geophysical Research: Oceans 120(11): 7316-7328. doi.org/10.1002/2015JC011244.

Budd WF, Jacka TH and Morgan VI (1980) Antarctic iceberg melt rates derived from size distributions and movement rates. Annals of Glaciology 1: 103-112.

Budge JS and Long DG (2018) A comprehensive database for Antarctic iceberg tracking using scatterometer data. IEEE Journal of Selected Topics in Applied Earth Observations and Remote Sensing 11(2): 434-442. doi:10.1109/JSTARS.2017.2784186. 
BYU/NIC (2017) Consolidated Database. v. 1.2. Available online: www.scp.byu.edu/iceberg. Accessed on 14 May 2018.

Campbell Scientific (2016) Rugged acoustic distance sensor. 2 pp. https://s.campbellsci.com/documents/ca/product-brochures/sr50a_br.pdf.

Canatec (2015) Ice Drift Beacons. Specifications sheet. Canatec and Associates International Ltd., Calgary, Canada. 2 pp.

Canty A (2002) Resampling methods in R: The boot package. $R$ News. Vienna, Austria: R Foundation for Statistical Computing. pp: 2-7.

Carroll D, Sutherland DA, Shroyer EL, Nash JD, Catania GA and Stearns LA (2015) Modeling Turbulent subglacial meltwater plumes: Implications for fjord-scale buoyancy-driven circulation. Journal of Physical Oceanography 45(8): 2169-2185. doi:10.1175/JPO-D-150033.1 .

C-CORE (2005) Characterization of Ice-Free Season for Offshore Newfoundland. Report R-04091-341 V2.0. Prepared for C-NOFB. St. John's, Canada: C-CORE and Ian Jordaan and Associates. $50 \mathrm{pp}$.

C-CORE 2017 Field Program (2017) Available online: https://www.ccore.ca/2017FieldProgram. Accessed on 18 January 2018.

CIS (Canadian Ice Service) (2005) Manual of Standard Procedures for Observing and Reporting Ice Conditions. Ottawa, Canada: Canadian Ice Service, Environment Canada. 146 pp.

Cloud Compare (2015) 2.5D Volume. CloudCompareWiki. Available online: http://www.cloudcompare.org/doc/wiki/index.php?title $=2.5 \mathrm{D}$ _Volume. Accessed on 8 September 2016.

Cloud Compare (n.d.) Cloud Compare User Manual (v. 2.6.1). 181 pp.

Chernick MR and LaBudde RA (2011) An Introduction to Bootstrap Methods with Applications to $R$. Hoboken, United States: Wiley. $216 \mathrm{pp}$.

Cook S, Rutt IC, Murray T, Luckman A, Zwinger T, Selmes N, Goldsack A and James TD (2014) Modelling environmental influences on calving at Helheim Glacier in eastern Greenland. The Cryosphere 8: 827-841. doi:10.5194/tc-8-827-2014.

Copland L, Mortimer CA, White A, Richer-McCallum M and Mueller D (2017) Factors contributing to recent ice shelf losses. In Copland L and Mueller D (eds) Arctic Ice Shelves and Ice Islands. Dordrecht, Netherlands: Springer. pp. 263-286.

Crawford A (2013) Ice Island Deterioration in the Canadian Arctic: Rates, Patterns and Model Evaluation. MSc Thesis. Ottawa, Canada: Department of Geography and Environmental Studies, Carleton University. 140 pp. 
Crawford AJ, Crocker G, Mueller D, Desjardins L, Saper R and Carrieres T (2018) The Canadian Ice Island Drift Deterioration and Detection (CI2D3) Database. Journal of Glaciology. doi: 10.1017/jog.2018.36.

Crawford A, Desjardins L, Saper R and Mueller D (2017) Canadian Ice Island Drift, Deterioration and Detection (CI2D3) Database Documentation V1.0. Project documentation. Ottawa, Canada: Water and Ice Research Lab, Department of Geography and Environmental Studies Carleton University. $20 \mathrm{pp}$.

Crawford A, Mueller DR, Humphreys E, Carrieres T and Tran H (2015) Surface ablation model evaluation on a drifting ice island in the Canadian Arctic. Cold Regions Science and Technology 110: 170-182. doi: 10.1016/j.coldregions.2014.11.011.

Crawford A, Wadhams P, Wagner T, Stern A, Abrahamsen P, Church I, Bates R and Nicholls KW (2016) Journey of an Arctic ice island. Oceanography 29(2). https://doi.org/10.5670/oceanog.2016.30.

Crocker G, Carrieres T and Tran H (2013) Ice island drift and deterioration forecasting in Eastern Canada. Proceedings of the $22^{\text {nd }}$ International Conference on Port and Ocean Engineering Under Arctic Conditions. Espoo, Finland. POAC13-166.

Crocker G, English J, McKenna R and Gagnon R (2004) Evaluation of bergy bit populations on the Grand Banks. Cold Regions Science and Technology 38(2-3): 239-250. doi:10.1016/j.coldregions.2003.12.001.

Crocker G, Sazidy M, Mueller D and Smith J (2017). A computationally efficient finite element model to simulate large scale fracture in ice island. Oral presentation. International Arctic Change Conference. Quebec, Canada.

Curry B, Lee CM, Petrie B, Moritz RE and Kwok R (2014) Multiyear volume, liquid freshwater and sea ice transports through Davis Strait, 2004-10. Journal of Physical Oceanography 44: 1245-1266. doi.org/10.1175/JPO-D-13-0177.1.

De Abreu R, Flett D, Scheuchl B and Ramsay B (2003) Operational sea ice monitoring with RADARSAT-2-a glimpse into the future. Proceedings of the IEEE International Geoscience and Remote Sensing Symposium. pp. 1308-1310.

Delignette-Muller M-L, Dutang C, Pouillot R, Denis J-B and Siberchicot A (2017) Package 'fitdistrplus'. CRAN Repository. v. 1.0-9. https://lbbe.univ-lyon1.fr/fitdistrplus.html.

Desjardins L, Crawford A, Saper R, Shepherd J, Mueller DR and Schaad C (2018) Canadian Ice Island Drift, Deterioration and Detection (CI2D3) Database. Ottawa, Canada: Water and Ice Research Laboratory, Carleton University.

Diemand D, Nixon WA and Lever JH (1987) On the splitting of icebergs: natural and induced. Proceedings of the $6^{\text {th }}$ International Offshore Mechanical and Arctic Engineering Symposium. Houston, United States. pp. 1-9. 
Divine DV, Pedersen CA, Karlsen TI, Aas HF, Granskog MA, Hudson SR and Gerland S (2016) Photogrammetric retrieval and analysis of small scale sea ice topography during summer melt. Cold Regions Science and Technology 129: 77-84.

Doerry AW and Dickey FM (2004) Synthetic aperture radar. Optics and Photonics News 15(11): 28-33. doi:10.1364/OPN.15.11.000028.

Dowdeswell JA and Bamber JL (2007) Keel depths of modern Antarctic icebergs and implications for sea-floor scouring in the geological record. Marine Geology 243(1-4): 120131. doi:10.1016/j.margeo.2007.04.008.

Duprat LP, Bigg GR and Wilton DJ (2016) Enhanced Southern Ocean marine productivity due to fertilization by giant icebergs. Nature Geoscience: 1-3. https://doi.org/10.1038/NGEO2633.

Eisen B (2012) Acoustic Mapping of a Moving Iceberg in the Canadian Arctic. BEng. Thesis. Fredricton, Canada: University of New Brunswick. 69 pp.

El-Tahan M, Venkatesh S and El-Tahan H (1987) Validation and quantitative assessment of the deterioration mechanisms of Arctic icebergs. Journal of Offshore Mechanics and Arctic Engineering 109: 102-108.

Enderlin EM, Carrigan CJ, Kochtitzky WH, Cuadros A, Moon T and Hamilton GS (2018) Greenland iceberg melt variability from high-resolution satellite observations. The Cryosphere 12:565-575. doi:10.5194/tc-2017-185.

Enderlin EM and Hamilton GS (2014) Estimates of iceberg submarine melting from highresolution digital elevation models: application to Sermilik Fjord, East Greenland. Journal of Glaciology 60(224): 1084-1092. doi:10.3189/2014JoG14J085.

Enderlin EM, Hamilton GS, Straneo F and Sutherland DA (2016) Iceberg meltwater fluxes dominate the freshwater budget in Greenland's iceberg-congested glacial fjords. Geophysical Research Letters. doi:10.1002/2016GL070718.

Enderlin EM, Howat IM, Jeong S, Noh M-J, van Angelen JH and van den Broeke MR (2014) An improved mass budget for the Greenland ice sheet. Geophysical Research Letters 41(3), 866872. doi:10.1002/2013GL059010.

Falkner KK, Melling H, Munchow AM, Box JE, Wohlleben T, Johnson HL, Gudmandsen P, Samelson R, Copland L, Steffen K, Rignot R and Higgins AK (2011) Context for the recent massive Petermann Glacier calving event. EOS 92(14): 117-119.

Fissel DB (1982) Tidal currents and inertial oscillations in northwestern Baffin Bay. Arctic 35(1): 201-210.

Fletcher T, Budge J, Robinson E, Prigmore E, Hill J, Madsen N, Reeves S, Stuart K, Lambert B, Ballantyne J, Long DG (2016) The Antarctic Iceberg Tracking Database. http://www.scp.byu.edu/data/iceberg/databasel.html 
Fofonoff NP and Millard RC (1983) Algorithms for Computation of Fundamental Properties of Seawater. Technical Papers in Marine Science Vol. 44. Paris, France: UNESCO.

Foldvik A, Gammelsrød T and Gjessing Y (1980) Measurements of the radiation temperature of Antarctic icebergs and the surrounding surface water. Annals of Glaciology 1: 19-22. doi:10.3189/S026030550001689X.

Fonstad MA, Dietrich JT, Courville BC, Jensen JL and Carbonneau PE (2013) Topographic structure from motion: a new development in photogrammetric measurement. Earth Surface Processes and Landforms 38(4): 421-430. doi:10.1002/esp.3366.

Forrest AL, Hamilton AK, Schmidt VE, Laval BE, Mueller DR, Crawford A, Bucker S and Hamilton T (2012) Digital terrain mapping of Petermann Ice Island fragments in the Canadian High Arctic. Proceedings of the the $21^{\text {st }}$ IAHR International Symposium on Ice. Dalian, China. pp. 710-721.

Fried MJ, Catania GA, Bartholomaus TC, Duncan D, Davis M, Stearns LA, Nash J, Shroyer E and Sutherland D (2015) Distributed subglacial discharge drives significant submarine melt at a Greenland tidewater glacier: Terminus melt from distributed discharge. Geophysical Research Letters 42(21): 9328-9336. doi:10.1002/2015GL065806.

Fuglem M and Jordaan I (2017) Risk analysis and hazards of ice islands. In Copland L and Mueller D (eds) Arctic Ice Shelves and Ice Islands. Dordrecht, Netherlands: Springer. pp. 395-415. doi:10.1007/978-94-024-1101-0_15.

Fugro (2014) Integrated 3D iceberg mapping brochure. Leidschendam, The Netherlands: Fugro. $2 \mathrm{pp}$.

Gantert S, Kern A, Düring, R, Janoth J, Petersen L and Herrmann J (2013) The future of X-band SAR: TerraSAR-X Next Generation and WorldSAR Constellation. Proceedings of the AsiaPacific Conference on Synthetic Aperture Radar. Tsukuba, Japan. TU1.R1.4.

Gillard LC, Hu X, Myers PG and Bamber JL (2016) Meltwater pathways from marine terminating glaciers of the Greenland Ice Sheet. Geophysical Research Letters 43(20): 10,873-10,882. doi:10.1002/2016GL070969.

Gillespie C (2017) Package "poweRlaw" - Analysis of heavy tailed distributions. CRAN repository. v. 0.70.1. https://github.com/csgillespie/poweRlaw.

Girardeau-Montaut D. No Date. CloudComare v2.6.1 User manual. 181 pp. http://www.cloudcompare.org/doc/qCC/CloudCompare\%20v2.6.1\%20$\% 20$ User\%20manual.pdf.

Girod L, Nuth C, Kääb A, Etzelmüller B and Kohler J (2017) Terrain changes from images acquired on opportunistic flights by SfM photogrammetry. The Cryosphere 11: 827-840. doi:10.5194/tc-11-827-2017. 
Gladstone RM, Bigg GR and Nicholls KW (2001) Iceberg trajectory modeling and meltwater injection in the Southern Ocean. Journal of Geophysical Research 106(C9): 19903-19915.

Goodman DJ, Wadhams P and Squire VA (1980) The flexural response of a tabular ice island to ocean swell. Annals of Glaciology 1(1): 23-27.

Haas C (2012) Distribution and Thickness of Different Sea Ice Types and Extreme Ice Features in the Beaufort Sea. Field Report for the Beaufort Regional Environmental Assessment. Edmonton, Canada: University of Alberta.

Haas C and Druckenmiller M (2009) Ice thickness and roughness measurements. In Eicken H, Gradinger R, Salganek M, Shirasawa K, Perovich D and Leppäranta M. (eds) Field techniques for Sea Ice Research. Fairbanks, United States: University of Alaska Press. 49-117. 9 pp.

Habib AF, Ghanma MS and Tait M (2004) Integration of LIDAR and photogrammetry for close range applications. International Archives of Photogrammetry, Remote Sensing and Spatial Information Sciences 35: 1045-1050.

Halliday EJ, King T, Bobby P, Copland L and Mueller DR (2012) Petermann Ice Island "A" survey results, offshore Labrador. Proceedings of the Arctic Technology Conference. Houston, United States. OTC 23714.

Hamilton AK, Forrest AL, Crawford A, Schmidt V, Laval BE, Mueller DR, Brucker S and Hamilton T (2013) Project ICEBERGS. Technical report. Ottawa, Canada: Canadian Ice Service, Environment Canada. 36 pp.

Hamley TC and Budd WF (1986) Antarctic iceberg distribution and dissolution. Journal of Glaciology 32(111): 242-251.

Held D, Levinson J, Thrun S and Savarese S (2014) Combining 3D shape, color, and motion for robust anytime tracking. Proceedings of Robotics: Science and systems. Berkeley, United States.

Hellmer HH and Olbers DJ (1989) A two-dimensional model for the thermohaline circulation under an ice shelf. Antarctic Science 1(04): 325-336. doi:10.1017/S0954102089000490.

Helly JJ, Kaufmann RS, Stephenson GR and Vernet M (2011) Cooling, dilution and mixing of ocean water by free-drifting icebergs in the Weddell Sea. Deep Sea Research Part II: Topical Studies in Oceanography 58(11): 1346-1363.

Henderson FM and Lewis JL (1998) Principles and Applications of Imaging Radar. Hoboken, United States: John Wiley and Sons, Inc. 866 pp.

Herdes E, Copland L, Danielson B and Sharp M (2012) Relationships between iceberg plumes and sea-ice conditions on northeast Devon Ice Cap, Nunavut, Canada. Annals of Glaciology 53(60): 1-9. doi:10.3189/2012AoG60A163. 
Herdman HFP (1959) Early discoverers XII: Some notes on sea ice observed by Captain James Cook, RN, during his circumnavigation of Antarctica, 1772-75. Journal of Glaciology 3(26): 534-541.

Higgins AK (1989) North Greenland ice islands. Polar Record 25(154): 207-212.

Higgins AK (1991) North Greenland glacier velocities and calf ice production. Polarforschung 60(1): 1-23.

Hill EA, Carr JR and Stokes CR (2017) A review of recent changes in major marine-terminating outlet glaciers in Northern Greenland. Frontiers in Earth Science 4. doi:10.3389/feart.2016.00111.

Hill BT, Ruffman A and Ivany K (2008) Historical data added to the Grand Banks Iceberg Database. Proceedings of the International Conference on Performance of Ships and Structures in Ice. Banff, Canada. ICETECH08-109-R0.

Hogg A and Gudmundsson GH (2017) Impacts of the Larsen-C Ice Shelf calving event. Nature Climate Change 7: 540-542.

Holland DM and Jenkins A (1999) Modeling thermodynamic ice-ocean interactions at the base of an ice shelf. Journal of Physical Oceanography 29(8): 1787-1800.

Hubbard B and Glasser NF (2005) Field Techniques in Glaciology and Glacial Geomorphology. West Sussex, United Kingdom: John Wiley \& Sons Ltd. 420 pp.

Hulth J (2010) Using a draw-wire sensor to continuously monitor glacier melt. Journal of Glaciology 56(199):922-924.

IOC, SCOR and IAPSO (2010) The international thermodynamic equation of seawater - 2010: Calculation and use of thermodynamic properties. Manuals and Guides No. 56, Paris, France: Intergovernmental Oceanographic Commission, UNESCO. 196 pp.

IPCC (2014) Climate Change 2013: The Physical Science Basis. Working Group I contribution to the Fifth Assessment Report of the Intergovernmental Panel on Climate Change. New York, United States: Cambridge University Press. 1535 pp.

Jacka TH and Giles AB (2007) Antarctic iceberg distribution and dissolution from ship-based observations. Journal of Glaciology 53(182): 341-356.

Jackson RH, Shroyer EL, Nash JD, Sutherland DA, Carroll D, Fried MJ, Catania GA, Bartholomaus TC and Stearns LA (2017) Near-glacier surveying of a subglacial discharge plume: Implications for plume parameterizations. Geophysical Research Letters 44(13): 6886-6894. doi:10.1002/2017GL073602.

Jansen D, Sandhäger H and Rack W (2005) Model experiments on large tabular iceberg evolution: ablation and strain thinning. Journal of Glaciology 51(174): 1-11. 
Jansen D, Schodlok M and Rack W (2007) Basal melting of A-38B: A physical model constrained by satellite observations. Remote Sensing of Environment 111(2-3): 195-203. doi:10.1016/j.rse.2007.03.022.

Javernick L, Brasington J and Caruso B (2014) Modeling the topography of shallow braided rivers using structure-from-motion photogrammetry. Geomorphology 213: 166-182.

Jeffries MO (1992) Arctic ice shelves and ice islands: Origin, growth and disintegration, physical characteristics, structural-stratigraphic variability, and dynamics. Reviews of Geophysics 30: 245-267.

Jeffries MO and Sackinger WM (1989a) Airborne SAR characteristics of Arctic ice shelves and multiyear landfast sea ice, and the detection of massive ice calvings and ice islands. Proceedings of the $12^{\text {th }}$ Canadian Symposium on Remote Sensing - Remote Sensing: An Economic Tool for the Nineties. International Geoscience and Remote Sensing Symposium. Vancouver, Canada. 4: 2715-2718.

Jeffries MO and Sackinger WM (1989b) Analysis and interpretation of an airborne synthetic aperture radar image of "Hobson's Choice" Ice Island. Proceedings of the $10^{\text {th }}$ International Conference on Port and Ocean Engineering Under Arctic Conditions. Luleå, Sweden. 10 pp.

Jeffries MO and Sackinger WM (1990) Ice island detection and characterization with airborne synthetic aperture radar. Journal of Geophysical Research 95(C4): 5371-5377.

Jeffries MO, Sackinger WM and Shoemaker HD (1987) Geometry and physical properties of ice islands. Proceedings of the $9^{\text {th }}$ International Conference on Port and Ocean Engineering Under Arctic Conditions. Fairbanks, United States. 1: 69-83.

Jensen TS, Box JE and Hvidberg CS (2016) A sensitivity study of annual area change for Greenland ice sheet marine terminating outlet glaciers: 1999-2013. Journal of Glaciology 62(231): 72-81. https://doi.org/10.1017/jog.2016.12.

Johnson HL, Münchow A, Falkner KK and Melling H (2011) Ocean circulation and properties in Petermann Fjord, Greenland. Journal of Geophysical Research 116(C1): C01003.

Joyal G, Lajeunesse P, Morissette A and Bernatchez P (2016) Influence of lithostratigraphy on the retreat of an unconsolidated sedimentary coastal cliff (St. Lawrence estuary, eastern Canada). Earth Surface Processes and Landforms 41(8): 1055-1072. doi:10.1002/esp.3886.

Kamintzis JE, Jones JPP, Irvine-Fynn TDL, Holt TO, Bunting P, Jennings SJA, Porter PR and Hubbard B (2017) Assessing the applicability of terrestrial laser scanning for mapping englacial conduits. Journal of Glaciology 1-12. doi:10.1017/jog.2017.81.

Karlsen HG, Bille-Hansen J, Hansen KQ, Andersen HS and Skourup H (2001) Distribution and Variability of Icebergs in the Eastern Davis Strait $63^{\circ} \mathrm{N}$ to $68^{\circ} \mathrm{N}$. Report No. 2001-1. Denmark: Bureau of Minerals and Petroleum, Greenland Survey, ASIAQ. 38 pp. 
Kimball PW and Rock SM (2015) Mapping of translating, rotating icebergs with an autonomous underwater vehicle. IEEE Journal of Oceanic Engineering 40: 196-208. doi:10.1109/JOE.2014.2300396.

Kimball P and Rock S (2011) Sonar-based iceberg-relative navigation for autonomous underwater vehicles. Deep Sea Research Part II Topical Studies in Oceanography 58: 13011310.

Kirkham JD, Rosser NJ, Wainwright J, Vann Jones EC, Dunning SA, Lane VS, Dunning SA, Lane VS, Hawthorn DE, Strzelecki MC and Szczuinski W (2017) Drift-dependent changes in iceberg size-frequency distributions. Scientific Reports 7(1). doi:10.1038/s41598-017-148632 .

Kubat I, Sayed M, Savage SB and Carrieres T (2005) An operational model of iceberg drift. International Journal of Offshore Polar Engineering 15(2): 125-131.

Kubat I, Sayed M, Savage SB, Carrieres T and Crocker G (2007) An operational iceberg deterioration model. Proceedings of the $17^{\text {th }}$ International Offshore and Polar Engineering Conference. International Society of Offshore and Polar Engineers. Lisbon, Portugal. 652657.

Lague D, Brodu N and Leroux J (2013) Accurate 3D comparison of complex topography with terrestrial laser scanner: Application to the Rangitikei Canyon (NZ). ISPRS Journal of Photogrammetry and Remote Sensing 82: 10-26.

Landy J, Ehn J, Shields M and Barber D (2014) Surface and melt pond evolution on landfast firstyear sea ice in the Canadian Arctic Archipelago. Journal of Geophysical Research: Oceans 119: 3054-3075. doi:10.1002/2013JC009617.

Landy JC, Isleifson D, Komarov AS and Barber DG (2015) Parameterization of centimetre-scale sea ice surface roughness using terrestrial LiDAR. IEEE Transactions on Geoscience and Remote Sensing 53: 1271-1286. doi:10.1109/TGRS.2014.2336833.

Latypov D (2002) Estimating relative lidar accuracy information from overlapping flight lines. ISPRS Journal of Photogrammetry and Remote Sensing 56(4): 236-245. doi:10.1016/S09242716(02)00047-3.

Leberl F (2010) Point clouds: Lidar versus 3D vision. Photogrammetric Engineering and Remote Sensing 76: 1123-1134.

Leucci G, Negri S and Carrozzo MT (2003) Ground penetrating radar (GPR): An application for evaluating the state of maintenance of the building coating. Annals of Geophysics 46(3): 481489.

Lewis-Paley G (2015) Ice Island Variability in Polarimetric Synthetic Aperture Radar: An Exploratory Analysis to Improve Detection and Ice Classification. MSc Thesis. Ottawa, Canada: Department of Geography and Environmental Studies, Carleton University, 165 pp. 
Li F, Sackinger WM, Jeffries MO and Lu M (1989) Computer simulations of the probability of ice island movements in the Arctic Ocean. Proceedings of the $10^{\text {th }}$ International Conference on Port and Ocean Engineering under Arctic Conditions. Luleå, Sweden. 2: 1063-1072.

Liu Y, Moore JC, Cheng X, Gladstone RM, Bassis JN, Liu H, et al. (2015) Ocean-driven thinning enhances iceberg calving and retreat of Antarctic ice shelves. Proceedings of the National Academy of Sciences 112(11): 3263-3268.

Long DG, Ballantyne J and Bertoia C (2002) Is the number of Antarctic icebergs really increasing? Eos 83(42): 473-474.

Løset S (1993) Numerical modelling of the temperature distribution in tabular icebergs. Cold Regions Science and Technology 21(2): 103-115.

Luckman A, Padman L and Jansen D (2010) Persistent iceberg groundings in the western Weddell Sea, Antarctica. Remote Sensing of Environment 114(2): 385-391. doi:10.1016/j.rse.2009.09.009.

MacAyeal DR, Okal MH, Thom JE, Brunt KM, Kim Y-J and Bliss AK (2008) Tabular iceberg collisions within the coastal regime. Journal of Glaciology 54(185): 371-386.

Macheret YY, Moskalevsky MY and Vasilenko EV (1993) Velocity of radio waves in glaciers as an indicator of their hydrotherlnal state, structure and regime. Journal of Glaciology 39(132): 373-384.

Madec G and the NEMO team (2015) NEMO Ocean Engine. No. 27. France: Note du Pole de modélisation de l'Institut Pierre-Simon Laplace. 396 pp.

Marani R, Reno V, Nitti M, D'Orazio T and Stella EA (2016) Modified iterative closest point algorithm for 3D point cloud registration. Computer-Aided Civil and Infrastructure Engineering 31: 515-534.

Marsh R, Ivchenko VO, Skliris N, Alderson S, Bigg GR, Madec G, Blaker AT, Aksenov Y, Sinha B, Coward AC, Le Sommer J, Merino N and Zalesny VB (2015) NEMO-ICB (v1.0): interactive icebergs in the NEMO ocean model globally configured at eddy-permitting resolution. Geoscientific Model Development 8(5): 1547-1562. doi:10.5194/gmd-8-15472015.

Marson J, Myers P, Hu X and Le Sommer J (2018) Using vertically-integrated ocean fields to characterize Greenland icebergs' distribution and lifetime. Geophysical Research Letters. doi: 10.1029/2018GL077676.

Martin T and Adcroft A (2010) Parameterizing the fresh-water flux from land ice to ocean with interactive icebergs in a coupled climate model. Ocean Modelling 34(3-4): 111-124. doi:10.1016/j.ocemod.2010.05.001. 
Martin S, Drucker R, Aster R, Davey F, Okal E, Scambos T and MacAyeal D (2010) Kinematic and seismic analysis of giant tabular iceberg breakup at Cape Adare, Antarctica. Journal of Geophysical Research 115(B6). doi:10.1029/2009JB006700/

McGill PR, Reisenbichler KR, Etchemendy SA, Dawe TC and Hobson BW (2011) Aerial surveys and tagging of free-drifting icebergs using an unmanned aerial vehicle (UAV). Deep Sea Res. Part II Topical Studies in Oceanography 58: 1318-1326.

McGonigal D, Hagen D and Guzman L (2011) Extreme ice features distribution in the Canadian Arctic. Proceedings of the $21^{\text {st }}$ International Conference on Port and Ocean Engineering under Arctic Conditions. Montreal, Canada. POAC11-045.

McGuire P, Younan A, Wang Y, Bruce J, Gandi M, King T, Keeping K and Regular K (2016) Smart Iceberg Management System - Rapid Iceberg Profiling System. OTC-27473-MS. Proceedings of the Offshore Technology Conference. St. John's, Canada. doi:10.4043/27473MS.

McKenna R (2005) Iceberg shape characterization. Proceedings of the $18^{\text {th }}$ International Conference on Port and Ocean Engineering Under Arctic Conditions. 2: 555-564. Potsdam, United States.

McKenna R and Ralph F (2007) Determination of iceberg size and shape from multiple views. In: Yue (ed) Recent Development of Offshore Engineering in Cold Regions. Dalian, China: Dalian University of Technology Press. pp. 527-536.

Merino N, Le Sommer J, Durand G, Jourdain NC, Madec G, Mathiot P and Tournadre J (2016) Antarctic iceberg melt over the Southern Ocean: Climatology and impact on sea ice. Ocean Modelling 104: 99-110. doi:10.1016/j.ocemod.2016.05.001.

Mingo L and Flowers G (2010) An integrated lightweight ice-penetrating radar system. Journal of Glaciology 56(198):709-714.

Mitzenmacher M (2004) A brief history of generative models for power law and lognormal distributions. Internet Mathematics 1(2): 226-251.

Moon T, Sutherland DA, Carroll D, Felikson D, Kehrl L and Straneo F (2018) Subsurface iceberg melt key to Greenland fjord freshwater budget. Nature Geoscience 11(1): 49-54. doi:10.1038/s41561-017-0018-z.

Mortimer CA, Copland L and Mueller DR (2012) Volume and area changes of the Milne Ice Shelf, Ellesmere Island, Nunavut, Canada, since 1950. Journal of Geophysical Research. 117(F04011). doi:10.1029/2011JF002074.

Mueller D, Copland L and Jeffries MO (2017) Changes in Canadian Arctic ice shelf extent since 1906. Copland L and Mueller D (eds) Arctic Ice Shelves and Ice Islands. Netherlands, Dordrecht: Springer. pp. 109-148. doi:10.1007/978-94-024-1101-0_5. 
Mueller DR, Crawford A, Copland L and Van Wychen W (2013) Ice Island and Iceberg Fluxes from Canadian High Arctic Sources. Report to the Northern Transportation Assessment Initiative. Ottawa, Canada: Innovation Policy Branch, Transport Canada. 23 pp.

Münchow A, Padman L and Fricker HA (2014) Interannual changes of the floating ice shelf of Petermann Gletscher, North Greenland, from 2000 to 2012. Journal of Glaciology 60(221): 489-499. doi:10.3189/2014JoG13J135.

Münchow A, Padman L, Washam P and Nicholls K (2016) The ice shelf of Petermann Gletscher, North Greenland, and its connection to the Arctic and Atlantic oceans. Oceanography 29(4): 84-95. doi:10.5670/oceanog.2016.101.

Nacke M (2016) Characterization of the Coastal Marine Environment in the Vicinity of a Grounded Iceberg, Canadian Arctic Archipelago. MSc Thesis. Ottawa, Canada: Department of Geography and Environmental Studies, Carleton University, 82 pp.

NASA (2010) Ice island calves off the Petermann Glacier. http://earthobservatory.nasa.gov/IOTD/view.php?id=45112. Accessed 13 May 2015.

NASA (2012) GMS: Petermann Ice Island 2012. http://svs.gsfc.nasa.gov/cgibin/details.cgi?aid=11114. Accessed 23 June 2016.

NASA (2017) Massive iceberg breaks off from Antarctica. https://www.nasa.gov/feature/goddard/2017/massive-iceberg-breaks-off-from-antarctica. Accessed 17 January 2018.

National Geophysical Data Center (2006) ETOPO2v2 2-minute Global Relief Model. National Geophysical Data Center: Boulder, United States.

Natural Resources Canada (2016) Tools and Applications | Natural Resources Canada. http://www.nrcan.gc.ca/earth-sciences/geomatics/geodetic-reference-systems/toolsapplications/10925\#ppp. Accessed 16 June 2016, 28 December 2016 and 30 June 2017.

Neshyba S and Josberger G (1980) On the estimation of Antarctic iceberg melt rate. Journal of Physical Oceanography 10: 1681-1685.

Newell JP (1993) Exceptionally large icebergs and ice islands in eastern Canadian waters: A review of sightings from 1900 to present. Arctic 46(3): 205-211.

Nick FM, Luckman A, Vieli A, van der Veen CJ, van As D, van de Wal RSW, Pattyn F, Hubbard AL and Floricioiu D (2012) The response of Petermann Glacier, Greenland, to large calving events, and its future stability in the context of atmospheric and oceanic warming. Journal of Glaciology 58(208): 229-239.

Nick FM, Vieli A, Anderson ML, Joughin I, Payne A, Edwards TL, Pattyn F and van de Wal RSW (2013) Future sea-level rise from Greenland's main outlet glaciers in a warming climate. Nature 497: 235-238. 
Paul F, Barrand NE, Baumann S, Berthier E, Bolch T, Casey K, Frey H, Joshi SP, Konovalov V, Bris RL, Mölg N, Nosenko G, Nuth C, Pope A, Racoviteanu A, Rastner P, Raup B, Scharrer K, Steffen S and Winsvold S (2013) On the accuracy of glacier outlines derived from remotesensing data. Annals of Glaciology 54(63): 171-182. doi:10.3189/2013AoG63A296.

Pellicciotti F, Brock B, Strasser U, Burlando P, Funk M and Corripio J (2005) An enhanced temperature-index glacier melt model including the shortwave radiation balance: development and testing for Haut Glacier d'Arolla, Switzerland. Journal of Glaciology 51(175): 573-587. doi:10.3189/172756505781829124.

Peterson IK (2005) Large tabular icebergs and ice islands off eastern Canada in 2001-2003 and their probable source. Proceedings of the $18^{\text {th }}$ International Conference on Port and Ocean Engineering Under Arctic Conditions. Potsdam, United States. 1:143-152.

Peterson IK (2011) Ice island occurrence on the Canadian East Coast. Proceedings of the $21^{\text {st }}$ International Conference on Port and Ocean Engineering under Arctic Conditions. Montreal, Canada. POAC11-044.

Peterson IK, Prinsenberg SJ, Pittman M and Desjardins L (2009) The drift of an exceptionallylarge ice island from the Petermann Glacier in 2008. Proceedings of the $20^{\text {th }}$ International Conference on Port and Ocean Engineering under Arctic Conditions. Luleå, Sweden. 130140.

Quan L (2010) Image-Based Modeling. Boston, United States: Springer. doi:10.1007/978-14419-6679-7. $257 \mathrm{pp}$.

R Core Team (2013) R: A language and environment for statistical computing. R Foundation for Statistical Computing: Vienna, Austria.

Rackow T, Wesche C, Timmermann R, Hellmer HH, Juricke S and Jung T (2017) A simulation of small to giant Antarctic iceberg evolution: Differential impact on climatology estimates. Journal of Geophysical Research: Oceans. 122. doi:10.1002/2016JC012513.

Raiswell R, Hawkings JR, Benning LG, Baker AR, Death R, Albani S, Mahowald N, Krom MD, Poulton SW, Wadham J and Tranter M (2016) Potentially bioavailable iron delivery by iceberg-hosted sediments and atmospheric dust to the polar oceans. Biogeosciences 13(13): 3887-3900. doi:10.5194/bg-13-3887-2016.

Rajewicz J (2017) Channelized Epishelf Lake Drainage Beneath the Milne Ice Shelf, Ellesmere Island, Nunavut. MSc Thesis. Ottawa, Canada: Department of Geography and Environmental Studies, Carleton University, 133 pp.

Reeh N, Thomsen HH, Higgins AK and Weidick A (2001) Sea ice and the stability of north and northeast Greenland floating glaciers. Annals of Glaciology 33: 474-480.

Rignot E and Steffen K (2008) Channelized bottom melting and stability of floating ice shelves. Geophysical Research Letters 35(2). doi:10.1029/2007GL031765. 
Robe RQ and Farmer LD (1976) Part I. Height to draft ratios of icebergs. Part II. Mass Estimation of Arctic Icebergs. In Physical Properties of Icebergs. Report CG-D-102-76. Springfield, United States: Department of Transportation, United States Coast Guard. 26 pp.

Robe RQ, Maier DC and Kollmeyer RC (1977) Iceberg deterioration. Nature 267(9): 505-506.

Romanov YA, Romanova NA and Romanov P (2012) Shape and size of Antarctic icebergs derived from ship observation data. Antarctic Science 24(01): 77-87. doi:10.1017/S0954102011000538.

Rudkin P, King T, Ralph F and Stoermer SA (2005) Investigations into the increased sightings of ice islands in the North Atlantic. Proceedings of the $18^{\text {th }}$ International Conference on Port and Ocean Engineering Under Arctic Conditions. Potsdam, United States. 2:605-614.

Ryan JC, Hubbard AL, Box JE, Todd J, Christoffersen P, Carr JR, Holt TO and Snooke N (2015) UAV photogrammetry and structure from motion to assess calving dynamics at Store Glacier, a large outlet draining the Greenland ice sheet. The Cryosphere 9: 1-11. doi:10.5194/tc-9-12015.

Sackinger WM, Jeffries MO, Li F and Lu M (1991) Ice Island Creation, Drift, Recurrences, Mechanical Properties, and Interactions with Arctic Offshore Oil Production Structures. Final Report for the U.S. Department of Energy. Fairbanks, United States: University of Alaska. 38 pp.

Sackinger WM, Jeffries MO, Lu MC and Li FC (1988) Arctic Ice Islands. Final Report for the U.S. Department of Energy. Fairbanks, United States: University of Alaska. 291 pp.

Sackinger WM, Serson HV, Jeffries MO, Shoemaker HD and Yan M-H (1985) Ice island generation and trajectories north of Ellesmere Island, Canada. Proceedings of the $8^{\text {th }}$ International Conference on Port and Ocean Engineering under Arctic Conditions. Narssarssuaq, Greenland. 1009.

Sackinger WM, Shoemaker HD, Serson H, Jeffries MO and Yan M-H (1985) Ice islands as hazards to Arctic offshore production structures. Proceedings of the $17^{\text {th }}$ Annual Offshore Technology Conference. Houston, United States. OTC 4943. 14 pp.

Saper R (2011) Preliminary Research Plan for Glacial Ice Hazards. Preliminary Report. Ottawa, Canada: Canadian Ice Service, Marine and Ice Services Division, Environment Canada. 40 pp.

Saper R and Crawford A (2016) Canadian Ice Island Drift, Deterioration and Detection (CI2D3) Database. Requirements Specification Document V1.0. Ottawa, Canada: Water and Ice Research Lab, Department of Geography and Environmental Studies, Carleton University. 11 pp.

Saper R, Tivy A, Mueller D and Nacke M (2015) Report of the Inaugural Meeting of the Glacial Ice Hazards Working Group (GIHWG). Ottawa, Canada: Carleton University. 30 pp. 
Savage SB (2001) Aspects of iceberg deterioration and drift. In: Balmforth NJ, Provenzale A (eds) Geomorphological Fluid Mechanics. Berlin, Germany: Springer, 279-318

Scambos T, Ross R, Bauer R, Yermolin Y, Skvarca P, Long D, Bohlander J, Haran T (2008) Calving and ice-shelf break-up processes investigated by proxy: Antarctic tabular iceberg evolution during northward drift. Journal of Glaciology 54(187): 579-591.

Scambos T, Sergienko O, Sargent A, MacAyeal D and Fastook J (2005) ICESat profiles of tabular iceberg margins and iceberg breakup at low latitudes. Geophysical Research Letters 32: S2309.

Schild K, Sutherland D, Straneo F and Elosegui P (2017) Direct measurements of iceberg melt in Greenland tidewater glacier fjords. Oral presentation. American Geophysical Union Fall Meeting. New Orleans, United States.

Schodlok MP, Hellmer HH, Rohardt G and Fahrbach E (2006) Weddell Sea iceberg drift: Five years of observations. Journal of Geophysical Research 111(C6). doi:10.1029/2004JC002661.

Seguin G, Srivastava S and Auger D (2014) Evolution of the RADARSAT Program. IEEE Geoscience and Remote Sensing Magazine 2(2): 56-58. doi:10.1109/MGRS.2014.2321381.

Shroyer EL, Padman L, Samelson RM, Münchow A and Stearns LA (2017) Seasonal control of Petermann Gletscher ice-shelf melt by the ocean's response to sea-ice cover in Nares Strait. Journal of Glaciology 1-7. doi:10.1017/jog.2016.140.

Silva TAM, Bigg GR and Nicholls KW (2006) Contribution of giant icebergs to the Southern Ocean freshwater flux. Journal of Geophysical Research 111(C3): C03004. doi:10.1029/2004JC002843.

Smith KL (2011) Free-drifting icebergs in the Southern Ocean: An overview. Deep Sea Research Part II: Topical Studies in Oceanography 58(11-12): 1277-1284. doi:10.1016/j.dsr2.2010.11.003.

Smith SD and Donaldson NR (1987) Dynamic modelling of iceberg drift using current profiles. Canadian Technical Report of Hydrography and Ocean Sciences. Minister of Supply and Services Canada. No. 91. 125 pp.

Smith GC, Roy F, Mann P, Dupont F, Brasnett B, Lemieux J-F, Laroche S and Bélair S (2014) A new atmospheric dataset for forcing ice-ocean models: Evaluation of reforecasts using the Canadian Global Deterministic Prediction System: CGRF Dataset for Forcing Ice-Ocean Models. Quarterly Journal of the Royal Meteorological Society 140(680): 881-894. doi:10.1002/qj.2194.

Smith KL, Sherman AD, Shaw TJ and Sprintall J (2013) Icebergs as unique Lagrangian ecosystems in Polar Seas. Annual Review of Marine Science 5(1): 269-287. doi:10.1146/annurev-marine-121211-172317. 
Snavely N, Simon I, Goesele M, Szeliski R and Seitz SM (2010) Scene reconstruction and visualization from community photo collections. Proceedings of the IEEE 98(8):1370-1390. https://doi.org/10.1109/JPROC.2010.2049330.

Solara Remote Data Delivery. (2010) FieldTracker 2100 User's Manual. Solara Remote Data Delivery: Winnipeg, Canada. 20 pp.

Soudarissanane S, Lindenbergh R, Menenti M and Teunissen P (2011) Scanning geometry: Influencing factor on the quality of terrestrial laser scanning points. ISPRS Journal of Photogrammetry and Remote Sensing 66: 389-399. doi:10.1016/j.isprsjprs.2011.01.005.

Spahn F, Vieira Neto E, Guimarães AHF, Gorban AN and Brilliantov NV (2014) A statistical model of aggregate fragmentation. New Journal of Physics 16(1): 013031. doi:10.1088/13672630/16/1/013031.

Stanton TP, Shaw WJ, Truffer M, Corr HFJ, Peters LE, Riverman KL, Bindschadler R, Holland $\mathrm{D}$ and Anandakrishnan S (2013) Channelized ice melting in the ocean boundary layer beneath Pine Island Glacier, Antarctica. Science 341(6151): 1236-1239.

Stephenson GR, Sprintall J, Gille ST, Vernet M, Helly JJ and Kaufmann RS (2011) Subsurface melting of a free-floating Antarctic iceberg. Deep Sea Research Part II Topical Studies in Oceanography 58(11-12): 1336-1345. doi:10.1016/j.dsr2.2010.11.009.

Stern AA, Adcroft A and Sergienko O (2016) The effects of Antarctic iceberg calving-size distribution in a global climate model. Journal of Geophysical Research: Oceans 121(8): 5773-5788. doi:10.1002/2016JC011835.

Stern AA, Adcroft A, Sergienko O and Marques G (2017) Modeling tabular icebergs submerged in the ocean. Journal of Advances in Modeling Earth Systems 9(4): 1948-1972. doi:10.1002/2017MS001002.

Stern AA, Johnson E, Holland DM, Wagner TJW, Wadhams P, Bates R, Abrahamsen EP, Nicholls K, Crawford A, Gagnon J, Tremblay J-E (2015) Wind-driven upwelling around grounded tabular icebergs. Journal of Geophysical Research: Oceans 120(8): 5820-5835. doi:10.1002/2015JC010805.

Straneo F, Heimbach P, Sergienko O, Hamilton G, Catania G, Griffies S, Hallberg R, Jenkins A, Joughin I, Motyka R, Pfeffer WT, Price SF, Rignot E, Scambos T, Truffer M and Vieli A (2013) Challenges to understanding the dynamic response of Greenland's marine terminating glaciers to oceanic and atmospheric forcing. Bulletin of the American Meteorological Society 94(8): 1131-1144.

Stuart KM and Long DG (2011) Tracking large tabular icebergs using the SeaWinds Ku-band microwave scatterometer. Deep Sea Research Part II: Topical Studies in Oceanography 58(11-12): 1285-1300. doi:10.1016/j.dsr2.2010.11.004. 
Sulak DJ, Sutherland DA, Enderlin EM, Stearns LA and Hamilton GS (2017) Iceberg properties and distributions in three Greenlandic fjords using satellite imagery. Annals of Glaciology 58: 92-106. doi:10.1017/aog.2017.5.

Tang CC, Ross CK, Yao T, Petrie B, DeTracey BM and Dunlap E (2004) The circulation, water masses and sea-ice of Baffin Bay. Progress in Oceanography 63(4): 183-228. doi:10.1016/j.pocean.2004.09.005.

Thomson L and Copland L (2016) White Glacier 2014, Axel Heiberg Island, Nunavut: mapped using structure from motion methods. Journal of Maps 12(5): 1-9. doi:10.1080/17445647.2015.1124057.

Topcon (2016) Hiper V Dual-Frequency GNSS Receiver specification sheet. Topcon Corporation, Japan. p. 4.

Tournadre J, Bouhier N, Girard-Ardhuin F and Rémy F (2015) Large icebergs characteristics from altimeter waveforms analysis. Journal of Geophysical Research: Oceans 120(3): 19541974. doi:10.1002/2014JC010502.

Tournadre J, Bouhier N, Girard-Ardhuin F and Rémy F (2016) Antarctic icebergs distributions 1992-2014. Journal of Geophysical Research: Oceans 121(1): 327-349. doi:10.1002/2015JC011178.

Tournadre J, Girard-Ardhuin F and Legrésy B (2012) Antarctic icebergs distributions, 20022010. Journal of Geophysical Research 117(C5). doi:10.1029/2011JC007441.

Trigg B, McLauchlan PF, Hartley RI and Fitzgibbon AW (2000) Bundle Adjustment - A Modern Synthesis. In Trigg B, Zisserman A, Szeliski R (eds) Vision Algorithms: Theory and Practice, Proceedings of the International Workshop on Vision Algorithms. Berlin, Germany: Springer. 1883: 298-372. doi:10.1007/3-540-44480-7_21.

Van Wychen W and Copland L (2017) Ice Island Drift Mechanisms in the Canadian High Arctic. In Copland L and Mueller D (eds) Arctic Ice Shelves and Ice Islands. Dordrecht, Netherlands: Springer. pp. 287-316. doi:10.1007/978-94-024-1101-0_11.

Venkatesh S, El-Tahan M and Mitten PT (1985) An Arctic iceberg deterioration field study and model simulations. Annals of Glaciology 6: 195-199.

Vernet M, Sines K, Chakos D, Cefarelli AO and Ekern L (2011) Impacts on phytoplankton dynamics by free-drifting icebergs in the NW Weddell Sea. Deep Sea Research Part II Topical Studies in Oceanography 58(11-12): 1422-1435. doi:10.1016/j.dsr2.2010.11.022.

Vernet M, Smith K, Cefarelli A, Helly J, Kaufmann R, Lin H, Long D, Murray A, Robison B, Ruhl H, Shaw T, Sherman A and Sprintall J (2012) Islands of ice: Influence of free-drifting Antarctic icebergs on pelagic marine ecosystems. Oceanography 25(3): 38-39. doi:10.5670/oceanog.2012.72. 
Wagner TJW and Eisenman I (2017) How climate model biases skew the distribution of iceberg meltwater: Biases in iceberg meltwater distribution. Geophysical Research Letters 117:88-96. doi:10.1002/2016GL071645.

Wagner TJW, Wadhams P, Bates R, Elosegui P, Stern A, Vella D, Abrahamsen EP, Crawford A, Nicholls KW (2014) The "footloose" mechanism: Iceberg decay from hydrostatic stresses. Geophysical Research Letters 41(15): 5522-5529. doi:10.1002/2014GL060832.

Wang Y, deYoung B and Bachmayer R (2015) A method of above-water iceberg 3D modelling using surface imaging. Proceedings of the $25^{\text {th }}$ International Ocean and Polar Engineering Conference. Kona, United States. International Society of Offshore and Polar Engineers (ISOPE): Mountain View, United States.

Weeks WF and Campbell WJ (1973) Icebergs as a fresh-water source: An appraisal. Journal of Glaciology 12(65): 207-233.

Wesche C and Dierking W (2015) Near-coastal circum-Antarctic iceberg size distributions determined from synthetic aperture radar images. Remote Sensing of Environment 156: 561569. doi:10.1016/j.rse.2014.10.025.

Westoby MJ, Brasington J, Glasser NF, Hambrey MJ and Reynolds JM (2012) 'Structure-frommotion' photogrammetry: A low-cost, effective tool for geoscience applications. Geomorphology 179: 300-314. doi:10.1016/j.geomorph.2012.08.021.

Westoby MJ, Dunning SA, Woodward J, Hein AS, Marrero SM, Winter K and Sugden DE (2016) Interannual surface evolution of an Antarctic blue-ice moraine using multi-temporal DEMs. Earth Surface Dynamics 4: 515-529. doi:10.5194/esurf-4-515-2016.

White FM, Spaulding ML and Gominho L (1980) Theoretical Estimates of the Various Mechanisms Involved in Iceberg Deterioration in the Open Ocean. Technical report. Washington DC, United States: Office of Research and Development, United States Coast Guard.

Whitehead K, Moorman BJ and Hugenholtz CH (2013) Low-cost, on-demand aerial photogrammetry for glaciological measurement. The Cryosphere 7: 1879-1884. doi: $10.5194 /$ tc-7-1879-2013.

Wilson N (2012) Characterization and Interpretation of Polythermal Structure in Two Subarctic Glaciers. MSc Thesis. Vancouver, Canada: Department of Earth Science, Simon Fraser University, $241 \mathrm{pp}$.

$\begin{array}{lllllll}\text { Wilson N (2013) Radar Tools. Software program. Release } & 0.4 .\end{array}$ http://doi.org/10.5281/zenodo.43972

Wolter T (2015) Package 'truncgof'. CRAN Repository. v. 0.6-0. https://CRAN.Rproject.org/package=truncgof. 
Yang Q, Dixon TH, Myers PG, Bonin J, Chambers D and van den Broeke MR (2016) Recent increases in Arctic freshwater flux affects Labrador Sea convection and Atlantic overturning circulation. Nature Communications 7: 10525. doi:10.1038/ncomms10525.

Younan A, Ralph F, Ralph T and Bruce J (2016) Overview of the 2012 Iceberg Profiling Program. Proceedings of the Offshore Technology Conference. OTC-27569-MS. doi:10.4043/27469MS.

Zhang J, Lindsay R, Schweiger A and Steele M (2013) The impact of an intense summer cyclone on 2012 Arctic sea ice retreat. Geophysical Research Letters 40(4): 720-726. doi:10.1002/grl.50190.

Zhou M, Bachmayer R and de Young B (2014) Working towards seafloor and underwater iceberg mapping with a Slocum glider. Proceedings of the Institute of Electrical and Electronics Engineers/Ocean Engineering Society Conference - Autonomous Underwater Vehicles (AUV). Oxford, United States. 5 pp. 


\section{Appendices}

\section{Appendix A: Stationary ice penetrating radar details}

The stationary ice penetrating radar receiver and transmitter (Icefield Instruments Inc., Whitehorse, Canada) were contained in two waterproof cases separated by $4.8 \mathrm{~m}$ and connected by $\sim 1 \mathrm{~m}$ lengths of 2 inch diameter PVC pipe which housed the antennas as well as a fiber-optic cable. A timer switch was programmed to supply power at a daily interval to a microUPS (universal power source). After this charged, power was distributed to a PicoScope 4424 digital oscilloscope, a Moxa V2101 computer, a RockBLOCK+ satellite modem and a fiber-optic trigger which ran the transmitter at a pulse repetition frequency of $128 \mathrm{~Hz}$. The radar was controlled by customized software developed by Blue System Integration Ltd. (Vancouver, Canada). The oscillocope sample rate was set to 125 mega-samples (MS) s${ }^{-1}$, and the system recorded 256 consecutive signal 'traces'. These were collected and averaged ('stacked') to increase the signal to noise ratio (Hubbard and Glasser, 2005). This averaged trace was telemetered daily as a shortburst data message via the Iridium satellite network.

The sIPR system and the weather station tripod were designed to 'float' with the melting ice surface. Stability was provided by sets of PVC conduit, drilled $\sim 5.5 \mathrm{~m}$ into the ice, and larger PVC sleeves that slid over the stakes and remained on the ice surface and to which the equipment was connected. 


\section{Appendix B: Image processing and polygon digitization error}

Custom Python (v. 2.7) scripts were used to convert the Level 1b SAR data to amplitude images in a Lambert Conformal Conic projection (WGS 1984 datum) with bilinear resampling using gdal utilities. The images were then stretched to improve contrast. The resulting geotif files were viewed in ArcMap (v. 10.2-10.5; ESRI, Redlands, California) and a polygon was digitized to represent PII-A-1-f in each image. Digitization followed the 'polygon trimming' method of Crawford et al. (2018). An error assessment based on the work of Paul et al. (2013), Mueller et al. (2017) and Crawford et al. (2018) was conducted to determine the precision in manual polygon digitizing. The 'polygon trimming' workflow was conducted five times with at least 1 day between attempts for one pair of Fine-Quad RADARSAT-2 images (i.e., the polygon representing PII-A1-f in the first image was rotated and trimmed to fit the ice island as captured in the second image). The coefficient of variation $(0.07 \%)$ of polygon area was calculated from the five fitted polygons as a measure of uncertainty in the digitized areal dimension. 


\section{Appendix C: List of symbols and acronyms}

$\begin{array}{ll}\text { Symbol or } & \text { Definition } \\ \text { acronym } & \\ A & \text { area } \\ \text { ADCP } & \text { acoustic Doppler current profiler } \\ \text { AUV } & \text { autonomous underwater vehicle } \\ \text { AMOC } & \text { Atlantic meridional overturning circulation } \\ \text { BYU } & \text { Bringham Young University } \\ c & \text { speed of light in a vacuum } \\ C & \text { bulk heat transfer coefficient } \\ \text { CCGS } & \text { Canadian Coast Guard Ship } \\ \text { CGRF } & \text { global deterministic prediction system reforecasts } \\ \text { CIS } & \text { Canadian Ice Service } \\ \text { CI2D3 } & \text { Canadian Ice Island Drift, Deterioration and Detection (Database) } \\ \text { CTD } & \text { conductivity, temperature, depth (profile and instrument) } \\ D & \text { diameter used to calculate normal direction of point clouds } \\ d & \text { distance } \\ d x, d y & \text { distance in x and y directions } \\ \text { DDF } & \text { degree day factor } \\ \text { DDT } & \text { deterioration detection threshold } \\ \text { ECCC } & \text { Environment and Climate Change Canada } \\ \text { FIT } & \text { floating ice tongue } \\ f & \text { freeboard } \\ \text { GCP } & \text { ground control point } \\ \text { GNSS } & \text { global navigation satellite system } \\ \text { GPS } & \text { global positioning system } \\ \text { Gt } & \text { gigatonne } \\ \text { GUI } & \text { graphical user interface } \\ \text { H } & \text { horizontal } \\ h G P S & \text { heading between the two GPS units } \\ h O F F & \text { heading offset between } h_{p} \text { and } h_{G P S} \\ h_{p c} & \text { heading between the cloud point and a second GPS unit } \\ \text { i1, i2 } & \text { 'iceberg-1', 'iceberg-2' } \\ \text { IBRF } & \text { iceberg reference frame } \\ \text { ICESat } & \text { Ice, Cloud and land Elevation Satellite } \\ \text { IMU } & \text { inertial measurement unit } \\ \text { INS } & \text { inertial navigation system } \\ \text { IPR } & \text { ice penetrating radar } \\ \text { IQR } & \text { inter-quartile range } \\ & \end{array}$




\begin{tabular}{ll} 
ISE & inter-survey error \\
$K$ & relative permittivity of ice \\
L & length \\
LiDAR & light detection and ranging \\
LADCP & lowered acoustic Doppler current profiler \\
$M$ & mass \\
$M_{b}$ & basal ablation rate \\
$M_{p}$ & melting temperature of ice \\
$M_{s}$ & surface ablation rate of the upper, horizontal surface of an ice island \\
M3C2 & Multiscale Model-to-Model Cloud Comparison (algorithm) \\
MHz & megahertz \\
mIPR & mobile ice penetrating radar \\
MODIS & Moderate Resolution Imaging Spectroradiometer \\
mSv & milli-Sverdrups \\
$\mathrm{n}$ & sample size \\
$n$ & number of cloud points \\
NASA & National Aeronautics and Space Administration \\
NEMO & Nucleus for European Modeling of the Ocean \\
NIC & National Ice Center \\
$P$ & pressure \\
$p$ & projection scale diameter \\
PC $d i s t-i$ & distances between core points in the reference cloud and analogous points in \\
PDD & a compared point cloud \\
PII & positive degree day \\
PPP & Petermann ice island \\
$Q$ & precise point positioning \\
$r$ & quartile \\
R1, R2 & radius \\
$s$ & RADARSAT-1 and RADARSAT-2 \\
$S$ & antenna spacing \\
$S_{A}$ & salinity \\
SAR & absolute salinity \\
SfM & synthetic aperture radar \\
sIPR & aerial photography with structure-from-motion processing \\
SPAN & stationary ice penetrating radar \\
SQL & synchronous position, attitude and navigation \\
$t$ & structured query language \\
T & time \\
$T_{A}$ & thickness \\
& air temperature \\
\hline
\end{tabular}




$\begin{array}{ll}T_{e} & \text { water temperature at keel depth } \\ T_{f} & \text { freezing temperature of ocean water at keel depth } \\ \text { TLS } & \text { terrestrial laser scanning } \\ \text { TWTT } & \text { two-way travel time } \\ \mathrm{u} & \text { ocean current velocity } \\ u_{i} & \text { uncertainty at core points } \\ \text { UAV } & \text { unmanned/uninhabited aerial vehicle } \\ \text { UTM } & \text { Universal Transverse Mercator } \\ v & \text { velocity } \\ \text { V } & \text { vertical } \\ V & \text { volume } \\ \text { W } & \text { width } \\ \text { WIRL } & \text { Water and Ice Research Lab } \\ 2 \mathrm{D}, 3 \mathrm{D} & \text { 2-Dimensional, 3-Dimensional } \\ \Theta & \text { Conservative temperature } \\ \alpha & \text { alpha parameter in power-law size distribution model } \\ \Delta \mathrm{u} & \text { differential velocity } \\ \Delta T & \text { driving temperature } \\ \delta & \text { maximum search distance } \\ \xi & \text { normal scale assessment criterion } \\ \varepsilon & \text { bootstrapped DDT statistic } \\ \lambda & \text { centre frequency wavelength } \\ \rho_{i} & \text { ice density } \\ \rho_{p} & \text { point cloud density } \\ \rho_{w} & \text { water density } \\ \sigma & \text { standard deviation } \\ \sigma_{b x}, \sigma_{b y}, \sigma_{b z} & \text { GPS positional uncertainty in the x, y and z directions } \\ \sigma_{i}(D) & \text { surface roughness around core points }\end{array}$

